\title{
The Myth of the Benevolent Autocrat? Internal constraints, external constraints, and economic development in autocracies
}

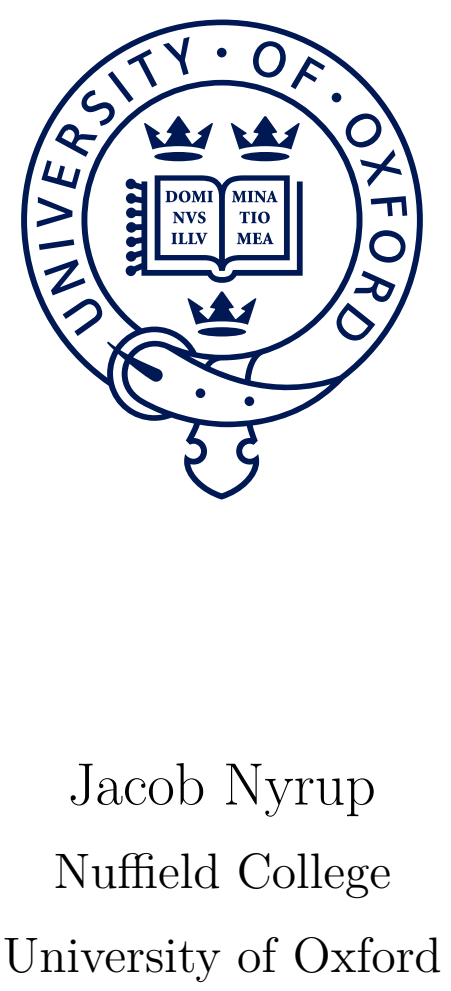

Thesis submitted in partial fulfilment of the requirements for the degree of DPhil in Politics in the Department of Politics and International Relations at the University of Oxford.

Michaelmas 2020

[Word count: 80,290] 


\section{Acknowledgements}

This dissertation - and the adventure on the side - would not have been possible without the help and support of colleagues, friends, and family. A long list of people have in different ways contributed to realize this project.

First of all, I am extremely thankful to my advisor Ben Ansell. His advice, comments, and many suggestions have improved the thesis enormously. Apart from being a brilliant researcher, Ben is also the most supportive advisor. His help has stretched far beyond the thesis. I will always be grateful to Ben for taking me on board, helping me secure funding, co-authoring papers, and guiding me through the labyrinth of academia.

I am also grateful to my colleagues, both former and present, at the University of Oxford. Oxford is a magical place, mostly due to the people who inhabit it. I was lucky to study together with a group of talented and ambitious people. Ilona Lahdelma, Zack Grant, Vuk Vukovic, Tanushree Goyal, Seung Hoon Chae, Tuuli-Anna Huikuri, and Matthias Dilling deserve special mention. Oxford is also, or has been, the home of many talented lecturers and professors, whose advice, support and detailed comments have helped me throughout this project. These are especially Nancy Bermeo, Andy Eggers, Ezequiel González Ocantos, David Doyle, Jane Green, John Darwin, Andrea Ruggeri, Andreas Wiedemann, and Nelson A. Ruiz. In addition, I would like to thank my colleagues in the WEALTHPOL-team; Laure Bokobza, Jonas Markgraf, Asli Cansunar, Mads Elkjær, and Helen Steffens. Being a part of this gifted group has been one of the best parts. Too many others to name made an impact on my time in Oxford and I acknowledge them all.

Furthermore, I am deeply indebted to my co-authors who I learned so much from. I am particularly grateful to Stuart Bramwell who joined me in creating WhoGov. Through cooperation, persistence, hard work, and extreme amounts of coffee we managed to push the boundaries of our field. Also, a big thanks to Lasse Aaskoven, my good friend, and the co-author of the first article I started writing. The first article is the hardest and I am happy it finally has found a home in Comparative Politics. Moreover, I would like to thank Malte Dahl, whom I co-authored my first publication with. While the topic is far from this thesis, the experiences were priceless in later projects. Additionally, I would like to thank Martin Vinæs Larsen. Martin has been supportive of my research since he taught me statistics during my undergraduate degree. This support has mattered a lot. Today, Martin is my co-author and has employed me at Aarhus University. In addition, I would like to thank Frederik Hjorth, Casper Sakstrup, Suthan Krishnarajan, 
and Hikaru Yamagishi. Luckily, I am still involved in projects with most of you and I am looking much forward to see how these will develop.

I would also like to thank Cecilia Ambrosius Høgfeldt, Winnie Faarvang, Camilla Therkildsen, Jakob Vikner, Sirimon Thomas, Ruairi Maguire, Sara Pripitu, and Isabella Salkeld who helped gather the dataset, WhoGov, which stems from this dissertation.

Throughout my DPhil program I have been fortunate to get great comments on my work from a number of brilliant scholars outside of Oxford to whom I am grateful. I would like to in particular thank Alexander Coppock, Victor Menaldo, Lasse Lykke Rørbæk, Alejandro Quiroz Flores, Mogens Kamp Justesen, Rasmus Fonnesbæk Andersen, Anna Pauls, Nathan Grubman, Anders Woller Nielsen, Jeremy Wallace, Jacob Gerner Hariri, and Peter Thisted Dinesen. Also, I am thankful to Milan Svolik for hosting my stay at Yale University. In addition, I thank Ryan Kennedy for sharing his data and code that is used in Chapter 7.

Furthermore, I am grateful to Reinhold W. Jorck og Hustru, Aage og Johanne LouisHansen, Knud Højgaard, Laurits Andersen, Frimodt-Heineke, Ludvig Augustinus, William Demant, and Garvermester C. W. Gericke. All these people were deceased long before I began this project. Yet, they helped make it possible by establishing scholarships that provided much of the financial support that made it possible for me to fund my stay. I am lucky to originate from a country where such funds are available. In the absence of such funds, I would not have commenced on this project.

Additionally, I would like to thank my many new friends which I have met when travelling across the world to visit some of the world's many remaining autocracies. It is abstract to study autocracies, when you are from Denmark, and I have learned more from you than I could from reading a hundred books. Maybe this project or the data originating from it will change something, somewhere.

Finally, I would like to thank my friends and family back in Denmark who have supported me throughout this project. While I do not for a second regret my stay at University of Oxford, I am looking much forward to be closer to you again. 


\section{Abstract}

Why do some autocracies produce high economic development while others falter? Despite the large literature comparing democracies and autocracies we know little about differences amongst autocratic regimes. I focus on the rule of one autocrat over time instead of comparing across regimes, and argue that an autocrat can be constrained by both a strong ruling elite (internal constraints) and an organized civil society (external constraints). I depart from the literature focusing on institutional constraints and use Arendt's concept of isolation to conceptualize constraints. The two types of constraints generate political accountability. This will result in a pluralistic and thoughtful decision-making process and a better environment for investment. I theorize that both types of constraints are associated with better economic outcomes, but that only external constraints promote better human development. To test this, I rely on three analyses. First, I conduct a cross-national analysis using a novel dataset, WhoGov, which provides information on the ruling elites. I show that only constrained autocrats are punished for governing over a severe recession. Furthermore, the same dictator governs over better economic outcomes when his rule is constrained. That said, only external constraints are related to improvements in human development. Second, I use a synthetic control design to investigate the effect of the Tulip Revolution in Kyrgyzstan, and show that the regime, despite not democratizing, increased public spending on health care and education. Third, I show that there is a cost to the ruling elite if they unsuccessfully try to coup the autocrat. In addition, I find that a successful coup is associated with better growth when there is an orderly transfer of power to a new, constrained autocrat, but not if the coup causes political instability. Overall, I show that the belief in the developmental benefits of having a strong autocrat is not supported empirically. Instead, autocrats govern over worse economic development when they become more powerful. 


\section{Contents}

List of Figures $\quad$ ix

\begin{tabular}{lll}
\hline 1 & Introduction & 1
\end{tabular}

2 Autocracy as a process of isolation 9

2.1 Introduction . . . . . . . . . . . . . . . . . . . . . . . . . . 9

2.2 Why are autocracies different? . . . . . . . . . . . . . . . . . . 12

2.3 Classifications of dictatorships . . . . . . . . . . . . . . . 15

2.3 .1 Institutions over time within leader . . . . . . . . . . . . . . . . 19

2.4 The two challenges to the dictator . . . . . . . . . . . . . 20

2.4 .1 Getting into and staying in office . . . . . . . . . . . . . 20

2.4 .2 No leader governs alone . . . . . . . . . . . . . . . . . . . . . . . . . . . . . . . . . . 22

2.4 .3 Power and isolation . . . . . . . . . . . . . . . . . . . . . . . . . . 24

2.5 A new typology . . . . . . . . . . . . . . . . . . . 26

2.6 Conclusion $\ldots \ldots \ldots \ldots$

$\begin{array}{|ll|}3 & \text { A model of decision making in authoritarian regimes }\end{array}$

3.1 Introduction . . . . . . . . . . . . . . . . . . . . . . . 31

3.2 The model . . . . . . . . . . . . . . . . . . . . . . . . . . . 33

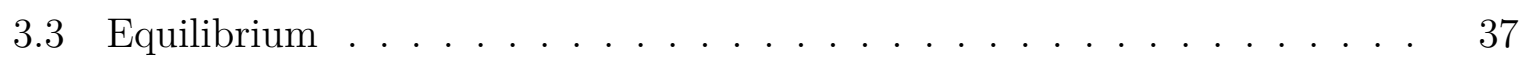

3.4 A theoretical example . . . . . . . . . . . . . . . . . 50

3.5 Discussions . . . . . . . . . . . . . . . . . . . . . . . . . 53

3.5 .1 The case of a very strong opposition or very strong ruling coalition 53

3.5 .2 The size of the opposition . . . . . . . . . . . . 56

$3.5 .3 \quad$ Exogenous and endogenous rent . . . . . . . . . . . . . . . . . . 58

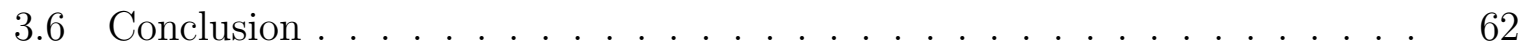

4 Internal constraints, external constraints, and economic development 63

4.1 Introduction . . . . . . . . . . . . . . . . . 63

4.2 Regime types and economic development . . . . . . . . . . . . . . 65

$4.2 .1 \quad$ Authoritarian regimes and economic development . . . . . . . . . 68

4.2 .2 Do leaders matter? . . . . . . . . . . . . . . . . . . 71

4.3 Explaining economic development in authoritarian regimes . . . . . . . . 74 
$4.3 .1 \quad$ Preference diversification . . . . . . . . . . . . . . . . . . 75

$4.3 .2 \quad$ A more competent and thoughtful decision making process . . . . 77

4.3 .3 Better environment for investment . . . . . . . . . . . . . . . 79

4.4 Theoretical expectations $\ldots \ldots \ldots \ldots$

$4.4 .1 \quad$ Economic growth $\ldots \ldots \ldots \ldots \ldots$

4.4 .2 Human development $\ldots \ldots \ldots$. . . . . . . . . . . . . . . 82

4.5 Conclusion $\ldots \ldots \ldots \ldots \ldots \ldots \ldots$

5 Who governs? A new global dataset on members of cabinets $\quad 87$

5.1 Introduction . . . . . . . . . . . . . . . . . . . . . 87

5.2 Existing datasets $\ldots \ldots \ldots \ldots$

5.3 Creation of the dataset $\ldots \ldots \ldots \ldots$

5.4 Validation . . . . . . . . . . . . . . . . . . . . . . . . . . . 94

5.5 Applications . . . . . . . . . . . . . . . . . . . . . . 97

5.6 Conclusion $\ldots \ldots \ldots \ldots \ldots \ldots$

6 Assessing the relationship between constraints and economic develop$\begin{array}{ll}\text { ment within leader } & 107\end{array}$

6.1 Introduction . . . . . . . . . . . . . . . . . . . . . . . . . 107

6.2 Quantitative research on democracy, dictatorship and economic development 109

6.3 Inclusion of cases and operationalization of the two types of constraints . 111

6.4 Empirical analysis . . . . . . . . . . . . . . . . . . . . . . . . . . 122

6.4 .1 Recession and removal of the leader . . . . . . . . . . . . 125

6.4 .2 Economic outcomes . . . . . . . . . . . . . . . . . . . . . 140

6.4 .3 Human development . . . . . . . . . . . . . . . . . . . . . 159

6.5 Conclusion $\ldots \ldots \ldots \ldots \ldots \ldots$

7 Unsuccessful revolutions and public spending patterns: Evidence from $\begin{array}{ll}\text { The Tulip Revolution } & 174\end{array}$

7.1 Introduction . . . . . . . . . . . . . . . . . . . . . . . 174

7.2 The Tulip Revolution . . . . . . . . . . . . . . . . . . . . . . . 177

7.3 Data . . . . . . . . . . . . . . . . . . . . . . . 181

7.4 Synthetic control method . . . . . . . . . . . . . . . . . . . . . 183

7.5 Results . . . . . . . . . . . . . . . . . . . . . . . . . 185

$7.5 .1 \quad$ Placebo plot and robustness checks . . . . . . . . . . . 188

7.6 Conclusion and discussion $\ldots \ldots \ldots$. . . . . . . . . . . . . . . . . 191 
8 The costs and benefits to the ruling coalition after a failed coup attempt 195

8.1 Introduction . . . . . . . . . . . . . . . . . . . 195

$8.2 \quad$ Coups and coup attempts $\ldots \ldots \ldots \ldots \ldots$

8.3 The cost of unsuccessful coup attempts . . . . . . . . . . . . . 201

$8.3 .1 \quad$ Empirical set-up . . . . . . . . . . . . . . . . . . 201

8.3 .2 Analysis $\ldots \ldots \ldots \ldots \ldots$

8.4 The benefit of successful coup attempts . . . . . . . . . . . . . . 214

$8.4 .1 \quad$ Empirical set-up . . . . . . . . . . . . . . . . . 214

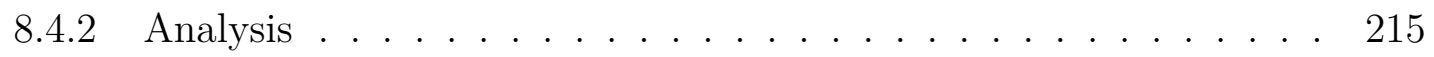

8.5 Conclusion $\ldots \ldots \ldots \ldots \ldots$

$\begin{array}{lll}9 \text { Conclusion } & 222\end{array}$

\begin{tabular}{ll}
\hline Works Cited & 232
\end{tabular}

\section{Appendices}

\begin{tabular}{|ll}
\hline A Appendices to chapter 3 & 246
\end{tabular}

A.1 Appendix to the formal model . . . . . . . . . . . . . . . . . 246

A.1.1 Calculations . . . . . . . . . . . . . . . . . . . . 246

\begin{tabular}{|lll}
\hline A.1.2 The case of a very strong ruling coalition and/or opposition $\ldots$ & 249
\end{tabular}

\begin{tabular}{ll}
\hline B Appendices to chapter 5 & 250
\end{tabular}

B.1 Codebook for the within-country dataset . . . . . . . . . . . 250

B.2 Codebook for the cross-sectional dataset . . . . . . . . . . . . . . 252

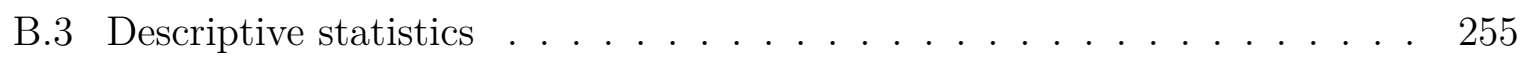

B.4 List of countries . . . . . . . . . . . . . . . . . . . 256

B.5 Description of the data gathering process $\ldots \ldots \ldots \ldots \ldots$

B.6 Title Classifications . . . . . . . . . . . . . . . . . . . . . . . . 262

\begin{tabular}{lll}
\hline C Appendices to chapter 6 & 265
\end{tabular}

C.1 Log-transformation . . . . . . . . . . . . . . . . . . . 266

C.2 Cox proportional hazard with interaction . . . . . . . . . . . 266

C.3 Repeating the analysis with The Maddison Project Database . . . . . . . 268

C.4 Logit regression for economic recession . . . . . . . . . . . . . . . . 271

C.5 Human development in poor democracies . . . . . . . . . . . . 272

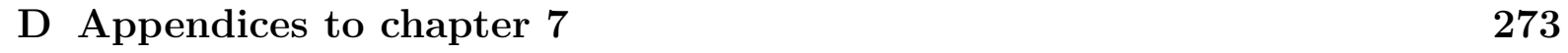

D.1 Only including autocracies . . . . . . . . . . . . . . . 274

D.2 Leave one out . . . . . . . . . . . . . . . . . . . . 275 
\begin{tabular}{lll}
\hline E Appendices to chapter 8 & 277
\end{tabular}

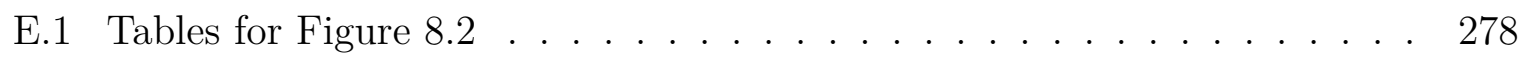

E.2 Alternative measure of failed coup . . . . . . . . . . . . . . . . 281

E.3 Using polity as a democratic/autocratic classification variable . . . . . . 282

E.4 Tables for Figure $8.3 \ldots \ldots \ldots \ldots \ldots \ldots$

E.5 Alternative measure of failed coup - Individual results . . . . . . . . . 285

E.6 Alternative democracy measure - Individual results . . . . . . . . . 286

E.7 Importance index . . . . . . . . . . . . . . . . . . . . . . . . 287

E.8 $\quad$ Alternative measure of successful coup for table 8.2. . . . . . . . . . 288

E.9 Using average years of experience as an alternative measure of political instability . . . . . . . . . . . . . . . . . . . . . . . 289 


\section{List of Figures}

2.1 Presentation of the causal mechanism . . . . . . . . . . . . . . . . . . . . 11

2.2 Types of authoritarian regimes over time $\ldots \ldots \ldots \ldots$

3.1 Game tree . . . . . . . . . . . . . . . . . . . . . . . . . . . . . . . . . 38

3.2 The probability that a bad dictator will choose $e_{1}=s_{1} \ldots \ldots$. . . . 51

3.3 The probability that a bad dictator will choose $e_{1}=s_{1} \ldots \ldots$. . . . 55

3.4 The size of $\mathrm{m} \ldots \ldots \ldots \ldots \ldots$

3.5 The probability that a bad dictator will choose $e_{1}=s_{1} \ldots$. . . . . . . 60

$3.6 \quad$ The probability that a bad dictator will choose $e_{1}=s_{1} \ldots \ldots$. . . . . 61

4.1 Distribution of growth rates amongst democracies and autocracies . . . . 67

4.2 Presentation of the causal mechanism . . . . . . . . . . . . 75

5.1 The cabinet in the Central African Republic, July 1968. . . . . . . . . . . 92

5.2 Final output for Denmark, July $1968 \ldots \ldots$. . . . . . . . . . . 93

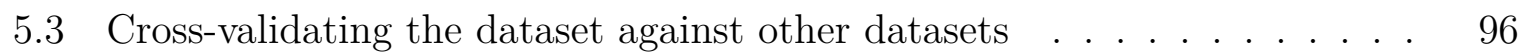

5.4 Country averages in the period 2000-2016 . . . . . . . . . . . . . . 98

5.5 Four puzzles in autocracies . . . . . . . . . . . . . . . . . . 102

$5.6 \quad$ Experience and retention rates in autocracies . . . . . . . . . . . . . . 105

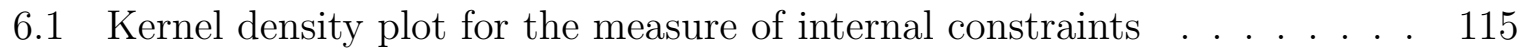

6.2 Relationship between the tenure of the autocrat and average tenure of core cabinet members for selected autocrats . . . . . . . . . . . . . . . . 116

6.3 Average retention rate over time by retention rate in the first two years . 117

6.4 Histogram for the measure of external constraints . . . . . . . . . . . . . 119

6.5 Survival and hazard rate for three types of leaders dependent on their level of constraints. . . . . . . . . . . . . . . . . . . . . . . . . . . 132

6.6 Survival plots for leaders who experience a recession and the matched sample, who did not experience a recession, dependent on the level of constraints. . . . . . . . . . . . . . . . . . . . . . 135

6.7 Association between average retention rate, civil society and economic growth 142

6.8 Effect of relative experience on economic growth dependent on the strength of civil society . . . . . . . . . . . . . . . . . . . . . . . . . 148 
6.9 Interaction plot for the effect of the level of constraints on changes in infant mortality . . . . . . . . . . . . . . . . . 165

6.10 Interaction plot for the effect of the level of constraints on changes in primary school enrolment . . . . . . . . . . . . . . . . 166

7.1 Actual versus the synthetic Kyrgyzstan on the four measures of human development. . . . . . . . . . . . . . 186

7.2 Placebo plots for the four variables . . . . . . . . . . . . . . . . 191

8.1 Distribution of retention rates in years with and without a coup attempt. 207

8.2 Main results . . . . . . . . . . . . . . . . . . . . 209

8.3 Who is purged? . . . . . . . . . . . . . . . . . . . . . 213

8.4 Distribution of replacement rates in years with and without a successful coup. 216

8.5 Marginal effect of a successful coup on difference in economic growth three years after and three years before a coup dependent on the replacement rate in the year of the coup. . . . . . . . . . . . . . . . . . . . . . 220

E.1 Cabinet-level results: Bjornskov and Rode measure of coup . . . . . . . . 281

E.2 Cabinet-level results: Polity $(<7)$ as classification variable for autocracy . 282

E.3 $\quad$ Individual analysis using Bjørnskov and Rode (2019) . . . . . . . . . . . 285

E.4 Individual analysis using Polity IV . . . . . . . . . . . . . . . . 286

E.5 Distribution of replacement rates in years with and without a successful coup.289

E.6 Marginal effect of a successful coup on difference in economic growth three years after and three years before a coup dependent on the replacement rate in the year of the coup. . . . . . . . . . . . . . . . . . . . . . . . . 291 
Isolated men are powerless by definition

— Hannah Arendt (1951, p. 474)

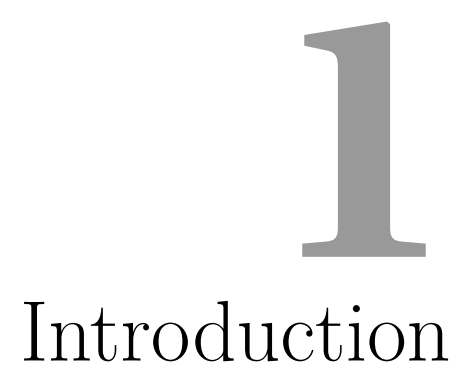

Autocrats and their supporters argue that constraints on the leader hinder economic development. For example, an editorial in The Global Times, a Chinese newspaper, argued that "We are increasingly confident that the key to Chinas path lies in upholding strong party leadership and firmly following the leadership of the Party Central Committee with Comrade Xi Jinping at the core" following the removal of term limits on the Chinese president (Reuters 2018). Furthermore, these claims are often being repeated by journalists, researchers and politicians in democratic countries. A piece in The Times reads that "Trump, Putin, Erdogan and Duterte are unpalatable demagogues in many ways but at least they get things done" (Foges 2018), while another piece in the New York Times read that "One-party autocracy certainly has its drawbacks. But when it is led by a reasonably enlightened group of people, as China is today, it can also have great advantages" (Friedman 2009). New research show that these sentiments are being shared to an increasing degree amongst the wider population, and that significant minorities in some countries are in favour of rule by a strong leader (Brown 2014; Foa and Mounk 2016; Foa et al. 2020; 
Wike et al. 2017). In this thesis, I show that the belief in the developmental benefits of having a strong authoritarian leader is not supported empirically. Instead, autocrats govern over worse economic development when they become more powerful.

The study has a broad view of economic development as a process where the wellbeing of the inhabitants of a country is improved. Economic development is therefore an umbrella term covering different concepts of development such as economic growth, human development, human rights and the level of inequality. Covering all aspects of economic development is an enormous task and the study will therefore focus on two aspects; namely economic outcomes (economic growth and recessions) and human development outcomes (infant mortality and primary school enrolment). Despite the huge literature that compares autocracies with democracies and democracies with other democracies, we know little about why development outcomes differ among - or within - authoritarian regimes (Gandhi 2008; Miller 2015; Przeworski 2000). Data show that autocracies and democracies, on average, have about the same rate of growth, but that autocracies have more dispersed growth rates. 1 This indicates that we are missing important insights by focusing on the dichotomy between autocracy and democracy. Furthermore, it suggests that autocracies are more likely to produce both high growth, but also catastrophic results which cause great human suffering. Przeworski et al. (2000, p. 178) argue that "the lists of miracles and disasters are still populated almost exclusively by dictatorships". For example, China has within a 50 year time frame both experienced a famine where

\footnotetext{
${ }^{1}$ Data from Penn World Tables $(2015)$ show that the growth rate in real GDP per capita on average is 1.8 per cent for autocracies and 2.4 per cent for democracies in the period from 1950 to 2016. The standard deviation is 4.6 per cent for democracies and 7.7 per cent for autocracies. The data is plotted in Figure 4.1.
} 
20-45 million people died (Dikötter 2010; Peng 1987), and an economic boom where hundreds of millions of people were lifted out of poverty.

Apart from this introduction, the thesis consists of 8 other chapters. The first 3 are mainly theoretical, the next four are mainly empirical, while the last chapter is the conclusion.

In the second chapter, I will introduce the approach to authoritarian regimes taken in this thesis. First, I define authoritarian regimes and argue that the essence of dictatorship is the absence of an independent authority which can enforce agreements among key political players. Then I discuss existing approaches to classifying authoritarian regimes, and contend that the literature focuses too much on the regime or type of dictator. Instead, I propose that we should focus more on the rule of one leader or one country over time. I argue that a dictator can be constrained by both the ruling coalition (internal constraints) and the masses (external constraints). This thesis does not define constraints in institutional terms as has been the norm in recent literature within the field (Brownlee 2007; Gandhi 2008; Geddes 1999; Gehlbach and Keefer 2012; Miller 2015). Instead, constraints are perceived to be the empirical manifestation of the distribution of power. Thus other powerful actors can constrain the leader with the threat of violence. Based on Hannah Arendt's (1951) concept of isolation I argue that when the masses or the ruling coalition are atomized they become powerless and therefore unable to hold the autocrat accountable. Building on this, I put forward a dynamic typology for classifying autocracies according to the level of constraints on their rule.

In the third chapter, I present a formal model on how an autocrat will change 
his actions dependent on the level of constraints. When the ruling coalition and/or the civil society are strong, the dictator faces a credible threat of removal. The dictator can then be held accountable for hi: $2^{2}$ actions and risks being removed in the case of bad economic performance. This increases the likelihood that he will choose actions which are costly for him individual, but yields benefits to others.

Based on the model, I, in chapter four, connect constraints with economic development. There are two prevailing explanations for the diverging developmental patterns in autocracies. One line of research argues that quasi-democratic institutions, such as elections and parliaments, in authoritarian regimes promote development by improving state accountability and deliberative decision making (Blaydes and Kayser 2011; Chandra and Rudra 2015, Gandhi 2008, Miller 2015). Another line of research argues that a strong ruling coalition can hold the dictator accountable and thereby foster economic growth (Besley and Kudamatsu 2008, De Mesquita et al. 2005: Gehlbach and Keefer 2012; Svolik 2012). I combine these two arguments and argue that we should focus both on the ruling coalition (internal constraints) and the masses (external constraints). The two types of constraints will result in higher economic development through three channels. First, the level of constraints is decisive for whose preferences get to influence the policy making process. It is expected that the preferences of the ruling coalition and - in particular - the masses are more pro-developmental than the autocrat's. Second, constraints on the autocrat will promote a more thoughtful, less rushed decision-making process, where competence and experience play a larger role. Third, constraints will create policy stability

\footnotetext{
${ }^{2}$ There are no female autocrats in the dataset and I will therefore consistently use male pronouns in this thesis.
} 
and foster an environment that is conducive to economic investment. I therefore theorize that the two types of constraints are associated with better economic development. However, one type of constraints should be sufficient to avoid a situation where the dictator acts unconstrained. The two types of constraints are therefore substitutes and the interaction between them should be negative. However, while both types of constraints are expected to be associated with higher economic growth, this does not entail that the economic gains are distributed equally. The average citizen benefits more from investments in healthcare and education than the elite. It is, therefore, expected that only external constraints are associated with better human development.

In order to test the theory, I construct a new dataset, WhoGov, on governing elites in both autocracies and democracies. In the fifth chapter, I introduce this new dataset. WhoGov contains yearly data on members of cabinets in 177 countries during the period 1966 to 2016, making it the largest of its kind. An article presenting the data has been published in the American Political Science Review (Nyrup and Bramwell 2020). This adds up to 4,210 authoritarian country years and 3,169 democratic country years..$^{3}$

In the sixth chapter, I present the main cross-sectional analysis. Based on Arendt's concept of isolation I operationalize internal and external constraints. Internal constraints are operationalized as the average experience of core cabinet members divided by the tenure of the dictator. The expectation is that more experienced and consolidated cabinet ministers are able to form cliques and coordinate between them. This enables the ruling coalition to provide both opposition and guidance to the authoritarian leader. This

\footnotetext{
${ }^{3}$ The analysis relies on fewer observations. This is primarily due to missing observations on other variables
} 
measure of internal constraints is advantageous compared to other measures of intra-elite balance since it is time-variant and objective. I rely on a new measure on the strength of the civil society, which is provided by V-Dem, to measure external constraints (Bernhard et al. 2015). This index "sees civil society as an emergent realm of contestation with dictatorship" (Bernhard et al. 2015, p. 3). A robust civil society is understood as one that enjoys autonomy from the state and in which citizens freely and actively can pursue their political and civic goals, however one may conceive them.

In the cross-national analysis, I first find that autocrats who are facing internal and/or external constraints are more likely to be removed in the wake of an economic crisis. Thereby, I show that the level of constraints do act as an accountability mechanism in the absence of democratic elections. Afterwards, I look at the relationship between the two types of constraints and economic growth, and find that a dictator governs over worse economic growth when he becomes unconstrained. In addition, I show that the two types of constraints are substitutes, so one type of constraints matters less when there is more of the other. Finally, I find that only external constraints are related to better human development outcomes. We now know that unconstrained dictators produce lower growth and are less likely to be punished for this. Combined, these two findings indicate a vicious circle. This can account for the divergence in economic growth outcomes in authoritarian regimes.

Apart from the cross-national study, I also conduct two studies to support the theoretical model. The study presented in chapter seven focuses on external constraints and investigates how authoritarian regimes respond to revolutions which do not cause 
democratization. Namely, I focus on the Tulip Revolution that took place in Kyrgyzstan in 2005. I argue that a revolution can be perceived as a shock to the level of external constraints which should cause the dictator to focus more on the needs of the civil society. Using a synthetic control design, I show that the revolution caused public spending on education and health care to increase. However, I am unable to find such effects for actual development outcomes such as infant mortality and primary school enrolment.

In chapter eight, I focus on internal constraints. In dictatorships politics are highly informal, secretive, and marred by conflict and tensions. On the one hand, the dictator is trying to avoid a coup by reshuffling and purging members of the ruling coalition. On the other, members of the ruling coalition often are trying to establish their own independent power bases, and involved in plotting against the autocrat. Sometimes this conflict escalates when members of the ruling coalition try to dethrone the dictator. This is what we call a coup d'etat. In the light of the theory, I investigate what happens when a coup d'etat either fails or succeed. First, I show that failed coup attempts are followed by large purges of the ruling coalition. Therefore, it is costly for the ruling coalition to challenge the dictator openly. Next, I turn to what happens when the ruling coalition successfully removes the dictator. Not surprisingly, this causes political instability. In the majority of cases most of the ruling coalition is replaced. However, sometimes the majority of the ruling coalition remains in office. There is merely a change of guards, where a new and more constrained dictator enters. I show that a successful coup is associated with a higher growth equilibria when the majority of the ruling coalition stays, but that this is not the case when a coup results in political instability. 
In the ninth chapter, I conclude and summarize the results. At last, I discuss avenues for future research and how the findings of this thesis relates to current debates.

The manuscript represents a major contribution to the literature on authoritarian regimes in several ways. It adds to our understanding of authoritarian regimes and why development outcomes diverge in these regimes. Second, the work presents a new typology for classifying authoritarian regimes which is useful in a world where authoritarian regimes are becoming increasingly institutionalized. Furthermore, the thesis presents and uses a new dataset on elites in both authoritarian and democratic countries. This dataset is already being used by hundreds of researchers from all over the world. Lastly, and most important, this thesis fills an important empirical gap. We see strongmen becoming more powerful. They often do so by portraying themselves as mythical creatures who can save the nation and bring about both stability and economic development (Arendt 1951, Brown 2014; Snyder 2018). This thesis shows that these promises more often than not are false. 
Mao's fixation of steel went largely unquestioned, as did other of his obsessions. He took a dislike to sparrows - they devour grain. So every household was mobilized. We sat outside ferociously beating any metal object, from cymbals to saucepans, to scare the sparrows off the trees so they would eventually drop dead from exhaustion. Even today I can vividly hear the din made by my siblings and me, as well as by the government officials, sitting under the mammoth wolfberry tree in the courtyard. - Jung Chang, Wild Swans (2003)

\section{Autocracy as a process of isolation}

\section{Contents}

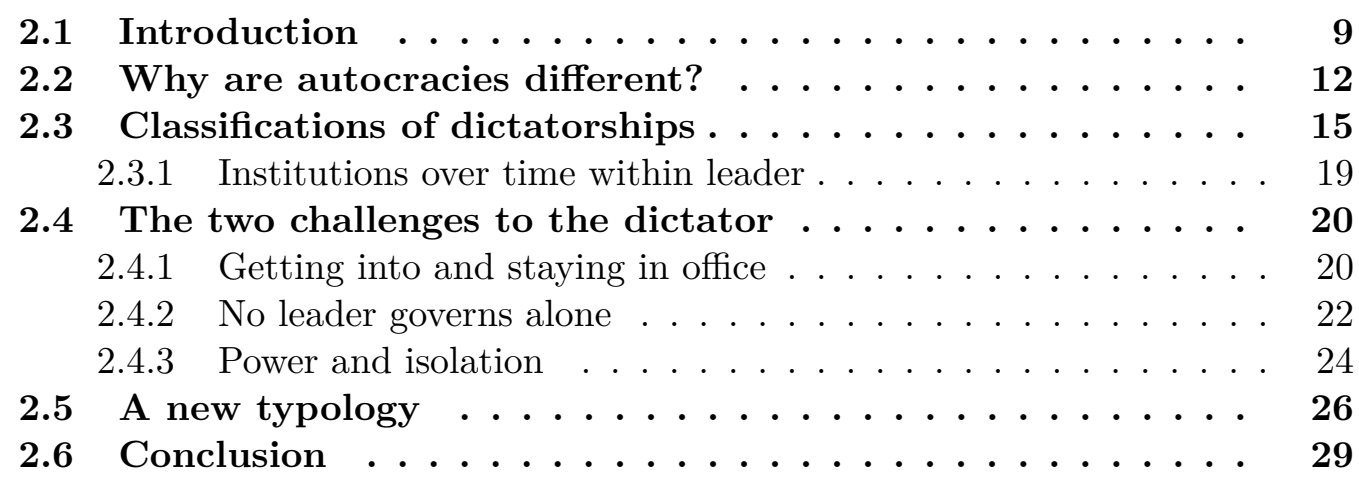

\section{$2.1 \quad$ Introduction}

The policy of eradicating sparrows was a part of the Great Leap Forward which was a set of policies the Chinese Communist Party launched in 1958 with the aim of increasing China's industrial output. The policy was effective and within a year the sparrow was almost exterminated in China. However, as the Chinese leaders came to realize, sparrows do not only eat grain, but also insects that destroys the crops. Soon locust populations 
ballooned, and this policy, compounded with a set of other policies, including deforestation, a reduction in agricultural labour, and misuse of pesticides, led to famine. Overall, the Great Leap Forward had catastrophic consequences for the Chinese population, and an estimated 20-45 million people died (Dikötter 2010 Peng 1987). This example shows two things which are of relevance for the theoretical argument presented in this thesis. First, authoritarian countries may be highly effective in implementing the ideas or preferences of the autocrat (Wintrobe 2000). Ideas, which can have an effect on the most intimate and trivial parts of people's lives. Second, these ideas may be self-interested, ill-informed, counter-productive or downright crazy, and when implemented they can have devastating consequences with grave human costs. However, not all autocrats act in a vacuum. Instead, they may be constrained by a ruling coalition and/or a civil society which credibly can threaten to overthrow the autocrat. The dictator can then be held accountable for his actions. This will result in a more pluralistic and thoughtful decision-making process, a more competent ruling elite, more policy stability, and a better environment for investments. Overall, this is expected to lead to better economic development.

A simple version of the causal mechanism presented in the following theoretical chapters is presented in figure 2.1. The mechanism can be exemplified with the case of Mao. Teiwes (2001, p. 79) argues that Mao's tenure "can essentially be divided between the period before 1958 when the Chairman listened to interests within the system and sought results that took those interests into account..., and the subsequent 'later Mao' period when he simply overrode interests...". Unfortunately for the Chinese population, Mao was governing unconstrained and launched the Great Leap Forward. This enabled him to 
implement a series of devastating policies without facing any personal consequences and hardly any critique or opposition (Dikötter 2010). In the following three chapters, I will argue that he would have been more careful had he been constrained by either a ruling coalition or an organized opposition who credibly could threaten to remove him when observing the grave human costs of his policies. He would, therefore, be forced to implement policies better for economic development to stay in power. Alternatively, he would have been forced from power and replaced with another leader. Thus constraints on the leader would have increased the level of economic development in China.

Figure 2.1: Presentation of the causal mechanism

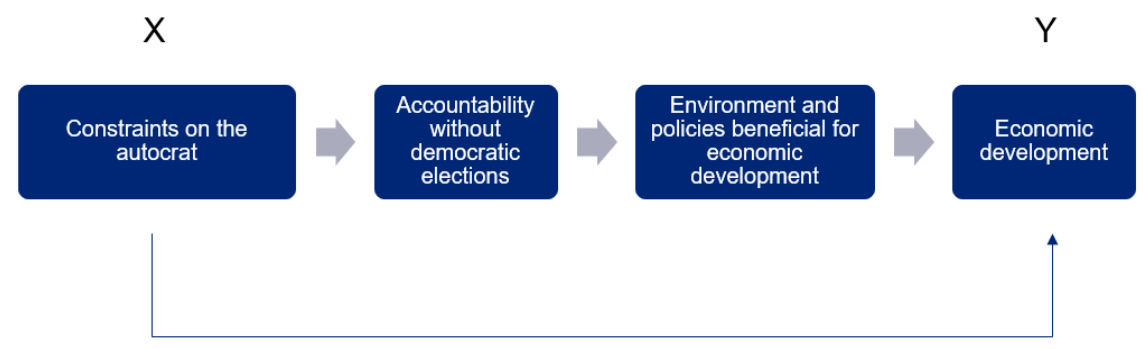

This chapter is the first of three theoretical chapters. Here, I will present the concepts related to authoritarian governing. More specifically, I will argue that autocracies are different from democracies. Then I will discuss how the literature differ between types of autocracies, and argue that we need to perceive authoritarian rule as a process rather than a static category. Based on this, I present a new way of categorizing autocracies. This approach is based on Svolik's (2012) two challenges to the dictator. I argue that the dictator can be constrained by a strong ruling coalition (internal constraints) or an 
organized civil society (external constraints) who can threaten the dictator with rebellion. Next, I turn to how to perceive constraints, and argue that they are the result of power relationships. I then rely on Arendt's concept of isolation to conceptualize power. Then, I put all these parts together and present a new typology.

\subsection{Why are autocracies different?}

Democracies and autocracies are in this thesis perceived to be two substantially different types of political systems with their own internal political processes. The distinction between democracies and autocracies is, however, not clear-cut. No one will place the Soviet Union, North Korea or Nazi Germany in the democratic category. But other regimes are harder to place. Consider for example Mexico where a new president was elected every six years for almost seven decades. Nevertheless, until the election in 2000, the same party's candidate always won (Magaloni 2006). Or Singapore where elections are held regularly, but with the People's Action Party (PAP) as the clear winner every time (Er 1999). In the latest election in the summer of 2020 the PAP won 83 out of 93 seats. These borderline cases makes it difficult to draw a clear line and results in inconsistencies between indices (Coppedge 2012, Munck and Verkuilen 2002; Skaaning et al. 2015).

One of the reasons for the confusion is that autocracies are incredibly diverse. Some have institutionalized systems with legislatures, parties, and elections, while other regimes seem chaotic, uncoordinated, and without functioning institutions. Authoritarian regimes are perhaps only unified by the failure to meet the established criteria set up for democracy, and in most analyses autocracies therefore are defined as the residual category to democracies (Gandhi 2008, p. 3). In the light of this manuscript's research question 
this definition is insufficient and does not provide much insight. It must be clear why it makes sense to study autocracies as a separate category and how they differ substantially from democracies. Here, I use a procedural and minimalist classification of regime types based on Joseph Schumpeter's definition of the democratic method where it is an institutional arrangement for arriving at political decisions in which individuals acquire the power to decide by means of a competitive struggle for the peoples vote (Schumpeter 1976, p. 269). Following this definition, I define autocracies as regimes in which rulers acquire power by means other than a competitive election, with the exception being when the ruler first enters into power by an electoral process and then consolidates his power at the expense of democracy. ${ }^{1}$

The essential part of this definition is the notion of a competitive election. Regimes with no electoral processes aimed at choosing an executive ruler for the country are thereby autocracies. The same goes for regimes that do have elections, but where the elections do not fulfil the competitive criteria. A competitive election is an election where there is the existence of a reasonably level playing field between incumbents and opposition (Levitsky and Way 2010, p. 6). When incumbent manipulation of state institutions and resources is so excessive and one-sided that it seriously limits political competition through the ballot box, it is incompatible with democracy. From this it also follows that a regime can slide from being democratic to autocratic if it no longer fulfil these criteria. Going back to previous examples it is evident that the Mexican and Singaporean regimes cannot be included in the democratic group. In Mexico the governing party skewed the elections and engaged in massive fraud (Magaloni 2006). In Singapore the

\footnotetext{
${ }^{1}$ A comparable definition is used in Gandhi's (2008) and Svolik's (2012) work.
} 
PAP has effectively restricted the oppositions chance of competing (Mutalib 2000). This definition entails a sharp dichotomy between democratic and authoritarian regimes and it implies two different ways of organizing political lives; of selecting rulers; of processing conflicts and making and implementing public decisions. In this manuscript, I will use the terms dictatorship and authoritarian regime interchangeably and refer to the head of governments as either dictators or autocrats.

As discussed before, the absence of competitive elections is central to the definition used here. In a democracy, elections function as an independent authority which puts constraints on the ruler and enable the electorate to punish him if they are not satisfied with his work (Besley 2006; Svolik 2012). Thus, the absence of an independent authority which can enforce agreements among key political players constitutes the essence of dictatorship (Svolik 2012, p. 14). This implies that agreements made at one point can be broken later when they become inconvenient. Yet, breaking promises is not without risk and the option of violence is therefore always on the table to solve disputes in authoritarian politics. The political life in a dictatorship is therefore fundamentally different than in a democracy. In democracies disputes should be solved through functioning institutions, the rule of law, and ultimately through the electoral process (Besley 2006). On the other hand, in autocracies claims and commitments can only be backed up with the threat of brute force. Under a dictatorship institutions therefore cannot be taken at face value (Pepinsky 2014). Instead, they mirror the power relations among the dictator, his ruling elite and the opposition which is excluded from power. This is not to say that institutions do not matter, and that they do not have the capacity to prevent conflicts and change the 
behaviour of actors, but this is only so when the institutionalized "rules of the game" rest on mutual advantage and respect for the power of key participants (Svolik 2012, p. 15).

\subsection{Classifications of dictatorships}

It is now clear how democracies and autocracies differ from each other and why they constitute two different types of regimes. The manuscript sets out to investigate whether autocrats govern over worse economic development when they become more powerful. To examine this question I will discuss previous approaches to classifying authoritarian regimes, and argue that we need to perceive the rule of an autocrat as a process rather than a type.

Early classifications focus on the difference between authoritarian/tinpot and totalitarian regimes (Linz 2000 Tullock 1987; Wintrobe 2000) or autocrats with short and long time horizons (McGuire and Olson 1996, Olson 1993). Scholars, particularly within political science, have since moved beyond these distinctions and provided us with a great number of different typologies and classifications. In the following, I will focus on two different groups of classifications which have great prominence in the literature; one group that focuses on descriptive characteristics, such as the type of dictator and his background (Gandhi 2008, Geddes 1999, Magaloni and Kricheli 2010), and another group that focuses on the degree of institutionalization and the level of competition (Diamond 2002; Levitsky and Way 2010).

The arguably most used classification of authoritarian regimes is Geddes' (1999) classification with three categories. These are: 1) single-party, 2) personal, and 3) military regimes. A fourth category, the monarchic regime, is later added to the dataset (Geddes et al. 2014 Hadenius and Teorell 2007). What distinguishes the different types in Geddes 
definition is the way that the leader assumes power, and how the leader manages the relationship with the rest of the elite. Another classification is Gandhi's trichotomy (2008), where authoritarian regimes are categorized according to the organization the leader belongs to. She classifies autocracies as either civilian, military, or monarchic. A third classification is Magaloni and Kricheli's (2010) who divide regimes into military, monarchic, single-party, and dominant-party authoritarian regimes.

These typologies face shortcomings. First, the classifications face theoretical problems. This is best exemplified by using Geddes' classification. One problem is that some, or all, personalist dictators did not rise to power as personalist dictators. Instead, they became personalist over time. An example is Muammar al-Gaddafi who came to power in Libya in a military coup in 1969, and ruled through the 12 member central committee of the Free Officers until 1977. In 1975, two members of the committee launched a failed coup against Gaddafi, and in the aftermath only five members remained. In 1977, the council was abolished. Gaddafi then increasingly centralized political power by murdering opponents and replacing them with people loyal to him. Gaddafi is therefore an example of an autocrat whose regime in the early years would belong in the military category, but became increasingly personalist over time. This example shows the problem with Geddes' categories; they are added post-hoc, are not mutually exclusive, and does not allow variation over time. This leads to problems. This is especially the case when the regime type is used as an independent analytical category with the purpose of explaining variations in variables such as leader tenure, since a personalist autocrat became personalist because of a long tenure. Another example is Singapore that currently could be classified 
simultaneously as a monarchy, a military regime, and a civilian-regime. The current prime minister, Lee Hsien Loong, who is the son of the former prime minister, Lee Kuan Yew, has a distinguished military career and is the leader of the dominating PAP (Holler 2019).

Figure 2.2: Types of authoritarian regimes over time

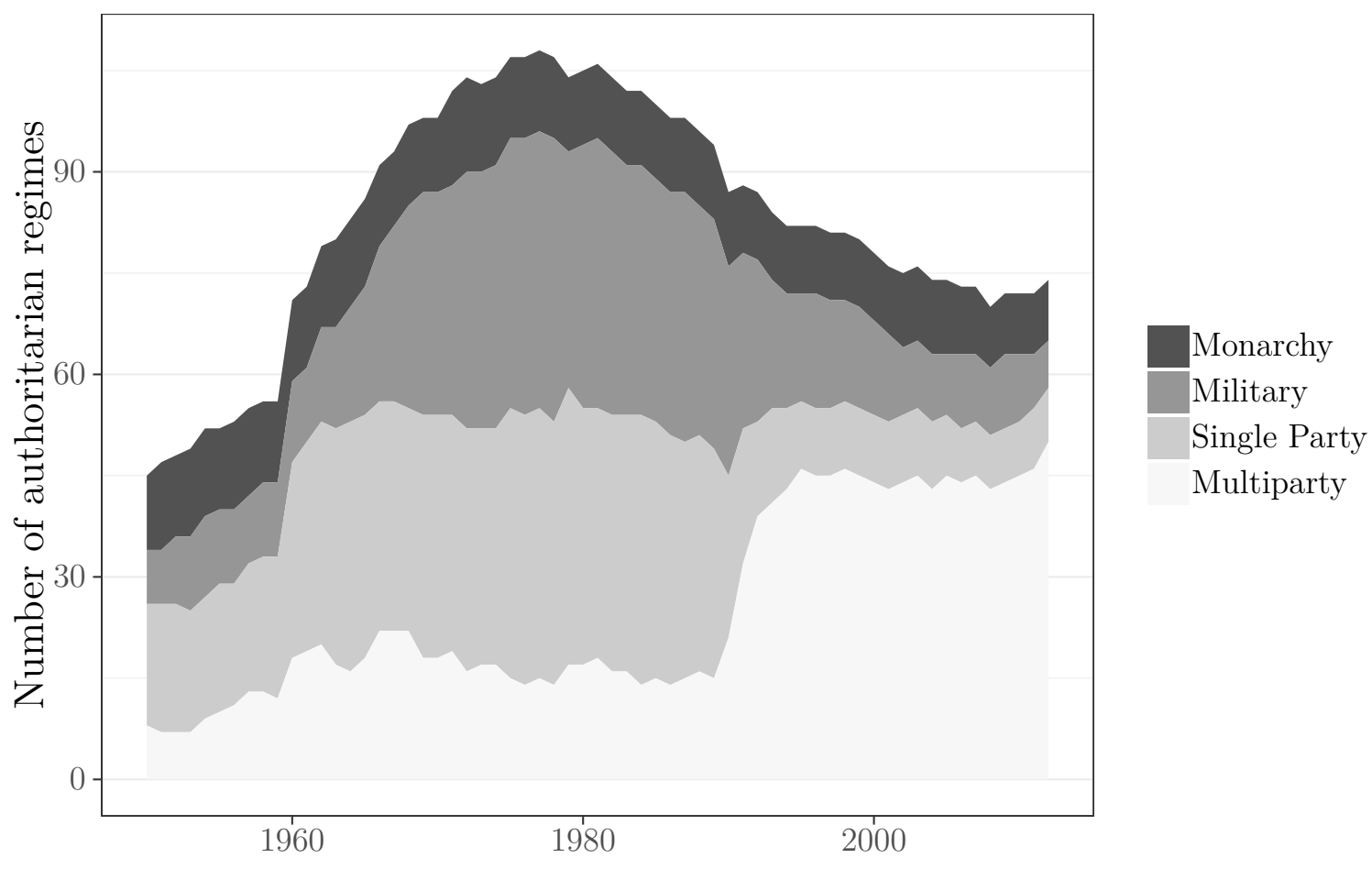

Source: Magaloni and Min (2013)

Another group of scholars focus on whether the regime is open to competition or not. Here, non-democratic regimes are divided into those with multi-party electoral competition of some kind ${ }^{2}$ and those that are politically closed. The electoral authoritarian regimes can then be divided into competitive authoritarian, where competition is real but unfair, and non-competitive (Levitsky and Way 2010) or hegemonic regimes (Schedler 1998). These distinctions provide an important insight into the world of modern dictatorships and are useful for describing recent trends in the institutional set-up. Nonetheless, they tend to

\footnotetext{
${ }^{2}$ These are described with terms such as "illiberal democracy" ,"electoral authoritarian", "pseudodemocratic", or "hybrid regimes".
} 
focus exclusively on the relationship between the regime and the opposition, and therefore ignores the relationship between the ruling coalition and the autocrat. They therefore have difficulty explaining developments within non-competitive regimes with a strong ruling party such as China or Vietnam. Alongside these definitions there are researchers conducting empirical research where they classify autocracies based on the descriptive existence of certain institutions. For example, Gandhi (2008) defines "institutionalized" dictatorships as ones with more than one political party in the legislature, Miller 2015; 2020) defines electoral autocracies "as regimes with legal multiparty competition in legislative elections", and Gehlbach and Keefer (2012) define the ruling party as institutionalized if it was founded before the leader took power.

We are from an empirical point of view facing a world where authoritarian countries are becoming increasingly institutionalized and cluster in what Geddes calls the single-party regime group ${ }^{3}$, what Gandhi calls the civilian group, or what Magaloni and Kricheli call single-party and dominant party authoritarian regimes. This is seen in figure 2.2 . Today, there are only 5 autocratic regimes in the world where there is no existence of a party system ${ }^{4}$. Furthermore, today virtually all autocracies have legislatures and parliaments (Meng 2020; Wig et al. 2015) . $^{5}$ We are therefore facing a world where there is one dominant type of authoritarian regime; the party regime with elections and legislatures. In other words, there is simply minimal variation in the existence of institutions in modern day autocracies. This thesis is therefore a response to an empirical

\footnotetext{
${ }^{3}$ Other parties may exist, but access to office is controlled by a single party

${ }^{4}$ These are United Arab Emirates, Swaziland, Saudi Arabia, Qatar, and Oman, while other regimes, such as Morocco, do have political parties which do not compete for the executive power.

${ }^{5}$ In 2010 only one country in the IAEP dataset did not have a legislature; Myanmar, which installed one in 2011
} 
trend where the existing distinctions between authoritarian regimes with and without legislatures and/or parties are becoming less relevant.

\subsubsection{Institutions over time within leader}

This also leads me to a broader point about institutions in the framework I will present. The approach in this thesis departs in an important way from much of the recent literature on autocracies, since it pays limited role to institutions. The argument is, however, not that institutional features are inconsequential. There is a large and convincing literature on the role of institutions in autocracies (Acemoglu et al. 2005, Bizzarro et al. 2018, Gandhi 2008, Gandhi and Lust-Okar 2009, Miller 2015). Economic development is a complex phenomena where many non-institutional and institutional factors play a role.

However, the main argument presented here relates to economic development over time for one leader. Institutions are better suited to explain variation when they either are inherited from a previous leader (Gandhi and Przeworski 2007; Gehlbach and Keefer 2012 Miller 2015) or are established in the beginning of a new ruler's tenure (Brownlee 2007; Meng 2020). Easily identifiable institutions, such as the existence of parliaments and elections, are relatively static.

Furthermore, if institutions do change it may be due to changes in the underlying power distribution. As mentioned above, Gaddafi removed the central committee of the Free Officers. Gadaffi is far from alone in changing the constitutional set-up when being very powerful. Prominent recent examples are Putin changing the constitution allowing him to rule until 2036, Erdogan giving himself sweeping powers as president through a constitutional referendum, and Xi Jinping removing term limits. Likewise, 
institutions can be forced upon the dictator if other actors become more powerful. A strong opposition may demand elections as a concession, while a strong ruling elite may demand term limits. Institutions can therefore be a symptom of underlying changes in the power distribution (Pepinsky 2014). At last, there can also be institutional changes that do not reflect any changes in the power distribution, but more or less are arbitrary choices of the dictator. After all, if a dictator can create an institution, then he can also dismantle it again (Meng 2020).

Thus, I will try to go beyond institutions and focus on the underlying power distribution.

\subsection{The two challenges to the dictator}

In the previous section, I argued that we need a new approach to authoritarian regimes to explain economic development over time for the same leader. This approach should take into account the dynamic nature of authoritarian regimes, it should not take institutions as a given, and respond to the fact that authoritarian regimes increasingly cluster in one category in existing typologies. To do this, I start with two simple and fundamental ideas which there is broad agreement on in the literature on autocratic regimes. First, the predominant goal of the autocrat is to enter office and stay there, and, second, when he is in office, he never governs alone.

\subsubsection{Getting into and staying in office}

There is universal agreement in the literature on that the primary goal of an autocrat is to gain power and then retain it (De Mesquita et al. 2005; Gandhi 2008, Geddes et al. 
2018; Svolik 2012, Tullock 1987; Wintrobe 2000). This leads to a very dim view of how authoritarian politics works where leaders are self-interested and do what is necessary to come to power and stay there. Subsequently, they try to fulfil secondary goals such as implementing policies in accordance with their belief, engaging in grandiose projects, or reaping the rents from being in office (Gandhi 2008; Gjerløw and Knutsen 2019, p. 82). Gerschewski (2013) identifies three strategies which the dictator can rely on to stay in office; repression, co-optation, and legitimation.

Repression is when the autocrat employs either soft coercion by, for example, administrative discrimination or hard coercion, such as violence by military forces. Co-optation is the capacity of the autocrat to tie strategically relevant actors to him so they become complicit. This strategy can be pursued by buying off discontent actors materially, through patronage, or by delivering public goods in order to co-opt specific groups (Svolik 2012, p. 9). Legitimation seeks to guarantee the active consent or passive obedience of both the population and the ruling coalition, by convincing them of the legitimacy of the regime (Gerschewski 2013, p. 19). This can be achieved through the utilization of propaganda, arguing in favour of the regimes desirability or by increasing performance and delivering public goods. A fourth strategy can, however, be added. This is "policy concessions" (Gandhi 2008, p. 76) which is related to Gerschewskis concept of "specific support", i.e. the fulfilment of concrete demands from people. Policy concessions are related to co-optation, but different in nature, since it is used as a response to concrete demands which can be backed up with the use of violence in case these are not met. It can be defined as "quid pro quo for the fulfilment of demands" (Gerschewski 2013, p. 20). The group is 
therefore not co-opted into the regime and does not become complicit, but refrain from using violence when their demands are met. The autocrat has an incentive to meet these demands if he deems it better to give concessions than risking a conflict. The downside for the autocrat of giving concessions is that he risks encouraging and empowering other groups which may prove a risky strategy in the long run.

Not all dictators rely on the same mix of these strategies nor is the level the same over time within a specific regime (Wintrobe 2000). Some regimes are notorious for their use of repression to remove both opponents within the elite and to clamp down on opposition, while other regimes only rely on little repression. Likewise, some regimes engage in redistributive policies which benefit the wider population, while other regimes ignore their population (Eibl and Hertog 2017; Mesquita and Smith 2010).

\subsubsection{No leader governs alone}

If we want to explain how a dictator gets into office and stay there, we must look at the second point mentioned above; no leader governs alone. Even the most powerful dictators depend on subordinates to carry out their orders, control the country, and create rents. In the absence of elections we must look elsewhere for threats to the rule of the dictator. Scholars of authoritarian rule have for long distinguished between the masses/the common people and the government/the noble men (Arendt 1951; Hume 1994; Machiavelli 1961; "The Dictator's Power-Sharing Dilemma"). The distinction is most clearly described by Svolik (2012, p. 3). According to Svolik (2012, p. 3), all autocrats face two fundamental challenges. The first comes from the masses over which they rule. How are the masses kept under control? This is the problem of authoritarian control. 
The second challenge arises from those with whom they rule. How do rulers keep the ruling coalition under control? This is the problem of authoritarian power-sharing. This creates a balancing act; the dictator must rely on some people in order to rule, but if he looses support he risks being removed.

In the absence of elections, we must look at these relationships to understand how authoritarian leaders are constrained and the two challenges therefore constitute the two types of constraints which an autocrat faces. All dictators must constantly ask themselves the two questions mentioned before and act accordingly. Dictators who do not provide sufficient answers to these questions will be removed from power and risk facing harsh punishment and even death.

The combination of the use of the strategies mentioned above will vary dependent on the likelihood that either the masses and/or the ruling coalition successfully can rebel against the dictator. If there is a high likelihood that an eventual rebellion will succeed, repression may be a dangerous strategy since it may ignite a revolt. Therefore, the dictator will have to act accordingly and instead of solely maximizing his own utility, he has to listen to the demands of the ruling coalition and the masses to stay in office. He will, therefore, have to use strategies that are less confrontational such as co-optation, legitimation, and policy concessions. Thus, the actions of the autocrat depends on the relative strength of the autocrat versus the strength of both the ruling coalition and the masses. This idea of authoritarian politics is not alien in the literature. Wintrobe $(2000$, p. 4) writes that "Perhaps the central point of departure in what follows is that although the dictator may have a formal monopoly with regard to political power, the policies pursued on 
all these matters is conditioned by constraints which arise both from the behaviour of other actors - including the administration or bureaucracy, as well as the military - and from the extent of support of opposition from the dictator's subjects", and Svolik (2012, p. 53) distinguishes between "a contested autocracy" and "an established autocracy". In a contested autocracy, politics is balancing between the dictator and his allies, and the latter are capable of using the threat of a rebellion to deter the dictator's opportunism, even if imperfectly. By contrast, in an established autocracy the autocrat has acquired enough power, so he can no longer be credibly threatened by his allies' rebellion.

\subsubsection{Power and isolation}

This thesis does not define constraints in institutional terms, which has been the norm in recent literature within the field (Brownlee 2007; Gandhi 2008; Geddes 1999; Miller 2015). Instead, the perception of constraints follows Pepinsky (2014, p. 635) who argues that "The presence of dominant parties, the nature of institutional rules, forms of legislative competition, and other aspects of authoritarian institutions will reflect the distribution of power in authoritarian regimes rather than exogenously shape it". Institutions are, therefore, seen as the empirical manifestations of the distributions of power. Constraints are, therefore, perceived as being the result of power relationships where other powerful actors can constrain the leader with the threat of violence (Svolik 2012).

Power is, in this thesis, defined as the probability that an actor will prevail in the case of a conflict with another actor. There are many variables which determines whether an autocrat will prevail in a conflict with the ruling coalition or the civil society. These are, for example, relative arms technology (McNeill 1983), bureaucratic capacity, strategic 
superiority, and foreign support (Bunce and Wolchik 2011). However, one factor is arguably more important and fundamental than the rest, namely the ability of either the ruling coalition or the masses to "act in concert" and stay united when facing the autocrat (Burke 1842, p. 131). This argument is found through out the literature on authoritarian regimes (see for example Bunce and Wolchik (2011), Gehlbach and Keefer (2011; 2012) and Svolik (2012)).

At the end of the day, every autocrat is no more than a mortal human made of flesh and blood, just like everyone else. If the ruling coalition unanimously decides to remove the autocrat, he has no other option than to leave. Likewise, if every single member of the civil society rises up against the regime and stands firm, the regime will collapse.

Arendt discusses this intensively in The Origins of Totalitarianism, and puts forward the concept of "isolation". She writes that "isolation is that impasse into which men are driven when the political sphere of their lives, where they act together in the pursuit of a common concern, is destroyed" (Arendt 1951, p. 474). Based on this, she argues that "Isolated men are powerless by definition". Ultimately, an autocrat, therefore, derives his powers from the ability to isolate his opponents. Both the civil society and the ruling elite are, therefore, more powerful if they can overcome collective action problems.

Earlier on I argued that there are two dimensions on which the autocrat can be constrained. Likewise, Arendt focuses on both the masses and the ruling coalition in her work and argues that "The evidence of Hitlers as well as Stalins dictatorship points clearly to the fact that isolation of atomized individuals provides not only the mass basis for totalitarian rule, but is carried through to the very top of the whole structure" (Arendt 
1951, p. 407). Thus, both Hitler and Stalin coup-proofed their rule by destroying the fabric of the civil society and by hindering cliques within the ruling coalition by purging elite members. The thesis will rely on Arendt's concept of isolation to derive measures for the level of internal and external constraints.

\subsection{A new typology}

Based on the discussion above, there are two dimension on which the autocrat can be constrained and held accountable for his actions. He can be constrained by the the ruling coalition, which I call internal constraints, and the masses, which I call external constraints. The distinction between the different dimensions can be summed up in a typology as seen below. It should be noted that the four categories are extreme cases, and that the two dimensions will be treated as degrees and not as dichotomous:

Table 2.1: A new typology of authoritarian regimes

\begin{tabular}{llll|} 
& & \multicolumn{2}{c}{ Level of external constraints } \\
Level of internal constraints & $\underline{\text { Low }}$ & $\underline{\text { High }}$ \\
\cline { 2 - 4 } & $\underline{\text { High }}$ & Machine & Baliath \\
& & Balanced
\end{tabular}

The typology leads to four ideal types: 1) One-man, 2) Machine, 3) Goliath, and 4) Balanced. A one-man regime resembles Geddes' (1999) personalist regime or Svolik's (2012) established autocracy. In these regimes the dictator has successfully removed both external and internal constraints on his rule by isolating individuals. He, therefore, has a monopoly over policy and does not have any credible threats to his rule. In this group we find the most notorious dictators once they have consolidated their rule. Examples 
are Joseph Stalin after 1938 (Montefiore 2004, Suny 1997), who eliminated all resistance through the Great Purges, and Mao Zedong after 1958 (Teiwes 2001). Contrary to Geddes' typology it is, however, no longer assumed that a dictator belongs to one category during the full length of his tenure. Instead, he can move between categories over time.

In machine regimes, which is a term borrowed from Daniel Slater (2003), there are no external constraints on the regime. The opposition outside the ruling coalition has therefore effectively been eliminated. However, there are still internal constraints on the autocrat, since the ruling party manages to control the dictator. The rule is, therefore, oligarchic, and the autocrat has to govern collectively with fellow party members. Examples are Vietnam after 1976, where North and South Vietnam was merged, and China after 1989, where Deng Xiaoping was replaced by Jiang Zemin. Both regimes have a strong party structure where there is a formalized way of choosing and removing the executive, albeit more so in Vietnam than in China (Malesky et al. 2011; McGregor 2010) $!^{6}$

A Goliath regime is characterized by a strong leader who has effectively consolidated the power within his ruling coalition, and therefore does not face any internal constraints. Nonetheless, he still faces an organized civil society who credibly can rebel against the regime and have a fair chance of succeeding. Civil society can be strong and organized for historical reasons or due to ethnic or geographical cleavages. The ruler, therefore, has to take this into account when conducting policy. An example is Gambia (1994-2016). Yahya Jammeh came to power in a coup d'etat in 1994 together with three other officers. Shortly after the coup two of the other putschist were imprisoned. In 1996, he formed his

\footnotetext{
${ }^{6}$ With Xi Jinping's repeal of presidential term limits and Nguyen Phu Tron of Vietnam's nomination as president both regimes seems to be moving in the direction of a one-man regime.
} 
party 'Alliance for Patriotic Reorientation and Construction' and ruled it with a firm hand and with little opposition from inside the party. Of the 16 original ministers appointed in 1996 only 2 were still in office by 1999. Nonetheless, Jammeh did not manage to thwart external competition. In the period from 1996-2012 his party on average received 62 per cent of the votes in presidential elections and 54 per cent of the votes in elections for the National Assembly despite repression and fraud.7 In 2017, Jammeh reluctantly stepped down after an electoral defeat and substantial international pressure.

In balanced regimes there are both internal and external constraints on the autocrat, and he therefore faces credible threats both from within the ruling coalition and from the masses. Examples are Singapore after Lee Kuan Yew stepped down and Mexico until 2000 under the Institutional Revolutionary Party. Both regimes governed with a relatively strong opposition and an organized party structure with selection mechanisms for the leader.

This typology has similarities with other typologies. For example, one-man regimes are reminiscent of personalist regimes and, likewise, balanced regimes closely align with the definition of competitive regimes found elsewhere in the literature (Levitsky and Way 2010). The typology does, however, differ in essential aspects which are beneficial for the purpose of this thesis, and can provide new insight into authoritarian regimes. First, it is dynamic and allows for variation over time within the same regime. Second, the typology is a response to the clustering in existing typologies, and is able to distinguish between present-day authoritarian regimes. Third, it is no longer assumed that the ruler is constrained in his actions solely because there is a parliament or a party. Instead, this typology focuses on the underlying patterns. The obvious challenge to the typology

\footnotetext{
${ }^{7}$ This is based on data from the African Elections Database (http://africanelections.tripod.com/)
} 
presented here is that the terms "internal constraints" and "external constraints" are fuzzy and difficult to measure objectively compared to, for example, the existence of elections or parties. In order to measure the level of constraints, I will rely on the concept of isolation presented above. The operationalization is presented in Chapter 6 .

\subsection{Conclusion}

In this chapter, I contend that we need a dynamic approach to studying authoritarian regimes. This rests on two arguments. Over the last decades we have seen autocracies becoming more institutionalized by adopting institutions traditionally found in democracies such as elections and parliaments. Therefore, autocracies tend to cluster in existing classifications, and there is limited variation to leverage. In addition, existing typologies and institutional theories are not well-suited to studying changes happening over time within the rule of one leader, because they are too static and may be endogenous to the underlying power distributions. This is particularly relevant when studying changes over time within one leader.

Therefore, I present a new framework for thinking about autocratic regimes. I perceive the rule of a leader as a process where two actors are trying to hold the autocrat accountable for his actions, namely the the ruling coalition (internal constraints) and the broader civil society (external constraints). This constitutes the two types of constraints, I will focus on for the remainder of the thesis. To conceptualize power I rely on Arendt's concept of atomization, and argue that the dictator increases his power by destroying the ability of other actors to "act in concert". Based on this, I propose a new typology for classifying authoritarian regimes. 
In the next chapter I will show that an autocrat changes his actions dependent on the level of constraints. 
We were faced with a dilemma. To take over the party would put us in a quandary, for we would not have enough votes to implement our policy. Not to take over would mean losing control to the communist and having the party reorganized further to our disadvantage. - Lee Kuan Yew, The Singapore Story: Memoirs of Lee Kuan Yew (1998, p. 269)

\section{A model of decision making in authoritarian regimes}

\section{Contents}

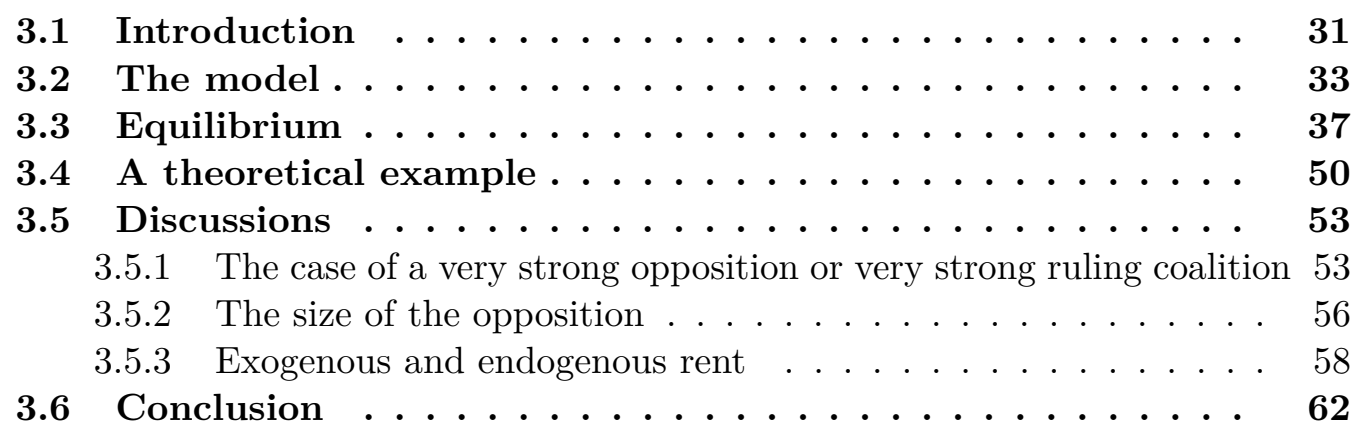

\subsection{Introduction}

In his memoirs Lee Kuan Yew describes the difficult political situation he was in when he became the leader of Singapore. He faced a credible threat in the form of the Communists who constituted a separate political entity within his party, the PAP. If he clamped down on them he both risked loosing his base and igniting an open rebellion. He could, 
therefore, not repress too much, but had to accommodate to the wishes of other people, seek compromises, and, in some cases, bypass his own preferences. In his own words, he followed this strategy (Lee 1998, p. 304):

We shall not be intimidated or browbeaten, nor will we use repression as the means of government. We shall govern with the will and support of the people, firmly, wisely and justly.

This part of the theory chapter is not an analysis of the politics of Singapore, but an explanation for why some authoritarian leaders choose actions which are costly for them personally, but yields benefits to others. In the following, I will formalize the problem which Lee Kuan Yew and all other authoritarian leaders have faced; When do I have to bypass my own preferences, and instead listen to the the ruling coalition and the masses in order to stay in power? Following the discussion above, the model argues that the dictator will have to bypass his preferred action if he risks facing a rebellion from either the ruling coalition or the masses due to this action. Instead, he will have to choose an action which is preferred by a larger section of the population, and therefore increases the collective utility. This is worthwhile for the dictator, since he survives until the next round where he can reap the benefits from being in office. The chance of facing a rebellion increases if he is constrained by the ruling coalition or an organized civil society. Again, constraints are defined as the probability that the ruling coalition or the civil society will succeed in the case of a rebellion. The dictator, therefore, becomes a reluctant agent of the ruling coalition or the civil society. As discussed later, this has positive consequences for economic development. 
The model presented here is based on the model put forward by Besley and Kudamatsu (2008). In their model, they alter the standard model of democracy as described in Besley (2006, Chapter 3) to an autocracy by assuming that there is no regularized contest for public office and by assuming that a contest only arises when the ruling coalition replaces its leader. In this model, I instead assume that the opposition group in each round can choose whether they want to compete against the ruling coalition or not. Furthermore, I do not assume that the ruling coalition by default can overthrow the dictator, but that there instead is a fight between the dictator and the ruling coalition. The dictator, therefore, lives in a world where he constantly has to take into consideration, whether he faces a revolt from either the people with whom he rules and/or the civil society (Svolik 2012, p. 3) and choose his actions dependent on the size of the threat. The model builds on the definition of authoritarianism put forward previously where autocracies are defined by the absence of a competitive election (Levitsky and Way 2010, p. 6). This also entails that the setting, dependent on the level of certain variables, might be very alike the situation in a democratic country.

\subsection{The model}

There are $\mathrm{N}$ citizens in our autocracy. Each of these citizens belongs to either group A or group $\mathrm{B} \mathrm{1}^{1}$ Group $\mathrm{A}$ comprises a fraction, $\beta$, of the population, while the remainder of the population belongs to group B. The country is ruled by a dictator who is a member of one of the two groups of citizens. In the game it is assumed that there are two time periods that are denoted by $t \in\{1,2\}$. In the first period the dictator and the ruling

\footnotetext{
${ }^{1}$ In the model it is for simplicity assumed that the actors do not discount the future
} 
coalition belong to group A, while group B is the masses organized outside the ruling coalition; or what I also refer to as the civil society. In the model they take the role as the opposition to the ruling coalition.

The dictator has to make two policy decisions at the beginning of the game:

1. The first is a discrete "general interest" policy denoted by $e_{t} \in\{0,1\}$. The pay-off to the citizens and the dictator from this policy depends on a state of the world, $s_{t} \in\{0,1\}$, which is only observed by the ruling dictator. Each state occurs with equal probability. The citizens and the ruling coalition receive a pay-off $\Delta$ if $e_{t}=s_{t}$ and zero if the dictator chooses otherwise.

2. The second policy decision is redistributive. The dictator has to divide an exogeneous revenue of size $\mathrm{T}$ between the two groups. $\sigma_{J t} \in[\underline{\sigma}, \bar{\sigma}]$ denotes the fraction of this revenue that is allocated to group $J \in\{A, B\}$ in period $t$. In the most extreme case $\bar{\sigma}=1$ and $\underline{\sigma}=0$. This might, however, not be possible for the dictator because of institutional or practical limits. The salience of the distributional policy is for simplicity defined as $(\bar{\sigma}-\underline{\sigma}) T \equiv \tau$.

In addition to the group identity a dictator can either be good or bad. $\pi$ denotes the probability that a randomly picked individual from either group is good. It is not observed by the citizens whether the dictator is good or bad. Both good and bad dictators receive $\Delta$ as a citizen if they choose $e_{t}=s_{t}$. However, a good dictator gets no pay-off from choosing $e_{t} \neq s_{t}$. We can think of this as a moral stance or ideological belief. Following this logic a good dictator will always act in the interest of the citizens on the general interest 
issue. Contrary, a bad dictator gets a private benefit of $r$ from picking $e_{t} \neq s_{t}$, where $\mathrm{r}$ is drawn independently each period from a distribution whose cumulative distribution function is $G(r)$ with $E(r)=\mu, \mathrm{G}(\Delta)=0$, and $G(r)>0$ for $r>\Delta$. A bad dictator will therefore always obtain a higher personal rent, $r$, from choosing the policy that deviates from the general will. The rent in period $\mathrm{t}$ is denoted by $r_{t}$.

Following Svolik (2012), I from now on will refer to the ruling group as the ruling coalition. The dictator's share of power is denoted by $b \in[0,1]$, while the ruling coalition's share of power is denoted by $1-b$. Thereby, the term $b$ measures the balance of power between the dictator and the ruling coalition. I denote the probability that a rebellion succeeds by $l \in[0,1]$ and it is for simplicity assumed that $l=1-b$. Thus the stronger a ruling coalition is relative to the dictator, the more likely it is that it will succeed if it rebels against the dictator. If the rebellion is successful, the dictator is removed and a new dictator is selected. If the rebellion fails, the dictator punishes the ruling coalition, so each member of the ruling elite pays a cost of $c_{a}$. If the ruling elite does not revolt against the dictator, it is assumed that the dictator will try to consolidate his power by increasing his power relative to the ruling elite. Therefore, each member of the ruling elite pays a cost of $o$. It is assumed that $c_{a}>o$.

Group B decides whether they want to compete against the dictator and become the ruling group. The competition can take place in different ways, but in this model it is assumed that it resembles an election. Nonetheless, it can easily be altered to take form as a rebellion; it is merely a choice of terminology. A fraction of the citizens in each group is enfranchised and are therefore endowed with the power to select the policy maker when 
there is a contest for power. Let $n \leq N$ be the total number of enfranchised citizens of which a fraction, $\phi$, belongs to the ruling coalition. We suppose that in the event of an open contest, group A's candidate has the support of a fraction, $\kappa$, of the enfranchised citizens. We allow the popularity of group B's candidate versus group A's to be affected by a uniformly distributed shock to the popularity of group B's candidate which we denote by $\eta \in\left[-\frac{1}{2}, \frac{1}{2}\right]$. The group A's candidate wins if $\kappa>(1-\kappa)+\eta$. The probability that a candidate from group $\mathrm{A}$ wins the contest, denoted by $\gamma(\kappa)$, is then:

$$
\gamma(\kappa)= \begin{cases}1 & \text { if } \kappa>\frac{3}{4} \\ 2(\kappa)-\frac{1}{2} & \text { otherwise } \\ 0 & \text { if } \kappa<\frac{1}{4}\end{cases}
$$

This model does, however, assume that all citizens are enfranchised and that each citizen has one vote. Following this, the probability that group A wins would be $\gamma(\kappa)$ when all citizens vote along group identity lines. However, in an autocratic world, not all citizens are enfranchised and an election is neither free nor fair. Group B's enfranchised citizens are being repressed by, for example, vote fraud and limited access to resources (Levitsky and Way 2010). This is represented in the model by a parameter $(v \geq 1)$ with $k=v \phi /(v \phi+(1-\phi)) \geq \phi$. If a sufficiently large fraction of the population, $\phi$, supports group $\mathrm{A}$, or if there is strong repression, $v$, the ruling coalition in the first period is certain to hold onto power in the second period. If group B decides to compete, but fails to overthrow group A, they are punished and suffers a cost, $c_{b}$. Finally, if the period one dictator is removed from office, he is punished by the group that removes him. It is assumed that the punishment is brutal, and that the dictator in the worst 
case is executed. He, therefore, receives a period two pay-off of 0 if he is removed after the first period. The timing of the game is as follows:

1. Nature determines $\left(s_{1}, r_{1}\right)$ and whether the period one dictator is good or bad. This is private information to the dictator.

2. The dictator picks $\left(\sigma_{A 1}, \sigma_{B 1}, e_{1}\right)$ and period one pay-offs are realized.

3. Members of the ruling coalition decide whether they should rebel in order to remove the dictator or retain the dictator.

4. Members of the opposition decides whether to compete against the dictator.

5. Nature determines $\left(s_{2}, r_{2}\right)$.

6. The period two dictator chooses $\left(\sigma_{A 2}, \sigma_{B 2}, e_{2}\right)$.

\subsection{Equilibrium}

I will solve for the perfect Bayesian equilibrium of the model. This requires that, in every period, each type of dictator behaves optimally given the rules that are in place and the information they have at that point. The game is seen in figure 3.1. The figure contains all the pay-offs dependent on the choices of the different actors. The game will be solved through backwards induction.

\section{Period 2}




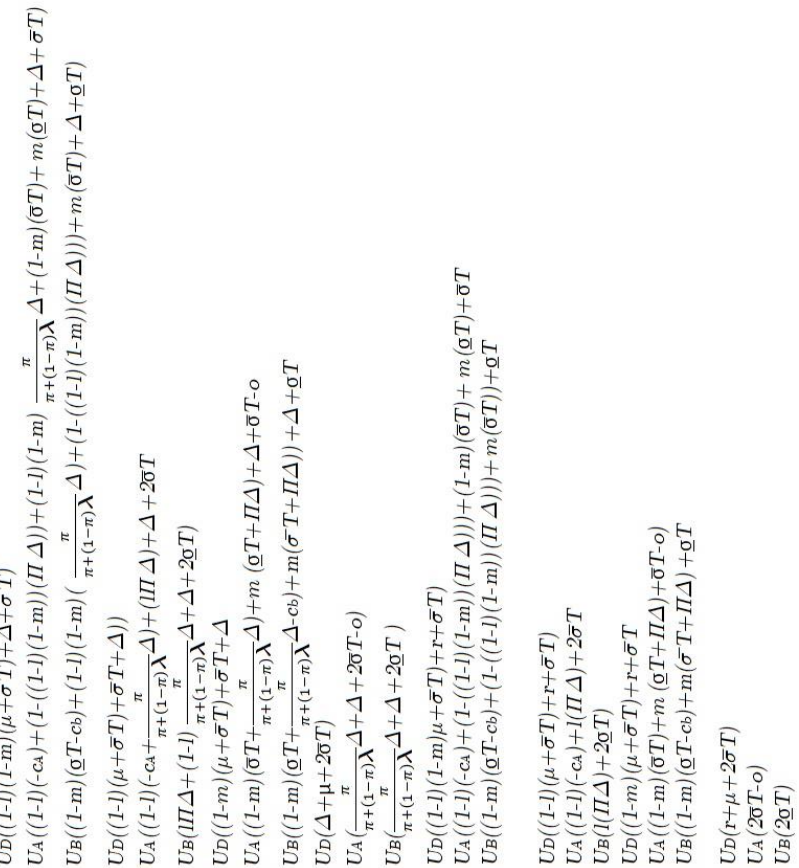

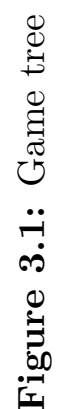

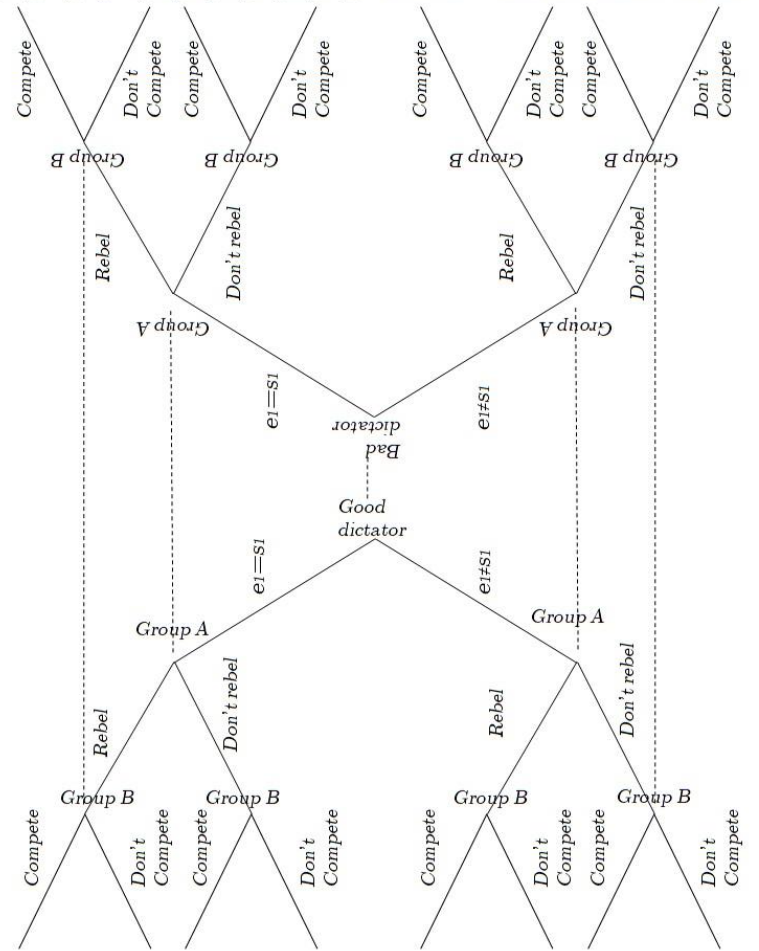

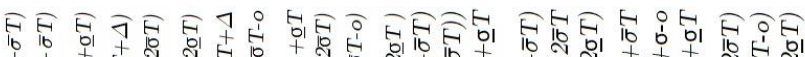

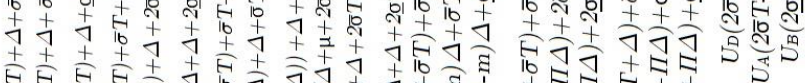

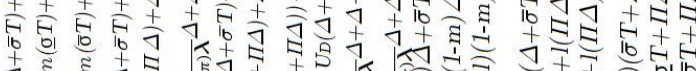

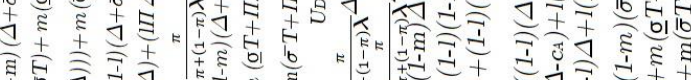

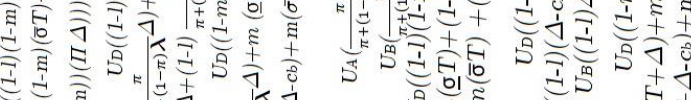

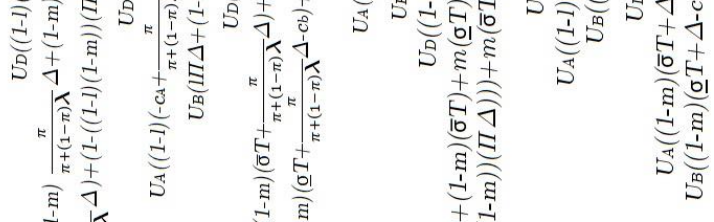

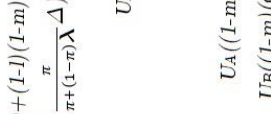

弯迹

方

栾

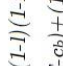

紊然

竞峦

空

38

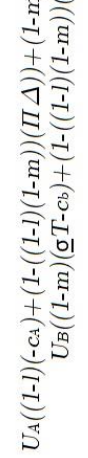


Since the game ends after period 2, it is very easy to find the equilibrium behaviour of the dictator in period two. The dictator will take his short term optimal action. Therefore, $e_{2}=s_{2}$ for a good dictator and $e_{2} \neq s_{2}$ for a bad dictator. The bad dictator will, on average, get the outcome $\mu$ for choosing the action that is not consistent with the general will in period 2. Regarding the distributive policy, the policy maker of group $J$ chooses $\sigma_{J 2}=\bar{\sigma}$ and $\sigma_{k 2}=\underline{\sigma}$ for $K \neq J$. He, therefore, gives the biggest reward he possibly can to his own group and neglects the other group.

\section{Period 1}

The choice of group $B$ in period 1

Since we now know the policy choices of the dictator in period 2, we can consider the behaviour of the opposition. They must decide whether to challenge the ruling coalition or not. In this case the challenge takes the form of an election where the dictator, who represents group A, competes against a randomly chosen candidate from group B. If they choose to compete, they credibly contest in an election and actively tries to take the power. We know that the dictator will choose to favour his own group and set $\sigma_{J 2}=\bar{\sigma}$ and $\sigma_{K 2}=\underline{\sigma}$ in round 2. Furthermore, the opposition realizes that the dictator must be bad if they do not receive $\Delta$ after the first round. This is so because only bad dictators receive rents from choosing $e_{t_{1}} \neq s_{t_{1}}$. If they, instead, observe $\Delta$ they use Bayes' rule and infer that the dictator is of a good type with the probability $\frac{\pi}{\pi+(1-\pi) \lambda}$, where $\lambda$ is the probability that a bad policy maker chooses the right general interest action in period one. 
If the dictator is overthrown a new dictator takes over. It is assumed that the two groups are equally likely to produce a good dictator, and this probability is denoted by $\pi$. The new dictator will, therefore, produce $\Delta$ with $\pi$ probability despite the group of origin. The citizens of group J will, therefore, always prefer their own group's candidate since $\sigma_{J 2}=\bar{\sigma}$ is strictly larger than the other group's candidate preferred choice which is $\sigma_{J 2}=\underline{\sigma}$. All group A's enfranchised citizens will, therefore, prefer the candidate from their own group and vice versa for group B's enfranchised citizens. It is implied that the share of support for group A's candidate is $v \phi /(v \phi+(1-\phi))$. The probability that group A retains power in an election is therefore:

$$
2(v \phi /(v \phi+(1-\phi)))-\frac{1}{2}=2(\kappa)-\frac{1}{2} \equiv \Gamma(\phi, v)
$$

I denote the chance that a competition from group B succeeds as $m \in[0,1]$ and it is assumed that $m=1-\Gamma(\phi, v)$. As mentioned before group B suffers a cost, $c_{b}$, if they compete but fail to overthrow group A, since they may use resources in the attempt to overthrow group A or be punished for trying. Three parameters are then essential for whether group B chooses to compete; $\left\{m, \tau, c_{b}\right\}$.

From figure 3.1 it can be seen that group B can face eight different situations which each induce a payoff. However, we know that a good dictator never will choose $e_{1} \neq s_{1}$, so this part of the game-tree can be discounted. Furthermore, group B does not know whether they face a good dictator or a bad dictator who pretends to be good when they observe a good action. Instead, they must act upon the signal they receive as discussed above. In practice, group B can face one of four different situations: 
1. They observe the bad action and group A does not rebel against the dictator

2. They observe the bad action and group A does rebel against the dictator

3. They observe the good action and group A does not rebel against the dictator

4. They observe the good action and group A does rebel against the dictator

To find the optimal choice of group B, the pay-off for competing is set equal to the payoff for not competing for each of the four different situations and $m$ is isolated. Thereby, the optimal choice of group B is dependent on the probability that they will win the competition. The calculations can be found in appendix A.1. Group B should then compete if:

1. Bad action, A does not rebel: $m \geq \frac{c_{b}}{c_{b}+\tau+\pi \Delta}$

2. Bad action, A does rebel: $m \geq \frac{c_{b}}{c_{b}+\tau+(1-l) \pi \Delta}$

3. Good action, A does not rebel: $m \geq \frac{c_{b}}{c_{b}+\tau+\left(\pi-\frac{\pi}{\pi+(1-\pi) \lambda}\right) \Delta}$

4. Good action, A does rebel: $m \geq \frac{c_{b}}{c_{b}+\tau+(1-l) \pi \Delta+(l-1) \frac{\pi}{\pi+(1-\pi) \lambda} \Delta}$

From this, it is not surprising to see that the opposition is more likely to rebel when the group rent, $\tau$, increases and when the costs from a failed rebellion goes down, $c_{b}$. It is, however, more interesting to look at how the equations change dependent on whether the autocrat takes the bad action or the good action. As discussed, when group B observes the bad action, they know that the dictator must be of the bad type. Thus, there is a benefit from overthrowing the dictator and replacing him with another leader who is good with probability $\pi$. Their proneness to rebellion, therefore, increases with the probability 
of a good dictator, $\pi$, and the benefit from the good action, $\Delta$. In equation 2 , it is seen that group B is less likely to compete when group A decides to rebel first and the dictator has revealed that he is of the bad type. In this case, group B can free ride on the effort of group A by letting them do the dirty work and try to remove the dictator.

When the dictator instead takes the choice which yields benefit to all citizens, group $\mathrm{B}$ does not know whether it is a good dictator or a bad dictator that pretends to be good. Group B must therefore infer that it is a good dictator based on Bayes' law where $\frac{\pi}{\pi+(1-\pi) \lambda}$ is the chance of a good dictator when a good action is observed. This is at least as large as $\pi$. We can, therefore, see that group B is less likely to compete when they observe the good action, because there is no longer a prospective benefit from overthrowing a dictator in order to obtain the rent from the good choice. Instead, they risk overthrowing a good dictator and replace him with a bad dictator. Contrary to the case, where group B with certainty knew they faced a bad dictator, they are now more likely to rebel against the dictator when group A also rebels. This is so because group A bears some of the risk of replacing a good dictator with a bad dictator. Based on the discussion above we can infer that the following must be the case;

$$
\begin{aligned}
& \underbrace{\frac{c_{b}}{c_{b}+\tau+\pi \Delta}}_{\text {Bad action, A not rebel }} \leq \underbrace{\frac{c_{b}}{c_{b}+\tau+(1-l) \pi \Delta}}_{\text {Bad action, A rebel }} \leq \underbrace{\frac{c_{b}}{c_{b}+\tau+(1-l) \pi \Delta+(l-1) \frac{\pi}{\pi+(1-\pi) \lambda} \Delta}}_{\text {Good action, A rebel }} \leq \\
& \underbrace{\frac{c_{b}}{c_{b}+\tau+\left(\pi-\frac{\pi}{\pi+(1-\pi) \lambda}\right) \Delta}}_{\text {Good action, A not rebel }}
\end{aligned}
$$

From this we can see that if $m<\frac{c_{b}}{c_{b}+\tau+\pi \Delta}$ group B is weak and cannot credibly threaten the dictator and under no circumstances will rebel. The dictator does therefore not take 
the opposition into account, when he decides whether he should choose the action which yields benefits to all citizens or not. In addition, if $m>\frac{c_{b}}{c_{b}+\tau+\left(\pi-\frac{\pi}{\pi+(1-\pi) \lambda}\right)}$, then the dictator knows that group B is strong and will compete against him no matter what he does. However, at intermediate values, where $\frac{c_{b}}{c_{b}+\tau+\pi \Delta} \leq m \leq \frac{c_{b}}{c_{b}+\tau+\left(\pi-\frac{\pi}{\pi+(1-\pi) \lambda}\right)}$, a bad dictator might find it beneficial to pretend to be a good dictator and choose $e_{1}=s_{1}$. Thereby, he avoids a competition from group B who no longer finds it beneficial to remove him.

The choice of group $A$ in period 1

From the discussion above we know how group B will act based on group A's actions, and we can therefore consider the actions of group A who can choose either to rebel against the dictator or stay passive after observing their pay-off at $t_{1}$. Based on the size of $\mathrm{m}$, group A anticipates the following response function from group $\mathrm{B}$, when the dictator takes the bad choice:

$$
B_{1}\left(A_{1} \mid D_{b a d}\right)= \begin{cases}\text { Don't compete } & \text { if } m \leq \frac{c_{b}}{c_{b}+\tau+\pi \Delta} \\ \text { Compete if } A \text { not rebel } & \text { if } \frac{c_{b}}{c_{b}+\tau+\pi \Delta} \leq m \leq \frac{c_{b}}{c_{b}+\tau+(1-l) \pi \Delta} \\ \text { Compete } & \text { if } m \geq \frac{c_{b}}{c_{b}+\tau+(1-l) \pi \Delta}\end{cases}
$$

We can now consider the choice of group A, when the dictator takes the bad choice. Using the same procedure as before, we can isolate $l$, which is the strength of the ruling coalition, to see when it is advantageous for group A to rebel dependent on the expected action of group B:

If $A$ doesn't expect that $B$ will compete: $l \geq \frac{c_{A}-o}{c_{A}+\pi \Delta}$

If $A$ only expects that $B$ will compete if $A$ does not rebel $: l \geq \frac{c_{A}-o+m(-\tau+\Delta \pi)}{c_{A}+\pi \Delta}$ If $A$ expects that $B$ will compete $: l \geq \frac{c_{A}-o}{c_{A}+(1-m) \pi \Delta}$ 
The calculations leading to these results are found in appendix ??. From this it can be inferred that the ruling coalition is more likely to rebel against the dictator who takes the bad choice, when the cost of rebelling, $c_{A}$ goes down, when the cost due to authoritarian consolidation, o, goes up, or when the estimated benefit from getting a new dictator, $\pi \Delta$, goes up. Furthermore, we can see that if $\tau \geq \pi \Delta$ then group A may rebel and remove the dictator in order to deter group B from competing, when group A expect that group B only will compete if A does not compete.

Just as with group B, group A does not know whether it is a good dictator or a bad dictator that pretends to be good when they observe $\Delta$. Likewise, group A infers that the dictator must be good with the probability $\frac{\pi}{\pi+(1-\pi) \lambda}$. From the discussion of group B's actions we can infer that B will have the following best response function when they observe the good action:

$B_{1}\left(A_{1} \mid D_{\text {good }}\right)= \begin{cases}\text { Don't compete } & \text { if } m<\frac{c_{b}}{c_{b}+\tau+(1-l) \pi \Delta+(l-1) \frac{\pi}{\pi+(1-\pi) \lambda} \Delta} \\ \text { Compete if A rebel } & \text { if } \frac{c_{b}}{c_{b}+\tau+(1-l) \pi \Delta+(l-1) \frac{\pi}{\pi+(1-\pi) \lambda}}<m<\frac{c_{b}}{c_{b}+\tau+\left(\pi-\frac{\pi}{\pi+(1-\pi) \lambda}\right)} \\ \text { Compete } & \text { if } m \geq \frac{c_{b}}{c_{b}+\tau+\left(\pi-\frac{\pi}{\pi+(1-\pi) \lambda}\right)}\end{cases}$

Group A anticipates this and bases their decision on their expectations of how group B will act. Then group A will do the following, dependent on the expected action of group B:

If $A$ doesn't expect that $B$ will compete $: l \geq \frac{c_{A}-o}{c_{A}+\left(\pi-\frac{\pi}{\pi+(1-\pi) \lambda}\right) \Delta}$

If $A$ only expects that $B$ will compete if $A$ rebel $: l \geq \frac{c_{A}-o+m\left(\tau+\left(\frac{\pi}{\pi+(1-\pi \lambda}-\pi\right) \Delta\right)}{c_{A}+(m-1)\left(\frac{\pi}{\pi+(1-\pi) \lambda}-\pi\right) \Delta}$

If $A$ expects that $B$ will compete $: l \geq \frac{c_{A}-o}{c_{A}+(1-m) \pi \Delta+(m-1)_{\frac{\pi}{\pi+(1-\pi) \lambda}}}$

In contrast to when group A observed the bad choice, they now are in doubt of whether they are facing a bad dictator pretending to be a good dictator or a good dictator. 
Therefore, they risk replacing a good dictator with a bad one if they rebel. Thus, they are less prone to rebel, when they observe the good action. In addition, they know that group B will be more likely to rebel, when group A rebels, since group A takes some of the risk of replacing a good dictator with a bad one. Therefore, there is an interval of $\mathrm{l}$ and $\mathrm{m}$ where group A will abstain from rebelling in order to deter group B from rebelling as well.

\section{The choice of the dictator in period 1}

We now know how group A and group B will behave dependent on the actions of the dictator. The dictator in period 1 has to make two choices, 1) a distributive and 2) a "general interest policy". The period one dictator, who is a member of group A, will as in round 2 maximize his own utility on the redistributive dimension and set $\sigma_{A 1}=\bar{\sigma}$ and $\sigma_{B 1}=\underline{\sigma}$. Furthermore, we know that a good dictator will choose $s_{1}=e_{1}$ because he gets no benefit from deviating, while he receives a benefit, $\Delta$, from choosing the congruent action. This leaves us with the issue of how a bad dictator will behave in period 1. From the discussion above, it is clear that a bad dictator at certain intervals of $l$ and $m$ can discourage group $\mathrm{A}$ and $\mathrm{B}$ from competing against him by taking a good action and signal that he is a good dictator. In order to work out when this is beneficial, we must compare his pay-off from the good and the bad action.

Let $\rho(\Delta)$ denote the probability that the period one policy maker will stay in office if he produces a pay-off of $\Delta \in\{0, \Delta\}$. The bad policy maker's period two pay-off from producing a pay-off of $\Delta$ to the citizens in period one is: 


$$
\rho(\Delta)(\mu+\bar{\sigma} T)-(1-\rho(\Delta)) 0
$$

where the first part of the equation is the pay-off if he stays in office, while the second part is the pay-off if he is removed, which gives him a benefit of 0 and therefore naturally is 0 . Using this it can be seen that the bad policy maker will produce the good action in period one if:

$$
[\rho(\Delta)-\rho(0)][\mu+\bar{\sigma} T]+\Delta>r
$$

Where $\Delta$ is the utility from producing the good action, while $[\rho(\Delta)-\rho(0)][\mu+$ $\bar{\sigma} T]$ is the expected loss of utility in the case of rebellion from either group A or B. Consequently, the probability that a bad policy maker chooses the right general interest action in period one, denoted by $\lambda$, is:

$$
\lambda=G(\rho(\Delta)-\rho(0)][\mu+\bar{\sigma} T]+\Delta)
$$

The bad dictator is motivated to take the good choice by two sources of future rent. The first is the personal rent $\mu$ he earns from deviating in the second round, and the second is the group specific rent $\bar{\sigma} T$. In order to understand $\rho(\Delta)-\rho(0)$ we need to examine the behaviour of group A and group B. From the discussion above we know that their behaviour depend on the size of the relative power towards the dictator of group A, $l$, and group B, $m$. Furthermore, we know that both groups are less likely to rebel against the dictator if he produces $\Delta$ compared to when he does not. This is so because both the ruling coalition and the opposition risk removing a good dictator and replace 
him with a bad dictator, when they observe $\Delta$, while if he does not produce $\Delta$ in the first round, they can remove him and perhaps receive $\Delta$ in the second round. We do, however, have to look at the size of $l$ and $m$ in order to evaluate the actions of the bad dictator in round 1. These can be combined in a number of different ways. However, the following the analysis is limited to 4 different types of equilibria which responds to the categories in the typology presented in the previous chapter. There are also other equilibria where the opposition or the ruling elite will rebel even if the dictator chooses the congruent action. These will be discussed later on.

\section{One-man: A weak ruling coalition and a weak opposition}

From the discussion of the behaviour of group A and B we know that a situation can arise, where both groups are so weak relative to the dictator that they do not find it worthwhile to rebel even if he chooses the action which is not congruent with the general will. In this case, a bad dictator will have no reason to pretend to be good. This leads us to the following proposition:

Proposition 1. If $m<\frac{c_{b}}{c_{b}+\tau+\pi \Delta}$ and $l<\frac{c_{A}-o}{c_{A}+\pi \Delta}$ then $\lambda=0$

This must be true since the dictator is sure to stay in office independent of the action he takes. Therefore $\rho(\Delta)=\rho(0)=1$. Then the benefit for the dictator from choosing $e_{1}=s_{1}$ is $[\rho(\Delta)-\rho(0)][\mu+\bar{\sigma} T]+\Delta=\Delta$. Furthermore, we know that $r>\Delta$, and it will therefore always be beneficial for the bad dictator to choose the bad action in this scenario. This is comparable to a type of personal rule where the dictator is all-powerful and can rule without fear of being removed. In this case the bad dictator will always choose 
$e_{1} \neq s_{1}$ and thereby choose the action that he prefers at the expense of the population. This situation is, therefore, optimal for the bad dictator, but will result in suboptimal outcomes for both the ruling coalition and the opposition, since they do not receive $\Delta$.

\section{Machine: Strong ruling coalition, weak opposition}

Furthermore, we can have a situation where group B is too weak to threaten the dictator $\left(m<\frac{c_{b}}{c_{b}+\tau+\pi \Delta}\right)$, and group A is strong enough to credibly threaten the dictator, but only find it worthwhile if he does not take the good action $\left(\frac{c_{A}-o}{c_{A}+\pi \Delta} \leq l<\frac{c_{A}-o}{c_{A}+\left(\pi-\frac{\pi}{\pi+(1-\pi \lambda)}\right) \Delta}\right)^{2}$. In this case the bad dictator knows that he for certain survives the first round and obtains $\mu+\bar{\sigma} T$ in the second round and gets the benefit from the congruent action $(\Delta)$ if he takes the good action, while he obtains $r$ from deviating in the first round, but at the same time risks being removed with the probability $l$. This leads to the following proposition:

Proposition 2. If $m<\frac{c_{b}}{c_{b}+\tau+\pi \Delta}$ and $\frac{c_{A}-o}{c_{A}+\pi \Delta} \leq l \leq \frac{c_{A}-o}{c_{A}+\left(\pi-\frac{\pi}{\pi+(1-\pi \lambda}\right) \Delta}$ then $\lambda=G((\mu+\bar{\sigma} T+$ $\Delta)-(1-l)(\mu+\bar{\sigma} T))$

In this situation there is some chance that the bad dictator will choose $e_{1}=s_{1}$ in order to avoid a rebellion and thereby risks being removed. On average, this situation will create an outcome which is better for both the opposition and the ruling coalition compared to when the dictator can rule without fear of being removed, because there is a higher chance that they both will receive $\Delta$. The chance of the bad dictator choosing the

\footnotetext{
${ }^{2}$ The situation can also arise, when group B will compete when A does not rebel $\left(\frac{c_{b}}{c_{b}+\tau+\pi \Delta} \leq m<\right.$ $\left.\frac{c_{b}}{c_{b}+\tau+(1-l) \pi \Delta}\right)$ and when group A find it worthwhile to rebel in order to deter group B from rebelling so $\tau>\pi \Delta$ and $l \geq \frac{c_{A}-o+m(-\tau+\Delta \pi)}{c_{A}+\pi \Delta}$ or when group A rebels despite the fact that group B intends to rebel, $l \geq \frac{c_{A}-o}{c_{A}+(1-m) \pi \Delta}$. In these cases group B does not rebel, when they observe group A rebelling.
} 
good action increases with the strength of the ruling coalition. In this scenario, there is no chance that the opposition will overthrow the ruling coalition, since they are too weak.

\section{Goliath: Strong opposition, weak ruling coalition}

Contrary, we can have a situation where group B rebels if they observe the bad action but not when they observe the good action $\left(\frac{c_{b}}{c_{b}+\tau+\pi \Delta} \leq m \leq \frac{c_{b}}{c_{b}+\tau+\left(\pi-\frac{\pi}{\pi+(1-\pi) \lambda}\right) \Delta}\right)$, and group A is either weak $\left(l<\frac{c_{A}-o}{c_{A}+\pi \Delta}\right)$ or expects that group B will compete $l<\frac{c_{A}-o}{c_{A}+(1-m) \pi \Delta}$ if they do not compete and therefore uses their first mover advantage and decides not to rebel under the expectation that group B will rebel. In this case $\lambda$ will be:

Proposition 3. If $\frac{c_{b}}{c_{b}+\tau+\pi \Delta} \leq m \leq \frac{c_{b}}{c_{b}+\tau+\left(\pi-\frac{\pi}{\pi+(1-\pi) \lambda}\right) \Delta}$ and $l<\frac{c_{A}-o}{c_{A}+\pi \Delta}$ then $\lambda=G((\mu+$ $\bar{\sigma} T+\Delta)-(1-m)(\mu+\bar{\sigma} T)$

There is therefore a chance that the bad dictator will choose $s_{1}=e_{1}$ in order to avoid a rebellion from the opposition after the first round, so he can stay on to the second round. On average this scenario will create a better outcome for society compared to the first scenario, since it is more likely that both the opposition and the ruling coalition will receive $\Delta$. This scenario does, however, also entail risk for the ruling coalition, since they risk being overthrown and therefore loose their privileged access to the exogenous rent, $\mathrm{T}$.

\section{Balanced: Strong opposition, strong ruling coalition}

We might also have a situation where both group A and group B are strong enough to threaten the dictator, but only decide to go against the dictator when they observe the bad action. In this case the dictator faces a revolt from both groups when he 
takes the bad action, while both groups stay put if he takes the good action. This results in the following proposition:

Proposition 4. If $\frac{c_{b}}{c_{b}+\tau+(1-l) \pi \Delta} \leq m \leq \frac{c_{b}}{c_{b}+\tau+\left(\pi-\frac{\pi}{\pi+(1-\pi) \lambda}\right) \Delta}$ and $\frac{c_{A}-o}{c_{A}+(1-m) \pi \Delta} \leq l \leq \frac{c_{A}-o}{c_{A}+\left(\pi-\frac{\pi}{\pi+(1-\pi) \lambda}\right) \Delta}$ then $\lambda=G((\mu+\bar{\sigma} T+\Delta)-(1-l)(1-m)(\mu+\bar{\sigma} T)$

In this case the dictator risks a revolt from both within the ruling coalition and from the opposition if he takes the bad action. He is therefore more likely to take the congruent action to avoid being overthrown, so he can reap the rents in round 2. From the formula, it is seen that $\lambda$ increases in both $l$ and $m$. This entails that there is an extra effect on the likelihood that the bad dictator chooses the action which is congruent with the general will, compared to when he only faces a revolt from one of the groups. Thus, this scenario is expected to be best for both the ruling coalition and the opposition.

\subsection{A theoretical example}

In the following, I will discuss a theoretical country based on the formal model. I focus on the four types of equilibria, which I discussed before, and shy away from equilibria where one of the groups are so strong that they will rebel no matter what. In the model, a country can vary dependent on a number of variables, such as the salience of the exogenous revenue, $T$, relative to the benefit from the policy which accommodates the general will, $\Delta$. The exogenous revenue can be rents from natural resources, such as oil, minerals, or even aid, which are given directly to the regime, while the utility from the policy which benefits all citizens can be perceived as returns from investment in public goods, such as human capital or infrastructure. 
Figure 3.2: The probability that a bad dictator will choose $e_{1}=s_{1}$

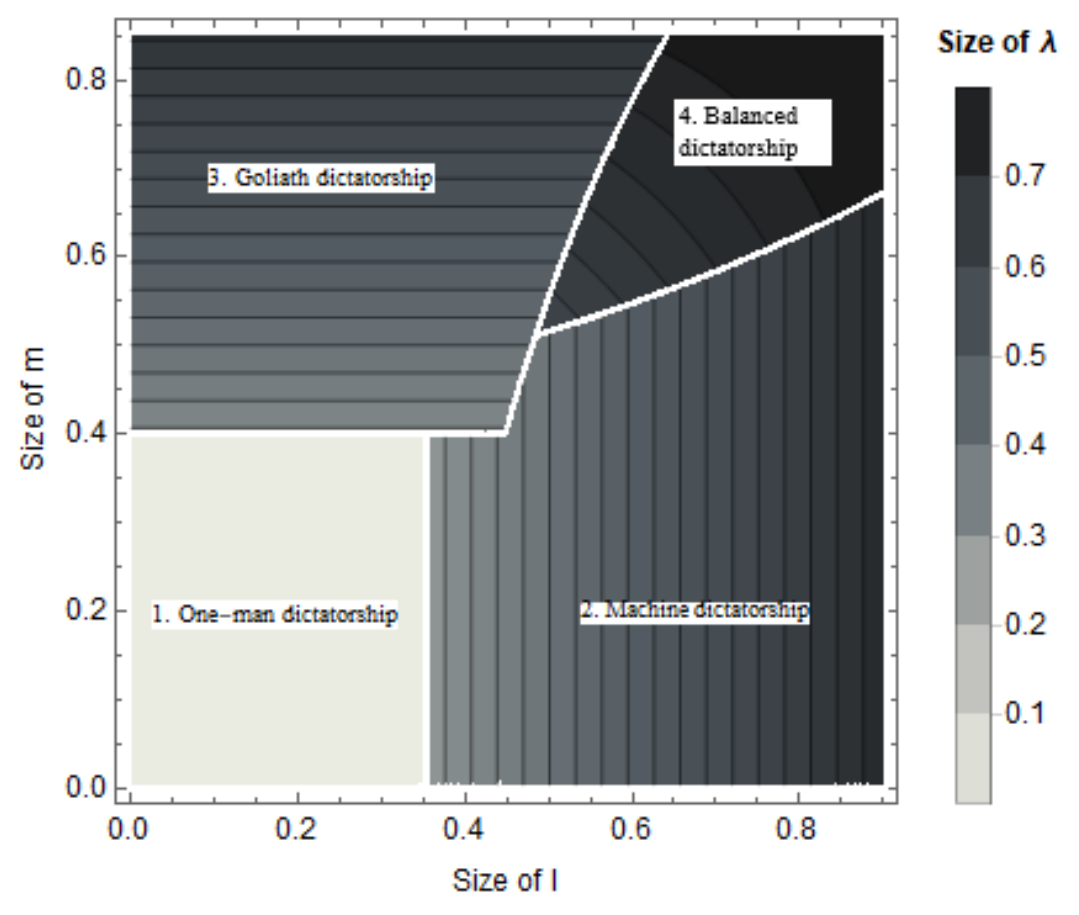

Notes: The probability, $\lambda$, that a bad dictator will choose $e_{1}=s_{1}$ as a function of the chance that the ruling coalition will be successful in a rebellion, 1 , and the chance that the opposition will be successful in a competition, $\mathrm{m}$. The parameters are as follows; $\Delta=0.9, \pi=0.5, \bar{\sigma}=0.65, c_{b}=c_{a}=0.4, T=$ $0.5, o=0.1 . \mathrm{G}(\mathrm{r})$ is a uniform cumulative distribution function with $\Delta$ as minimum and 5 as maximum. The figure is cut-off at $m=0.85$ and $l=0.90$, which is where the groups become so strong that they will rebel despite the choice of the dictator

The choice of the dictator as a function of the level of $l$ and $m$ is reflected in figure 3.2. Darker colours indicate a higher probability that the dictator will choose $e_{1}=s_{1}$.

Following the four types of equilibria discussed above, it is seen that when $l<0.35$ and $m<0.4$ the regime is a one-man dictatorship. Below these thresholds there is no chance that the bad dictator will choose the action which is costly for him, but yields benefit for the wider population. He will therefore maximize his own utility and ignore the preferences of both the ruling coalition and the opposition. As a result, it is predicted that these regimes produce lowest economic development. On the other hand, the dictator 
is constrained if either $l$ or $m$ is above their respective threshold, which implies that a dictator of the bad type can find it worthwhile to comply with the preferences of the ruling coalition and the opposition to stay in power, so he can reap the rents in the second round. It should be noted that both the ruling coalition and the opposition benefit from when the dictator chooses the action which is congruent with the general will, even if the other group provides the constrains on the autocrat.

We can distinguish between three types of constrained dictatorships. In the lower-right corner, the dictator is facing a credible threat from the ruling coalition but not from the opposition. Following the typology presented in chapter 2, this type of dictatorship is called a machine dictatorship. Here the dictator will have to listen to the preferences of the ruling coalition in order to stay in power, and the regime therefore becomes oligarchic. It is predicted that this type of regime produces higher economic development compared to when there are no constraints on the dictator.

In the upper-left corner the dictator is facing no credible threats from the ruling coalition, but he is still facing a strong opposition who credibly can rebel against his rule if he does not listen to their demands. This is what I call a Goliath regime in the typology presented earlier. It should be noted that this square crosses over the square of the machine dictatorship. This is so because the ruling coalition at these levels of $m$ and $l$ uses their first mover advantage and free-rides on the effort of the opposition, since they expect that the opposition will provide the opposition to the dictator. In the upper-right corner both the ruling coalition and the opposition credibly can rebel against the dictator. This drastically increases the likelihood that the dictator will choose the action that 
yields benefit to all citizens of a country. This is so because their effort is multiplicative according to proposition 4 . This type is named a balanced dictatorship in the typology. It is expected that this type of regime produces the highest level of economic development.

\subsection{Discussions}

In this section, I will discuss three aspects of the model, which can help us in understanding how autocracies function. First, I will discuss the cases where the opposition or the ruling coalition are so strong that they will rebel no matter what. Following this, I will unpack the two dependent variables of interest, $l$ and $m$, and discuss how they matter for the model. Thereafter, I will discuss how countries vary dependent on the level of exogenous rent, $T$, and endogenous rent, $\Delta$.

\subsubsection{The case of a very strong opposition or very strong ruling coalition}

In the presentation of the model above, I ignore the situations where the ruling coalition and/or the opposition are so strong that they will rebel even if the dictator chooses the action which is congruent with the general will. This happens when the opposition expects that it is very likely that they will win, so the estimated value of gaining control with the exogenous rent, $\mathrm{T}$, is higher than the estimated value of both being punished, $c_{b}$, and the expected loss from replacing a good dictator with a bad one. Likewise, if the ruling coalition is almost certain they will win, they might find it beneficial to remove the autocrat in order to avoid being punished and loose $o$ even though they risk removing a good dictator. There exists 5 different types of these situations; 
1. A very strong ruling coalition and a weak opposition

2. A weak ruling coalition and a very strong opposition

3. A very strong ruling coalition and a strong opposition

4. A strong ruling coalition and a very strong opposition

5. A very strong ruling coalition and a very strong opposition

Following the terminology used previously in this chapter, the ruling coalition or the opposition is weak if they do not rebel even if the dictator chooses the bad action, strong if they can credibly rebel, but choose not to if they observe $\Delta$ and very strong if they will rebel even if they observe $\Delta$. It is clear that a bad dictator will always choose $e_{1} \neq s_{1}$ when he cannot change the actions of the opposition or the ruling elite by pretending to be a good type, so when there is 1) a very strong ruling coalition and a weak opposition, 2) a weak ruling coalition and a very strong opposition and 3) a very strong ruling coalition and a very strong opposition the equilibria is that a bad dictator will choose the action, which is not congruent with the general will. Therefore, $\lambda=0$ in these three cases. This is seen in the appendix. However, when a bad dictator still can influence one actor, which is the case when there is 1) a very strong ruling coalition and a strong opposition or 2) a strong ruling coalition and a very strong opposition, he may still have an incentive to choose $e_{1}=s_{1}$. In the case where there is a very strong ruling coalition and a strong opposition the proposition is:

Proposition 5. If $\frac{c_{b}}{c_{b}+\tau+(1-l) \pi \Delta} \leq m \leq \frac{c_{b}}{c_{b}+\tau+(1-l) \pi \Delta+(l-1) \frac{\pi}{\pi+(1-\pi) \lambda} \Delta}$ and $\frac{c_{A}-o}{c_{A}+\left(\pi-\frac{\pi}{\pi+(1-\pi) \lambda}\right) \Delta} \leq$ $l$ then $\lambda=G((1-l)(\mu+\bar{\sigma} T+\Delta)-(1-l)(1-m)(\mu+\bar{\sigma} T)$ 
Furthermore, in the case where there is a strong ruling coalition and a very strong opposition the proposition is:

Proposition 6. If $\frac{c_{b}}{c_{b}+\tau+\left(\pi-\frac{\pi}{\pi+(1-\pi) \lambda}\right) \Delta} \leq m$ and $\frac{c_{A}-o}{c_{A}+(1-m) \pi \Delta} \leq l \leq \frac{c_{A}-o}{c_{A}+(1-m) \pi \Delta+(m-1) \frac{\pi}{\pi+(1-\pi) \lambda} \Delta}$ then $\lambda=G((1-m)(\mu+\bar{\sigma} T+\Delta)-(1-l)(1-m)(\mu+\bar{\sigma} T)$

Figure 3.3: The probability that a bad dictator will choose $e_{1}=s_{1}$

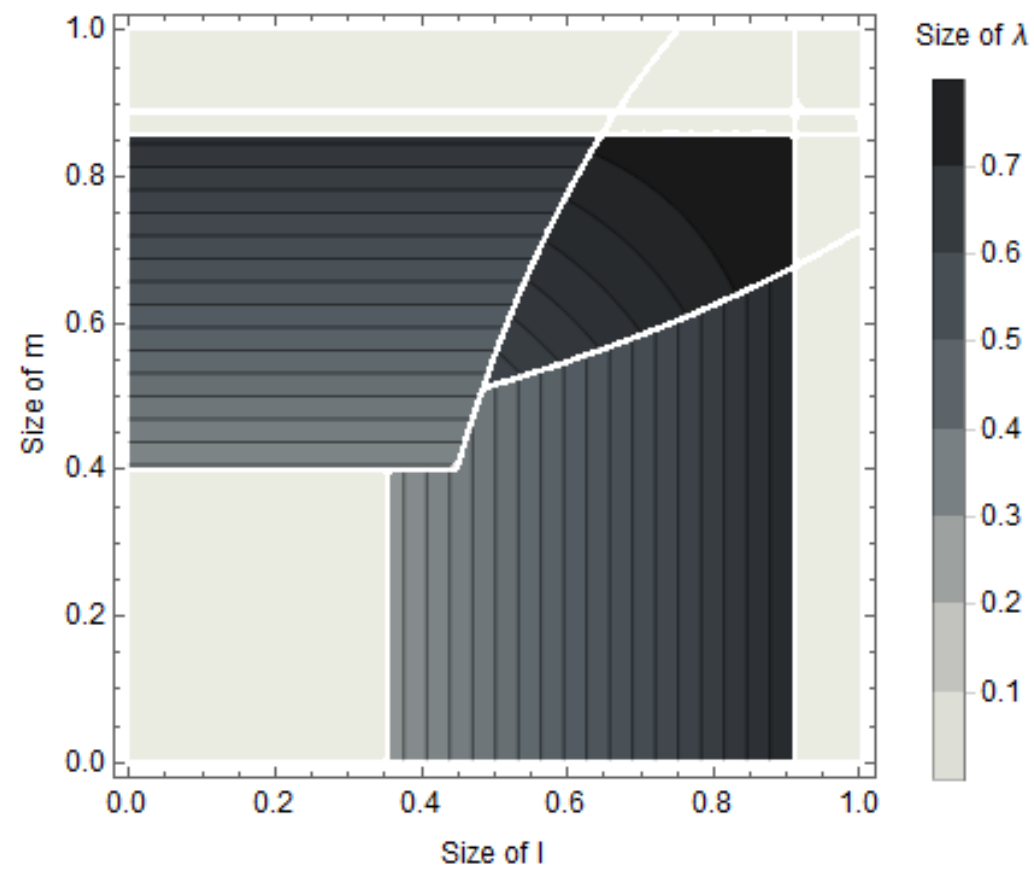

Notes: The probability, $\lambda$, that a bad dictator will choose $e_{1}=s_{1}$ as a function of the chance that the ruling coalition will be successful in a rebellion, 1 , and the chance that the opposition will be successful in a competition, $\mathrm{m}$. The parameters are as follows; $\Delta=0.9, \pi=0.5, \bar{\sigma}=0.65, c_{b}=c_{a}=0.4, T=$ $0.5, o=0.1$. $\mathrm{G}(\mathrm{r})$ is a uniform cumulative distribution function with $\Delta$ as minimum and 5 as maximum. The figure is cut-off at $m=0.85$ and $l=0.90$, which is where the groups become so strong that they will rebel despite the choice of the dictator

It becomes complicated, hard to conceive, and very difficult to program how the game will unfold, when $l$ and $m$ are in the intervals in proposition 5 and 6 . I am therefore relying on a slightly simplified, but functionally equivalent graphical explanation of this? where

\footnotetext{
${ }^{3}$ At high levels of $l$ and $m$ the dictator is almost certain he will loose against the rebelling actor even if he discourage the other actor from rebelling, and he will therefore almost with certainty choose $s_{1} \neq e_{1}$
} 
it is assumed that the dictator chooses the bad action when either the ruling coalition or the opposition is so strong that it will rebel independent of the chosen action. In figure 3.4 the figure from last section is shown with the full length of the axes. In the figure it is seen that the probability that a bad dictator will choose the action which yields benefit to all citizens in a country, drops to 0 when he can no longer influence the actions of the opposition or the ruling coalition by pretending to be of a good type. This can be compared to Olson's (1993) distinction between roving and stationary bandits. If an autocrat expects that he will be removed, he has no incentive to invest in the population, but may just as well reap the benefits, while he can. Furthermore, this predicts that the opposition and the ruling coalition should be strong, so they can credibly constrain the autocrat, but not too strong because this may result in anarchy ${ }^{4}$ It should be noted that it, in this case, requires an extremely strong opposition or ruling coalition before this scenario arise, which may be unlikely to happen.

\subsubsection{The size of the opposition}

The two main independent variables of interest are the chance that the ruling coalition is successful in the case of a rebellion, $l$, and the chance that the opposition is successful if they contest in an election, $m$. Based on the model, it is argued that the chance of the dictator choosing the optimal action for the population increases in both $l$ and $m$ up to a threshold. In other words, the more constrained the dictator is, the more likely is it that he will choose the action which is beneficial for the wider population.

\footnotetext{
${ }^{4}$ Another outcome might be democratization, where the different actors commit to fight each other through democratic means instead of violence due to the unstable equilibria. This is, however, outside the scope of this analysis
} 
We have defined $m$ as $1-\Gamma(\phi, v)$, where $\Gamma(\phi, v) \equiv 2(\kappa)-\frac{1}{2}=2(v \phi /(v \phi+(1-\phi)))-\frac{1}{2}$. In the figure below, the size of $m$ is a function of the level of repression, $v$, and the fraction of the population that belongs to the ruling coalition, $\phi$. Naturally, $m$ increases when the support goes up or repression is decreased. For example, if the opposition can mobilize 60 per cent of the population and there is no repression, they have a 70 per cent chance of winning $(m=0.7)$. However, if repression is increased so $v=2$ the opposition's chance of winning drops to 36 per cent $(m=0.36)$. This can be used to infer, when repression is effective. If the autocrat enjoys wide popular support $(\phi>0.75)$ he does not have to rely on repression since he is certain of winning. However, when the popular support drops, he will have to rely on an increased level of repression to uphold the chance of winning. As discussed in the theory section, repression can be a two-edged strategy, since the dictator may face a backlash from either the population or abroad. The prediction here is that the level of repression will increase when the size of $m$ is in proximity to the threshold where the dictator can deter the opposition from rebelling even if he does a bad job ( $m=0.4$ in figure 3.2 ) or when he is sure of facing a rebellion $(m=0.85$ in figure 3.2 . Here the dictator can enjoy relatively large benefits by drastically changing the behaviour of the opposition with a relatively small increase in repression.

The model is only applicable to dictatorships, where the option of violence always is on the table to solve disputes. The model does, however, have implications which help us in understanding the difference between autocracies and democracies. In the previous chapter it was seen that autocracies have more dispersed growth rates than democracies. Here, it is argued that we can end up in a situation (one-man autocracy), where the dictator 
Figure 3.4: The size of $m$

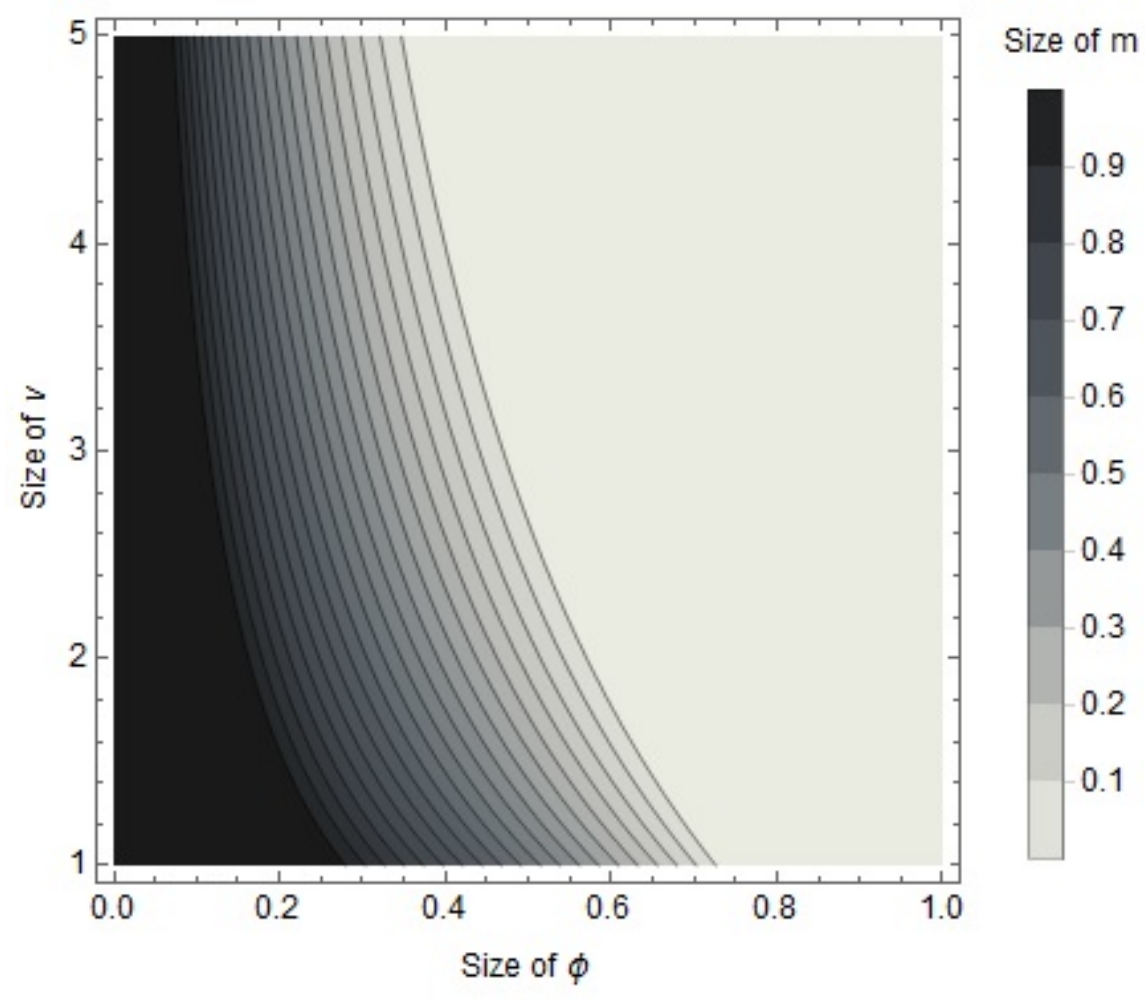

The graph shows the size of $\mathrm{m}$ dependent on the degree of repression, $v$ and the fraction of the population that belongs to the ruling coalition, $\phi$.

always will act upon his personal preferences and neglects the needs of the population. This can explain why we see catastrophic outcomes in some dictatorships. However, the model also shows that "more democratic" dictatorships, where there $\mathrm{m}$ is large due to little repression and/or popular dissatisfaction with the regime, can foster situations, where the dictator almost always will abide to the popular will; as in a democracy.

\subsubsection{Exogenous and endogenous rent}

There are two types of rent in the model, $T$, which can be thought of as an exogenous rent, such as oil revenues, and $\Delta$ that can be thought of as an endogenous rent, such as returns from investments in public goods. The size of these two variables varies from 
country to country dependent on factors such as geography and the amount of aid given directly to the regime. In the figure below, all parameters are the same as in figure 3.5 except for $\mathrm{T}$, which is now 1.5 instead of 0.5 . Thereby the importance of the exogenous rent goes up relative to the rent from the dictator choosing $e_{1}=s_{1}, \Delta$. The interval in which the dictator can deter the opposition from competing by choosing the good action is now much smaller. The opposition now have more to win by becoming the ruling group and therefore will compete at lower levels of $\mathrm{m}$. Furthermore, we see that the ruling coalition also has a slightly lower threshold for when they will rebel despite the choice of the dictator. In addition, the square of the ruling coalition now covers some of the square of the opposition contrary to in figure 3.2 . We see this because the ruling coalition now finds it beneficial to rebel and remove a bad dictator at these levels in order to deter the opposition from rebelling, so they do not risk losing control with the exogenous rent. Furthermore, we see that there is a lightly shaded area above the upper right square. In this area, the dictator cannot deter the opposition from rebelling, but he can still deter the ruling coalition from rebelling as discussed in Proposition 6 . 
Figure 3.5: The probability that a bad dictator will choose $e_{1}=s_{1}$

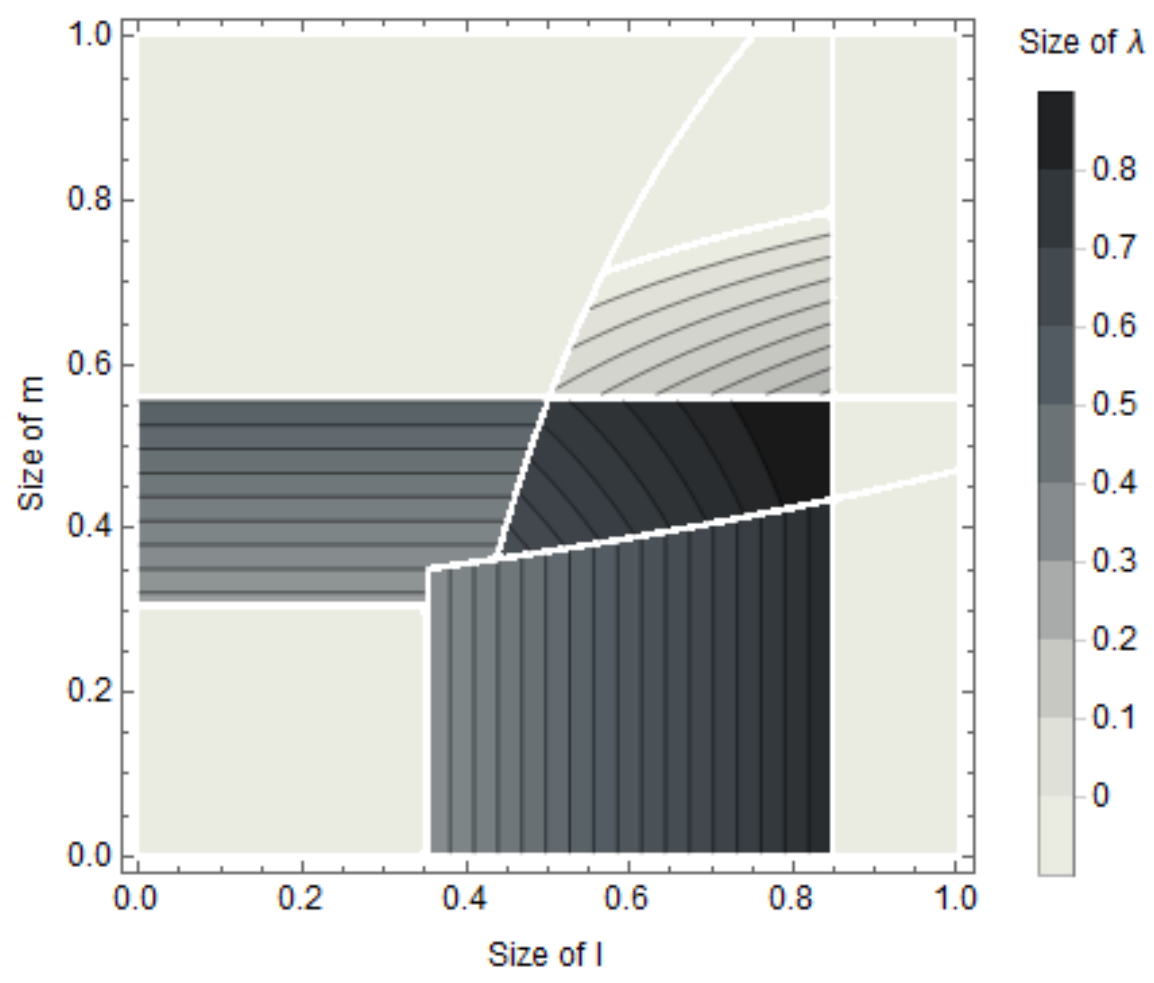

Notes: The probability, $\lambda$, that a bad dictator will choose $e_{1}=s_{1}$ as a function of the chance that the ruling coalition will be successful in a rebellion, 1 , and the chance that the opposition will be successful in a competition, $\mathrm{m}$. The parameters are as follows; $\Delta=0.9, \pi=0.5, \bar{\sigma}=0.65, c_{b}=c_{a}=0.4, T=$ 1.5, $o=0.1$. $\mathrm{G}(\mathrm{r})$ is a uniform cumulative distribution function with $\Delta$ as minimum and 5 as maximum. The figure is cut-off at $m=0.85$ and $l=0.90$, which is where the groups become so strong that they will rebel despite the choice of the dictator

In figure 3.6 the importance of the exogeneous rent decreases and is now 0.1 . In this scenario, the benefit to the ruling coalition and the opposition overwhelmingly comes from the general interest policy. This increases the intervals in which both the ruling coalition and the opposition will not rebel if they observe the good action. There is now little to win from being the ruling group, while there is much to win from having a dictator who takes choices that are in the general interest. 
Figure 3.6: The probability that a bad dictator will choose $e_{1}=s_{1}$

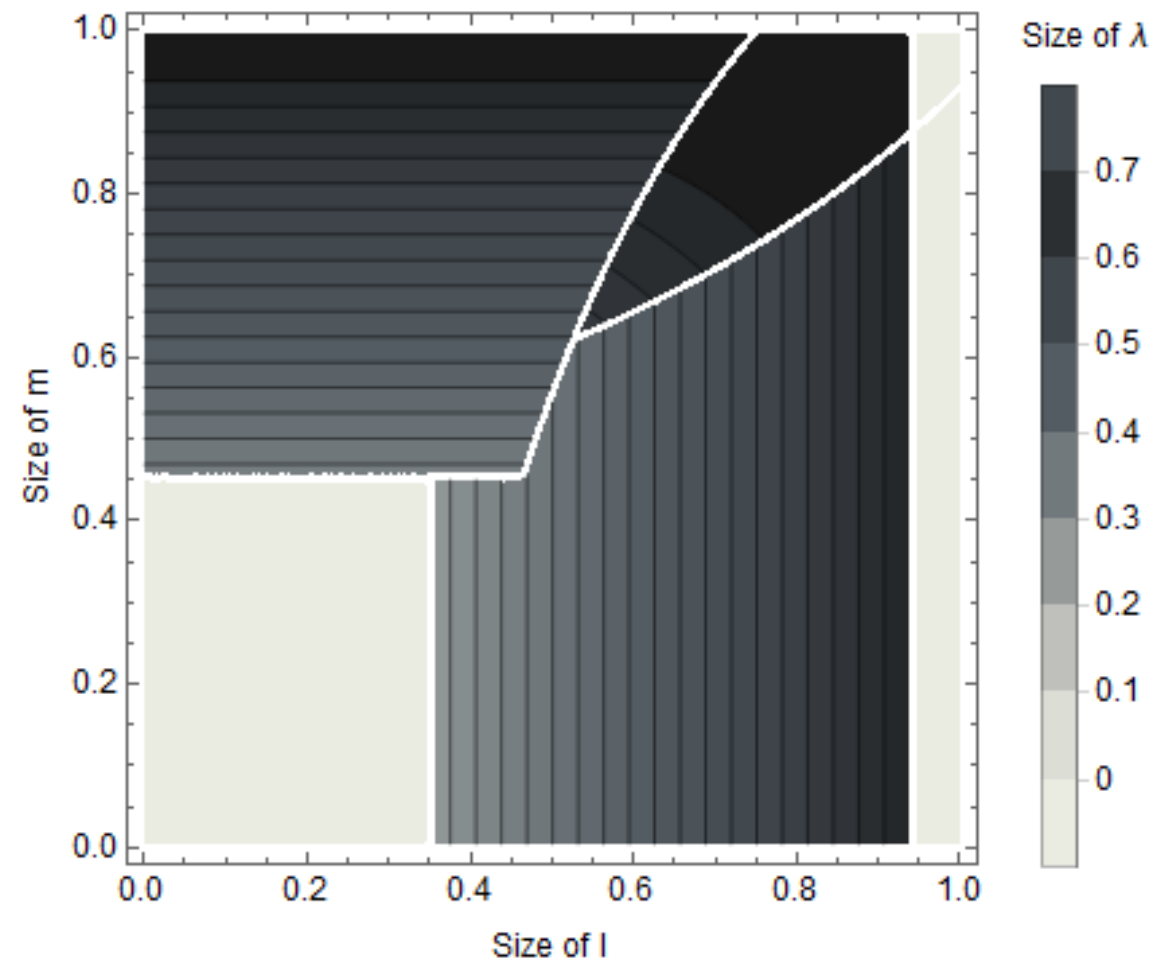

Notes: The probability, $\lambda$, that a bad dictator will choose $e_{1}=s_{1}$ as a function of the chance that the ruling coalition will be successful in a rebellion, l, and the chance that the opposition will be successful in a competition, $\mathrm{m}$. The parameters are as follows; $\Delta=0.9, \pi=0.5, \bar{\sigma}=0.65, c_{b}=c_{a}=0.4, T=$ $0.1, o=0.1$. $\mathrm{G}(\mathrm{r})$ is a uniform cumulative distribution function with $\Delta$ as minimum and 5 as maximum. The figure is cut-off at $m=0.85$ and $l=0.90$, which is where the groups become so strong that they will rebel despite the choice of the dictator

The implications of the model discussed here is an explanation for why states with abundant resource wealth perform worse than their resource-poor counterparts. This is commonly known as the "resource curse" (Ross 1999). Here, it is predicted that authoritarian states with high exogenous revenue are more likely to experience situations where it is not worthwhile for the ruler to provide public goods to stay in power. Instead, these regimes are more likely to experience situations with either high repression or chaotic periods where there is a competition for power. This aligns with other studies, such as Fearon (2005) who shows that oil production is positively associated with the risk of 
experiencing civil war. These considerations are important for the selection of cases.

\subsection{Conclusion}

Building on the framework presented in the last chapter where I put forward the concepts "internal constraints" and "external constraints", I construct a formal model. The model formalizes how constraints on the autocrat can cause the autocrat to change behavior. Instead of following through on his own preferences and pursue a policy which only benefits himself, he will have to seek compromises and pursue policies that are congruent with the general will. The next chapter will investigate how this can lead to higher economic development. 
There is no dispute in our party. We don't say what do you want, what is it? It is what Kamuzu says that goes. - Hastings "Kamuzu" Banda in Malawi: A turning point (1994, p. 12)

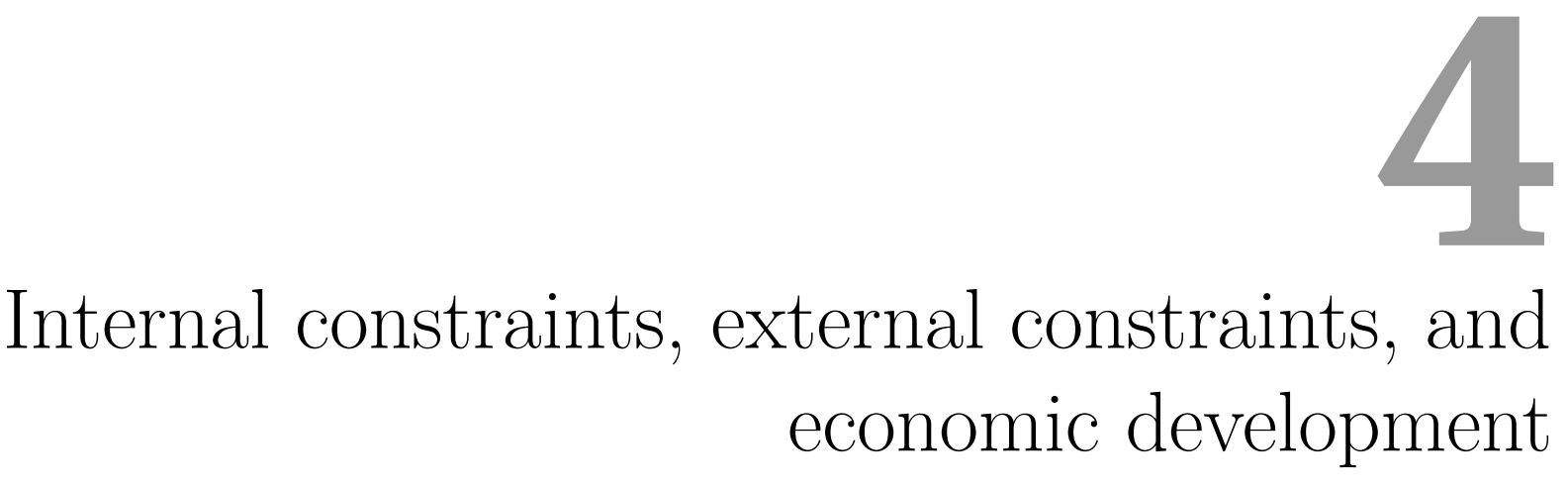

\section{Contents}

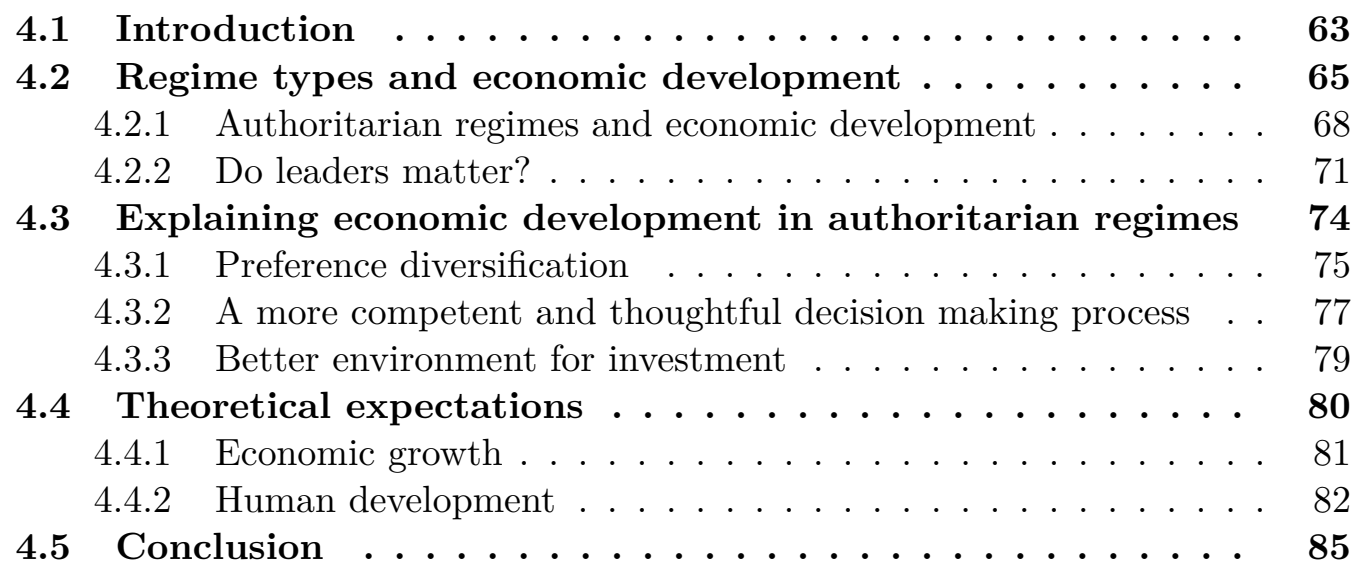

\subsection{Introduction}

In 1957, the leaders of Nyasaland African Congress (NAC) invited the expatriate Hastings Banda to Nyasaland to assume the leadership of NAC. He was popular because of his position as a highly qualified doctor in England, his generous support for the NAC 
since its founding, and his outspoken attacks against the British rulers. Furthermore, he was experienced, well-educated, and had a good reputation. The NAC organized an intensive publicity drive for Banda where he was hailed as the greatest of Nyasalands sons (Cullen 1994, p. 22) which made his popularity soar to the level of hero worship. Banda was then sworn-in as the Prime Minister of Nyasaland. Shortly after, he led Nyasaland to independence as Malawi in 1964.

In the years following independence, Malawi, with Banda at the steering wheel, was pursuing reasonable economic policies and governed over decent economic growth (Cammack and Kelsall 2011; Cullen 1994, Thomas 1975). This was in part because of the economic plans laid out by Dunduza Chisiza, a prominent young economist and Bandas potential rival for leadership. Yet, Banda soon centralized power by murdering his opponents, including Chisiza, and stifling civil society. With the emergence of Banda as the dominant decision maker, the economic objectives were reduced to policies linked with arbitrary objectives, such as minimizing budget deficits in order to secure independence of foreign creditors, or the accomplishment of prestige projects, such as a new capital and a new university (Thomas 1975). These policies were somewhat beneficial to economic growth. Thus, had Banda stepped down in the 70ies, he might have been remembered differently. Yet, he became increasingly corrupt and megalomaniacal. In combination with external shocks, an extensive patronage system, growing inequality, incompetent leadership, and an increased politicization of the bureaucracy, this made growth plummet. When he was forced out in 1993 at the age of 951 with help from the international

\footnotetext{
${ }^{1}$ Banda's precise date of birth is not known.
} 
community, Malawi was one of the worlds poorest countries and had experienced no economic progress under his rule.

Banda is not alone in the group of leaders who came into power with high expectations, but instead led their country to ruin. Based on the theory laid out in the previous two chapters, I will argue that the two types of constraints (or lack thereof) can help in explaining why so many autocrats fail to deliver on their promises.

\subsection{Regime types and economic development}

The idea that regime type is related to economic development has perhaps generated the largest body of literature within comparative politics (Przeworski 2000, p. 78). It is indisputable that democracies, on average, are richer, more developed, and provide higher living standards for their people than autocracies (Acemoglu et al. 2008; Lipset 1959; Przeworski 2000). Yet, the relationship between the type of regime and economic development is unclear. Here, I will focus on the discussion on whether democracy promotes growth or not, but there is a large and interesting discussion on the causal effect of development on democracy (Ansell and Samuels 2014; Inglehart and Welzel 2005 Lipset 1959; Przeworski and Limongi 1997).

The proponents of democracy argue that democracies are better at protecting property rights, resolving conflicts, and are more open towards critique and deliberation which causes growth. On the downside, some scholars argue that democracy is bad for investment and that democracies are more vulnerable to clientelistic behaviour which hampers growth (Przeworski 2000). These opposing forces have resulted in very contradictory advices regarding the preferred regime type for economic development. The World Bank is on 
the verge of advocating for authoritarianism with their findings from a study on growth success stories, stating that "growth at such pace, over such a long period, requires strong political leadership" (Spence et al. 2008) but only mentions authoritarian examples, such as China's Deng Xiaoping. Furthermore, Huntington and Nelson (1976, p. 23) argue that "political participation must be held down, at least temporarily, in order to promote economic development". In addition, John Maynard Keynes (1936), in the introduction to the German edition of his General Theory, argues that Nazi spending policies after 1933 exemplifies the superiority of totalitarian regimes in implementing the "right" policies to overcome the slump $\mathrm{L}^{2}$ On the other hand, some scholars strongly advocate for democracy to promote economic development. Amartya Sen (2001, p. 10) famously claims that freedom is not the end of development, but among its principal means and that no substantial famine has happened in a democratic country. William Easterly $(2014$, p. 7) writes that "that the cause of poverty is the absence of political and economic rights, the absence of a free political and economic system that would find the technical solutions to the poor's problems. The dictator whom the experts expect will accomplish the technical fixes to technical problems is not the solution; he is the problem". Overall, the empirical results are murky. Przeworski and Limongi (1995, p. 64) state that we do not know whether democracy fosters or hinders economic growth and Gerring et al. 2005, p. 323) conclude that "the net effect of democracy on growth performance cross-nationally over the last five decades is negative or null". These conclusions are supported by later meta-analyses (Doucouliagos and Ulubasogly 2008; Nooruddin 2010). However, a new study by Acemoglu

\footnotetext{
${ }^{2}$ Keynes was, however, in general very critical towards Nazism and authoritarianism, see Pernecky and Richter (2011) for a discussion of this.
} 
et al. (2019) provides evidence in favour of democracy. In Figure 4.1 all growth-rates since 1946 are plotted on a kernel density plot grouped by the regime type. It is seen that autocracies and democracies, on average, have about the same rate of growth, but that autocracies have more dispersed growth rates than democracies. This finding is summarized by Przeworski et al. (2000, p. 178), who write that "The lists of miracles and disasters are still populated almost exclusively by dictatorships. Thus, looking at best practice is misleading: The tigers may be dictatorships, but dictatorships are no tigers".

This discussion indicates that we may be missing important insights by focusing on the dichotomy between autocracy and democracy. Furthermore, it indicates that autocracies are more likely to produce both high growth, but also catastrophic results.

Figure 4.1: Distribution of growth rates amongst democracies and autocracies

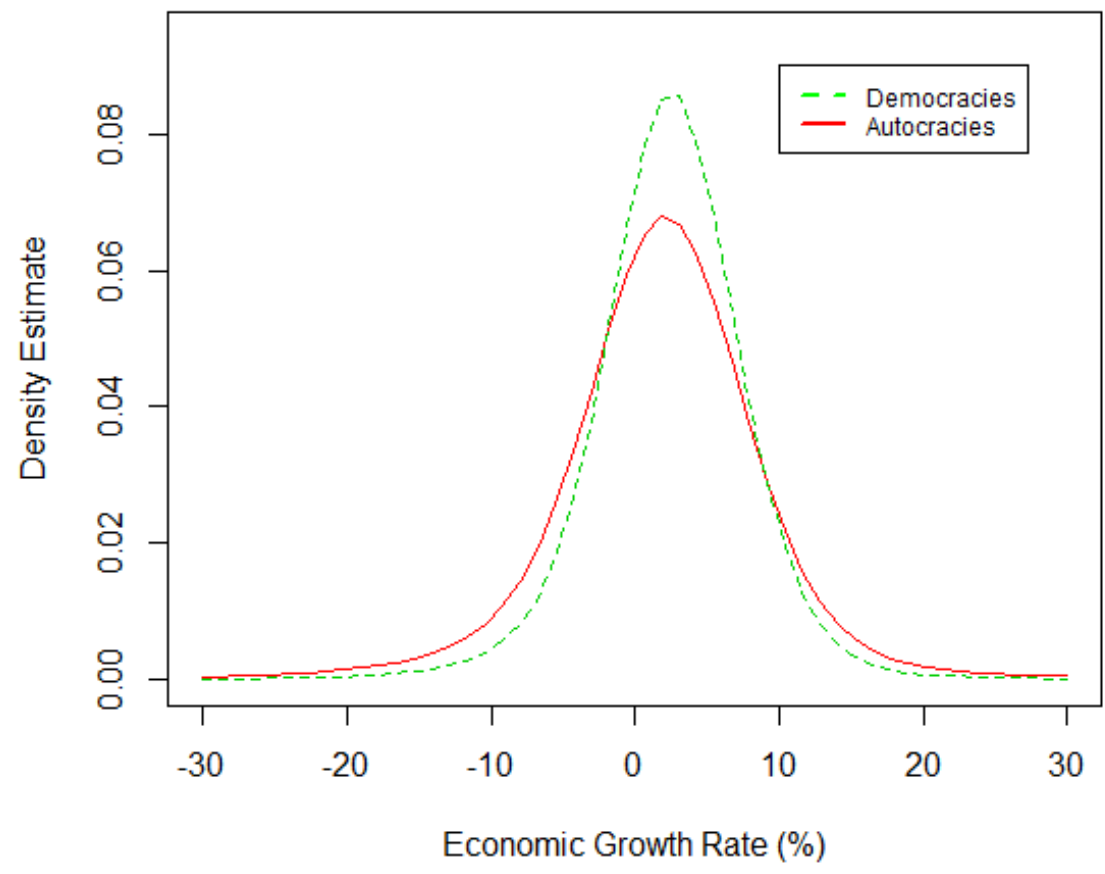

Source: Penn World Tables 2015 and Bjørnskov and Rode 2018, Notes: Plotted are the density functions estimated by using the Gaussian kernel and using 3 as a bandwidth. $\mathrm{N}=10.298$ country years. 


\subsubsection{Authoritarian regimes and economic development}

Despite the huge literature which compares democracies and autocracies, we know little about how economic development outcomes differ among autocratic regime types (Gandhi 2008 Miller 2015). There is a growing body of literature that focuses on authoritarian institutions and answers questions such as; Why do authoritarian regimes have elections? (Brownlee 2007; Frye et al. 2014, Gandhi and Lust-Okar 2009, Lust-Okar 2006), How do authoritarian parliaments function? (Malesky and Schuler 2010, Truex 2014) and Who is promoted in authoritarian regimes? (Aaskoven and Nyrup 2020; Egorov and Sonin 2011; Lü and Landry 2014; Reuter and Robertson 2012; Shih et al. 2012). Less work has, however, been done on how different types of authoritarian regimes influence policy.

Existing research on economic development in authoritarian regimes can be divided into two groups. One line of research argues that authoritarian countries with quasidemocratic institutions will provide better economic development. The most prominent study within this field is Gandhi's (2008). She argues that autocratic institutions are strategic responses from autocrats who need to compromise with a strong opposition. Legislatures and parliaments therefore serve as a controlled institutionalized channel, which outside groups can use to make demands. She shows that this also changes both policy and economic outcomes. Institutionalized regimes are better at protecting civil rights and they spend less on armed forces. Furthermore, they experience higher economic growth and are more transparent. Miller (2015) has built upon these ideas and shows that electoral authoritarianism decreases infant mortality and increases literacy rates, while Blaydes and Kayser (2011) show that the population in hybrid regimes have a 
higher calorie intake than the population in closed authoritarian regimes, and Fails $(2020)$ has shown that electoral autocracies are more likely to adopt social assistance programs. Another contribution is Wright (2008) who shows that legislatures in military and singleparty regimes increase growth and investment, while these institutions in personalist and monarchic regimes decrease growth. Overall, this literature clearly indicates that institutionalized authoritarian countries, where there is a strong opposition, are better at promoting economic development.

In the light of the discussion in Chapter 2, these studies have three limitations. First, they primarily focus on the relationship between the regime and the opposition, but neglect the relationship between the autocrat and the ruling coalition. They are therefore unable to explain why some closed regimes, such as China post-Mao and Vietnam after reunification, have been relatively successful in promoting economic growth. Second, these studies do not explain much variation in the world of contemporary authoritarian regimes due to the increasing institutional homogeneity amongst authoritarian regimes. Third, institutions such as legislatures and parliaments are relatively static over time within leader and if they change it may reflect changes in the underlying power structure (Pepinsky 2014).

Another group of studies focus on the dictator and his relationship with the elite. North and Weingast's (1989) argue that once the wealthy can act collectively to wage war against the king, the threat of expropriation declines and thereby spurs investment. Furthermore, Papaioannou and Van Zanden (2015) find a strong negative correlation between years in office and both economic growth and the quality of institutions. They attribute this primarily to personal factors, such as change in the personality of the 
dictator, or increasing information asymmetries due to the dictator's dilemma. This dilemma arises when the autocrat becomes all powerful. People will be reluctant to share their information with him, because the bearer of bad news may fall into disgrace and be punished. The unconstrained autocrat is then caught in information asymmetries and lacks a basis for sound economic decision making which will eventually lead to adverse economic performance (Wintrobe 2000). Along the same lines, Besley and Kudamatsu (2008) show that leadership turnover in successful autocracies is higher than in unsuccessful autocracies. They theorize this is because the ruling coalition can remove the autocrat without fear of losing their power. This implies that a weak opposition is conducive to economic growth which contradicts the argument made in Gandhi $(2008)$ and Miller's work (2015). Besley and Kudamatsu identify Romania (1948-1977), China (1976-2004), and Brazil (1965-1974) as some of the most successful authoritarian regimes. These regimes were all closed and non-competitive, but with organized leadership contests within the regime. They should therefore fare badly according to the literature which focuses on electoral institutions. Likewise, Gehlbach and Keefer $2011 ; 2012)$ argue that institutionalized parties increase capacity for collective actions and show that this is associated with higher investment in autocracies. A similar argument is found in Bizzarro et al. (2018). At last, a related theory to the one presented in this manuscript is selectorate theory. The proponents of selectorate theory argue that when the winning coalition, e.g. those whose support are essential for the leader to gain a victory, is small, the leader tends to use private goods to satisfy the coalition, while if it is large the leader tends to use public goods to satisfy the coalition. This explains why dictatorships, where the leader relies on a small number 
of people, perform worse economically than dictatorships where the power is based on a larger group of people (De Mesquita et al. 2005). The theory presented in this thesis aligns with selectorate theory in many ways. However, I argue that the cohesion and organization of the ruling coalition matters more than the size.

The drawback of the studies which focus on the elite is that they are unable to measure the power balance between the dictator and the ruling coalition. Instead, they rely on proxies such as leader duration, whether a party existed before the dictator came to power, or the size of the winning coalition. Furthermore, they tend neglect the role of the masses and argue that the development is solely elite driven. In the empirical chapter, I will present a new, time-variant measure for elite strength.

In sum, the literature points in two directions. One line argues that quasi-democratic and institutionalized authoritarian regimes will fare well, while another stream contends that authoritarian regimes with an organized and powerful elite will provide the best outcomes. In next section, I show that these two arguments are compatible.

\subsubsection{Do leaders matter?}

Much of the literature in economics that focuses on economic growth argues that bad growth performances and underdevelopment are caused either by misdirected policies or events beyond the control of the leader. This literature departs from a Machiavellian viewpoint and assumes that policy-makers are benevolent when it comes to economic policies and want to increase the welfare of their citizens, see for example Robinson (1998). This thesis rests on the opposite assumption; authoritarian leaders do not care about their population or about delivering good governance unless it is essential for their own survival. 
However, are leaders able to impact economic growth in a positive direction even if they wanted to? This is a contested question, and there are many scholars who argue that leaders are unable to impact economic growth (Easterly and Pennings 2016). This is particularly the case in developing countries heavily dependent on the export of commodities or countries reliant on remittance recipients (Campello and Zucco 2016 , Zucco and Campello 2020).

Anecdotally, it seems absurd to claim that Stalin or Mao had no direct impact on their respective countries. The notion that leaders are able to impact economic growth is supported by quantitative evidence. For example, Jones and Olken (2005) find robust evidence that leaders matter for growth by using the random death of a leader as an exogenous variable. Furthermore, Berry and Fowler (2017) uses randomization inference to show that world leaders matter for GDP growth, and Rizio and Skali Rizio and Skali (2019) show that autocratic leaders are more likely to provide negative growth than predicted by chance, while they are no more likely to provide positive growth. In addition, Kolstad (2020) shows that growth falls significantly when a long-term political leader leaves office, and argues that it is because of deliberate efforts by longterm leaders to concentrate power while in office and poison the post-reign economic or political environment. Thus, there seem to be good empirical evidence that leaders are able to impact their countries' economies.

The theory outlined in this thesis argues that leaders matter, but in a subtle way and through several pathways. First, it does not assume that the personality of the leader matters per se. Instead, the degree to which the personality matters is mediated 
through the level of constraints. If there are few constraints, the personality of the leader should matter more than if there are strong constraints. In a country with strong constraints the leader is interchangeable, since he will be forced to act in certain ways to stay in power; a bad dictator is punished. In addition, as I will argue below, the argument relating constraints to economic development does not only focus on personality or policy decisions, but also on the absence of policy decisions and the inability to provide a stable climate for investments.

Furthermore, much of the literature which argues that leaders are unable to impact growth either looks at the whole lifespan of the leader or the economic impact of fluctuations in prices of commodities or the inflow of remittances in a single year. Following the example of Banda it can be problematic to look at the lifespan of a leader and use the average. Many leaders govern over reasonable growth early in their tenure, but experience worse growth outcomes later on (Kolstad 2020, Papaioannou and Van Zanden 2015). Thus, using the average over the entire lifespan might be misleading. This may cover both periods with high and low growth. Likewise, focusing on a single year - or a few years - where there are fluctuations in commodity prices, may underestimate the impact a leader has on economic development over time. For example, the year-to-year growth in Venezuela during Hugo Chavez's rule may be highly dependent on the price of oil. However, in hindsight it is clear that Venezuela's ruin was a process that at least is partly attributable to decisions taken at the very top of the regime. Chavez purged officials in the national oil company, PDVSA, and took indirect control of the company. This turned out to be disastrous both for the company and the Venezuelan economy. In addition, he engaged in irresponsible 
public spending and made it difficult for foreign companies to invest (Johnson 2018).

Yet, this is not to say that everything is within control of the leader. This is clearly not the case. The models I will present later have much unexplained variation, and changes in commodity prices and remittances may account for some of this. Furthermore, we may expect that the model has less explanatory power in countries highly dependent on exogeneous revenues from natural resources. I will return to the role of natural resources later on.

Overall, there is little doubt that some actions such as investing in infrastructure, respecting the rule of law, facilitating private trade, and fighting corruption have a positive effect on the economy (Besley and Kudamatsu 2008, p. 455). The question is why some autocrats work in the general interest of their citizen by pursuing these policies, while others do not.

\subsection{Explaining economic development in authoritar- ian regimes}

The causal chain is presented in the figure 4.2. The basic argument here is that constraints on the autocrat result in economic development. As argued in the formal model, the two types of constraints ensure that the autocrat is being held accountable for his actions in the absence of democratic elections and that he may be punished in the case of bad outcomes. This will modify the actions of the dictator and - in general - be beneficial for economic development. The argument for why constraints lead to economic development rests on three channels; 1) preference diversification, 2) a more competent and thoughtful decision making process and 3) a better environment for investment. 
Figure 4.2: Presentation of the causal mechanism

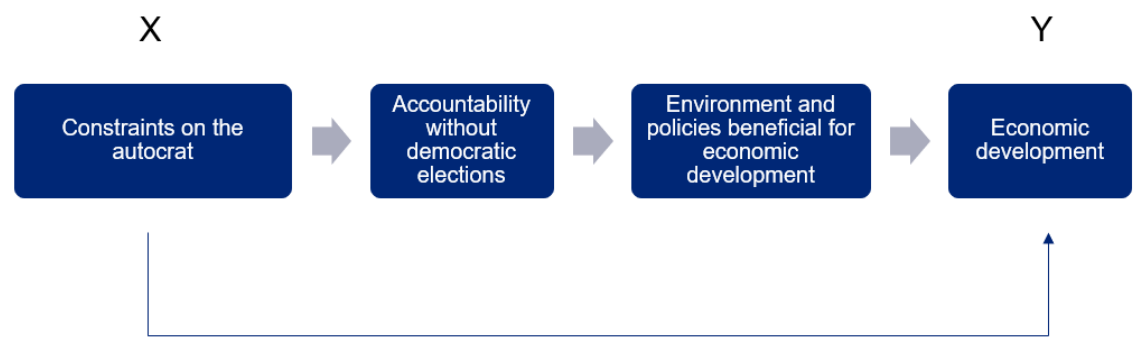

\subsubsection{Preference diversification}

First, the level of constraints is decisive for whose preferences get to influence the policy making process. This is one of the main points in the formal model. Here, I show that a dictator has an incentive to abandon his preferred policy if he faces a credible threat from the ruling coalition and/or the masses.

There are number of reasons for why the authoritarian leader may be against implementing economic policies that promote economic development, such as technological advancement and liberalization of the economy. First, economic growth can lead to a "political replacement effect", i.e. an increase in economic output will benefit groups other than the autocrat. These empowered groups will eventually want to have a larger say in politics and demand political and economic concessions. Economic development may therefore undermine the relative advantage of the autocrat and make it more likely that he will have to concede power (Acemoglu and Robinson 2006; Ansell and Samuels 2014). Furthermore, consolidated autocrats tend to focus their energy on implementing policies in accordance with their belief, engage in grandiose projects, or reaping the benefits from being in office (Gandhi 2008; Gjerløw and Knutsen 2019). Grotesque examples are 
Saparmurat Niyazov of Turkmenistan's affinity for golden statues, or Jean-Bédel Bokassa of Central African Republic's extremely lavish coronation ceremony which costed 25 per cent of the gross national product (Crabb 1978). It is hard to see how any one else than the dictator benefits from such projects, excluding the few people in the business of producing golden statues and arranging ceremonies.

However, if an organized civil society or a strong ruling coalition can credibly threaten the autocrat with removal, the autocrat will have to listen to their demands. There are good reasons to suspect that the civil society, on average, will have preferences that are more prodevelopment than the autocrat. The masses will be more interested in policies that favour broad-based growth, since it increases their overall utility, and thereby the utility of the individual person (De Mesquita et al. 2005). Throughout history we have seen that even the most infamous regimes had to cater to the population when they were cementing their power. For example, did the Nazi regime engage on a ambitious Autobahn construction project, which moved public sentiment in the regime's favour (Voigtländer and Voth 2017).

The ruling coalition is more tricky, and in some cases they may team up with the dictator and split the rents from being in office, while caring little about the wider population (De Mesquita and Smith 2011). This is, however, not always the case. The ruling coalition will often have an economic base and represent a specific group of people such as a tribe, a certain business sector or people in a specific geographic area (Brownlee 2007; Pepinsky 2009, p. 38). The authoritarian elite will have to provide rents to the group of people they represent, and may therefore be dependent on broad-based economic growth to provide such rents. In addition, members of the ruling elite are often wealth 
holders themselves and therefore wary of policies which disrupts the economy (Gehlbach and Keefer 2011). The dictator will therefore, when he is constrained, have to engage in policies which provide the right type of economic development to satisfy the demands of the ruling coalition and the broader civil society to stay in power. Or as Wintrobe writes 2000, p. 15): "One way to create loyalty, which is very common in the modern world, is to simulate economic growth".

\subsubsection{A more competent and thoughtful decision making pro- cess}

Second, constraints on the autocrat will promote a more thoughtful, less rushed decisionmaking process, where competence and experience plays a larger role. Here, it is expected that internal constraints matters most. In the model it is assumed that a dictator who is allowed to govern without constraints, will consolidate his power by purging competent members of the ruling elite and replace them with loyalist.

Competent members of the ruling elite are able to act more independently, might have higher ambitions, and have more resources than loyalists, and thus have better prerequisites for staging opposition to the dictator (Egorov and Sonin 2011; Svolik 2012; Zakharov 2016). This can result in competent subordinates being more likely to actively oppose certain policies with which they do not agree or even attempt to stage a coup against the dictator. The threat is most imminent from military officials, who have direct control over armed forces (Braithwaite and Sudduth 2016). However, other groups of officials also pose a threat to the leader such as officials who can wield large public followings. This is particularly the case for officials who have a strong local powerbase 
and/or have proven themselves capable of governing through good local performance (Aaskoven and Nyrup 2020, Gueorguiev and Schuler 2016). Thus, competent ministers might be more likely to be fired and Quiroz Flores (2016), indeed, finds that competent ministers in autocracies quickly are dismissed from their cabinet positions. However, ultimately, all members of the ruling coalition may be in risk of losing their jobs - or worse - as is evident from the broad purging of subordinates that has taken place in some authoritarian regimes (Kenyon 2018; Svolik 2012; Woldense 2018).

In sum, there are good reasons to suspect that the purging of the ruling coalition causes a loss of competence and experience. We have seen this in many autocracies around the world. For example, in Banda's Malawi. Shortly after Banda took power, Chisiza, the prominent young economist, died in a mysterious car accident. This incident was followed by more car accidents where members of the ruling elite died under suspicious circumstances. In that way Banda gradually replaced members of the elite with younger people who had no independent power base and were indebted to Banda (Williams 1978, p. 209). Most were poorly-educated without overseas experience or technical capacity (Cammack and Kelsall 2011).

Not only will the purging of regime officials cause a loss of competencies. Unopposed and almighty dictators may suffer from information asymmetries due to the dictator's dilemma (Papaioannou and Van Zanden 2015. Wintrobe 2000). People will then be reluctant to share the necessary information with the dictator, because the messenger of bad news may fall into disgrace and be punished. Instead, they will tell the dictator what he wants to hear. The dictator is aware of this, and will therefore not trust the information 
given to him by ministers and advisers. People will then try to flatter him by presenting too optimistic information about the state of the economy while suppressing the bad news, also because bad news may mean that they are not doing the expected good job (Papaioannou and Van Zanden 2015). Once such a disinformation equilibria has started, it is difficult to return to reality. The dictator becomes increasingly lonely and paranoid which slurs his decision making abilities. Thus, the result of this "disinformation trap" is that the dictator lacks a basis for sound economic decision making. This will eventually lead to adverse long term economic performance. Classical examples are Stalin's refusal to believe that the Soviet Union had been invaded by Nazi Germany (Montefiore 2004) and Mao's ignorance about the horrors taking place under the Great Famine (Dikötter 2010).

\subsubsection{Better environment for investment}

Third, constraints will foster an environment that is conducive to economic investment. As argued in the formal model, an unconstrained dictator can implement whatever policy he pleases, however harmful this policy may be. Since the policy-making is solely in the hands of the dictator, the government cannot credibly commit to a certain policy direction, because the dictator all of a sudden can change his mind. This will create great uncertainty for investors, who fear arbitrary policy reversals that will render their businesses unprofitable. Instead, investors respond by seeking opportunities outside the country for their capital or by choosing short-term and less risky forms of investments. This can be harmful for economic development, both in the short and the long run (Nooruddin 2010).

In grave cases, the dictator can capture the state and establish a patrimonial rule with no respect for the rule of law (Fukuyama 2014 North 1991). This enables him 
to expropriate investments without fear of retaliation. Investors, knowing this, will choose not to invest and may, if possible, even divest and remove capital from the country. North and Weingast (1989) emphasize the importance of governments' ability to credibly commit to uphold property rights for economic growth, and argue that this is the key to explaining economic growth. The importance of property rights for economic development is supported by a vibrant and large literature in political economy (Acemoglu and Robinson 2006, North 1990, Rodrik et al. 2004). How are investors guaranteed stability in autocracies which, as discussed above, are characterized by the absence of formal constraining institutions? Again, we need to look at internal and external constraints. If other actors credibly can retaliate against the dictator when they experience policies or expropriation that threaten their investments, investors have some security. This will stimulate investments and foster innovations (Gehlbach and Keefer 2012, Nooruddin 2010). This is especially the case for the broader civil society which are excluded from power and to a higher degree risks having their investments expropriated by the regime and its officials (Gandhi 2008). The canonical example is Mohamed Bouazizi, a Tunisian street vendor, who had his scales confiscated because he refused to pay a bribe. Out of frustration and hopelessness he set himself on fire and started the series of events that resulted in the Arab Spring.

\subsection{Theoretical expectations}

Based on the discussion above, the expectation is that both a strong ruling coalition and a strong civil society are associated with better economic development. The study takes a broad view of economic development and sees it as a process where the well-being of 
the inhabitants of a country is improved. Economic development is therefore an umbrella term covering different aspects such as economic growth, human development, happiness, absence of crime, improvements in infrastructure, and the level of inequality.

It is outside the scope of this thesis to cover all aspects of economic development. Instead, I will focus on two aspects of economic development, namely economic outcomes (economic growth and likelihood of recession) and human development outcomes (infant mortality and primary school enrolment). These two aspects are chosen because they are widely used in the literature, data is available over a long period of time for a long range of countries, and because they can be considered core elements in economic development. Furthermore, they reflect two qualitatively different aspects of economic development. Economic growth is, in general, correlated with outcomes such as higher life expectancy and lower poverty rates, but this is not guaranteed (Acemoglu 2009). In some cases, economic growth will only benefit a small share of the population. However, better human development outcomes will have a positive impact on a broader section of the population, including the very poorest. Below I will clarify my theoretical expectations.

\subsubsection{Economic growth}

Economic growth is the increase in the value of the goods and services produced by an economy over time. Economic growth therefore requires unleashing the productive capacities in a society by providing incentives to companies and workers. The discussion above provides three channels through which the lack of constraints can diminish economic growth. Taking all this together, the expectation is that both a strong ruling coalition 
Table 4.1: Theoretical expectations for economic growth

\section{Level of external constraints}

\begin{tabular}{llll} 
Level of internal constraints & \multicolumn{2}{l}{ Low } & $\underline{\text { High }}$ \\
\cline { 2 - 2 } & $\underline{\text { High }}$ & Medium growth & Medium growth \\
Medium-High growth
\end{tabular}

and an organized civil society are associated with pro-development policies and an environment which stimulates investment.

It is assumed that dictators move across categories over time. The two types of constraints are therefore handled as continuous variables with a linear effect on economic outcomes. An unconstrained dictator, who does not face any credible threats to his rule, will be able to act solely according to his own beliefs and preferences and with little guidance from competent subordinates, which, as discussed, may yield adverse - or even catastrophic - economic outcomes. It is therefore expected that economic development is lowest in regimes without any constraints (e.g. one-man regimes). The formal model argues that both internal and external constraints would have an effect on restraining the autocrat. Furthermore, there is an extra effect if there are both internal and external constraints. However, it also argued that there are diminishing marginal returns from having both types of constraints, because either type of constraints are enough to avoid the worst impulses of the autocrat and create (some) policy stability which will assure investors. Therefore, it is expected that the interaction between the two types of constraints will be negative. The overall expectations are shown in table 4.1

\subsubsection{Human development}

The United Nations Development Programme writes that "The human development approach is about expanding the richness of human life, rather than simply the richness of 
the economy in which human beings live" (Nations 2019). This entails improving people's lives by providing a decent standard of living and opportunities to develop their full potential. The empirical chapters focus on two aspects of human development, namely primary school enrolment and infant mortality.

The two measures of human development are different in essence. Child mortality is known to concentrate amongst the lowest incomes (Gwatkin 2004), and is related to conditions such as inequality, access to clean water and health care, calorie intake, and redistribution (Ross 2006). Decreases in infant mortality therefore mainly benefits poor people, while people in the economic elite will benefit little. Child mortality is therefore an ideal measure of poverty. School enrolment also primarily benefits the poorest people, who are unable to pay for private education, but it is more nuanced than most other fiscal transfers since it may change the long term dynamics in a society. Broad based education will promote a meritocratic system and give the population tools to pursue a better economic and political future. Highly educated people are a potential threat to the regime as is evident from protests around the world (Bunce and Wolchik 2011; Dahlum and Wig 2019). Thus education may undermine the relative advantage of the ruling coalition (Ansell 2010; Lipset 1959).

As discussed, the ruling elite in an autocracy cares about economic growth because they benefit directly from it. After all, it enables them to extract taxes and line their own pockets. On the other hand, they do not personally benefit from improvements in human development outcomes because they already have access to top-notch private health care and educational institutions (De Mesquita and Smith 2011; Sen 1999). In 
other words, helping poor children does not help them, and they therefore have little interest in improving the health care system nor expanding primary education. In fact, providing better human development can undermine the advantage of the ruling coalition relative to the masses. Sen (1999, p. 10) argues that human development will cause greater freedom and that "Greater freedom enhances the ability of people to help themselves and also to influence the world". An authoritarian ruling coalition is not interested in having masses that can influence the regime.

On the other hand, an organized civil society will have a strong interest in promoting policies beneficial for human development. Human development is promoted by increasing redistribution and by investments in effective public goods provision; especially in health services, education, and environmental protection (Miller 2015). Such policies are widely popular and the autocrat can then use public goods to defuse popular dissatisfaction. The incentive to implement policies beneficial for human development increases with the strength of the masses as argued in the formal model. Therefore, the expectation is that external constraints are related to better human development. Moreover, internal constraints are expected to have no independent effect on human development. I argue above that the ruling coalition may oppose policies that increase human development. At first, it should therefore be expected that a stronger ruling coalition will cause human development to decrease. However, this would require that the autocrat is more in favour of human development than the ruling coalition. This is unlikely to be the case; the autocrat faces the same adverse consequences as the ruling elite and the two actors should therefore be in agreement here. 
Table 4.2: Theoretical expectations for human development

\section{Level of external constraints}

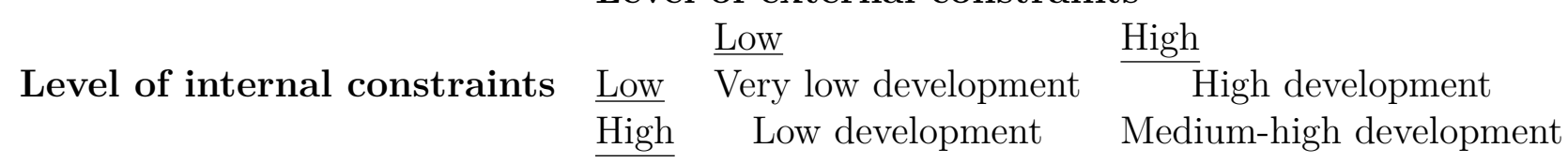

However, even though internal constraints are expected to have no independent effect on human development, this does not imply that there is no effect of internal constraints when interacted with external constraints. When the autocrat faces both a strong ruling coalition and an organized civil society, he has to prioritize resources to counter both threats. Thus, it is expected that a strong ruling coalition mutes the effect of an organized civil society. However, a strong ruling coalition is not always bad for human development. As discussed, the absence of any constraints can result in catastrophic outcomes. This will inevitable have a negative effect on human development, which was seen during, for example, The Great Famine under Mao and the Soviet Famine under Stalin, where government members who opposed or questioned the policies were punished (Dikötter 2010 Montefiore 2004). Therefore, a strong ruling coalition can work as a blocker and help avoiding the worst outcomes. An overview of the expectations is seen in table 4.2 .

\subsection{Conclusion}

Why do some autocracies experience better economic development than others? In this chapter, I discuss previous answers to this question, and argue that the approach taken in this thesis adds to existing explanations. The analytical framework focuses on both internal and external constraints, and argues that we should see these as varying over time for the same leader. I then argue that the two types of constraints will result in 
better economic development through three mechanisms, 1) preference diversification, 2) a more competent and thoughtful decision making process, and 3) a better environment for investment. Yet, the two types of constraints have different effects dependent on the outcome. I expect that both types of constraints are associated with higher economic development, and that the interaction between the two is negative. However, I expect that only external constraints will be positively associated with human development, while internal constraints only can block the autocrats worst impulses.

In the previous three chapters, I have put forward the theoretical framework. In the remainder of the thesis, I will test the claims outlined in the theory. 
Who's going to remember all this riffraff in ten or twenty years time? No one. Who remember the names now of the boyars Ivan the Terrible got rid of? No one. The people had to know he was getting rid of all his enemies. In the end, they all got what they deserved.

- Joseph Stalin in Stalin: The Court of the Tsar

(Montefiore 2004, p. 236)

\section{Who governs? A new global dataset on members of cabinets}

\section{Contents}

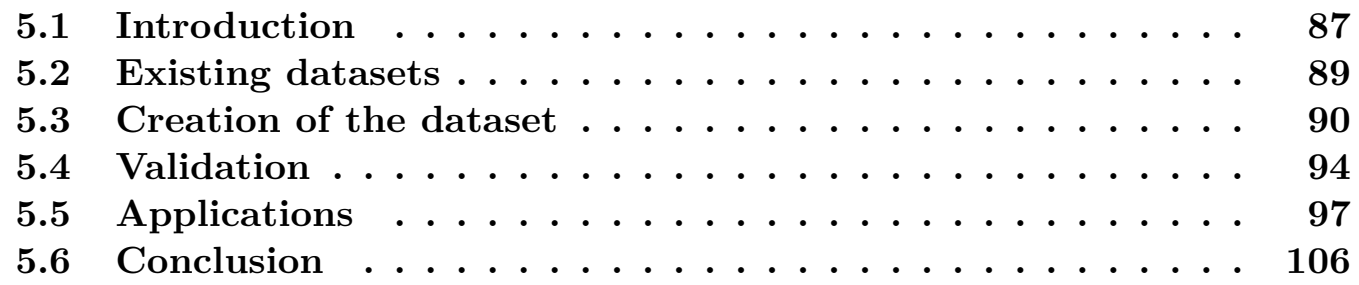

\subsection{Introduction}

There is an enormous literature on the composition of political elites, particularly in autocracies. Yet, there is currently no time-series dataset on governing elites in a large number of countries, and political scientists are therefore unable to answer even basic descriptive questions such as: what is the share of female cabinet members globally, which type of regime has the highest cabinet turnover, and have cabinets increased in size over time? This naturally also hampers our ability to answer questions of theoretical 
importance, including the questions asked in this manuscript.

The dissertation relies on a new dataset, WhoGov, which contains information on cabinet members in the period 1966-2016 in all countries with a population of more than 400,000 citizens. 1n total, the dataset contains yearly information on 50,197 cabinet members in 177 countries. WhoGov provides vastly greater cross-sectional and temporal coverage compared to existing datasets on cabinets, and therefore has the potential to be an invaluable resource for both comparativists and country experts.

The dataset has been collected for the purpose of this manuscript and in collaboration with Stuart Bramwell who needed the data for his own DPhil-thesis. We realized that the data has many more applications and decided to publish the data. Together we have co-authored an article, Who governs? A new global dataset on members of cabinets, which is published in the American Political Science Review. This chapter is based on this article, but has been rewritten to fit the manuscript, and it therefore focuses more on authoritarian regimes.

We created the dataset based on the Chief of State And Cabinet Members Of Foreign Governments directory compiled by the Central Intelligence Agency (CIA). The original documents were digitized through machine-learning and extensive manual cleaning. This provided the position and the name for every cabinet member for a given country in July of every year. To this, we added party affiliation, gender, and organized the portfolios into categories. The dataset is highly flexible and can be used to calculate countless

\footnotetext{
${ }^{1}$ We also include former sovereign states such as the Soviet Union. The data goes up to 2018 for some countries. A full list of countries and years covered by the dataset is available in Appendix B.4
} 
variables of interest, including the number of female ministers, ministerial experience, cabinet turnover, and cabinet size, at the country-year level.

I first present how the data was created and validate it against other datasets. Afterwards, I prove that the dataset can be used to gain new insights. First, I show four examples of how the data can give insight into four areas within the study of autocratic regimes and lay out questions for future research; some which I am already answering myself in other projects. Then I will present the variables, which I will use extensively in the analysis, namely variables on cabinet turnover and governing experience.

\subsection{Existing datasets}

The most comprehensive work utilizing minister-level data involves advanced industrial democracies. The bulk of this work focuses on the determinants of minister selection and survival on a country-by-country basis (e.g. Bäck et al. 2009; Berlinski et al. 2010, Fischer et al. 2006; Kam et al. 2010; Kerby 2011; Rodríguez-Teruel 2011; Smith and Martin 2017). Several previous studies employ cross-national data (e.g. Bright et al. 2015 Huber and Martinez-Gallardo 2008) and data resources have been made publicly available for researchers interested in comparisons. The Selection and Deselection of Political Elites (SEDEPE) research network offers a dataset on 19 European countries from 1945 to 1984 (Dowding and Dumont 2008), while Alexiadou (2016) offers data on 18 OECD countries from 1945 to 2000, and Bértoa (2020) presents a new dataset on European democracies since 1848.

The equivalent longitudinal data resources covering emerging democracies and autocracies are less developed. Many studies tend to focus on single countries (Buehler 
and Ayari 2018; Kung and Chen 2011; Schleiter 2013, Woldense 2018) while studies that aim at cross-country comparisons tend to focus on a small number of countries from a specific region such as Latin America (Camerlo and Martinez-Gallardom 2020 Camerlo and Pérez-Liñán 2015, Escobar Lemmon and Taylor-Robinson 2005), Central-Eastern Europe (Bego 2014; Semenova 2018) and Sub-Saharan Africa (Arriola and Johnson 2014; Francois et al. 2014, Kroeger 2018). Other scholars have reduced the temporal coverage, and increased the number of countries. The recent Global Leadership Project (GLP), for instance, limits temporal coverage of ministers from 2013 onward (Gerring et al. 2019) while an earlier dataset compiled by Braun and Raddatz (2010) only begins in 1996 . Furthermore, some studies only include specific positions, such as leaders (Goemans et al. 2009) or the foreign or finance minister (Alexiadou and Gunaydin 2019; Flores 2016).

To sum up, there is, to date, no global dataset on governments over a long time span. The lack of data is particularly striking for autocracies, and I am therefore unable to construct a measure of internal constraints based on existing data. This is necessary to test the theory presented in the previous chapters. Thus, the case for constructing such a dataset is clear. In the next section, I describe how Stuart and I collected the data. Table 5.1 compares WhoGov to existing prominent datasets on governments.

\subsection{Creation of the dataset}

In the following section, I briefly describe the data gathering process and choices of relevance. I refer to appendix B.5 for a more in depth description.

The original source of data is the "Chiefs of State and Cabinet Members of Foreign Governments", which is published by the United States' CIA. This directory contains the 
Table 5.1: Available time-series cross-sectional datasets on cabinets

\begin{tabular}{lcccc}
\hline \hline Dataset & Countries (N) & From & To & Region \\
\hline WhoGov & 177 & 1966 & 2016 & Global \\
Alexiadou (2016) & 18 & 1945 & 2000 & OECD \\
Bértoa (2020) & 48 & $1848^{a}$ & Present & W. and E. Europe \\
Braun \& Raddatz & 150 & 1996 & 2005 & Global \\
GLP (2019) & 145 & 2013 & Present & Global \\
Presidential Cabinets & 19 & $1958^{\natural}$ & Present & South and North America \\
SEDEPE (2008) & 19 & 1945 & 1984 & W. Europe \\
\hline \hline
\end{tabular}

${ }^{a}$ Varies by the country. Only contains information for democratic periods.

name, the position and title (if any) of all cabinet ministers and other members of the government in as many countries as practically possible. The earliest available version dates back to 1966 and the directory has been updated at least half-yearly until today. We have obtained the files for every July in the period from 1966 to 2016 and digitized the files. We have used July because data was most widely available for this month.$^{2}$

Figure 5.1 provides an example of the raw data for the Central African Republic in July 1968. The entries are comparable for all countries across all years. To digitize the data, we ran an optical character recognition (OCR) on all the files and developed a script, which turned the original files into digital data files. The script contained a long range of checks, which cleaned the data using matching methods and machine learning.

We then proceeded to an extensive manual cleaning of the data, which especially focused on ensuring that the same person's name is spelled consistently across years. This was important for the purposes of this thesis, where I need to follow the careers of individuals over time. Furthermore, we looked up every person when in doubt about the entry and used alternative biographical information to triangulate the data. All countries

\footnotetext{
${ }^{2}$ The directory began in September 1966, and we are therefore using September for 1966. Furthermore, it has not been possible to obtain the files from July in 1970. Instead, we use January for 1970.
} 
Figure 5.1: The cabinet in the Central African Republic, July 1968.

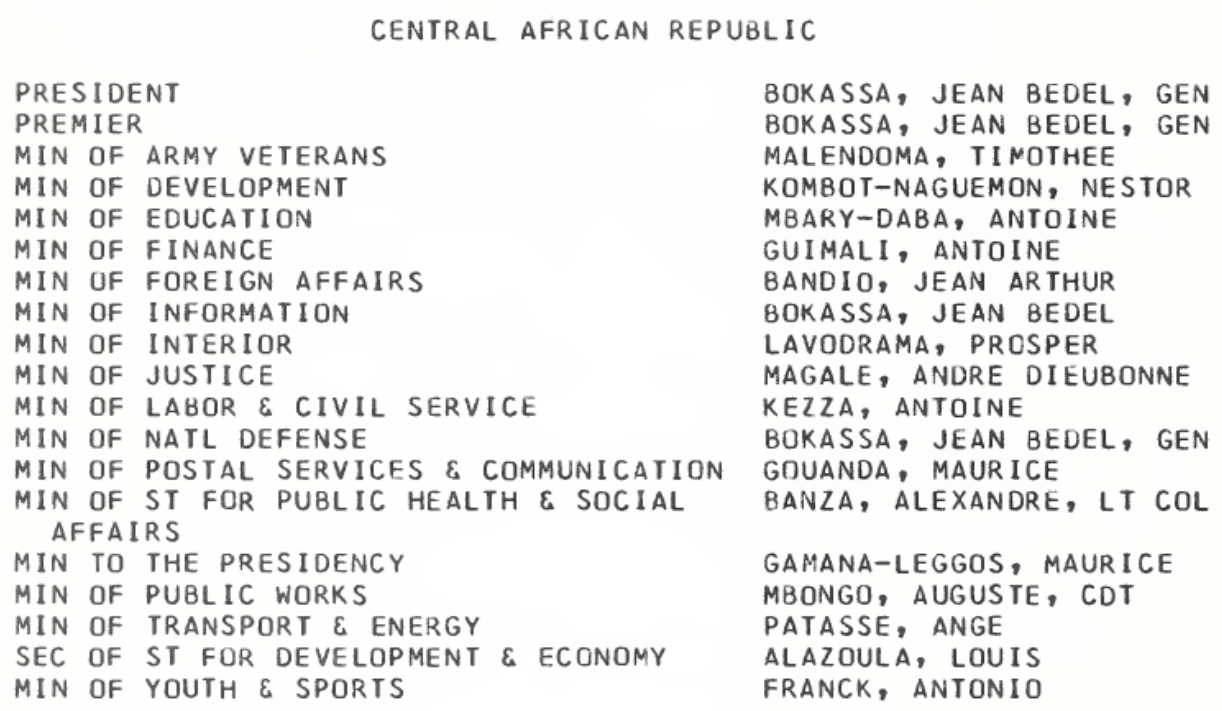

were independently checked by an two persons to ensure accuracy. The end product is a list of members of the cabinet for all years in a given country.

The original names for cabinet portfolios are idiosyncratic both across countries and over time. The Chancellor of the Exchequer in the United Kingdom is, for example, equivalent to the Minister of Finance in other countries. We therefore sorted all ministerial positions into 41 different types of portfolios based on the typology put forward in Krook and O'Brien (2012). Furthermore, we added a classification to every position, making it easy for researchers to distinguish between different groups of governing elites such as full cabinet ministers, junior ministers, presidents and royals. Lastly, many countries have several ministers covering the same portfolio. For example, Nigeria in 2003 simultaneously had a minister of the navy, a minister of the air-force, a minister for the army, and a general minister of defense. We have therefore singled out the most important portfolios and added a binary variable for whether a person is the minister of finance, the minister of defense, the minister of foreign affairs and the minister of agriculture. The choices 
for classifying positions are described further in Appendix B.6.

We also added the party affiliation and gender for all ministers and year of birth/death for ministers in all OECD, G20 and EU countries plus a handful of other countries $3^{3}$ The party affiliation is time variant and therefore takes into account if members of the elite change parties. We use the abbreviations from the PartyFacts' database (Döring and Regel 2019), which allows researchers to merge this dataset with other datasets on parties. The process for adding party affiliation is described in depth in Appendix F in Nyrup and Bramwell (2020).

An example of the final output for the raw data in figure 5.1 is shown in figure 5.2 . The final dataset contains 226,620 of such rows.

Figure 5.2: Final output for Denmark, July 1968

\begin{tabular}{|c|c|c|c|c|c|c|c|c|c|c|c|c|c|c|c|}
\hline ear & coun & is country_nid & position & name & title & gender & birthyear & deadyear & party & party_eng party_oth c & & minister I & leader & classificat portfolio & prestige \\
\hline 1968 & CAF & Central Af & 36 President & Jean-Bedel Bokass & ¿Gen. & Male & NA & NA & mesan & Movemen Mouveme & 1 & 0 & & 1 President NA & NA \\
\hline 1968 & CAF & Central Af & 37 Premier & Jean-Bedel Bokass & ¿Gen. & Male & NA & NA & mesan & Movemen Mouveme & 1 & 0 & & 0 Chief of SiNA & NA \\
\hline 1968 & CAF & Central Af & 38 Min. Of Army Vete & Timothee Malend & Capt. & Male & NA & NA & mesan & Movemen Mouveme & 1 & 1 & & 0 Minister ( Veterans & Low \\
\hline 1968 & CAF & Central Af & 39 Min. Of Developm & Nestor Kombot-Ní & ¿NA & Male & NA & NA & mesan & Movemen Mouveme & 1 & 1 & & 0 Minister ( Planning & \{Medium \\
\hline 1968 & CAF & Central Af & 40 Min. Of Education & Antoine Mbary-Da & NA & Male & NA & NA & mesan & Movemen Mouveme & 1 & 1 & & 0 Minister ( Education & Medium \\
\hline 1968 & CAF & Central Af & 41 Min. Of Finance & Antoine Guimali & NA & Male & NA & NA & mesan & Movemen Mouveme & 1 & 1 & & 0 Minister ( Finance, $\mathrm{E}$ & EHigh \\
\hline 1968 & CAF & Central Af & $42 \mathrm{Min}$. Of Foreign Af & Jean-Arthur Bandi & NA & Male & NA & NA & mesan & Movemen Mouveme & 1 & 1 & & 0 Minister ( Foreign Re & High \\
\hline 1968 & CAF & Central Af & 43 Min. Of Informatio & Jean-Bedel Bokass & ¿Gen. & Male & NA & NA & mesan & Movemen Mouveme & 1 & 1 & & 0 Minister ( Communi & i Medium \\
\hline 1968 & CAF & Central Af & 44 Min. Of Interior & Prosper Lavodram & NA & Male & NA & NA & mesan & Movemen Mouveme & 1 & 1 & & 0 Minister ( Governme & EHigh \\
\hline 1968 & CAF & Central Af & 45 Min. Of Justice & Andre Dieudonne & Brig. Gen. & Male & NA & NA & mesan & Movemen Mouveme & 1 & 1 & & 0 Minister ( Justice \& 1 & IMedium \\
\hline 1968 & CAF & Central Af & 46 Min. Of Labor \& Cis & Antoine Kezza & NA & Male & NA & NA & mesan & Movemen Mouveme & 1 & 1 & & 0 Minister ( Civil Servi & i Medium \\
\hline 1968 & CAF & Central Af & 47 Min. Of Natl Defen & Jean-Bedel Bokass & sen. & Male & NA & NA & mesan & Movemen Mouveme & 1 & 1 & & 0 Minister ( Defense, I & IHigh \\
\hline 1968 & CAF & Central Af & 48 Min. Of Postal Serv & Maurice Gouandjic & ¿NA & Male & NA & NA & mesan & Movemen Mouveme & 1 & 1 & & 0 Minister ( Communi & i Medium \\
\hline 1968 & CAF & Central Af & 49 Min. Of St For Publ & | Alexandre Banza & Lt. Col. & Male & NA & NA & mesan & Movemen Mouveme & 1 & 1 & & 0 Minister ( Health \& & §Medium \\
\hline 1968 & CAF & Central Af & 50 Min. To The Presid & Maurice Gamana-L & LNA & Male & NA & NA & mesan & Movemen Mouveme & 1 & 1 & & 0 Minister ( Other & NA \\
\hline 1968 & CAF & Central Af & 51 Min. Of Public Wor & r Auguste Mbongo & Cdt. & Male & NA & NA & mesan & Movemen Mouveme & 1 & 1 & & 0 Minister ( Construct & ti Medium \\
\hline 1968 & CAF & Central Af & 52 Min. Of Transport & ¿Ange Patasse & NA & Male & NA & NA & mesan & Movemen Mouvem€ & 1 & 1 & & 0 Minister ( Transport & t Medium \\
\hline 1968 & CAF & Central Af & $53 \mathrm{Sec}$ Of St For Devel & I Louis Alazoula & NA & Male & NA & NA & mesan & Movemen Mouvem€ & 0 & 0 & & 0 Minister (. General E & Medium \\
\hline 1968 & CAF & Central Af & 54 Min. Of Youth \& Sp & Antonio Franck & NA & Male & NA & NA & mesan & Movemen Mouveme & 1 & 1 & & 0 Minister ( Sports & Low \\
\hline
\end{tabular}

Based on the detailed dataset, we create a cross-national panel dataset with 8,057

country years. This dataset contains several variables, including, but not limited to, the size of cabinet, number of women, the retention rate for a given year, and the average

\footnotetext{
${ }^{3}$ See Appendix $\overline{B .4}$ for coverage on the party affiliation and birth year.
} 
experience of the cabinet ministers. We have also added information on the leader start/end date based on Archigos (Goemans et al. 2009) and the government start/end date based on ParlGov (2019) and Bértoa (2020), enabling researchers to merge WhoGov with these datasets. The full list of variables and how they are coded can be seen in Appendix B.2. The dataset is incredibly flexible, and it is possible to create many more variables than those provided in the cross-national panel dataset.

\subsection{Validation}

Researchers may reasonably express concerns about the quality of the WhoGov data given that other datasets are gathered manually, while we primarily rely on automatized methods. To address these concerns I cross-validate main variables from this dataset against main variables found in other datasets in figure 5.3 .

The value of the variable in the validation dataset is shown on the $\mathrm{x}$-axis, while our corresponding value is displayed on the y-axis. In the top panels, I match our measure of cabinet size against Arriola and Johnson's (2014) data on African ministers (1980-2005) and Indridason and Bowler's (2014) data on European cabinets (1945-2003). In the middle panels, I compare the share of female ministers derived from our data with Arriola and Johnson (2014) and Krook and O'Brien (2012), which has worldwide coverage for 2009. The bottom panels display our measure of the number of parties against Döring and Manow's (2019) data on parliamentary democracies (1966-2016) and Kroeger's (2018) measure of retention rates for African countries (1976-2010).

Two points are worth noting. Firstly, all measures correlate very strongly. Secondly, the figures highlight some interesting differences to other datasets. The correlation is 
lowest for Kroeger (2018) and Arriola and Johnson (2014). They base their data on the yearly volumes of Europa Publications Limited (Limited 1975), which records the composition of cabinets once a year, often at irregular intervals. Instead, we have data for July every year, which ensures consistency. This can explain the discrepancy, especially for replacement rate which is highly dependent on when it is measured. This variable is very important in the next chapter. The downside is that we do not record the cabinet exactly at the time when a new government enters office, which might be preferred by researchers studying government formation.

Another strength is that we record our data for every minister and then aggregate the data. WhoGov contains junior ministers and other members of the elite, which other datasets usually do not include. Most other datasets only present the aggregated data and we are therefore unable to say with certainty that the same people are included. This may explain some of the discrepancies we see in figure 5.3 .

Lastly, we tend to include more parties than ParlGov (Döring and Manow 2019). We do so for two reasons. First, we generally separate electoral alliances into parties. An example is the Solidarity Electoral Action in Poland, which we separate into eight different parties. Second, we do not code the governing coalition, but the party affiliation of ministers. There are cases, where a minister does not belong to a party in the governing coalition. For example, the Minister for Maori Development in New Zealand is often from one of the parties representing Maori rights, even when the latter are not in the governing coalition. 
Figure 5.3: Cross-validating the dataset against other datasets
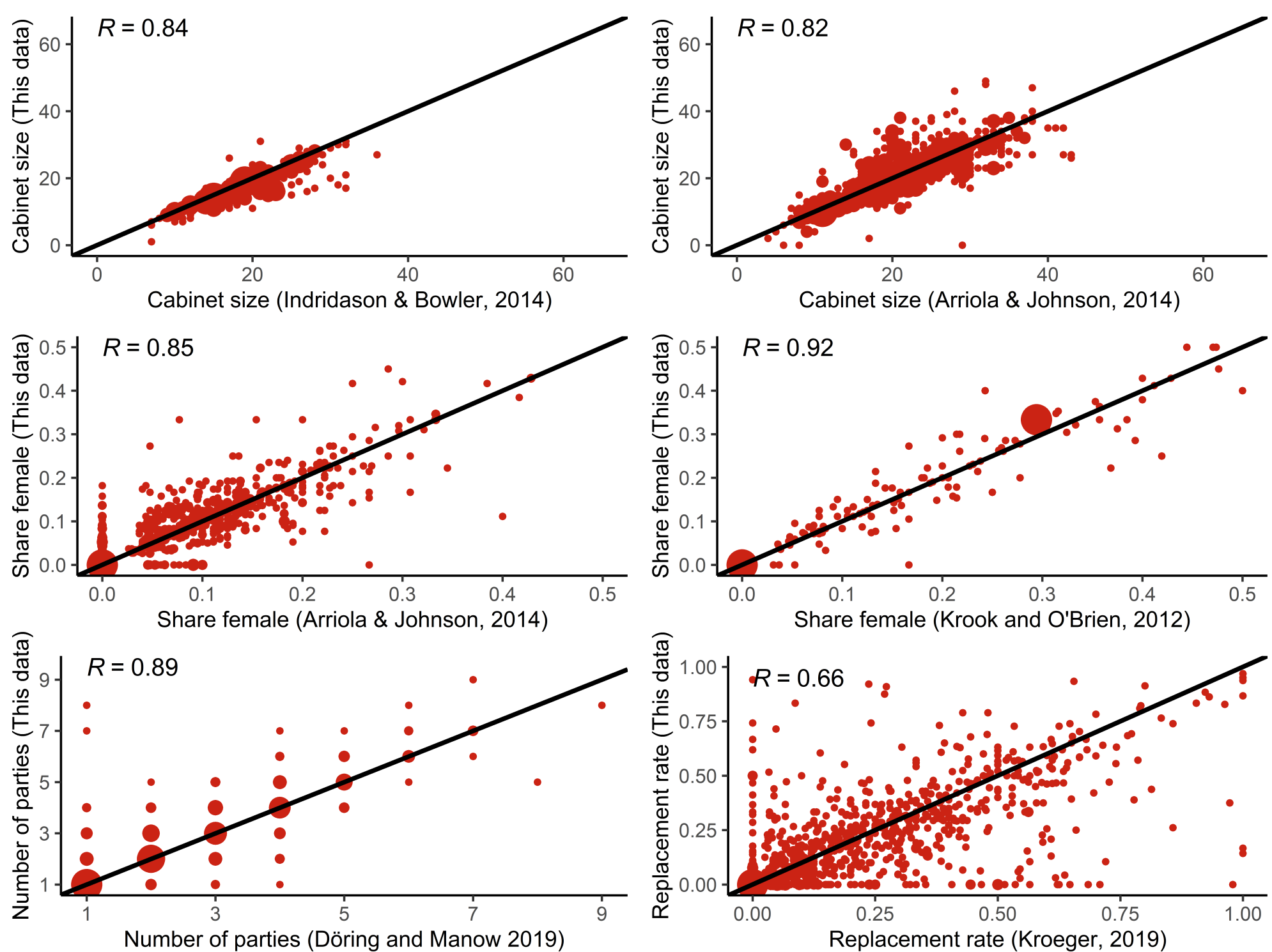


\subsection{Applications}

The data can give political scientists a better understanding of important political phenomena. This is particularly the case for researchers who study authoritarian regimes. In the following, I will give an introduction to the data using applications mainly from authoritarian regimes. ${ }^{4}$

Figure 5.4 sheds new light on the world map using four of the main variables from WhoGov, namely the replacement rate, the share of female ministers, cabinet size, and the number of parties. The color indicates the average for a given variable for each country in the period 2000-2016. Some of these findings confirm our intuitions. For instance, we see that Scandinavian countries have the most gender equal cabinets, while the cabinet in countries such as Saudi Arabia and North Korea is (almost) exclusively a men's club. This is in line with previous research (Krook and O'Brien 2012, Stockemer 2017).

On the other hand the fact that many autocracies, such as Iran or Côte dIvoire, have many parties represented in the cabinet may come as a surprise. Research on authoritarian countries tends to assume that one party controls the government, which is encapsulated by the term "single-party" regimes (Geddes et al. 2014; Miller 2019).

\footnotetext{
${ }^{4}$ In the analyses I only include data from what we consider core cabinet members. These are cabinet ministers, prime ministers, presidents, vice prime ministers, vice presidents, members of the politburo and members of a military junta. Thus, we exclude deputy and junior ministers, governors of the central bank, ambassadors to the US and Permanent Representatives to the UN from the analyses.
} 
Figure 5.4: Country averages in the period 2000-2016

$\infty$
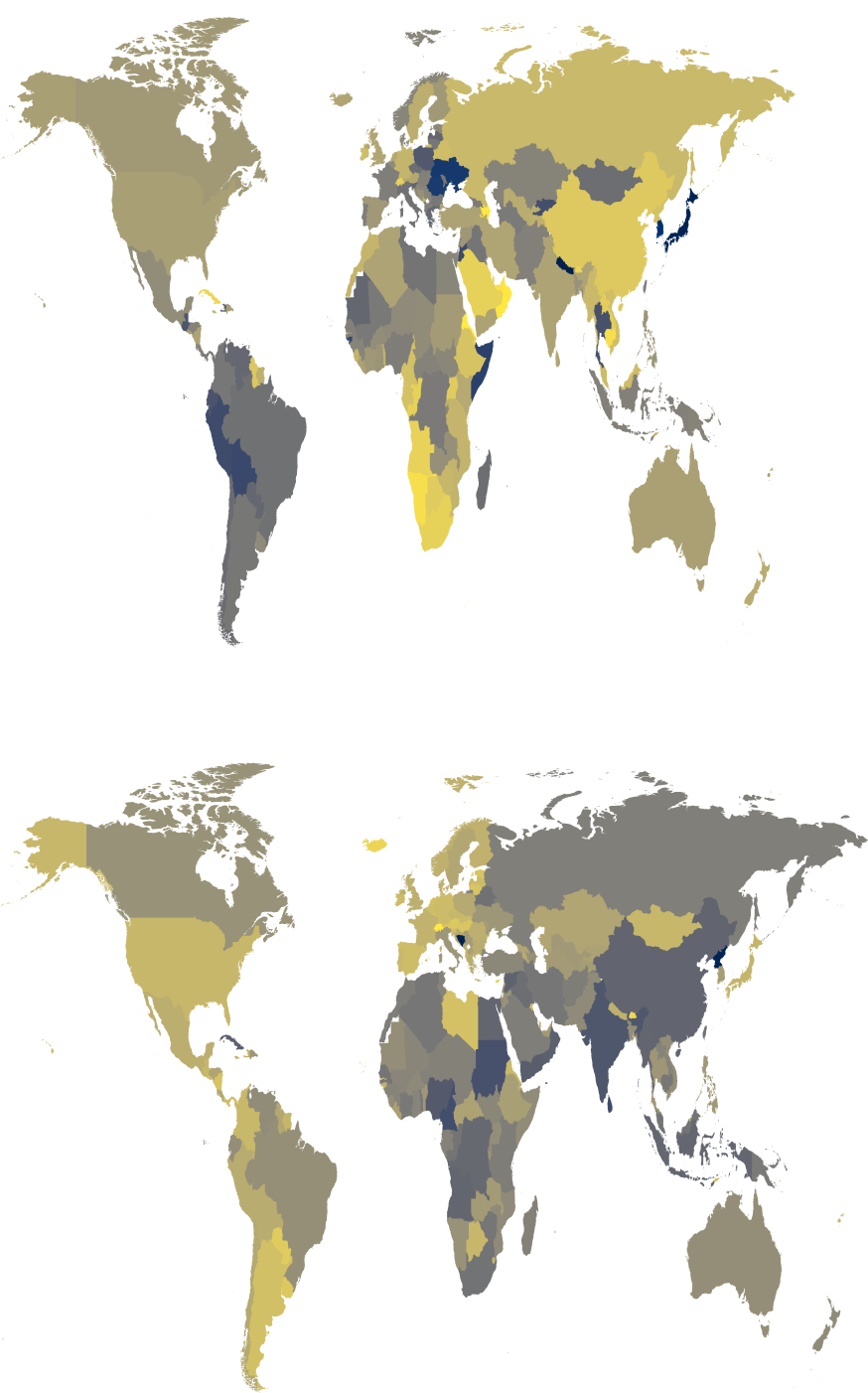

Replacement

rate

$60 \%$

$40 \%$

$20 \%$

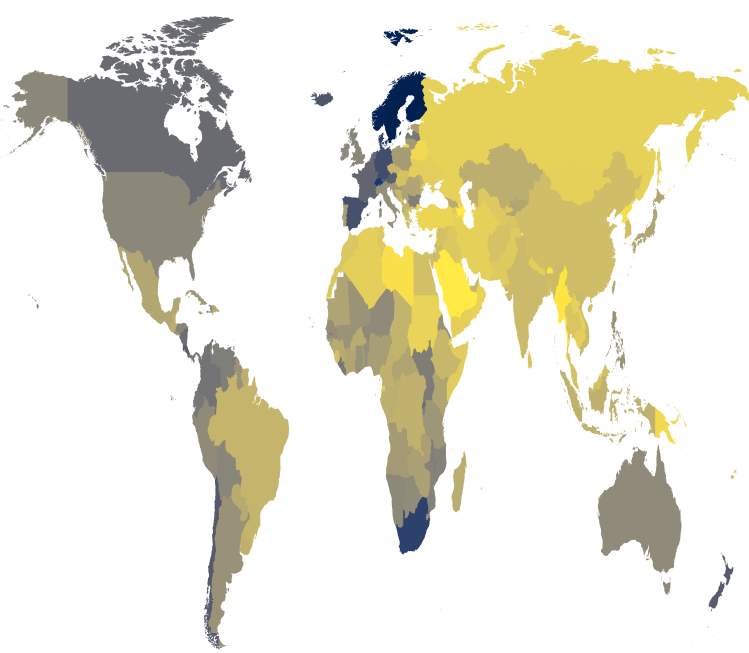

Cabinet

members

-50
-40
-30
-20
10

Share of

female ministers

$40 \%$

$30 \%$

$20 \%$

$10 \%$

$0 \%$

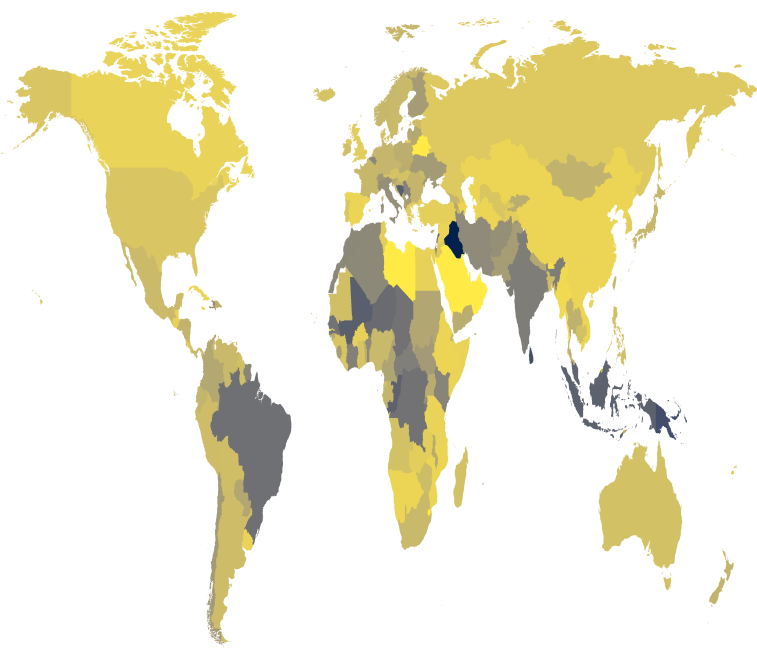

Average number of parties

- 8 parties

6 parties

4 parties

2 parties

0 parties 
Figure 5.5 highlights four puzzles that arises from the new dataset. In the upper left hand corner, we see that the average age of cabinet members in East Germany increased dramatically over the period, while the age for cabinet members in West Germany stayed fairly constant. The explanation for the increase in East Germany is twofold: cabinet members tend to stay longer and new cabinet members tend to be older, especially towards the last years of the regime. This indicates that autocratic systems with limited competition for power and an entrenched ruling elite risk running out of new, young talent, who can take over, which may be an overlooked explanation for the downfall of autocratic regimes.

Second, there has been a surge in the social science literature on the inclusion of women in government (Arriola and Johnson 2014; Barnes and O'Brien 2018; Bego 2014, Escobar Lemmon and Taylor-Robinson 2005 Jacob et al. 2014 Stockemer 2017). WhoGov is the first, to our knowledge, to offer yearly data on womens access to executive portfolios globally without sacrificing high cross-sectional, temporal, and portfolio coverage. The top-right panel shows the share of female cabinet members in both autocracies and democracies. We see that democracies have a larger share of female cabinet members, that there has been an increase in the share of female cabinet members, and that this development has been more pronounced in democracies. In 2016 around one out of four cabinet ministers are female in democracies, while it is only around one out of seven in autocracies. Thus, democracies have almost twice the share of female ministers. Why do democracies have more women in the government and do women have a different role in the government in autocracies relative to democracies? These are questions which I try to answer in a separate article (Yamagishi et al. 2020). 
Third, the bottom left panel shows the average number of parties represented in the government in both democracies and autocracies. Surprisingly, we see that the average number of parties partaking in government has increased in both democracies and autocracies. As mentioned before, research on autocracies tend to assume that one party controls the government. However, this is empirically not the case. An explanation may be that autocracies try to co-opt opposition figures (Gandhi and Przeworski 2006) and simulate democratic institutions without actually being democratic (Levitsky and Way 2010). Yet, this literature focuses on legislatures and elections, and do not investigate whether and why multiple parties are granted access to the governing machine itself. This is a question for future research on authoritarian regimes.

Fourth, there is little research on the size of cabinets in authoritarian regimes. This is puzzling since the size of the cabinet is important and has been connected to outcomes such as public spending and budget deficits (Elgie and McMenamin 2008; Wehner 2010), transparency laws and corruption (Michener 2015), and political stability (Arriola 2009). The panel in the bottom right panel shows the distribution of the size of cabinets in both autocracies and democracies. The distribution is more spread out in autocracies (standard deviation $=8.0$ ) than democracies (standard deviation $=6.4$ ). Thus, as seen in the graph, autocracies are more likely to have large cabinets, but equally likely to have very small cabinets. While an in-depth study is needed, this may be because autocrats have divergent incitements when deciding on the size of the cabinet. In uncertain conditions leaders may seek to expand the size of their coalitions as a means of reducing dependence on any single ally. This will complicate the coordination among their potential rivals, and make it harder 
for them to coordinate a coup attempt (Arriola 2009; Riker 1962). This gives an autocrat an incentive to increase the coalition size. On the other hand, autocrats also have incentives to minimize the size of the inner circle, because it reduces the number of individuals whom leaders must share both influence and the spoils of being in office with (De Mesquita et al. 2005, Frantz 2018). This will also make it easier for the dictator to better monitor potential competitors. We may, therefore, end up in two "extreme" equilibria. 
Figure 5.5: Four puzzles in autocracies
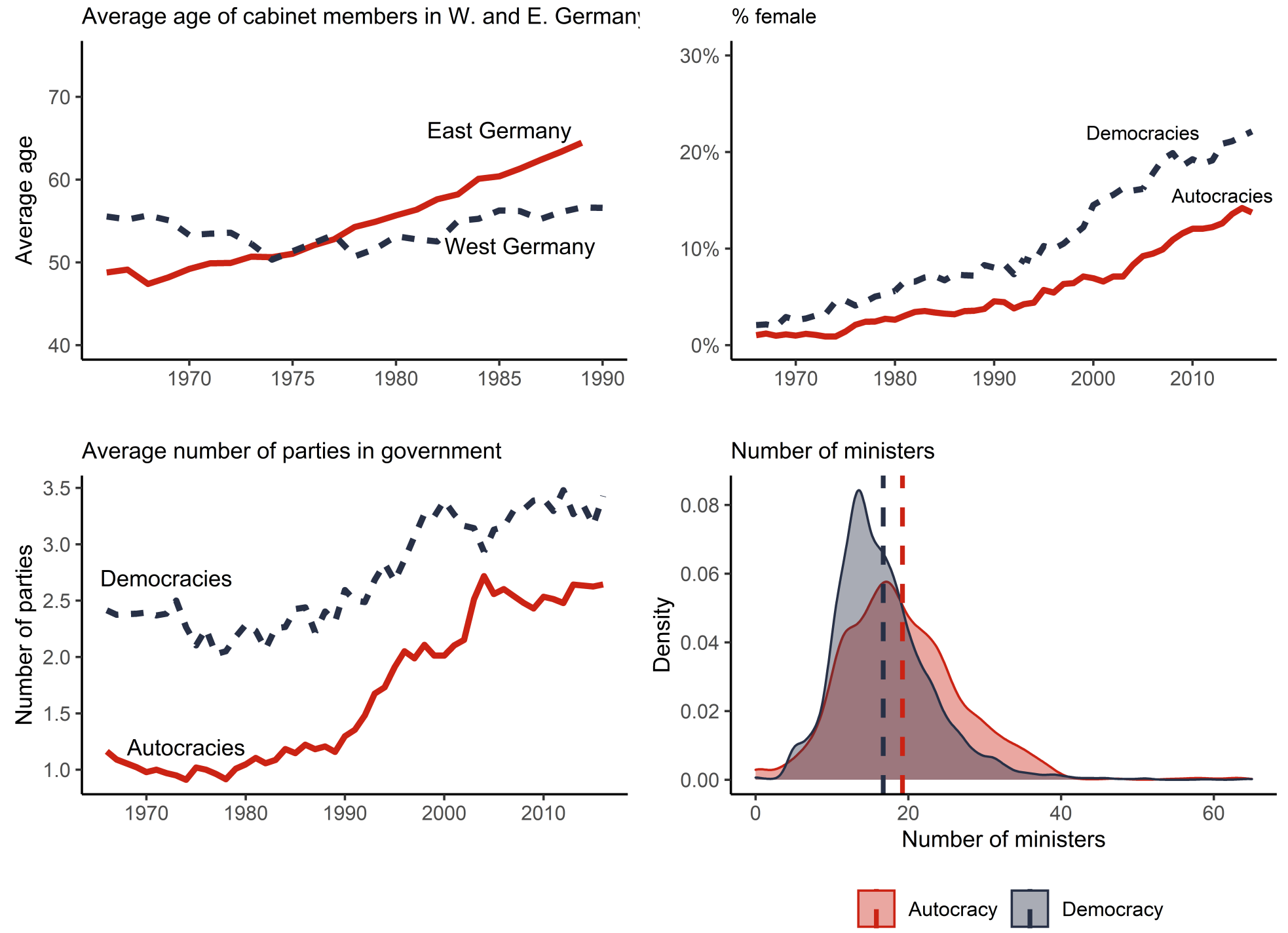
Figure E.4 uses two of the variables, which are of importance in the analysis in the next chapter. The top left panel shows boxplots over the average experience of the cabinet by the number of years the autocrat has been in office. Thus, each dot is the average experience for one autocrat in the given year.

It is interesting to note that some autocrats come to office with a cabinet which on average has many years of prior governing experience. The maximum is Lee Hsien Loong of Singapore, whose average cabinet member had been in office for 13.8 years when Lee entered office. Nonetheless, the median autocrat comes to office with a cabinet that has 1.6 years of prior experience. We see that the average number of years of experience increases gradually with the time the leader has been in office. However, the growth is not linear which is due to the autocrat replacing members of the ruling coalition with new members.

I plot the replacement rate in the right panel. The replacement rate is the share of cabinet members who are replaced from one year to the next. In the first year, where the leader enters office, the median dictator replaces 74 percent of the cabinet. The median replacement rate then drops to 15 percent, and remains stable between 10 and 20 percent for the remainder of the figure. Yet, we also see that there is much variation, and that some dictators purge more cabinet members, while others retain the entire cabinet.

In the lower half of the figure, I show the replacement rate for four countries, namely the Democratic Republic of the Congo, Mexico, Saudi Arabia and Singapore. The replacement rate in Singapore is consistently low, whereas it is highly unstable for the Democratic Republic of the Congo. Elite politics in Singapore is characterized by high levels of collective leadership and bureaucratic professionalism whereas Joseph Mobutu based his 
rule primarily on patronage and preventing alternative sources of power from emerging within his cabinet (Bellows 2009, Reno 1997). However, after Mobutu leaves office, the retention rates in the DRC become even more erratic under Laurent and Joseph Kabila a year of cabinet stability is often followed by a purge the next year.

Replacement rates in Mexico under the Institutional Revolutionary Party (PRI) are different in the sense that they reliably peak when new leaders are elected but remain low until the next leader transition occurs. After Mexicos transition to democracy, trends in cabinet stability remained essentially the same. The monarchic regime in Saudi Arabia overall exhibits a very low replacement rate. This is the case even when a new king takes over. However, the replacement rate has increased after King Abdullah died. Even though King Salman is the official ruler, country observers argue that the de facto ruler of Saudia Arabia is his son, Mohammed Bin Salman. After his rise to power, he has purged members of government and other influential figures (Beauchamp 2017). This indicates that the current leader of Saudia Arabia has another approach to ruling than his predecessors.

The differences between Singapore and Mexico are particularly striking given that they usually both are classified as party regimes (Cheibub et al. 2010, Geddes et al. 2014). In line with the argument made in the theory chapter, we do see that there are large differences within typologies of authoritarian regimes. WhoGov is a helpful resource to investigate these differences as shown in the next chapter. 
Figure 5.6: Experience and retention rates in autocracies
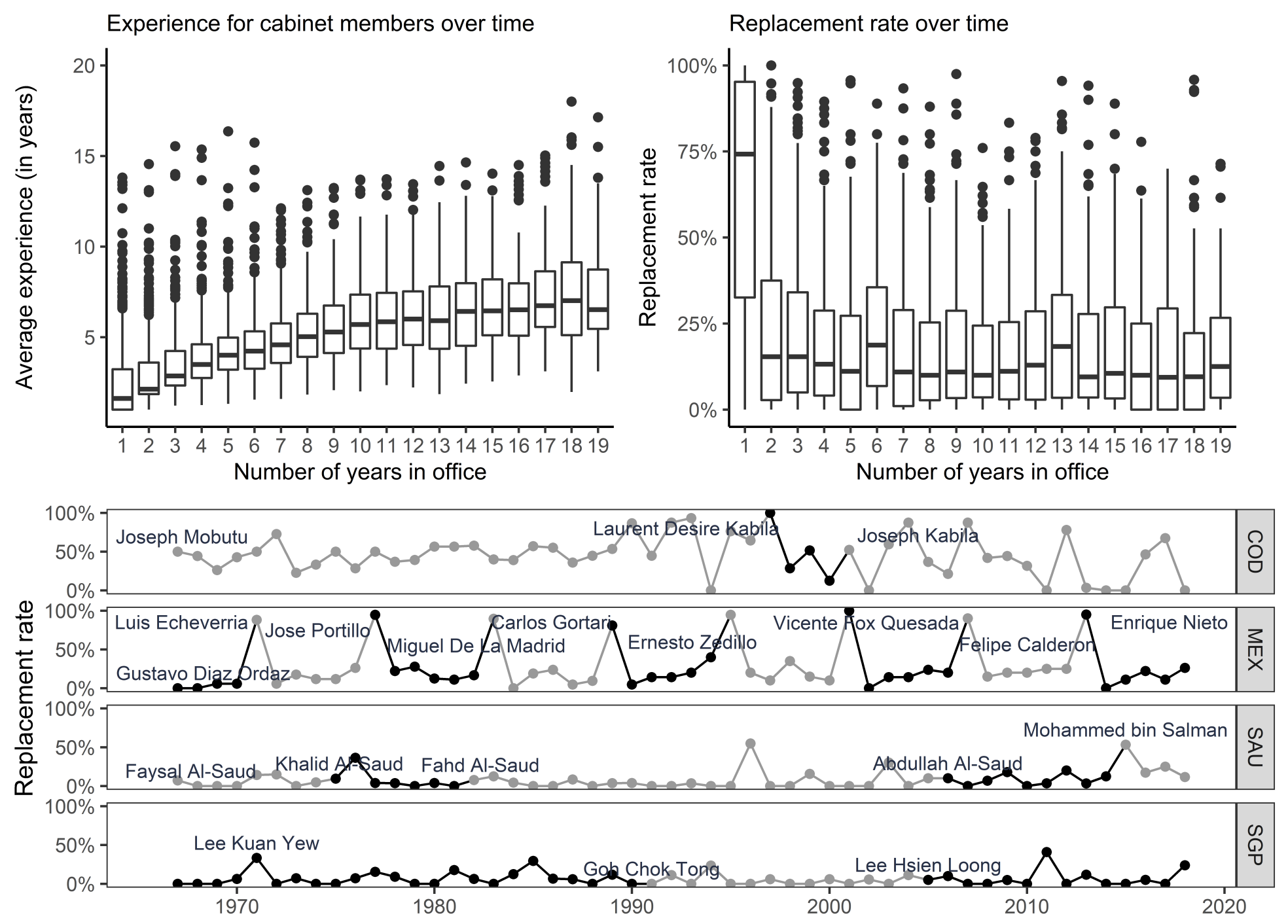


\subsection{Conclusion}

In this chapter, I have introduced WhoGov, which is the largest available dataset on members of cabinets. It may be that Stalin is right in that no one would remember Ivan the Terrible's boyars, but this dataset ensures that political scientists have access to detailed data on cabinet members in 177 countries in the period 1966-2016.

The dataset is particularly useful for researchers focusing on autocracies, where the inner workings of the ruling elite is characterized by secrecy. In this chapter, I highlight four examples of how WhoGov can contribute new knowledge to the study of authoritarian regimes.

Furthermore, I show how there is large variation in how autocrats shuffle their cabinets. I will exploit this in the next chapter, where I use WhoGov to test the implications of the theory outlined in the previous chapters. 
Our economy shows it but it's far better, a hundred times better than the average African economy. Outside South Africa, what country is (as good as) Zimbabwe?

— Robert Mugabe (Holland 2012, p. 240)

\section{Assessing the relationship between constraints and economic development within leader}

\section{Contents}

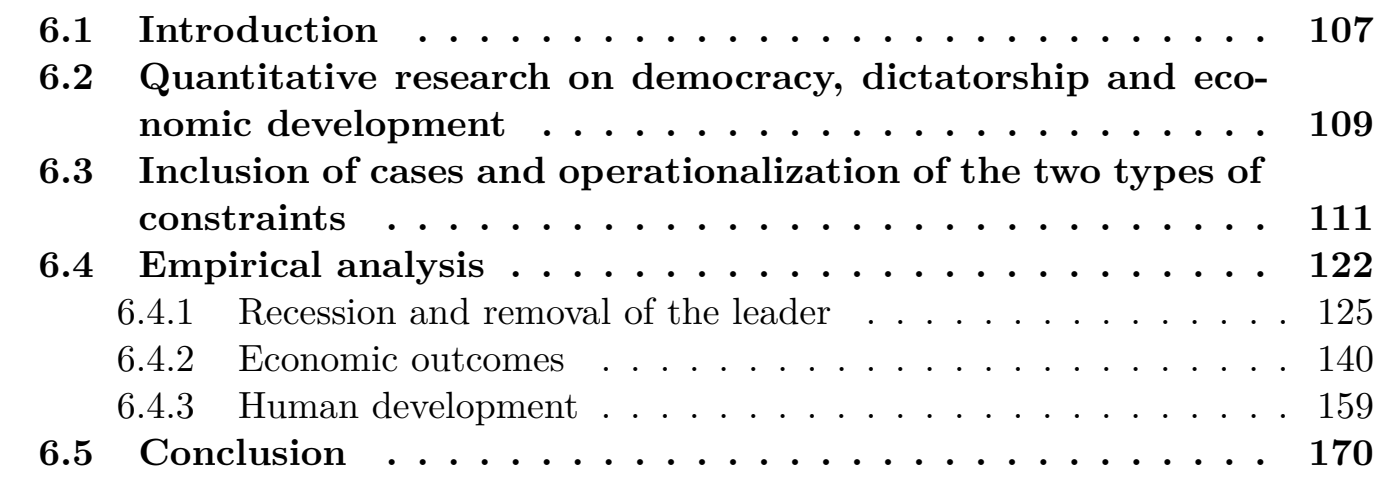

\subsection{Introduction}

The theoretical chapters presented a new framework for understanding decision making in authoritarian regimes. Based on this, I argue that constraints on the autocrat will result in higher economic development. This chapter tests the theoretical model by 
using the dataset presented in chapter 5 .

The chapter is divided into four different sections, excluding this introduction. In section 6.2. I summarize previous quantitative research on economic development in authoritarian regimes, and show how the approach used in this chapter is preferable and different from previous approaches. Then, in section 6.3, I discuss how I empirically differ between democracies and autocracies, operationalize internal and external constraints, and present the other variables used in the subsequent analyses.

The empirical analysis itself contains three different parts which are all in section 6.4. First, I find that constrained autocrats are much more likely to be overthrown in the wake of bad economic outcomes than their unconstrained counterparts. Constrained autocrats can therefore be held accountable for bad economic outcomes in the absence of democratic elections. This supports the theory and proves that economic development is an important factor for constrained autocrats if they want to stay in power.

I then move on to economic outcomes. I find that both types of constraints are positively related to economic growth and negatively related to the likelihood of recession. Furthermore, the two types of constraints are substitutes. Internal constraints, therefore, matter more, when there are less external constraints and vice versa. This part also examines how the two types of constraints relate to investment and the ease of doing business, thereby testing a part of the causal mechanism. The findings on investment and ease of doing business provide mixed support for the theory.

Whilst, I find that the two types of constraints are related to economic growth, this does not entail that the gains from economic growth are distributed to the wider population. 
Therefore, I test how the two types of constraints are related to policy outcomes which disproportionally benefits the poor, such as a decrease in infant mortality and an increase in primary school enrolment. I find that only external constraints are related to better human development outcomes. This supports the theory and furthermore backs the idea that an autocrat have to balance the preferences of the civil society and the ruling coalition. At last, I conclude on the chapter in section 6.5, and discuss the limitations of the analyses.

Overall, the findings in this chapter points towards a vicious circle; unconstrained autocrats are less likely to be punished for adverse economic outcomes and are more likely to govern over these adverse outcomes. This may be a part of the explanation for why autocracies are more likely to provide diverging outcomes for economic development.

\subsection{Quantitative research on democracy, dictatorship and economic development}

The quantitative analysis of the relationship between economic development and regime type began with Lipset $(1959)$ who used a simple comparative analysis to show that democratic countries were more developed than autocratic countries. The econometric methods have since become more complex. This has, however, not led to agreement in the literature on the benefits of democracy compared to autocracy. Although the thesis does not focus directly on the difference between autocracies and democracies, the analysis will draw on many of the methodological discussions within the field.

There is little quantitative literature that has tried to explain economic development in autocracies. Besley and Kudamatsu (2008) show that traditional predictors in the literature on the quality of government and institutions cannot explain why some autocracies are 
able to achieve better economic development. They then proceed to show that autocracies successful in promoting economic growth have a higher leadership turnover. In addition, they show that leadership turnover is not related to better human development. They argue that in successful autocracies the leader is accountable to a selectorate comprising of regime insiders who can fire him in case of bad economic outcomes, but that the selectorate cares little about human development. Besley and Kudamatsu's analysis provides some evidence in favour of the importance of what I call internal constraints for explaining economic growth, but their analysis is suggestive, does not rely on sophisticated statistical methods and therefore does not provide in depth quantitative evidence. Gandhi $(2008)$ shows that institutions, such as legislatures and political parties, have a positive impact on growth in autocracies using a random effects model and a Heckman selection model. Miller (2015) expands Gandhi's analysis by using a instrumental variable approach to show that electoral institutions are causally related to better human development outcomes. As discussed, I have two concerns with this approach. First, there is little variation in Gandhi and Miller's independent variables amongst present-day autocracies. Furthermore, their main independent variable is either the regime type or the existence of specific institutions. These are very static variables which rarely vary during the tenure on an autocrat. The model, I presented in the theoretical chapter, is dynamic in nature and argues that the level of constraints vary over time within the tenure of a dictator.

Therefore, I will depart from much of the previous literature on explaining growth in autocratic regimes and examine growth patterns within the rule of one leader. Essentially, I will use leader fixed effects to "open the black box" of autocracy and perceive the rule of a 
dictator as a process. This approach is also found in Papaioannou and Van Zanden (2015), where they link growth to the years of tenure for one dictator. However, their analysis solely looks at the tenure of an autocrat and does investigate other variables, such as constraints. I am unaware of other studies which have relied on leader fixed effects to investigate economic development in autocracies, while country fixed effects are very common in the literature comparing autocracies and democracies Acemoglu et al. (2019), Besley and Reynal-Querol (2011), Bizzarro et al. (2018), and Gerring et al. (2012). The theory presented in this thesis has high requirements to the availability of data. The dataset presented in the previous chapter will therefore be useful. In the next section, I discuss the operationalization of internal and external constraints and the selection of variables.

\subsection{Inclusion of cases and operationalization of the two types of constraints}

\section{Definition of regimes and selection of observations}

The article relies on Bjørnskov and Rode's (2018) dataset to distinguish autocracies from democracies.1 This is the most recent dataset available, and it classifies autocracies according to a definition which mirrors the definition outlined in the theoretical part. Dictators who came to power before 1965 are removed from the analysis due to missing observations on the measure of internal constraints. As discussed throughout the theoretical chapters autocrats heavily reliant on exogenous rent may act differently. Therefore, I will in some of the analyses exclude these. This will be discussed throughout the chapter.

\footnotetext{
${ }^{1}$ The dataset is an update and expansion of Cheibub, Gandhi and Vreeland's (2010) dataset
} 


\section{Internal constraints}

This study is not the first attempting to measure the dictator's consolidation of power in autocracies. There is a growing literature devoted to this. Some studies are qualitative in-depth studies (Brownlee 2007, O'Donnell et al. 1986). However, other researchers are using proxies. For example, Besley and Kudamatsu (2008) rely on leadership changes and regime duration, while Gehlback and Keefer (Gehlbach and Keefer 2012) use ruling party age, and De Mesquita et al. (2005) measure the size of the winning coalition. These quantitative measures are invariant within the rule of a leader, or do not capture Arendt's idea of isolation, and can therefore not be used in this study.

Recently, two new time-variant measures have been constructed. These are Geddes et al.'s (2017) new measure of personalism which focuses on whether the dictator controls key levers of power, and Gandhi and Sumner's (2020) new measure which conceives power consolidation as a latent trait that is revealed by numerous empirical manifestations of consolidation, such as freedom from military and party constraints or control over political offices. Both measures contribute significantly to the literature and offer many new avenues for research.

Yet, I will rely on a new measure of the power balance between the dictator and the ruling coalition. I do so because I intend to capture Arendt's concept of isolation. Arendt argues that when the ruling elite becomes atomized they are unable to act together in a common pursuit. Furthermore, she argues that this can be achieved by constantly purging and shuffling around members of the ruling coalition, making them unable to form bonds. This will undermine the ruling coalition's ability to overcome the collective action problem 
of holding the autocrat accountable. Recent research on cabinet ministers in autocracies corroborates the usefulness of this approach. Svolik (2012, p. 79) argues that the purging of members of the elite protects the dictator by preventing coalition partners from establishing an independent power base. Kroeger (2018) argues that in African autocracies, personal leaders more easily than party leaders can fire ministers without destabilizing the regime, and Woldense (2018) shows that Haile Selassie constantly shuffled around members of cabinet to avoid cliques. These studies are supported by a wealth of qualitative descriptions of how dictators have shuffled around or purged important ministers to consolidate their power (Arendt 1951; Kenyon 2018; Montefiore 2004). Perhaps the argument is best summarized by Han Fei Tzu (1964) who wrote that "The only reason that ministers do not assassinate their sovereign is that their cliques are not strong enough".

How do I practically measure the power balance? WhoGov contains detailed information on over 50,000 cabinet members, enabling me to follow the careers of individuals from the dictator's inner circle over time. The expectation is that cabinet ministers who are allowed to remain in the cabinet, will form personal relationships and over time coalesce into cliques. They will therefore be more likely to overcome collective action problems. This implies that more experienced cabinet ministers are more likely to provide both opposition and guidance to the dictator, meaning that the style of governing is more oligarchic rather than personal. The assumption is therefore that a low turnover reflects the dictators inability to change members of the ruling coalition without spurring a rebellion from remaining members.

The main measure of internal constraints is operationalized as the average governing 
experience of members of the ruling elite divided by the tenure of the dictator at a given point in time. The measure has two parts. First, I include the average governing experience of core members for the reasons described above. Second, I include the experience of the dictator to take into account that the experience of members of the ruling elite is dependent on how long the autocrat has been in office. Mathematically, the measure of internal constraints can be written as;

$$
r_{d t}=\frac{\frac{\sum_{i=1}^{n} y_{i t}}{n}}{y_{d t}},
$$

where $r_{d t}$ is the relative experience of the cabinet ministers, $i$, to the dictator, $d$, in year $t$, and $y$ denotes the experience of the given person. The variable is logged in the analysis since it is right-skewed due to the fact that 1) some dictators have ministers who are more experienced than them, and 2) substantively it makes sense that what matters is not absolute changes but relative changes in the relative experience. This is discussed further in appendix C.1.

A kernel density plot over the variable is shown in figure 6.1. The distribution is shown for both autocratic and democratic countries. We see that autocracies, on average, score lower than democracies and that the distribution is more dispersed for autocracies. Some dictators, therefore, have a ruling coalition that is much more experienced than them, while others effectively have purged most - or all - members of the ruling coalition. Naturally, this is a function of the time spent in office, which will be taken into account in the analysis. 
Figure 6.1: Kernel density plot for the measure of internal constraints

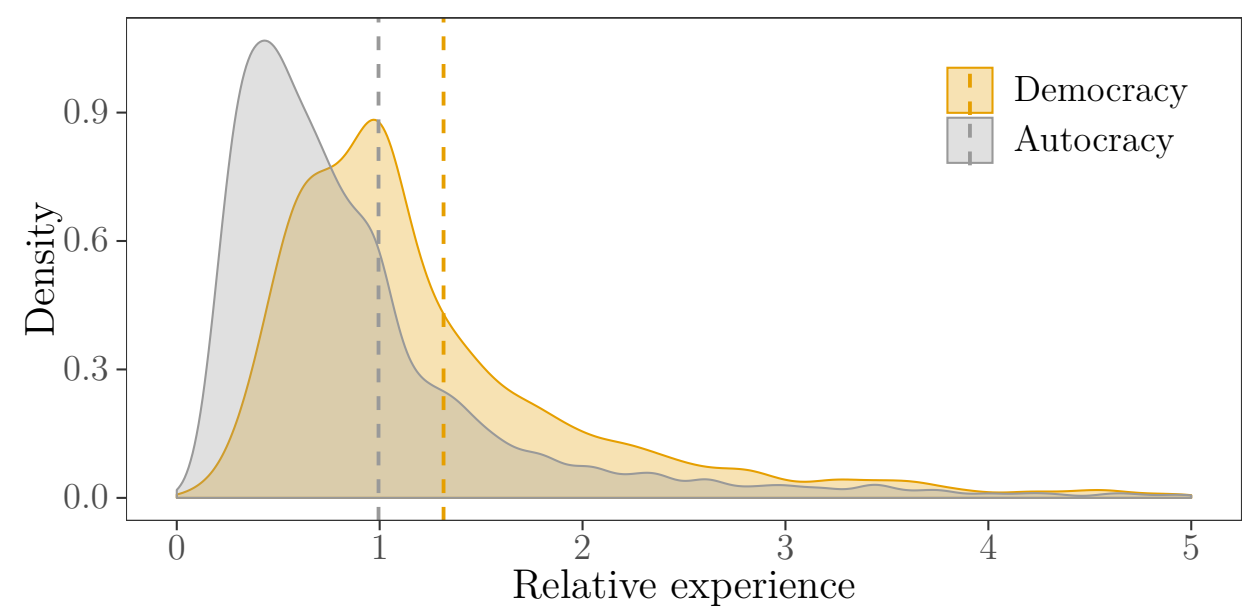

Figure 6.2 shows the tenure of the autocrat versus the average tenure of members of the ruling coalition. This is closely related to the measure of internal constraints. In fact, internal constraints are measured as the horizontal distance to the $\mathrm{x}$-axis for the line of the given dictator divided by the horizontal distance to the straight, diagonal, stippled line. It can be seen that there is huge variation amongst the dictators in the graph. Some autocrats, such as Lee Kuan Yew of Singapore, kept the same cabinet for most of their rule, while others, such as Muammar Qadhafi of Libya or Yahya Jammeh of Gambia, purged the ruling coalition shortly after coming to office and kept a high turnover throughout their rule. 
Figure 6.2: Relationship between the tenure of the autocrat and average tenure of core cabinet members for selected autocrats

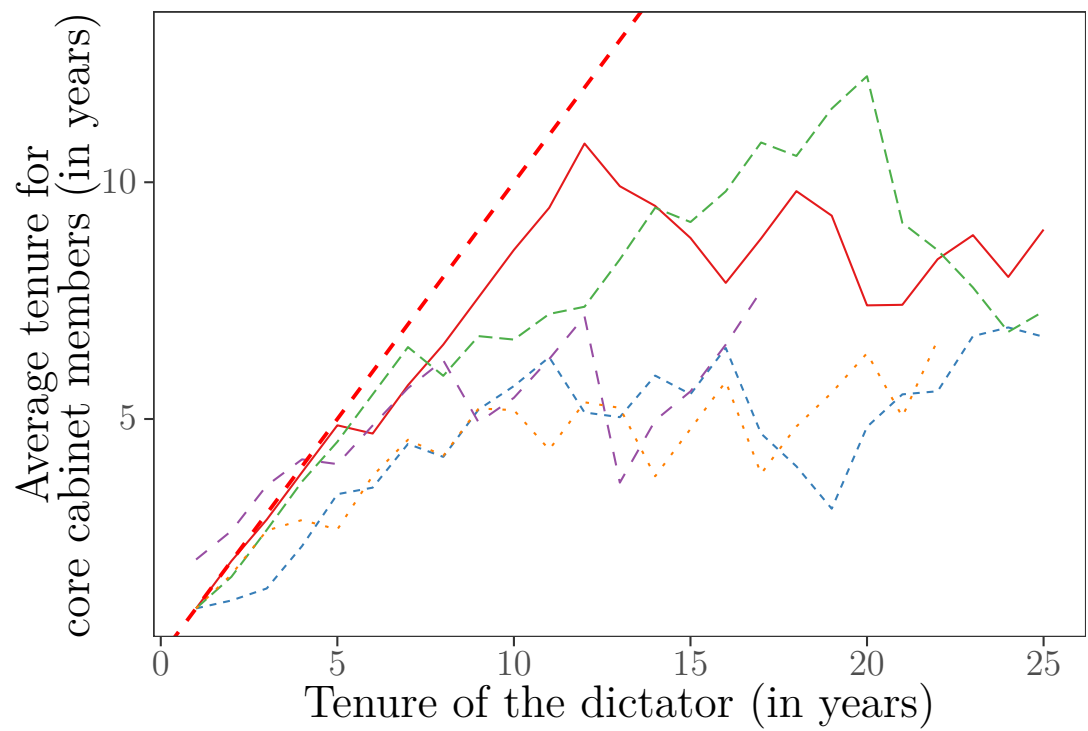

Dictator

- Lee Kuan Yew

-.- Muammar Qadhaf

-- Robert Mugabe

- - Vladimir Putin

Yahya Jammeh

Note: The straight, diagonal and stippled line is a baseline, where the ministers are as experienced as the dictator. The core cabinet members include cabinet ministers, prime minister in presidential systems, deputy president/deputy prime minister and members of a junta/ruling council/politburo.

The measure suffers from shortcomings. For example, the directory, which the dataset is based on, may not cover the entire ruling coalition. There might be members of the ruling coalition who do not possess formal positions. Furthermore, an argument against the main measure of internal constraints is that dictators may fire all non-loyalists, when they take power and replace them with a set of loyalists who remain in office. However, empirically this does not seem to be the case. As seen in figure 6.3, dictators who purge cabinet members when they take power, do not tend to have a lower retention rate throughout their tenure. While this measure may be deemed somewhat imperfect, it constitutes a substantial improvement compared to other measures since it is time-variant, objective, and has a broad temporal and geographical coverage. In order to triangulate the results, I will include two alternative operationalizations of internal constraints. First, I will use the 
retention rate, which is the share of members of the ruling coalition that were members of the ruling coalition in the previous year. Second, I will use the share of members of the ruling coalition who have been a part of the ruling coalition from the first year of governing.

Figure 6.3: Average retention rate over time by retention rate in the first two years

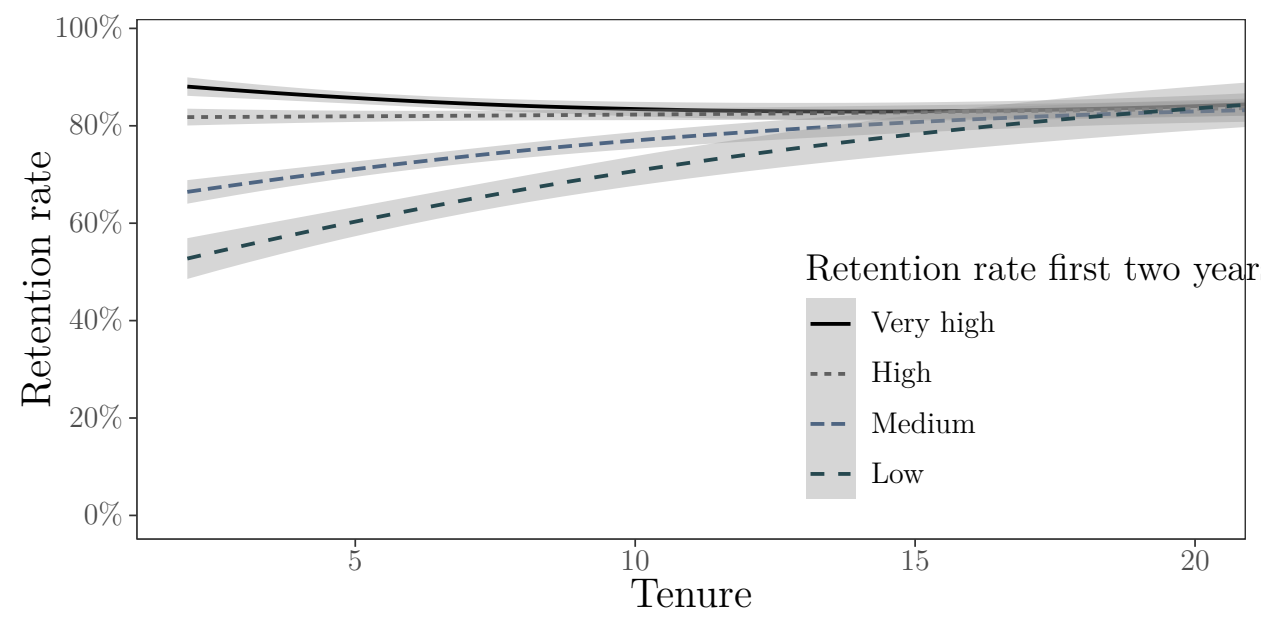

The graph plots the average retention rate (the percentage of cabinet ministers who stay in office from one year to the next) over time for four different group of dictators. Those classified as 'low' have an average retention rate below 40 per cent in the first two years after entering office. The corresponding numbers are between 40 and 70 per cent for 'medium', 70 to 90 per cent for 'high', and more than 90 per cent for 'very high'.

\section{External constraints}

External constraints are defined parallel to the definition of internal constraints, namely as the likelihood that the masses will prevail in the case of a conflict with the autocrat. Again, I rely on Arendt's concept of isolation. Earlier studies have focused on the existence of a multi-party system (Gandhi 2008; Svolik 2012), the existence of competitive elections (Miller 2015), or the number of seats the opposition holds in the legislature (Svolik 2012). Here, I use an index on the robustness of the civil society, namely the variable $v 2 x c s \_c c s i$, provided by the Varieties of Democracy project (2015). This index "sees civil society as an emergent realm of contestation with dictatorship" (Bernhard et al. 2015, p. 3). A 
robust civil society is understood as one that enjoys autonomy from the state and in which citizens freely and actively pursue their political and civic goals, however one may conceive them. This is closely related to the idea of isolation where isolated individuals are unable to act collectively to reach a common goal. This measure of civil society can therefore be construed as having the potential to liberalize and reshape a dictatorship. Here, it is expected that a strong and robust civil society will be more resistant and more easily can organize and protest against the regime. The costs of rebellion are therefore lower, and a rebellion will be more likely to succeed. The measure is based on in-depth knowledge from country experts. It is therefore not objective and there may be problems in terms of cross-national comparability. However, V-Dem runs an extensive number of inter-coder reliability tests and has used bridge coders to connect the units and ensure comparability across cases and over time (Bernhard et al. 2015, p. 12). Furthermore, it is advantageous due to its extensive geographic and temporal coverage, because it is interval-scaled, and varies over time within the same regime. The measure, therefore, represents the best available option at the moment.

The variable ranges between 0 , which are countries with a non-existing civil society, and 1, which are countries with a strong civil society. The distribution of the variable for autocracies and democracies is displayed in figure 6.4. Unsurprisingly, civil society is, on average, much stronger under democracy than autocracy. There are, however, autocracies with relatively strong civil societies. These are, for example, Taiwan before democratization and Tanzania under the Chama Cha Mapinduz. 
Figure 6.4: Histogram for the measure of external constraints

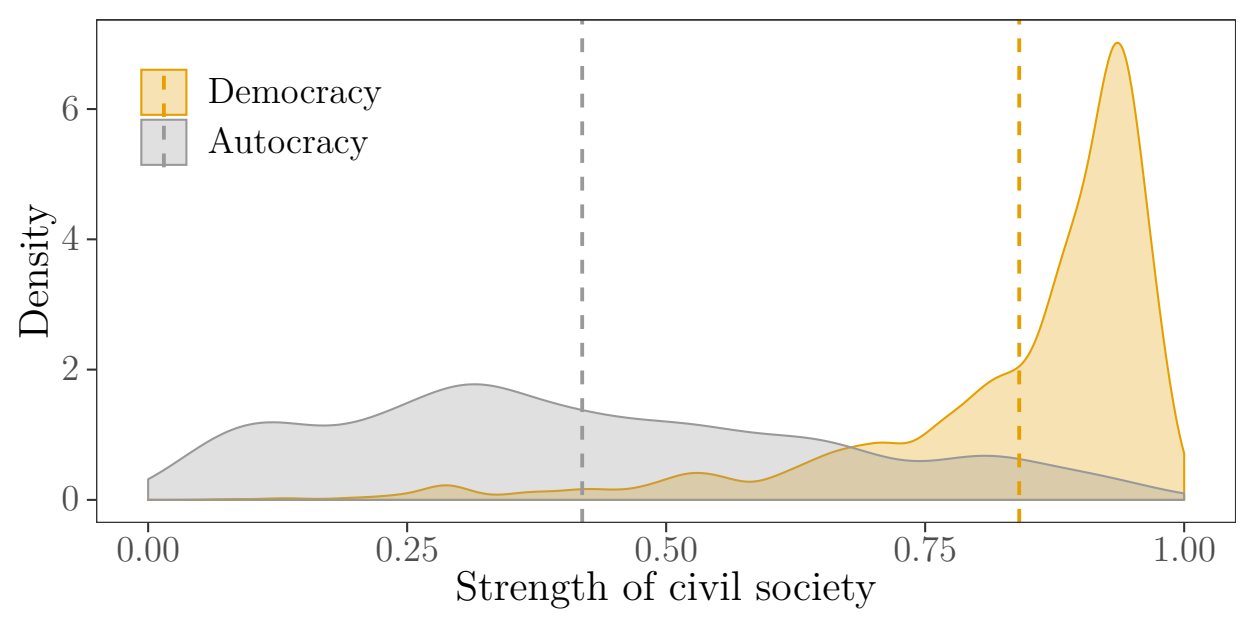

\section{Dependent variables}

The cross-national analysis focuses on three types of outcomes, namely the likelihood of leader replacement, economic outcomes, and human development outcomes.

In the first part of the analysis the dependent variable is leader replacement. Here, I use the information provided in the dataset developed for this thesis. In practice, I add a variable for last year to the dataset, where it takes the value 1 if the name of the leader in the subsequent year varies from the name of the leader in the current year.

In the second part of the analysis I focus on economic outcomes by looking at economic growth and the chance of experiencing a severe recession. Economic growth is measured as the growth in PPP-adjusted GDP Per Capita. This is based on the variable rgdpna from the Penn World Tables (Feenstra et al. 2015). Furthermore, I look at the likelihood that a country will experience a severe recession. Here, I define a severe recession as negative economic growth of more than three per cent in a given year. Growth rates from developing countries and dictatorships are notoriously unreliable (Easterly 2014; 
Martinez 2017, Wallace 2016), and I have therefore triangulated the results in appendix C.3 by using economic growth data from The Maddison Project Database (2018). The results remain unchanged when I use this measure.

In the second part I also look at investment patterns. I obtain data on private investment/GDP and foreign direct investment/GDP from the World Bank's World Development Indicators (WDI) (The World Bank 2017). The earliest entries for private investment are from 1960, while the data on foreign direct investment dates back to 1970. The data on "ease of starting an business" is from the "Doing Business project", which is initiated by the World Bank (2019). The project collects data on a long list of variables dating back to 2004. However, the database suffers from missing observations and inconsistent ways of measuring the variables. Thus, I rely on the variable "Starting a business - Score", which does not suffer from these problems, and provides a score from 0 (hard to start a business) to a 100 (easy to start a business).

In the third part, I focus on two types of development outcomes; infant mortality rate and primary school enrolment. Infant mortality rate is measured as the number of deaths prior to age one per 1,000 live births. I rely on estimates developed by the UN Inter-agency Group for Child Mortality Estimation. The data has been downloaded from the World Bank's WDI (The World Bank 2017). The data dates back to 1960 and includes the majority of the world's countries. Primary school enrolment is measured as the ratio of children of official school age who are enrolled in school to the population of the corresponding official school age (The World Bank 2017). The source is the UNESCO Institute for Statistics, but the data has been downloaded from the World 
Bank (The World Bank 2017). The earliest entries are from 1970, and there are much missing data. In the analysis, I look at yearly changes in absolute numbers for the two variables of human development.

\section{Control variables}

The models further include a set of control variables. First, I account for tenure of the autocrat and the number of core members of the cabinet. These are based on the data from WhoGov. Both independent variables are likely to be affected by the length of an autocrats tenure, since we expect that ministers are replaced over time and that dictators try to root out independent civil society (Papaioannou and Van Zanden 2015). In the analyses in this chapter, I use a linear specification of tenure, but the results remain similar if I insert the variable as a factor. Additionally, the average experience of the core members of the cabinet will drop if the cabinet is expanded even if the ministers already in the cabinet remain.

Second, I control for socio-economic characteristics, by controlling for the log of population (from the Maddison Project Database (2018)) and the percentage of the population living in urban areas (from the World Bank (2017)). These variables may be related to both the strength of civil society and the measures of economic development (Wallace 2013).

Third, domestic conflict may be related to both a decrease in the measures of constraints and economic development, and I therefore control for Political Violence (a 0-10 rating of domestic civil and ethnic violence) from Marshall (2017). Finally, I control for resource dependence by using oil rents as a percentage of GDP from the World Bank (2017). ${ }^{2}$ It is expected that resource dependence are related to economic growth and earlier research

\footnotetext{
${ }^{2}$ I have used alternative measures of resource dependence, such as resource income per capita (\% of GDP) from Haber and Menaldo (Haber and Menaldo 2011), and the results are similar.
} 
has shown that dictators who depend on natural resources, can rely more on repression and can give out fewer concessions (Eibl and Hertog 2017).

\subsection{Empirical analysis}

As discussed above the analysis is threefold. The first part of the analysis tests whether the likelihood of removal of the leader following an economic crisis is dependent on the degree of constraints, while the second part examines the relationship between the two types of constraints and economic outcomes, and the third part looks at the relationship between the two types of constraints and human development. Table 6.1 provides the descriptive statistics for the variables used in the analysis. The contemporaneous variables are used in the table for simplicity, but the right-side variables are generally lagged in the analysis. It is worth noticing that there are fewer observations for many variables than for the two measures of constraints, relative experience and strength of civil society. The dataset created for the analysis thereby provides broader coverage than most other datasets.

The correlation matrix, shown in table ??, largely confirms the theoretical expectations. For example, we see that tenure of the leader is negatively correlated with both the measure of internal constraints, the measure of external constraints and economic growth, indicating that it is important to control for this variable. Furthermore, it is seen that the two types of constraints are only weakly positively correlated. They do therefore not cluster at specific values. 
Table 6.1: Descriptive statistics (autocracies only)

\begin{tabular}{lccccc}
\hline \hline Statistic & N & Mean & St. Dev. & Min & Max \\
\hline Last year in office & 3,351 & 0.09 & 0.29 & 0.00 & 1.00 \\
Growth in GDP per capita, Penn & 3,178 & 1.64 & 8.02 & -67.01 & 94.14 \\
Recession of more than 3 percent, Penn & 3,178 & 0.17 & 0.37 & 0.00 & 1.00 \\
Recession of more than 6 percent, Penn & 3,178 & 0.09 & 0.29 & 0.00 & 1.00 \\
Private invest./GDP & 1,470 & 14.53 & 7.81 & 0.00 & 54.07 \\
FDI/GDP & 2,718 & 2.98 & 6.80 & -28.62 & 161.82 \\
Starting a business & 769 & 62.30 & 20.89 & 2.21 & 96.49 \\
Change in infant mortality (Per 1,000 births) & 3,346 & -1.83 & 1.90 & -27.70 & 25.20 \\
Change in primary school enrollment (\%) & 1,189 & 0.75 & 2.65 & -10.41 & 20.68 \\
log(Relative experience) & 3,474 & -0.31 & 0.75 & -2 & 3 \\
Strength of civil society & 3,345 & 0.40 & 0.24 & 0.01 & 0.97 \\
Tenure of the dictator & 3,474 & 9.19 & 8.13 & 1 & 46 \\
Log of GDP per capita & 3,173 & 8.37 & 1.27 & 5.06 & 12.93 \\
Log of population & 3,185 & 1.94 & 1.72 & -2.49 & 7.25 \\
Urban population (\%) & 3,444 & 42.96 & 23.74 & 2.50 & 100.00 \\
Civil violence & 3,387 & 0.87 & 1.89 & 0.00 & 10.00 \\
Number of core members of elite & 3,474 & 23.43 & 8.77 & 1 & 65 \\
Oil rents (\% of GDP) & 2,822 & 8.17 & 14.32 & 0.00 & 88.87 \\
Replacement rate & 3,427 & 0.25 & 0.27 & 0.00 & 1.00 \\
Purged more than 70 per cent & 3,471 & 0.54 & 0.50 & 0.00 & 1.00 \\
Purged more than 95 per cent & 3,471 & 0.21 & 0.41 & 0.00 & 1.00 \\
\hline
\end{tabular}


Table 6.2: Correlation matrix

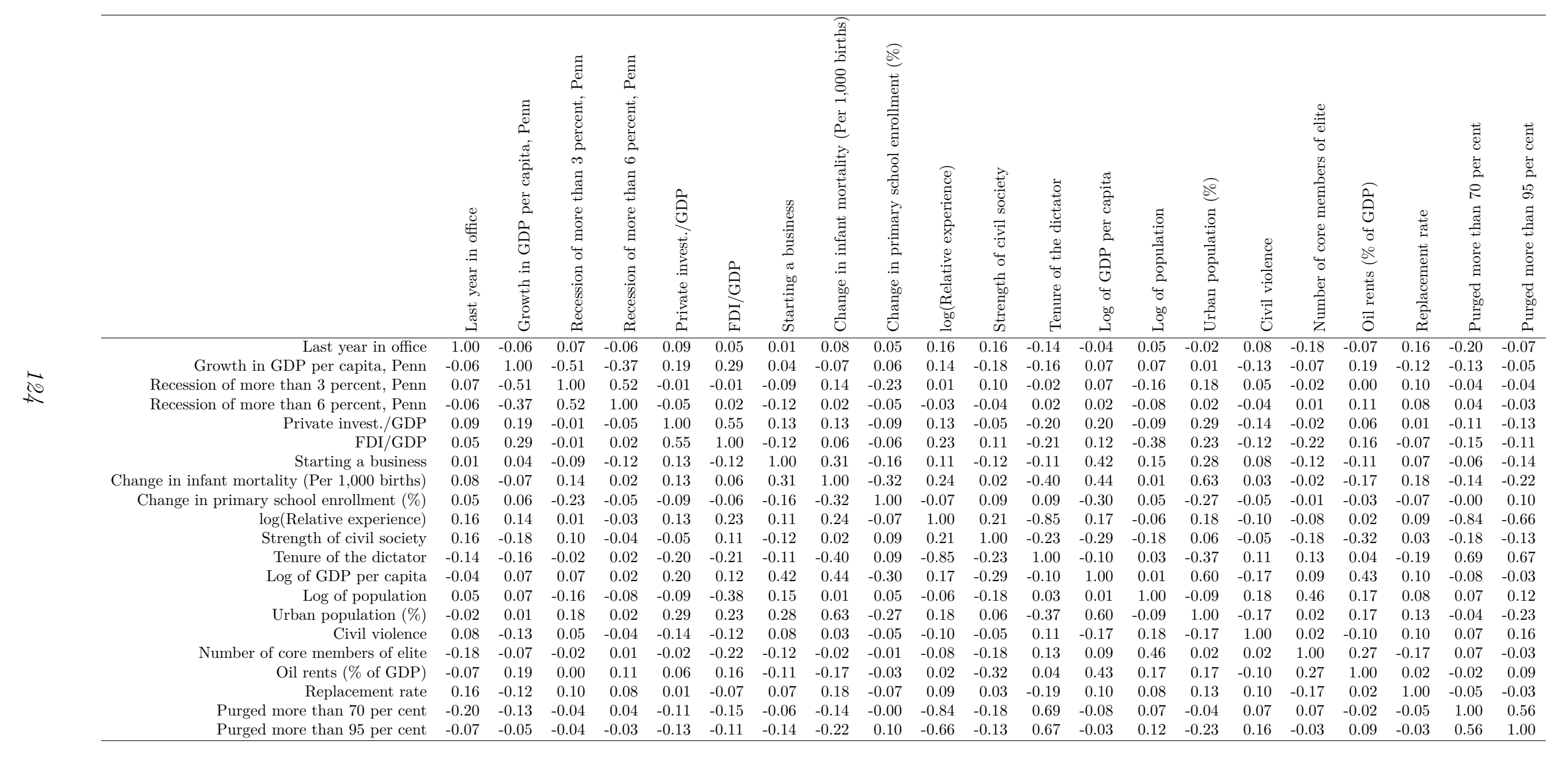




\subsubsection{Recession and removal of the leader}

In autocracies there are plenty of rivals that seek power (De Mesquita et al. 2005. Svolik 2012). However, as argued in the theoretical chapter, the dictator's opponents are better off biding their time and wait until they observe outcomes or actions which makes them worse off. They can then infer that the dictator is of a bad type and thus is unlikely to provide any future rents. In addition, a crisis will facilitate coordination amongst those who are unhappy with the leader and increase the chances of success for a rebellion against the leader. Nonetheless, even though a crisis may create fertile circumstances for a rebellion, it is not guaranteed that protests will materialize. If the ruling coalition is weak, disorganized, and/or blindly loyal to the dictator, they will not be able or willing to stage a rebellion even when the circumstances are favourable. Likewise, a subdued, fragmented, and repressed civil society is unlikely to rise up against the regime even in times of crisis. Thus, the likelihood of removal following a crisis should be determined by the level of constraints on the autocrat. The following analysis will test whether an autocrat is more likely to be removed from office following a recession, when he is constrained. The catalysing event here is the outbreak of a severe economic recession. First, I will discuss the economic approach and then present the analysis.

\section{Econometric approach}

The analysis will test whether autocrats are more likely to be removed following an economic recession if they are constrained. To test this, I will rely on two types of analysis. First, I will single out autocrats in the year where they first govern over a severe economic recession. A severe economic recession is defined as negative economic growth of more 
than three per cent in a given year, but the results will be triangulated using different thresholds. The analysis assumes that a recession is a shock which happens at $t=1$. At $t=1$ the autocrat faces a ruling coalition and a civil society that may or may not constrain the autocrat. I will then investigate how the survival rates and hazard rates differ for autocrats depending on the level of constraints at $t=1$. Thereby, I can examine whether constrained autocrats are more likely to lose power following a recession than unconstrained autocrats as the theory suggests. However, the underlying hazard rate may be different for constrained autocrats than for non-constrained autocrats. In other words, constrained autocrats might be more likely to be removed even when they do not face a recession. Different survival rates would, therefore, not be the result of the recession per se. The analysis will, therefore, rely on three tests to make it probable that the underlying survival function changes because of the recession. First, I will replicate the analysis, where I set $t$ to be a random point in time for all autocrats, and see whether the survival rate differs for constrained and non-constrained autocrats. Second, I will replicate the analysis for democracies. As argued, the theory does not apply to democracies. Therefore, we would not expect the survival rates to depend on the level of constraints in democracies. Third, I will use matching based on the method put forward in Broström (2012). Every time a dictator first governs over a severe recession a control will be selected from the subset of autocrats who does not govern over a severe recession. Thus, when a dictator experiences a recession, he is immediately censored as a control and starts as a case with a control linked to it. I use propensity score matching and match on the level of internal constrains, the level of external constraints, and time in office at the time when 
the dictator first experience a recession. The control group is therefore similar on the level of constraints. This enables me to compare dictators, who experience a recession, with equally constrained autocrats who do not experience a recession.

These analyses will be supported by a second analysis which uses the dynamic nature of the two independent variables and therefore relies on panel data models. First, I will primarily rely on a standard OLS-regression model with country fixed effects. The full specification is as follows:

$\left.Y_{c t}=\beta_{1} R_{c t-1}\right)+\beta_{1} \log \left(I_{c t-1}\right)+\beta_{2} E_{c t-1}+\beta_{4} R_{c t-1} * \log \left(I_{c t-1}\right)+\beta_{5} R_{c t-1} * \beta_{2} E_{c t-1}+\beta_{6} X_{i t-1}+\alpha_{c}+\epsilon_{c t}$ , where $\mathrm{R}$ is a variable for whether country $c$ in year $t-1$ is experiencing a recession, I and E are indicators for internal constraints and external constraints for country $c$ in year $t-1, \alpha_{c}$ denotes country fixed effects, which controls for whether some countries more frequently have leader changes, $X_{i t-1}$ is a set of control variables and $\epsilon_{i t}$ is the error term. The dependent variable, $Y_{c t}$, is the likelihood of removal. The model also includes the interaction terms between recession and the two measures of constrains. First, I will run the model without the interaction terms to see whether there is a direct effect of recession on the likelihood of removal. Afterwards, I will include the interaction terms and see whether the effect of recession is mediated through the level of constraints. It should be noted that all variables are lagged by one year. Thus, I investigate whether a recession impacts the likelihood of removal in the following year. This econometric set-up is advantageous because it is easy to interpret and takes into account that the two measures of constraints are time dependent. For example, I can include country fixed 
effects and thereby account for whether the level of constraints are below or above the average for a country. However, this set-up assumes that the effect of a recession on the likelihood of removal only lasts for one year, that there is no right-censoring in the dataset and that the residuals are distributed normally. These assumptions will be violated by OLS-regression, and I therefore rerun the regressions using the Cox proportional hazard model. This model assumes a common underlying hazard rate, $h(t)$, which represents the conditional probability of having an event at time $t$, conditional on having survived up to that time (Box-Steffensmeier and Jones 2004). Here, the event is the removal of a given leader from office. The hazard rate is modified by a set of exogenous variables, including a severe recession, the level of internal and external constraints, and their interaction with a severe recession. As discussed above, leaders from a given country may share frailty due to country-specific factors. I adjust for this by adding a country-specific frailty parameter. I then estimate the following model:

$$
h_{l, c}(t)=h_{0}(t) e^{X_{l, c}+\theta_{c}+\epsilon_{l, c}}
$$

where $\mathrm{X}$ is the set of covariates for leader $l$ in country $c$. The model will include the same set of variables as the OLS-regression used before. $\theta_{c}$ is the country-specific frailty parameter calculated using restricted maximum likelihood estimation (Therneau 2015). This is equivalent to estimating a model with a country-specific random effect in a standard time-series cross-sectional framework. The Cox-model assumes that hazard rates are proportional across units, which I test for using the Grambsch-Therneau test. The 
test suggests that the marginal effect of a severe recession, log of relative experience, and strength of civil society change with time in office. Therefore, I interact these terms with tenure in appendix C.2. Finally, I will triangulate the results by conducting the regressions for democracies using the OLS-specification. As argued before, the theory should not work in democracies. At last, it should be noted that I exclude autocrats who derive more than 20 per cent of GDP from natural resources. This is discussed in depth in section 6.4.2.

\section{Accountability in the absence of elections}

In figure 6.5 we see the Kaplan-Meier plots (left panel) and the Nelson-Aalen plots (right panel) for three different groups of leaders. Within each plot the leaders are stratified into the four types specified in the typology put forward in chapter 4 . In the top panel we have all autocrats the first time they govern over a decline in GDP per capita of three percentage points or more. One-man autocrats are those who score below the median on both internal and external constraints at the time when they first govern over a recession. Machine autocrats score above the median on internal constrains and below the median on external constraints, Goliath autocrats score above the median on external constraints and below the median on internal constrains, and finally, balanced autocrats score above the median on both types of constraints. Thus, autocrats are classified relative to each other and not according to a predetermined threshold. We see that autocrats who are classified as one-man autocrats, have a much higher probability of surviving following a recession than autocrats belonging to the other three strata. For example, two years after a severe recession 80 per cent of dictators in the one-man category are still in office. On the other hand, around 50 per cent of Goliath and machine autocrats are in office, 
while only 38 per cent of those in the balanced group remain in office. Yet, we do not know whether one-man autocrats would be more likely to survive even in a world, where they had not governed over a severe recession. Thus, the underlying survival rates may differ for the four groups, and not be affected by a severe recession.

In middle and bottom panel I conduct two placebo tests. First, I single out all autocrats after two years of governing and redo the analysis. This plot differs substantially from the plot, where $t=0$ is a recession. The lines are much closer to each other and are not ordered as predicted in the theory. We see that Machine autocrats are sitting most comfortably after two years of governing. These are autocrats who have a relatively stable ruling coalition which shares the power, and a weak civil society. We may see this because the ruling coalition does not feel threatened and therefore has little incentive to try to overthrow the leader (Svolik 2009). Simultaneously, there is little capacity for a rebellion amongst the opposition due to the weak civil society. On the other hand, we see that Goliath autocrats and balanced autocrats are those who are most likely to fall. Autocrats who are classified as one-man are in between and follow the same trajectory until $t=4$, which equals 6 years of governing, where one-man autocrats starts dying off at a slower rate. Thus, it is a risky strategy for an autocrat to purge members of the ruling coalition early on. Some will be couped, while others will manage to establish their rule (Svolik 2009). In the bottom plot, I apply the exact same methods to democratic leaders. The theory presented in this thesis should be unique to autocracies and consequently unable to explain outcomes in democracies. Autocracies are characterized by an absence of free and competitive elections that decide, who gets to hold power. As a result, the only form 
of accountability comes from powerful opponents. On the contrary, democratic leaders are accountable to the electorate, who can vote the leader out of office. The chance of re-election should be independent of two types of constraints, and therefore, the survival rates should not differ for democratic leaders dependent on the level of constraints in the aftermath of a recession. We see that the survival rates are much steeper for democratic leaders, but that there are no meaningful differences in the survival rates between the four strata. This is supported by the score log-rank test, which is a hypothesis test to compare the survival distributions. The p-value is 0.37 indicating no difference between the survival curves for the four groups in democracies. 
Figure 6.5: Survival and hazard rate for three types of leaders dependent on their level of constraints.

Autocrats after governing over a severe recession

— One man - - Goliath... Machine... Balanced
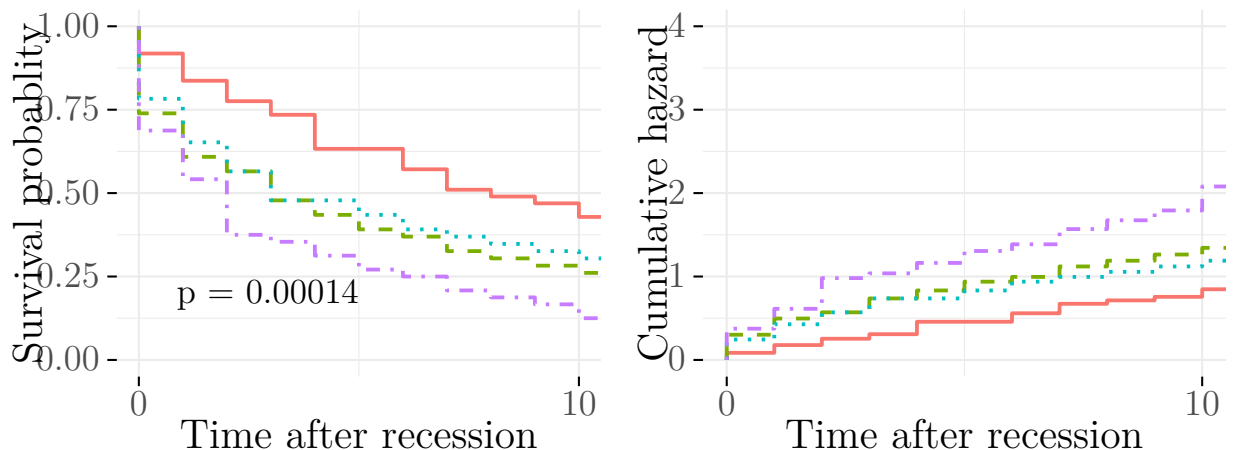

Autocrats after governing for two years
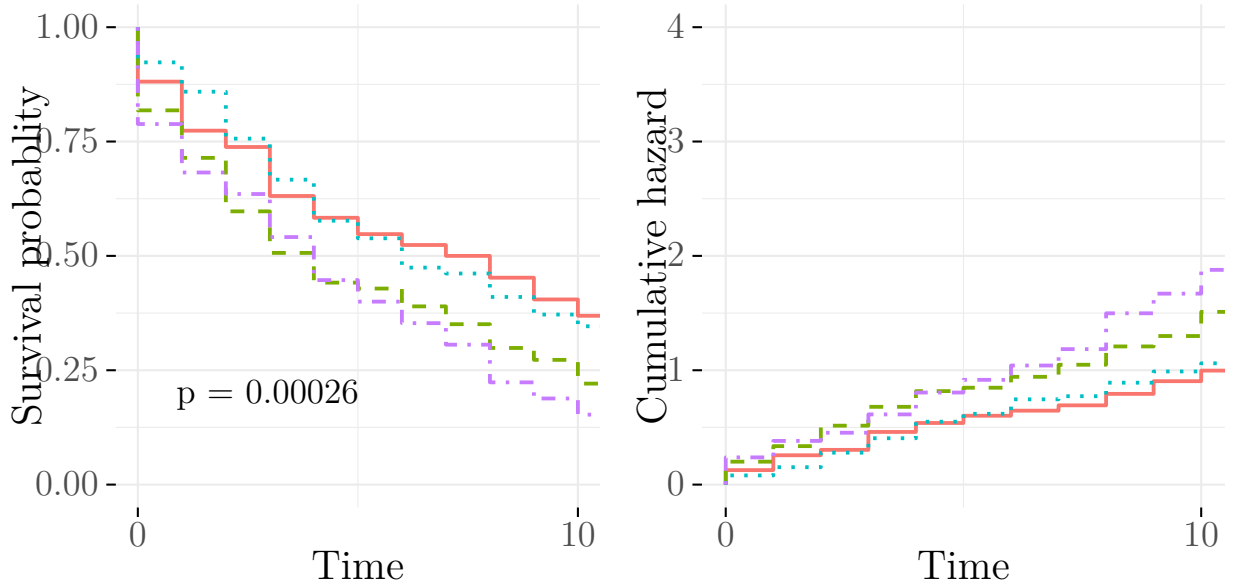

Democrats after governing over a severe recession

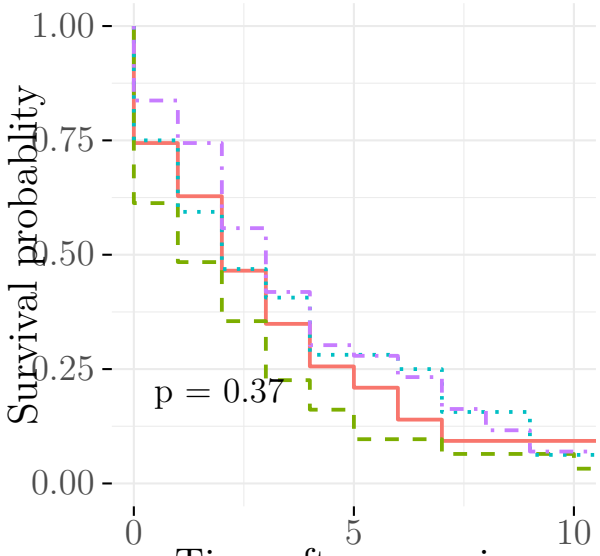

Time after recession

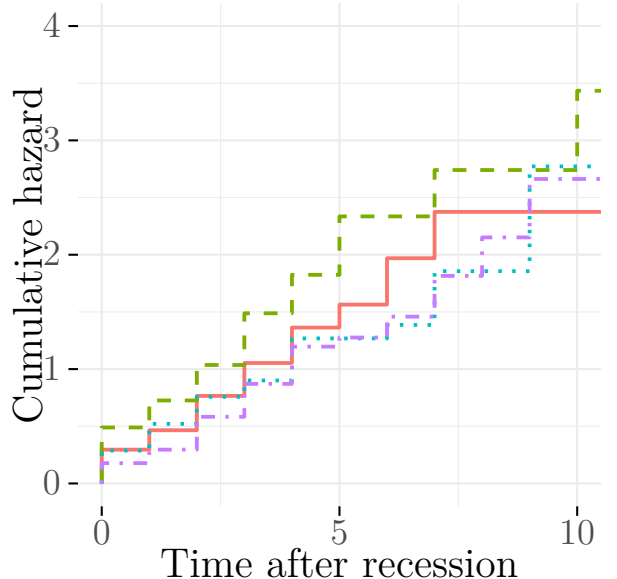

180 leaders in the top panel, 315 in the middle panel and 149 in the bottom panel. $\mathrm{P}$ value is based on the score log-rank test. 
The analysis based on figure 6.5 provides evidence in support of the theory, but does not use a proper counter-factual to test causality. I therefore expand the analysis in figure 6.6 by using propensity score matching. The dashed line represents autocrats, who experienced a recession, while the fully-coloured line are the matched group of autocrats, who did not experience a recession. In the left side of the panel the plots are shown for autocrats, who face a low level of constraints (one-man autocrats), while the right side are those with a medium to high-level of constraints (Goliath, machine and balanced autocrats). The three panels use different thresholds for when a recession is classified as a severe recession. The top panel uses a threshold of three per cent negative growth in a given year, the middle uses six per cent and the bottom uses ten per cent.

We see an interesting pattern in the top panel. Autocrats who face a low level of constraints, are more likely to remain in power following a recession of more than three per cent than their equally constrained peers who do not govern over such a recession. Worryingly, this suggests that an unconstrained autocrat can strengthen his grip on power by spoiling the economy. We have seen examples of autocrats using famines strategically to undermine and - literally - starve the opposition and disobedient parts of the population (De Mesquita and Smith 2011; Dikötter 2010). Furthermore, a crisis provides the autocrat with an excuse to replace competent subordinates with loyalist (Aaskoven and Nyrup 2020). Thus, an unconstrained autocrat can use a recession to undercut both the civil society and his ruling coalition. However, we do not find the same pattern for constrained autocrats. These are slightly more likely to die off in the years following a recession than the matched group, although the difference is not significant. 
In the two remaining panels the size of the shock increases. In the middle panel a severe recession is defined as a decline in GDP per capita of more than six per cent, while the bottom panel uses a threshold of ten per cent. Autocrats who face a low level of constraints, are no longer more likely to survive after such severe recessions than the control groups. This indicates that unconstrained autocrats only benefit from a recession up to a certain degree. If we look at constrained autocrats, we see that they are more likely to be removed in the wake of a very severe recession than their equally constrained counterparts in the control group. This is especially apparent for constrained autocrats who govern over a decline in GDP per capita of ten percentage points or more. These results are in line with the theoretical model which predicts that only constrained autocrats are punished for an economic recession, while unconstrained autocrats face no consequences. 
Figure 6.6: Survival plots for leaders who experience a recession and the matched sample, who did not experience a recession, dependent on the level of constraints.

\section{Low level of constraints}

\section{High level of constraints}

Severe recession $>-3$ percent

- No severe recession - - Severe recession
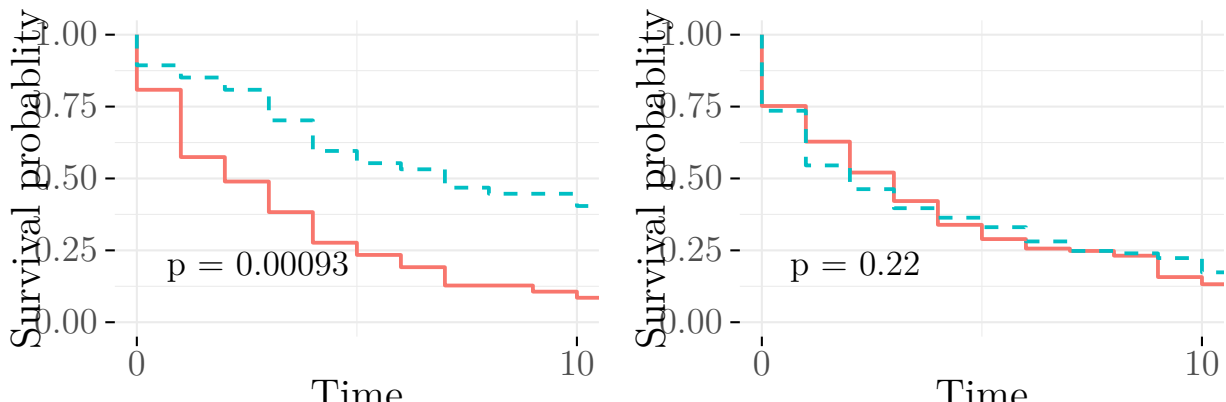

Time

Time

Severe recession $>-6$ percent
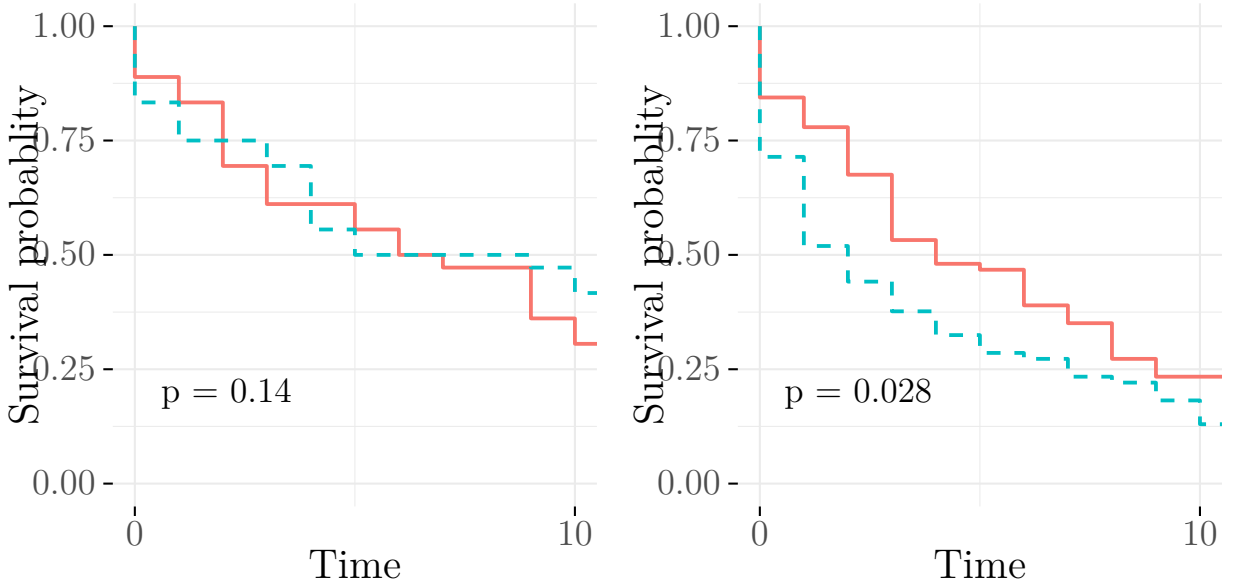

Severe recession $>-10$ percent
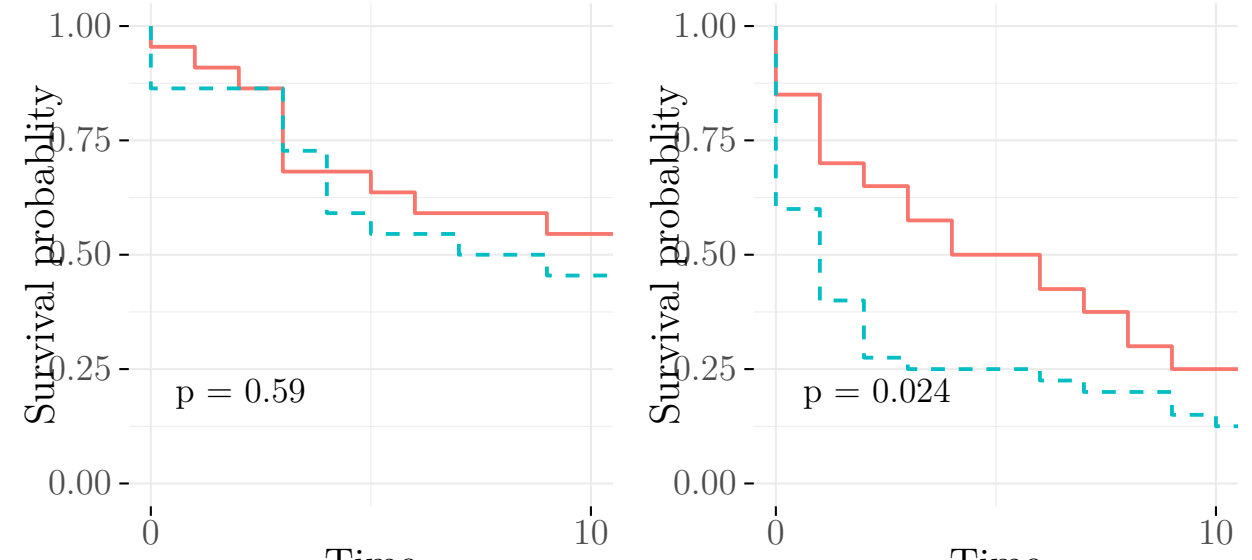

180 leaders in the top panel, 113 leaders in the middle panel and 62 leaders in the bottom panel. $P$ value is based on the score log-rank test. 
The first half of the analysis perceives a severe economic recession as an event, and then analyse the survival rates in the aftermath dependent on the level of constraints at the time when the event happens. The downside of this approach is that it assumes that both measures of constraints are static and, therefore, ignores the dynamic structure of the data. Furthermore, this type of analysis cannot utilize country fixed effects. This is problematic since some countries may be characterized by frequent replacement of the leader, a low degree of constraints, and many recessions. Thus, the results may be because of underlying differences and not changes in the variables of interest. I take this into account in table 6.3, where I use both OLS-regressions and Cox regressions.

In column 1, I only include severe recession and tenure of the leader. We see that a severe recession increases the likelihood that a dictator will be removed in the subsequent year by five percentage points. In comparison, a dictator is removed in 11 per cent of all years as seen in table 6.1. Furthermore, we see that the experience of a leader is positively associated with the likelihood of removal. In column 2 , I add the two measures of internal and external constraints. It is seen that severe recession still is significantly related to leader change. Furthermore, the coefficient for relative experience is negative and insignificant, while the coefficient for strength of civil society is positive and significant. Thus, a leader is more likely to be removed if the civil society becomes stronger, while he is less likely to be removed when he purges members of the ruling coalition. In column 3 , severe recession is interacted with the two measures of constraints. The coefficient for severe recession diminishes and becomes insignificant. The interactions between the two measures of constraints and severe recession are positive although not significant. 
In column 4, 5, and 6, I repeat the analysis from the first three columns, but with the inclusion of a set of control variables. The main findings become more apparent, when the set of control variables are added, and the interaction with internal constraints becomes significant. Overall, the results show that a dictator is more likely to fall in the year following a severe economic recession. However, the increase in risk depends on the strength of his opponents. If he faces a strong civil society or an experienced and organized ruling coalition, he is more likely to be removed. On the other hand, will a dictator with weak opponents have little to fear in the aftermath of a recession. Only two of the other variables added to the regression are significant, namely number of core members and GDP per capita. A dictator can therefore secure his power by increasing the size of his ruling coalition and thereby provide more patronage, which is a finding found elsewhere in the literature (Arriola 2009, De Mesquita et al. 2005). In addition, an autocrat becomes more secure when a country becomes richer which makes it easier to provide rents (Mesquita and Smith 2010).

As discussed in the econometric approach, there are issues with using OLS to model the relationship. In column 7 and 8, I redo the analysis in column 5 and 6 using Cox regression. Again, I find a positive and significant relationship between economic recession in the model without the interaction terms which disappears when the interaction terms are included. The interaction terms are both positive, while only the term for civil society is significant. The two measures of constraints are positive, indicating that constrained autocrats have higher mortality.

At last, I repeat the analysis for democracies. Democratic leaders in the sample are no 
more likely to lose power in the year following a severe recession than not. This result is robust to different specifications and goes contrary to much of the literature on economic voting (Lewis-Beck 1990; Lewis-Beck and Stegmaier 2000). There are two reasons for why we might see this pattern. First, contrary to autocrats, democrats are generally disposed in regular elections which may not coincide with a recession. Second, most of the literature looks at the effect of economic growth and not on the effect of recessions per se.

Overall, the analyses in this section provide strong support for the theory. Autocrats who have managed to thwart all opposition, both within and outside the regime, have little to fear in the aftermath of a recession. In fact, they may even strengthen their grip on power. On the other hand, the results indicate that autocrats who are threatened by a strong ruling coalition and/or a strong civil society, should be scared of governing over bad economic outcomes, given that they are much more likely to lose their job as a consequence of a recession. 
Table 6.3: Likelihood of removal following a severe recession dependent on the level of constraints

\begin{tabular}{|c|c|c|c|c|c|c|c|c|c|c|}
\hline & $(1)$ & $(2)$ & (3) & $(4)$ & $(5)$ & $(6)$ & $(7)$ & $(8)$ & (9) & $(10)$ \\
\hline Severe recession & $0.05^{* *}$ & $0.04^{* *}$ & 0.02 & $0.04^{* *}$ & $0.04^{*}$ & 0.02 & $0.62^{* * *}$ & 0.33 & -0.06 & 0.04 \\
\hline \multirow[b]{2}{*}{ Tenure of the leader } & $(0.02)$ & $(0.02)$ & $(0.04)$ & $(0.02)$ & $(0.02)$ & $(0.04)$ & $(0.17)$ & $(0.37)$ & $(0.04)$ & $(0.15)$ \\
\hline & $0.00^{* * *}$ & $0.00^{*}$ & $0.00^{*}$ & $0.00^{* * *}$ & $0.00^{* *}$ & $0.00^{* *}$ & & & $0.01^{* * *}$ & 0.01 \\
\hline & $(0.00)$ & $(0.00)$ & $(0.00)$ & $(0.00)$ & $(0.00)$ & $(0.00)$ & & & $(0.00)$ & $(0.01)$ \\
\hline \multirow[t]{2}{*}{$\log$ (Relative experience) } & & -0.02 & $-0.03^{*}$ & & -0.01 & -0.02 & $1.02^{* * *}$ & $0.91^{* * *}$ & & -0.02 \\
\hline & & $(0.01)$ & $(0.01)$ & & $(0.02)$ & $(0.02)$ & $(0.16)$ & $(0.17)$ & & $(0.04)$ \\
\hline \multirow[t]{2}{*}{ Strength of civil society } & & $0.17^{* *}$ & $0.16^{* *}$ & & $0.16^{*}$ & $0.14^{*}$ & $1.28^{* * *}$ & $1.01^{* *}$ & & 0.05 \\
\hline & & $(0.07)$ & $(0.07)$ & & $(0.08)$ & $(0.08)$ & $(0.45)$ & $(0.48)$ & & $(0.09)$ \\
\hline \multirow[t]{2}{*}{ Severe recession* $\log (\mathrm{RE})$} & & & 0.04 & & & $0.07^{* *}$ & & $0.44^{*}$ & & -0.09 \\
\hline & & & $(0.03)$ & & & $(0.03)$ & & $(0.24)$ & & $(0.08)$ \\
\hline \multirow[t]{2}{*}{ Severe recession*SC } & & & 0.09 & & & 0.12 & & 0.99 & & -0.15 \\
\hline & & & $(0.08)$ & & & $(0.09)$ & & $(0.74)$ & & $(0.19)$ \\
\hline \multirow[t]{2}{*}{ Log of gdp per capita } & & & & -0.05 & -0.04 & -0.04 & -0.23 & -0.21 & $0.19^{* * *}$ & $0.20^{* * *}$ \\
\hline & & & & $(0.03)$ & $(0.03)$ & $(0.03)$ & $(0.22)$ & $(0.22)$ & $(0.07)$ & $(0.07)$ \\
\hline \multirow[t]{2}{*}{ Log of population } & & & & $-0.13^{*}$ & $-0.16^{*}$ & $-0.16^{*}$ & $0.31^{* * *}$ & $0.31^{* * *}$ & $0.51^{* * *}$ & $0.53^{* * *}$ \\
\hline & & & & $(0.07)$ & $(0.09)$ & $(0.09)$ & $(0.12)$ & $(0.12)$ & $(0.14)$ & $(0.13)$ \\
\hline \multirow[t]{2}{*}{ Urban population (\%) } & & & & -0.00 & -0.00 & -0.00 & -0.00 & -0.00 & $-0.01^{* * *}$ & $-0.01^{* * *}$ \\
\hline & & & & $(0.00)$ & $(0.00)$ & $(0.00)$ & $(0.01)$ & $(0.01)$ & $(0.00)$ & $(0.00)$ \\
\hline \multirow[t]{2}{*}{ Number of core members } & & & & $-0.00^{* *}$ & $-0.00^{* *}$ & $-0.00^{* *}$ & $-0.09^{* * *}$ & $-0.09^{* * *}$ & 0.00 & 0.00 \\
\hline & & & & $(0.00)$ & $(0.00)$ & $(0.00)$ & $(0.01)$ & $(0.01)$ & $(0.00)$ & $(0.00)$ \\
\hline \multirow[t]{2}{*}{ Resource income per capita ( $\%$ of GDP) } & & & & -0.03 & -0.07 & -0.07 & -1.18 & -1.20 & -0.25 & -0.24 \\
\hline & & & & $(0.08)$ & $(0.08)$ & $(0.08)$ & $(0.78)$ & $(0.78)$ & $(0.17)$ & $(0.16)$ \\
\hline Model: & OLS & OLS & OLS & OLS & OLS & OLS & Cox & Cox & OLS (Democracy) & OLS (Democracy) \\
\hline Estimation method: Within country & Yes & Yes & Yes & Yes & Yes & Yes & Yes & Yes & Yes & Yes \\
\hline Estimation method: Within country & Yes & Yes & Yes & Yes & Yes & Yes & No & No & Yes & Yes \\
\hline Observations: & 2940 & 2875 & 2875 & 2333 & 2289 & 2289 & 2289 & 2289 & 1112 & 1112 \\
\hline Countries: & 112 & 109 & 109 & 104 & 102 & 102 & & & 65 & 65 \\
\hline $\mathrm{R}^{2}$ & 0.11 & 0.11 & 0.11 & 0.13 & 0.13 & 0.14 & & & 0.15 & 0.15 \\
\hline AIC & & & & & & & 2709.25 & 2708.15 & & \\
\hline Removed leaders: & & & & & & & 221 & 221 & & \\
\hline
\end{tabular}




\subsubsection{Economic outcomes}

The previous analysis shows that autocrats who are constrained, are punished for bad economic outcomes. The threat of removal, therefore, gives impetus to constrained autocrats to provide economic growth and avoid recessions. Fortunately for constrained autocrats, the theoretical section also provides reasons for why they should be more likely to deliver economic growth, since constrains on the leader will cause a more thoughtful and competent decision making process and a better environment for investment.

In the theoretical chapter, I argued that both types of constraints would be related to better economic outcomes and that the two types of constraints are substitutes. In other words, one type of constraints should matter less, when there is more of the other. This I test in the following.

\section{Econometric approach}

Constraints on the autocrat are not randomly distributed across countries. I therefore use an OLS-regression with country and leader fixed effects to examine what happens to economic growth when constraints on the autocrat decrease or increase for a given dictator. Furthermore, it may be the case that autocrats fire ministers or clamp down on civil society in response to bad economic outcomes. Thus, I lag all independent variables with one time period. This separates the dependent variable from the predictors and offers some protection against reverse causality. I run the model with two different specifications. First, I run the model with both country and leader fixed effects:

$$
Y_{i t+1}=\beta_{1} \log \left(I_{i t}\right)+\beta_{2} E_{i t}+\beta_{3} X_{i t}+\phi_{l}+\alpha_{i}+\epsilon_{i t}
$$


, where I and E are indicators of internal constraints and external constraints for leader and country $i$ in year $t, \alpha_{i}$ denotes country fixed effects and $\phi_{l}$ denotes leader fixed effects $\mathrm{3}^{3}$ These controls for time-invariant characteristics of the leader and country. $X_{i t}$ is the set of control variables and $\epsilon_{i t}$ is the error term. The dependent variable, $Y_{i t+1}$, is economic growth. Furthermore, I will include an interaction between internal and external constraints in some specifications. The regression formula for the interaction effect is not shown here. Afterwards, I will include both leader, country fixed effects and time fixed effects in the same model:

$$
Y_{l c t+t}=\beta_{1} \log \left(I_{l c t}\right)+\beta_{2} E_{l c t}+\beta_{3} X_{i t}+\phi_{l}+\alpha_{c}+\gamma_{t}+\epsilon_{l c t}
$$

Compared to the previous specification this specification includes $\gamma_{t}$, which represents year fixed effects and control for shocks in a given year. Thus, this model estimates growth as a function of the level of constraints, when both leader, country and year are held constant.

\section{Across autocrats}

While the main analysis focuses on changes over time for one leader, it is useful to compare across autocrats to provide an introduction to the data and a preliminary check of the theoretical expectations. Therefore, I calculate the average values for every autocrat on economic growth, strength of civil society, and retention rate. The retention rate is a measure of the share of the ruling coalition which survives from one year to the next. The average retention rate is therefore a measure of cabinet instability over the whole tenure

\footnotetext{
${ }^{3}$ Statistically it makes no difference whether country fixed are added to the regression, since a leader rarely governs over different countries, making country invariant within leader.
} 
of an autocrat. The main measure of internal constraints, relative experience, is highly dependent on the time in office for a given leader, and it is therefore not meaningful to calculate an average for the full tenure of an autocrat.

Figure 6.7: Association between average retention rate, civil society and economic growth
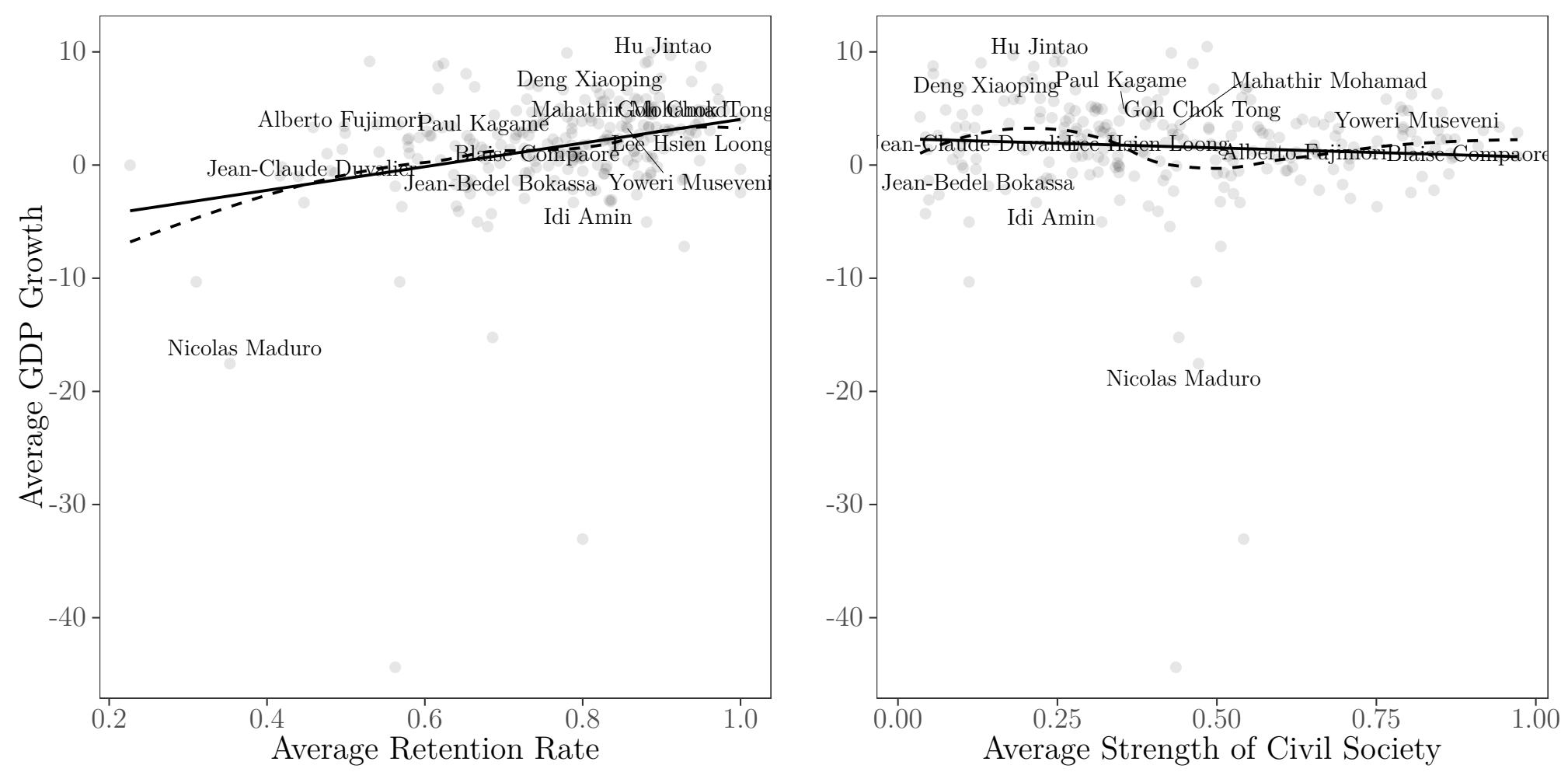

Notes: Bivariate relationship. Solid line is linear fit and dashed line is a lowess fit. $\mathrm{N}=276$ autocrats.

In figure 6.7 we see the bivariate relationship between the retention rate and strength of civil society and economic growth for leaders with a tenure of two years or more. In general leaders with a stable ruling coalition govern over higher growth than those with an unstable ruling coalition. The labels are shown for a handful of well-known autocrats. Leaders such as Lee Kuan Yew of Singapore, Hu Jintao of China and Paul Kagame of Rwanda govern over both high growth rates and a stable ruling coalition, while leaders such as Jean-Bedel Bokassa of the Central African Republic and Jean-Claude Duvalier of Haiti 
Table 6.4: Internal and external constraints and economic growth across leaders

\begin{tabular}{lcccc}
\hline & $(1)$ & $(2)$ & $(3)$ & $(4)$ \\
\hline Intercept) & $-5.95^{* *}$ & & $-6.92^{* *}$ & \\
& $(2.58)$ & & $(3.37)$ & \\
Retention rate & $10.69^{* * *}$ & $10.87^{* *}$ & $12.22^{* * *}$ & $20.20^{* * *}$ \\
& $(3.02)$ & $(5.46)$ & $(3.99)$ & $(7.47)$ \\
Strength of civil society & -1.37 & $4.89^{*}$ & -1.36 & $4.65^{*}$ \\
& $(0.93)$ & $(2.72)$ & $(0.87)$ & $(2.56)$ \\
\hline Sample: & $>2$ & $>2$ & $>4$ & $>4$ \\
Estimation method: Within country & No & Yes & No & Yes \\
Observations: & 234 & 234 & 182 & 182 \\
$\mathrm{R}^{2}$ & 0.08 & 0.46 & 0.10 & 0.48 \\
\hline${ }^{* * *} p<0.01 ;{ }^{* *} p<0.05 ;{ }^{*} p<0.1$. & & &
\end{tabular}

govern with an unstable ruling coalition and low growth rates. Contrary, there is little relationship between the strength of civil society and economic growth. If anything, leaders with a weak civil society govern over lower growth than leaders with a strong civil society.

The patterns are confirmed in table 6.4 where I run a simple linear model, regressing average economic growth on average retention rate and average strength of civil society. The first column includes all autocrats who have governed for at least two years. The coefficient for 'retention rate' is 10.69 percentage points, indicating that autocrats with a completely stable ruling coalition govern over a growth rate that is 10.69 percentage points higher than autocrats who change the entire ruling coalition every year. On the other hand, the coefficient for 'strength of civil society' is negative, indicating that autocrats with a stronger civil society, on average, govern over lower growth rates. In column 2 , I include country fixed effects. I therefore compare autocrats within the same country. The coefficient for retention rate remains large and significant, while the coefficient for 
strength of civil society changes direction. Thus, autocrats from the same country govern over higher growth, when civil society is stronger. In the remaining two columns I only include leaders who have time to cement their power by restricting the sample to autocrats who have been in power for four years or more. These results are similar; although the coefficient for strength of civil society is larger.

The preliminary results are informative, and suggest that especially stability of the ruling coalition is related to economic growth, while civil society only is related to economic growth when looking within country. However, needless to say, these findings suffer from serious endogeneity issues, and they do not answer the main question posed in this thesis, namely how the two measures of constraints are related to growth over time when holding leader constant.

\section{Within the tenure of one leader}

Next, I investigate how the two measures of constraints are related to economic growth using panel data where leader and country are held constant. The main results are seen in table 6.5. In model 1 all leaders are included. The two coefficients for the measures of constraints, relative experience (internal constraints) and strength of civil society (external constraints) are both positive, albeit both are far from statistical significance.

The mechanism presented does not work when leaders have access to large rents from natural resources. I discussed this in the theory section, and there are two reasons for why. First, dictators can use the large inflow of external rents to govern alone by suppressing both the opposition and coalition partners (Boix and Svolik 2013 Eibl and Hertog 2017). Thus, it is predicted that authoritarian states with high exogenous revenue are more likely 
to experience situations where it is not worthwhile for the ruler to compromise to stay in power. Instead, these regimes are more likely to experience situations with either high repression or chaotic periods, when there is a competition for power. Second, constraints may matter less in countries highly dependent on exogeneous rents where the leader has less control over the economy (Campello and Zucco 2016). In column 2, I therefore only include leaders who govern over countries, where more than 20 per cent of GDP comes from natural resources. $4^{4}$ The relationship between the two measures of constraints and economic growth is negative in this sample. This indicates that economic growth is lower in regimes highly dependent on natural resources, when civil society is stronger and the elite is oligarchic. Therefore, I exclude these leaders in the remainder of the table.

In column 3, I regress growth on the two measures of constraints in the set of autocrats without access to excessive oil revenues. In this subset of the data the two measures of constraints are related to higher economic growth, albeit only the measure of external constraints is significant. In column 4, I include the interaction term between the measures of internal and external constraints. The coefficient for the interaction term is negative. As theorized the two types of constraints therefore function as substitutes. It should be noted that the log of relative experience can take negative values. The coefficient for strength of civil society is, therefore, not directly interpretable, when the interaction term is added. An interaction plot based on column 8 is seen in figure 6.8. Here, we see that strength of civil society becomes significant, when the dictator faces an inexperienced ruling coalition.

In column 5, I include the set of potential confounders. This leaves the coefficient for relative experience unchanged, but increases the coefficient for strength of civil society. This

\footnotetext{
${ }^{4}$ The results are similar if a cut-off of 25 per cent or 15 per cent are used.
} 
is primarily due to the inclusion of oil revenues. This support the findings from before where oil revenues seems to moderate the positive relationship between civil society on economic growth. In column 6, I again add the interaction between the two measures of constraints. In column 7 and 8, I repeat the analysis with year fixed effects. This decreases the sizes of the coefficients, but they remain both substantively large and statistically significant.

In column 9, I run the model with the extra variables, but without the measures of internal and external constraints. Here, the measure of tenure is negatively related to growth. This indicates that growth deteriorates over time, when the same dictator stays in office. This is in line with the existing literature (Kolstad 2020; Papaioannou and Van Zanden 2015). However, in the remaining columns, where the measures of constraints are included, we see that the tenure of the dictator is positively related to economic growth. Decreasing growth rates are therefore mainly a function of a decrease in constraints on the autocrat. A dictator can therefore sustain high growth rates - or even increasing growth rates - if they do not purge members of the ruling elite or suppress civil society. 
Table 6.5: Internal and external constraints and economic growth in autocracies

\begin{tabular}{|c|c|c|c|c|c|c|c|c|c|}
\hline & (1) & $(2)$ & (3) & $(4)$ & $(5)$ & $(6)$ & $(7)$ & $(8)$ & $(9)$ \\
\hline \multirow[t]{2}{*}{ Log(Relative experience) } & 0.13 & -2.82 & $1.08^{* *}$ & $2.34^{* * *}$ & $1.13^{* *}$ & $2.74^{* * *}$ & $0.93^{*}$ & $2.45^{* * *}$ & \\
\hline & $(0.56)$ & $(1.82)$ & $(0.50)$ & $(0.58)$ & $(0.52)$ & $(0.71)$ & $(0.52)$ & $(0.69)$ & \\
\hline \multirow[t]{2}{*}{ Strength of civil society } & 0.37 & -4.91 & 3.17 & 1.85 & $7.83^{* *}$ & $6.29^{* *}$ & $7.35^{* *}$ & $5.96^{*}$ & \\
\hline & $(2.61)$ & $(5.48)$ & $(2.42)$ & $(2.50)$ & $(3.03)$ & $(2.95)$ & $(3.30)$ & $(3.35)$ & \\
\hline \multirow[t]{2}{*}{ Tenure of the leader } & 0.00 & $-0.19^{*}$ & 0.09 & 0.09 & 0.05 & 0.05 & 0.02 & 0.02 & $-0.10^{*}$ \\
\hline & $(0.09)$ & $(0.10)$ & $(0.10)$ & $(0.10)$ & $(0.08)$ & $(0.08)$ & $(0.08)$ & $(0.08)$ & $(0.06)$ \\
\hline \multirow[t]{2}{*}{$\log (\mathrm{RE}) * \mathrm{SC}$} & & & & $-2.86^{* * *}$ & & $-3.45^{* * *}$ & & $-3.21^{* * *}$ & \\
\hline & & & & $(1.05)$ & & $(1.13)$ & & $(1.12)$ & \\
\hline \multirow[t]{2}{*}{ Log(Population) } & & & & & $-12.13^{* * *}$ & $-12.73^{* * *}$ & $-10.80^{* * *}$ & $-11.80^{* * *}$ & $-7.65^{* *}$ \\
\hline & & & & & $(4.29)$ & $(4.19)$ & $(3.72)$ & $(3.69)$ & $(3.76)$ \\
\hline \multirow[t]{2}{*}{ Urban population (\%) } & & & & & -0.23 & -0.25 & -0.11 & -0.15 & -0.11 \\
\hline & & & & & $(0.27)$ & $(0.27)$ & $(0.26)$ & $(0.26)$ & $(0.28)$ \\
\hline \multirow[t]{2}{*}{ Civil violence } & & & & & $-0.30^{* *}$ & $-0.30^{* *}$ & $-0.28^{* *}$ & $-0.29^{* *}$ & $-0.26^{*}$ \\
\hline & & & & & $(0.12)$ & $(0.12)$ & $(0.13)$ & $(0.13)$ & $(0.13)$ \\
\hline \multirow[t]{2}{*}{ Number of core members } & & & & & 0.09 & $0.10^{*}$ & 0.08 & 0.08 & 0.08 \\
\hline & & & & & $(0.06)$ & $(0.06)$ & $(0.06)$ & $(0.06)$ & $(0.06)$ \\
\hline \multirow[t]{2}{*}{ Oil rents ( $\%$ of GDP) } & & & & & $0.09^{*}$ & $0.09^{*}$ & 0.07 & 0.06 & 0.06 \\
\hline & & & & & $(0.05)$ & $(0.05)$ & $(0.06)$ & $(0.06)$ & $(0.06)$ \\
\hline \multirow[t]{2}{*}{ Year } & -0.02 & 0.02 & -0.02 & -0.01 & $0.39^{* * *}$ & $0.41^{* * *}$ & & & \\
\hline & $(0.07)$ & $(0.09)$ & $(0.08)$ & $(0.08)$ & $(0.13)$ & $(0.12)$ & & & \\
\hline Sample & All & Oil & -Oil & -Oil & -Oil & -Oil & -Oil & -Oil & -Oil \\
\hline Estimation method: Within leader & Yes & Yes & Yes & Yes & Yes & Yes & Yes & Yes & Yes \\
\hline Estimation method: Within country & Yes & Yes & Yes & Yes & Yes & Yes & Yes & Yes & Yes \\
\hline Estimation method: Within year & No & No & No & No & No & No & Yes & Yes & Yes \\
\hline Observations & 2908 & 458 & 2450 & 2450 & 2012 & 2012 & 2012 & 2012 & 2030 \\
\hline Leaders: & 353 & 28 & 325 & 325 & 276 & 276 & 276 & 276 & 277 \\
\hline Countries: & 107 & 18 & 104 & 104 & 98 & 98 & 98 & 98 & 99 \\
\hline $\mathrm{R}^{2}$ & 0.26 & 0.08 & 0.38 & 0.38 & 0.37 & 0.37 & 0.41 & 0.41 & 0.40 \\
\hline
\end{tabular}

${ }^{*} \mathrm{p}<0.1,{ }^{* *} \mathrm{p}<0.05, * * * \mathrm{p}<0.01$. Dependent variable: Growth (Penn World Tables). All right-side variables lagged by one year. Clustered standard errors in parentheses. RE $=$ Relative experience, $\mathrm{SC}=$ Strength of Civil Society. 
Overall, the results support the theory. The empirical analysis uses the dynamic nature of the two variables, and we see that the same dictator governs over worse economic outcomes when there are less constraints on his rule. Furthermore, the two types of constraints function as imperfect substitutes. An increase in one type of constraints decreases the importance of the other. This is seen graphically in figure 6.8, where the association between relative experience and economic growth diminishes, when the strength of civil society increases and vice versa.

Figure 6.8: Effect of relative experience on economic growth dependent on the strength of civil society
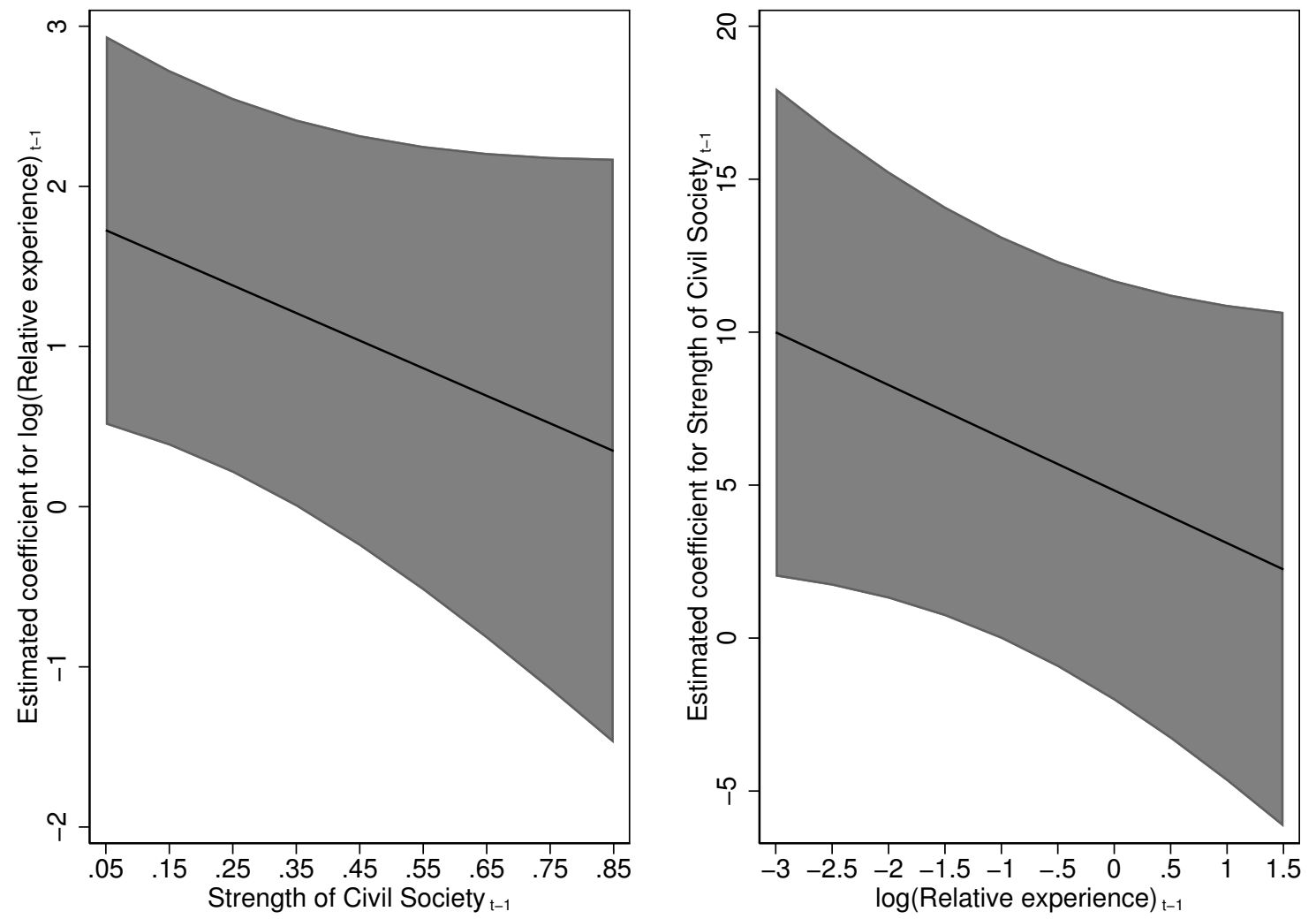

Notes: Based on column 8 in table 6.5. Whiskers represents 95 per cent confidence intervals. 
The effect sizes are hard to interpret due to the logarithmic specification of relative experience. In addition, the interaction term complicates the interpretation further. In column 8 in table 6.5, where the interaction term is included, the coefficient for log of relative experience is 2.45 percentage points, while it is 5.96 percentage points for strength of civil society, and the interaction term is -3.21 percentage points. If we keep the measure of relative experience at its mean $(\log (0.7)=-0.33)$, the coefficient for strength of civil society is 7.3 percentage points. A country will in this case, on average, experience a growth rate which is 3.15 percentage points higher per year if the strength of civil society increases by a half. This is roughly equivalent to the increase in the strength of civil society in Cambodia under Khmer Rouge to when Hun Sen took power. If we instead look at relative experience and assume that the strength of civil society is at its mean (0.40), the coefficient for log of relative experience is 1.2 percentage points. In this case a halving of the relative experience of the ministers relative to the dictator is associated with a decrease in the annual growth rate of 0.80 percentage points. We see a large jump for Mugabe in this variable in figure 6.2 after 20 years of rule, where he purges much of his cabinet.

\section{Alternative specifications}

The measure used of internal constraints is novel and although it is based on theory, it may not convince all readers. I therefore construct two alternative measure of ruling coalition strength based on the new data set to triangulate the findings. The results are seen in table 6.6. The statistical model is similar to the model in column 8 in table 6.5.

In column 1, I use the replacement rate, which measures the share of the ruling cabinet that is replaced from one year to the next. If the whole cabinet is replaced and civil 
Table 6.6: Internal and external constraints and economic growth in autocracies (Alternative measures)

\begin{tabular}{|c|c|c|c|}
\hline & $(1)$ & $(2)$ & $(3)$ \\
\hline Replacement rate & $\begin{array}{c}-2.32^{*} \\
(1.35)\end{array}$ & & \\
\hline Purged more than 70 per cent & & $\begin{array}{l}-1.43 \\
(0.88)\end{array}$ & \\
\hline Purged more than 95 per cent & & & $\begin{array}{c}-2.28^{*} \\
(1.26)\end{array}$ \\
\hline Strength of civil society & $\begin{array}{c}5.19 \\
(3.33)\end{array}$ & $\begin{array}{c}4.07 \\
(3.92)\end{array}$ & $\begin{array}{c}4.61 \\
(3.74)\end{array}$ \\
\hline Replacement rate*SC & $\begin{array}{c}3.90^{*} \\
(2.33)\end{array}$ & & \\
\hline Small purge*SC & & $\begin{array}{l}3.64^{* *} \\
(1.69)\end{array}$ & \\
\hline Big purge*SC & & & $\begin{array}{l}5.87^{* *} \\
(2.84) \\
\end{array}$ \\
\hline Sample & $-O i l$ & $-O i l$ & $-O i l$ \\
\hline Controls & Yes & Yes & Yes \\
\hline Estimation method: Within leader & Yes & Yes & Yes \\
\hline Estimation method: Within country & Yes & Yes & Yes \\
\hline Estimation method: Within year & Yes & Yes & Yes \\
\hline Observations & 2015 & 2026 & 2026 \\
\hline $\mathrm{R}^{2}$ & 0.38 & 0.39 & 0.39 \\
\hline
\end{tabular}

${ }^{*} \mathrm{p}<0.1,{ }^{* *} \mathrm{p}<0.05,{ }^{* * *} \mathrm{p}<0.01$. Dependent variable: Growth (Penn World Tables). All right-side variables lagged by one year. Clustered standard errors in parentheses. SC $=$ Strength of Civil Society. 97 countries and 265 leaders.

society is weak, the growth rate drops by 2.32 percentage points in the following year.

In the remaining two columns I use a binary measure of purges. In column 2 it takes the value 1 if more than 70 per cent of the original ruling coalition has been replaced, while column 3 uses a threshold of 95 per cent 5 The coefficient for purge is negative in both columns, indicating that growth is lower when most of the original ruling coalition has been replaced. Furthermore, we see that the coefficient is larger, when the 95 per cent cut-off is used.

\footnotetext{
${ }^{5}$ The original ruling coalition is the group of cabinet members that entered office simultaneously with the autocrat.
} 
The findings in this subsection corroborate the main finding, namely that economic growth plummets, when the autocrat becomes established by replacing members of the ruling coalition. This finding holds independent on the measure of atomization.

\section{Running the analysis under democracy}

The theory outlined in this section should apply only to autocracies. As discussed, they are characterized by an absence of free and competitive elections that decide who gets to hold power. As a result, the only form of accountability comes from powerful opponents. On the contrary, the two types of constraints should matter less in democracies. Here, disputes should be solved through functioning institutions, the rule of law and ultimately through the electoral process (Besley 2006). Therefore, democratic leaders should have an electoral incentive to provide economic growth and investors do not need fear expropriation when the ruling coalition or the civil society becomes weaker. However, there are alternative explanations that can explain the patterns presented in the analyses above. For example, it may be the case that the measure of experience is related to fundamental political instability; which we do not necessarily expect to have a different effect on economic development in democracies than in autocracies. To test whether the results are specific to autocracies, I replicate the analyses under democracy. 
Table 6.7: Internal and external constraints and economic growth in democracies

\begin{tabular}{|c|c|c|c|c|c|c|c|c|c|}
\hline & $(1)$ & $(2)$ & (3) & (4) & (5) & (6) & $(7)$ & (8) & $(9)$ \\
\hline Log(Relative experience) & $\begin{array}{l}-0.02 \\
(0.24)\end{array}$ & $\begin{array}{l}-0.98 \\
(1.73)\end{array}$ & $\begin{array}{c}0.03 \\
(0.25)\end{array}$ & $\begin{array}{l}-0.91 \\
(1.37)\end{array}$ & $\begin{array}{c}0.02 \\
(0.26)\end{array}$ & $\begin{array}{l}-0.91 \\
(1.40)\end{array}$ & $\begin{array}{l}-0.01 \\
(0.25)\end{array}$ & $\begin{array}{l}-0.94 \\
(1.35)\end{array}$ & \\
\hline Strength of civil society & $\begin{array}{l}-0.23 \\
(2.73)\end{array}$ & $\begin{array}{l}-2.37 \\
(26.77)\end{array}$ & $\begin{array}{c}0.04 \\
(2.28)\end{array}$ & $\begin{array}{c}0.09 \\
(2.27)\end{array}$ & $\begin{array}{c}0.16 \\
(2.05)\end{array}$ & $\begin{array}{c}0.24 \\
(2.08)\end{array}$ & $\begin{array}{c}0.48 \\
(2.03)\end{array}$ & $\begin{array}{c}0.52 \\
(2.06)\end{array}$ & \\
\hline Tenure of the leader & $\begin{array}{l}-0.05 \\
(0.05)\end{array}$ & $\begin{array}{l}-0.33 \\
(0.23)\end{array}$ & $\begin{array}{l}-0.04 \\
(0.05)\end{array}$ & $\begin{array}{l}-0.04 \\
(0.05)\end{array}$ & $\begin{array}{l}-0.04 \\
(0.04)\end{array}$ & $\begin{array}{l}-0.04 \\
(0.04)\end{array}$ & $\begin{array}{l}-0.05 \\
(0.04)\end{array}$ & $\begin{array}{l}-0.05 \\
(0.04)\end{array}$ & $\begin{array}{c}-0.06^{*} \\
(0.03)\end{array}$ \\
\hline $\log (\mathrm{RE}) * \mathrm{SC}$ & & & & $\begin{array}{c}1.10 \\
(1.53)\end{array}$ & & $\begin{array}{c}1.09 \\
(1.56)\end{array}$ & & $\begin{array}{c}1.09 \\
(1.48)\end{array}$ & \\
\hline Log(Population) & & & & & $\begin{array}{c}2.38 \\
(3.53)\end{array}$ & $\begin{array}{c}2.31 \\
(3.56)\end{array}$ & $\begin{array}{c}0.28 \\
(3.29)\end{array}$ & $\begin{array}{c}0.22 \\
(3.31)\end{array}$ & $\begin{array}{c}0.05 \\
(3.35)\end{array}$ \\
\hline Urban population (\%) & & & & & $\begin{array}{l}-0.26 \\
(0.19)\end{array}$ & $\begin{array}{l}-0.25 \\
(0.19)\end{array}$ & $\begin{array}{l}-0.15 \\
(0.21)\end{array}$ & $\begin{array}{l}-0.14 \\
(0.21)\end{array}$ & $\begin{array}{l}-0.16 \\
(0.22)\end{array}$ \\
\hline Civil violence & & & & & $\begin{array}{c}-0.14^{* * *} \\
(0.05)\end{array}$ & $\begin{array}{c}-0.13^{* *} \\
(0.05)\end{array}$ & $\begin{array}{c}-0.11^{*} \\
(0.06)\end{array}$ & $\begin{array}{c}-0.10^{*} \\
(0.06)\end{array}$ & $\begin{array}{c}-0.11^{*} \\
(0.06)\end{array}$ \\
\hline Number of core members & & & & & $\begin{array}{c}-0.04^{*} \\
(0.02)\end{array}$ & $\begin{array}{c}-0.04^{*} \\
(0.02)\end{array}$ & $\begin{array}{l}-0.02 \\
(0.02)\end{array}$ & $\begin{array}{l}-0.02 \\
(0.02)\end{array}$ & $\begin{array}{l}-0.02 \\
(0.02)\end{array}$ \\
\hline Oil rents ( $\%$ of GDP) & & & & & $\begin{array}{c}0.06 \\
(0.10)\end{array}$ & $\begin{array}{c}0.07 \\
(0.10)\end{array}$ & $\begin{array}{l}0.23^{* *} \\
(0.10)\end{array}$ & $\begin{array}{l}0.23^{* *} \\
(0.10)\end{array}$ & $\begin{array}{l}0.23^{* *} \\
(0.10)\end{array}$ \\
\hline Year & $\begin{array}{c}0.03 \\
(0.03)\end{array}$ & $\begin{array}{c}0.20 \\
(0.14)\end{array}$ & $\begin{array}{c}0.02 \\
(0.03)\end{array}$ & $\begin{array}{c}0.02 \\
(0.03)\end{array}$ & $\begin{array}{c}0.04 \\
(0.06)\end{array}$ & $\begin{array}{c}0.04 \\
(0.06)\end{array}$ & & & \\
\hline Sample & All & Oil & -Oil & -Oil & - Oil & - Oil & -Oil & -Oil & - -Oil \\
\hline Estimation method: Within leader & Yes & Yes & Yes & Yes & Yes & Yes & Yes & Yes & Yes \\
\hline Estimation method: Within country & Yes & Yes & Yes & Yes & Yes & Yes & Yes & Yes & Yes \\
\hline Estimation method: Within year & No & No & No & No & No & No & Yes & Yes & Yes \\
\hline Observations: & 2951 & 99 & 2852 & 2852 & 2634 & 2634 & 2634 & 2634 & 2677 \\
\hline Leaders: & 679 & 17 & 662 & 662 & 606 & 606 & 606 & 606 & 611 \\
\hline Countries: & 107 & 6 & 106 & 106 & 100 & 100 & 100 & 100 & 101 \\
\hline $\mathrm{R}^{2}$ & 0.39 & 0.37 & 0.39 & 0.39 & 0.40 & 0.40 & 0.49 & 0.49 & 0.49 \\
\hline
\end{tabular}

* $\mathrm{p}<0.1,{ }^{* *} \mathrm{p}<0.05, * * * \mathrm{p}<0.01$. Dependent variable: Growth (Penn World Tables). All right-side variables lagged by one year. Clustered standard errors in parentheses. RE $=$ Relative experience, $\mathrm{SC}=$ Strength of Civil Society. 
The main results are seen in table 6.7, and we see that the coefficients for the main variables of interest are reversed or muted to essentially zero, when I run the analysis in democracies. Furthermore, both are far from statistical significance. A democracy will therefore fare no worse - or even better - economically when the leader governs with a group of inexperienced cabinet ministers and a weaker civil society. This may relate to the criticism of democracy, where scholars argue that democracies are worse for economic growth because leaders are ineffective due to constraints on their rule. Furthermore, it is worth noticing that the coefficient for the interaction effects is reversed in democracies. To sum up, we see that the results are unique to autocracies, and the two types of constraints are therefore not associated with higher economic growth in a democratic system.

\section{Likelihood of governing over a big recession}

In table 6.8 I test the relationship between the two types of constraints and the likelihood of facing a recession of a certain size. All specifications are similar to the specification used in column 8 in table 6.5. I rely on a linear model to ease the interpretation, but the results are substantively similar - but stronger - when a logistic model is used as seen in appendix C.4.

Both the measure of internal and external constraints have negative coefficients across all columns, although they are not significant across all models. This indicates that stronger constraints are related to a decrease in the likelihood that a dictator will govern over a recession. We also see that the results get stronger, particularly for civil society, the more severe a measure I use for recession. Thus, a strong civil society can serve as a hindrance to avoid the worst economic outcomes, but may be of less importance for "minor" recessions. In addition, the coefficient for the interaction is positive, and we therefore see 
that the two measures of constraints again work as substitutes; either an organized ruling coalition or a strong civil society can steer the autocrat away from the worst decisions.

According to the descriptive statistics provided in table 6.1 the set of dictatorships in the sample experience a recession of more than 6 per cent in 8 per cent of all country years. In comparison, the set of democracies experience such a recession in 3 per cent of all years. Due to the nature of the econometric set-up, we cannot perceive these numbers as constants, but they do serve as a benchmark for comparison of the effects. We look at column 6 to get a impression of the effect sizes. If we keep log of relative experience at its mean, the coefficient for civil society is -0.31 . A country will therefore experience a decrease in the likelihood of experiencing a recession with 17.5 percentage points if the strength of civil society increases by a half. This is a large, substantive effect, and indicates that autocrats are much more prone to govern over a very severe recession when civil society has been demolished. Likewise, if we keep civil society at its mean, the size of the coefficient for log of relative experience is -0.024 . Here, a halving of the relative experience is associated with a decrease in the likelihood of experiencing a severe recession of just 2 percentage points. Thus, the effect of internal constraints is negligible when civil society is relatively strong, but it is important, when civil society is weak. 
Table 6.8: Internal and external constraints and recessions in autocracies

\begin{tabular}{|c|c|c|c|c|c|c|}
\hline & $(1)$ & $(2)$ & $(3)$ & $(4)$ & $(5)$ & $(6)$ \\
\hline Log(Relative experience) & $\begin{array}{l}-0.05 \\
(0.03)\end{array}$ & $\begin{array}{c}-0.12^{* * *} \\
(0.04)\end{array}$ & $\begin{array}{l}-0.03 \\
(0.03)\end{array}$ & $\begin{array}{c}-0.06^{*} \\
(0.03)\end{array}$ & $\begin{array}{l}-0.02 \\
(0.02)\end{array}$ & $\begin{array}{c}-0.06^{* *} \\
(0.03)\end{array}$ \\
\hline Strength of civil society & $\begin{array}{l}-0.21 \\
(0.24)\end{array}$ & $\begin{array}{l}-0.13 \\
(0.24)\end{array}$ & $\begin{array}{l}-0.27 \\
(0.22)\end{array}$ & $\begin{array}{l}-0.24 \\
(0.22)\end{array}$ & $\begin{array}{c}-0.38^{*} \\
(0.19)\end{array}$ & $\begin{array}{c}-0.34^{*} \\
(0.20)\end{array}$ \\
\hline Tenure of the leader & $\begin{array}{c}0.00 \\
(0.01)\end{array}$ & $\begin{array}{c}0.00 \\
(0.01)\end{array}$ & $\begin{array}{l}-0.00 \\
(0.01)\end{array}$ & $\begin{array}{l}-0.00 \\
(0.01)\end{array}$ & $\begin{array}{c}0.00 \\
(0.00)\end{array}$ & $\begin{array}{c}0.00 \\
(0.00)\end{array}$ \\
\hline $\log (\mathrm{RE}) * \mathrm{SC}$ & & $\begin{array}{l}0.16^{* *} \\
(0.07)\end{array}$ & & $\begin{array}{c}0.07 \\
(0.05)\end{array}$ & & $\begin{array}{l}0.09^{* *} \\
(0.04)\end{array}$ \\
\hline Log(Population) & $\begin{array}{c}0.40 \\
(0.28)\end{array}$ & $\begin{array}{c}0.45 \\
(0.28)\end{array}$ & $\begin{array}{l}0.48^{* *} \\
(0.18)\end{array}$ & $\begin{array}{c}0.50^{* * *} \\
(0.18)\end{array}$ & $\begin{array}{l}0.48^{* *} \\
(0.19)\end{array}$ & $\begin{array}{c}0.50^{* * *} \\
(0.19)\end{array}$ \\
\hline Urban population (\%) & $\begin{array}{c}0.02 \\
(0.01)\end{array}$ & $\begin{array}{c}0.02 \\
(0.01)\end{array}$ & $\begin{array}{c}0.01 \\
(0.01)\end{array}$ & $\begin{array}{c}0.01 \\
(0.01)\end{array}$ & $\begin{array}{l}0.01^{*} \\
(0.01)\end{array}$ & $\begin{array}{l}0.02^{*} \\
(0.01)\end{array}$ \\
\hline Civil violence & $\begin{array}{c}0.01 \\
(0.01)\end{array}$ & $\begin{array}{l}0.01^{*} \\
(0.01)\end{array}$ & $\begin{array}{l}0.01^{* *} \\
(0.01)\end{array}$ & $\begin{array}{l}0.01^{* *} \\
(0.01)\end{array}$ & $\begin{array}{l}0.01^{* * *} \\
(0.00)\end{array}$ & $\begin{array}{c}0.01^{* * *} \\
(0.00)\end{array}$ \\
\hline Number of core members & $\begin{array}{c}-0.01^{*} \\
(0.00)\end{array}$ & $\begin{array}{c}-0.01^{* *} \\
(0.00)\end{array}$ & $\begin{array}{c}-0.01^{* *} \\
(0.00)\end{array}$ & $\begin{array}{c}-0.01^{* *} \\
(0.00)\end{array}$ & $\begin{array}{c}-0.00^{*} \\
(0.00)\end{array}$ & $\begin{array}{c}-0.00^{*} \\
(0.00)\end{array}$ \\
\hline Oil rents ( $\%$ of GDP) & $\begin{array}{r}-0.00 \\
(0.00)\end{array}$ & $\begin{array}{l}-0.00 \\
(0.00)\end{array}$ & $\begin{array}{c}-0.01^{*} \\
(0.00) \\
\end{array}$ & $\begin{array}{c}-0.01^{*} \\
(0.00)\end{array}$ & $\begin{array}{r}-0.00 \\
(0.00)\end{array}$ & $\begin{array}{r}-0.00 \\
(0.00)\end{array}$ \\
\hline Size of recession & $<0$ & $<0$ & $<-3$ & $<-3$ & $<-6$ & $<-6$ \\
\hline Sample & -Oil & -Oil & -Oil & -Oil & -Oil & -Oil \\
\hline Estimation method: Within leader & Yes & Yes & Yes & Yes & Yes & Yes \\
\hline Estimation method: Within country & Yes & Yes & Yes & Yes & Yes & Yes \\
\hline Estimation method: Within year & Yes & Yes & Yes & Yes & Yes & Yes \\
\hline Observations: & 2012 & 2012 & 2012 & 2012 & 2012 & 2012 \\
\hline Leaders: & 276 & 276 & 276 & 276 & 276 & 276 \\
\hline Countries: & 98 & 98 & 98 & 98 & 98 & 98 \\
\hline $\mathrm{R}^{2}$ & 0.35 & 0.35 & 0.34 & 0.34 & 0.31 & 0.31 \\
\hline
\end{tabular}

* $\mathrm{p}<0.1,{ }^{* *} \mathrm{p}<0.05, * * * \mathrm{p}<0.01$. Dependent variable: Likelihood of a severe recession (Penn World Tables). All right-side variables lagged by one year. Clustered standard errors in parentheses. $\mathrm{RE}=$ Relative experience, $\mathrm{SC}=$ Strength of Civil Society. 


\section{Environment for investment}

The causal mechanism presented in the theoretical framework implies that constraints on the autocrat will encourage private economic actors to engage in increased investment activity, since potential investors do not have to worry about whether the autocrat will change policies arbitrarily or are risking getting their investments expropriated. This part of the empirical chapter tests this theoretical mechanism. The following analysis looks at three different dependent variables. First, I use a measure of private investments as a share of GDP. Second, I look at foreign direct investment as a share of GDP, and third, I look at how easy it is to start a business by using data from the "Doing Business project" which provides a score from 0 (hard to start a business) to a 100 (easy to start a business). All data is provided by the World Bank. The econometric methods are similar to those used above, and, again, I use the specification in column 8 in table 6.5 .

Table 6.9 presents the results from the panel data analysis. Column 1 displays the results for private investment as a share of GDP. Strength of civil society is related to an increase in private investment. However, while the effect is substantively large, it is far from statistical significance. Likewise, we see that the measure of internal constraints, relative experience, is negatively related to private investment but far from significant. In column 2, the interaction is added. The interaction is negative and the coefficient for relative experience becomes positive. This hints at a similar mechanism as for economic growth, but all coefficients are insignificant.

In column 3 and 4 the dependent variable is foreign direct investment per capita. Strength of civil society is positive and significant at $p<0.10$, indicating that the same 
dictator has higher foreign direct investment, when civil society is strong. Contrary, relative experience is negative and insignificant. Again, I add the interaction and find that the interaction effect itself is negative - but insignificant -, and that relative experience becomes positive.

In the last two columns the dependent variable is an index for how easy it is to start a business. This variable is from "Ease of doing business index" and is chosen because it has relatively broad temporal coverage and large within country variation, which allows it to be used in a panel data regression. In column 5 , I find that both measures of constraints are related to better scores on the index, but that neither is significant. When the interaction is added in column 6 , the measure of internal constraints becomes significant at $p<0.10$, while the interaction is negative. This is in line with the theory and indicates that potential investors find it easier to start a business when the dictator faces a strong ruling elite. 
Table 6.9: Internal, external constraints and investment

\begin{tabular}{|c|c|c|c|c|c|c|}
\hline & \multicolumn{6}{|c|}{ Dependent variable: } \\
\hline & \multicolumn{2}{|c|}{ Private invest./GDP } & \multicolumn{2}{|c|}{ FDI/GDP } & \multicolumn{2}{|c|}{ Starting a business } \\
\hline & $(1)$ & $(2)$ & $(3)$ & $(4)$ & $(5)$ & $(6)$ \\
\hline $\log ($ Relative experience) & $\begin{array}{l}-0.05 \\
(0.48)\end{array}$ & $\begin{array}{c}0.67 \\
(1.09)\end{array}$ & $\begin{array}{l}-0.49 \\
(0.31)\end{array}$ & $\begin{array}{c}0.11 \\
(0.52)\end{array}$ & $\begin{array}{c}0.23 \\
(1.14)\end{array}$ & $\begin{array}{l}4.59^{*} \\
(2.62)\end{array}$ \\
\hline Strength of civil society & $\begin{array}{c}5.04 \\
(4.83)\end{array}$ & $\begin{array}{c}4.41 \\
(4.83)\end{array}$ & $\begin{array}{l}2.60^{*} \\
(1.56)\end{array}$ & $\begin{array}{l}2.41^{*} \\
(1.39)\end{array}$ & $\begin{array}{c}13.76 \\
(15.56)\end{array}$ & $\begin{array}{c}10.81 \\
(15.14)\end{array}$ \\
\hline Tenure of the leader & $\begin{array}{c}0.08 \\
(0.08)\end{array}$ & $\begin{array}{c}0.09 \\
(0.09)\end{array}$ & $\begin{array}{l}-0.08 \\
(0.07)\end{array}$ & $\begin{array}{l}-0.07 \\
(0.08)\end{array}$ & $\begin{array}{c}0.11 \\
(0.18)\end{array}$ & $\begin{array}{c}0.19 \\
(0.19)\end{array}$ \\
\hline Log of population & $\begin{array}{c}10.22 \\
(13.48)\end{array}$ & $\begin{array}{c}9.99 \\
(13.39)\end{array}$ & $\begin{array}{c}0.46 \\
(4.58)\end{array}$ & $\begin{array}{c}1.30 \\
(2.96)\end{array}$ & $\begin{array}{c}33.31 \\
(29.53)\end{array}$ & $\begin{array}{c}32.53 \\
(29.11)\end{array}$ \\
\hline Urban population ( & $(0.21)$ & $(0.21)$ & $(0.09)$ & $(0.09)$ & $(0.74)$ & $(0.74)$ \\
\hline Civil violence & $\begin{array}{l}-0.39 \\
(0.28)\end{array}$ & $\begin{array}{l}-0.41 \\
(0.28)\end{array}$ & $\begin{array}{l}-0.16 \\
(0.11)\end{array}$ & $\begin{array}{l}-0.17 \\
(0.11)\end{array}$ & $\begin{array}{l}-0.28 \\
(1.42)\end{array}$ & $\begin{array}{l}-0.19 \\
(1.42)\end{array}$ \\
\hline Number of core members & $\begin{array}{c}0.06 \\
(0.05)\end{array}$ & $\begin{array}{c}0.06 \\
(0.05)\end{array}$ & $\begin{array}{c}0.02 \\
(0.03)\end{array}$ & $\begin{array}{c}0.02 \\
(0.03)\end{array}$ & $\begin{array}{l}-0.19 \\
(0.15)\end{array}$ & $\begin{array}{l}-0.18 \\
(0.15)\end{array}$ \\
\hline Oil rents ( $\%$ of GDP) & $\begin{array}{l}-0.17 \\
(0.13)\end{array}$ & $\begin{array}{l}-0.17 \\
(0.13)\end{array}$ & $\begin{array}{l}-0.12 \\
(0.10)\end{array}$ & $\begin{array}{l}-0.12 \\
(0.10)\end{array}$ & $\begin{array}{c}0.13 \\
(0.18)\end{array}$ & $\begin{array}{c}0.12 \\
(0.18)\end{array}$ \\
\hline $\log (\mathrm{RE}) * \mathrm{SC}$ & & $\begin{array}{l}-1.32 \\
(1.68) \\
\end{array}$ & & $\begin{array}{l}-1.13 \\
(0.85) \\
\end{array}$ & & $\begin{array}{c}-6.46^{*} \\
(3.43) \\
\end{array}$ \\
\hline Estimation method: Within country & Yes & Yes & Yes & Yes & Yes & Yes \\
\hline Estimation method: Within leader & Yes & Yes & Yes & Yes & Yes & Yes \\
\hline Estimation method: Within year & Yes & Yes & Yes & Yes & Yes & Yes \\
\hline Leaders: & 173 & 173 & 270 & 270 & 106 & 106 \\
\hline Countries: & 72 & 72 & 96 & 96 & 60 & 60 \\
\hline Observations & 1,139 & 1,139 & 1,849 & 1,849 & 559 & 559 \\
\hline $\mathrm{R}^{2}$ & 0.76 & 0.76 & 0.56 & 0.56 & 0.89 & 0.89 \\
\hline
\end{tabular}


The coefficients are in the expected direction throughout the analysis, indicating that both types of constraints are related to both increased domestic private investments, an increase in foreign direct investment and a better environment for starting a business. However, I only find two significant coefficients, namely the effect of strength of civil society on FDI and of relative experience on starting a business (with the interaction). This represents a challenge to the theoretical mechanism presented in chapter 2 , and is surprising given earlier research, which finds a positive relationship between constraints on the leader and investment (Gehlbach and Keefer 2012; Nooruddin 2010).

There are various explanations for the mixed results. One explanation is that unconstrained autocrats may govern over countries that invest the same, but that the investments are wasteful. For example, Gjerløw and Knutsen (2019) find that very authoritarian countries are more likely to invest in wasteful skyscrapers. This would not be picked up by the data. Another explanation is that there are fewer observations due to missing data, and that the results would be significant if I had access to the same large datasets as for economic growth.

\subsubsection{Human development}

The analysis above shows that authoritarian leaders govern over better economic outcomes when they are constrained by a strong civil society and an organized ruling coalition. We may suspect that this results in better living conditions for the broader population. However, this is not necessarily the case. The prediction in the theoretical chapter was that external constraints would be related to better human development, while this should not be the case for internal constraints. Here, I examine how the two measures 
of constraints are related to improvements in human development. As mentioned in the data section, I focus on two types of human development, namely infant mortality and primary school enrolment.

\section{Econometric approach}

The econometric approach used in this part of the analysis is slightly different than the one used for economic outcomes. I try to use an approach, which is similar to the approach used in other previous work on human development and regime type (see for example Miller (2015), Gerring et al. (2012), Ross (2006) and Ansell (2010)). Again, I use the dynamic nature of the data and rely on a panel data model with country and leader fixed effects where the two main independent variables are lagged with one year. The analysis therefore links development outcomes to the level of constraints on the autocrat in the previous year. This enables me to look at what happens to human development when constraints on the autocrat increase or decrease in a given country. As discussed before, I look at two types of human development, namely infant mortality rate per 1,000 live births and percentage enrolment of children in school age in primary school. The analysis will look at absolute changes in the two measures of human development.

To limit the number of regression models, I will include leader and country fixed effects across all models. Furthermore, it is important to control for time effects for both of the dependent variables. There has been a global downward trend in in infant mortality rate, which likely is due to technological changes and increased focus on health outcomes amongst international donors (Gerring et al. 2012). I, therefore, use year fixed effects across all models. The specification is then; 


$$
Y_{l c t}=\beta_{1} \log \left(I_{l c t-1}\right)+\beta_{2} E_{l c t-1}+\beta_{3} X_{l c t}+\phi_{l}+\alpha_{c}+\gamma_{t}+\epsilon_{l c t}
$$

Here, the dependent variable $Y_{l c t}$ is a measure of human development. It is a function of $I$ and $E$, which are the measures of internal constraints and external constraints for leader $l$ in country $c$ in year $t$. The specification includes both country fixed effects, $\alpha_{c}$, and a control for each leader, $\phi_{l}$, and $\gamma_{t}$ which represents year fixed effects. $X_{i t}$ is a set of control variables and $\epsilon_{i t}$ is the error term. In addition to the control variables used in the analysis on economic outcomes, I add a control variable for economic growth. We know that the two measures of constraints are related to higher economic growth. Furthermore, economic growth may independently be related to improvements in human development. Thus, if I do not control for economic growth, improvements in human development outcomes may be the result of economic growth per se and not different policy priorities due to the various levels of constraints.

\section{Panel analysis}

Table 6.10 shows the results for both infant mortality and primary school enrolment. In the first six columns the dependent variable is the absolute change in infant mortality, while the dependent variable in the six last columns is the absolute change in primary school enrolment.

In column 1, I run the regression with the two main dependent variables and tenure of the leader. We see that strength of civil society is related to a year-to-year decrease in infant mortality, while the coefficient for relative experience is practically null. In column 2 , I include the interaction effect. It is seen that it is positive, but statistically insignificant. 
In column 3, I include the list of control variables. This causes the coefficient for civil society to increase in size and become statistically significant. I add the interaction effect again in column 4. It is positive and statistically significant. This indicates that there is a substitution effect for changes in infant mortality, which implies that one type of constraints is more effective, when the other is weaker. The interaction plot is seen in figure 6.9. Here, it is seen that relative experience is related to lower infant mortality, when civil society is very weak and related to higher infant mortality when civil society is strong, as predicted in chapter 4 .

In column 5, the measure of oil revenues per capita is included. This does not substantially changes the results. In column 6, I include leaders heavily dependent on natural resources, and find that the finding is somewhat weaker. Therefore, the mechanism for human development, contrary to economic growth, works for leaders dependent on natural resources.

Three other variables are significantly related to changes in infant mortality throughout the model, namely growth, civil violence, and the number of core members. It is not surprising that growth is associated with decreases in infant mortality, while civil violence is associated with higher infant mortality. However, it is somewhat surprising that an expansion of the size of the cabinet is associated with a decrease in infant mortality. This may be because more people are included in the elite and, therefore, receive rents from being in office, which they then can redistribute through a patronage system (De Mesquita and Smith 2011).

The results for infant mortality confirm the theoretical expectations. The same 
autocrat governs over larger year-to-year reductions in infant mortality, when he faces a strong civil society which can demand better services and redistribution, and threaten the autocrat if these demands are not met. On the contrary, relative experience is generally not related to lower infant mortality. Only in cases of a very weak civil society does an organized elite seem to be related to reductions in infant mortality. A strong ruling coalition can therefore help avoiding the worst outcomes, but a strong civil society is crucial for reducing infant mortality. 
Table 6.10: Internal and external constraints and human development in autocracies

\begin{tabular}{|c|c|c|c|c|c|c|c|c|c|c|c|c|}
\hline & \multicolumn{12}{|c|}{ Dependent variable: } \\
\hline & \multicolumn{6}{|c|}{ Change in infant mortality } & \multicolumn{6}{|c|}{ Change in primary school enrolment } \\
\hline & $(1)$ & $(2)$ & (3) & $(4)$ & $(5)$ & $(6)$ & $(7)$ & $(8)$ & (9) & $(10)$ & $(11)$ & $(12)$ \\
\hline $\log$ (Relative experience) & $\begin{array}{c}0.09 \\
(0.23)\end{array}$ & $\begin{array}{l}-0.07 \\
(0.25)\end{array}$ & $\begin{array}{l}-0.01 \\
(0.17)\end{array}$ & $\begin{array}{l}-0.24 \\
(0.20)\end{array}$ & $\begin{array}{l}-0.23 \\
(0.20)\end{array}$ & $\begin{array}{l}-0.19 \\
(0.15)\end{array}$ & $\begin{array}{l}-0.13 \\
(0.25)\end{array}$ & $\begin{array}{l}-0.26 \\
(0.31)\end{array}$ & $\begin{array}{l}-0.05 \\
(0.23)\end{array}$ & $\begin{array}{l}-0.15 \\
(0.32)\end{array}$ & $\begin{array}{l}-0.26 \\
(0.37)\end{array}$ & $\begin{array}{c}0.31 \\
(0.28)\end{array}$ \\
\hline Strength of civil society & $\begin{array}{c}-1.80^{* *} \\
(0.71)\end{array}$ & $\begin{array}{c}-1.59^{* *} \\
(0.78)\end{array}$ & $\begin{array}{c}-2.28^{* * *} \\
(0.69)\end{array}$ & $\begin{array}{c}-1.98^{* * *} \\
(0.73)\end{array}$ & $\begin{array}{c}-2.13^{* * *} \\
(0.77)\end{array}$ & $\begin{array}{c}-1.54^{*} \\
(0.85)\end{array}$ & $\begin{array}{c}4.10^{* * *} \\
(1.28)\end{array}$ & $\begin{array}{c}4.27^{* * *} \\
(1.46)\end{array}$ & $\begin{array}{c}4.40^{* * *} \\
(1.47)\end{array}$ & $\begin{array}{c}4.53^{* * *} \\
(1.66)\end{array}$ & $\begin{array}{c}4.51^{* * *} \\
(1.58)\end{array}$ & $\begin{array}{l}3.60^{* *} \\
(1.42)\end{array}$ \\
\hline Tenure of the leader & $\begin{array}{c}0.01 \\
(0.03)\end{array}$ & $\begin{array}{c}0.01 \\
(0.03)\end{array}$ & $\begin{array}{c}-0.002 \\
(0.03)\end{array}$ & $\begin{array}{c}-0.001 \\
(0.03)\end{array}$ & $\begin{array}{l}-0.01 \\
(0.03)\end{array}$ & $\begin{array}{c}-0.04^{*} \\
(0.02)\end{array}$ & $\begin{array}{c}0.02 \\
(0.05)\end{array}$ & $\begin{array}{c}0.02 \\
(0.05)\end{array}$ & $\begin{array}{c}0.02 \\
(0.04)\end{array}$ & $\begin{array}{c}0.02 \\
(0.05)\end{array}$ & $\begin{array}{c}0.03 \\
(0.04)\end{array}$ & $\begin{array}{c}0.04 \\
(0.04)\end{array}$ \\
\hline $\log (\mathrm{RE}) * \mathrm{SC}$ & & $\begin{array}{c}0.37 \\
(0.27)\end{array}$ & & $\begin{array}{l}0.56^{* *} \\
(0.27)\end{array}$ & $\begin{array}{c}0.44 \\
(0.27)\end{array}$ & & & $\begin{array}{c}0.29 \\
(0.61)\end{array}$ & & $\begin{array}{c}0.23 \\
(0.65)\end{array}$ & $\begin{array}{c}0.62 \\
(0.67)\end{array}$ & \\
\hline Growth & & & $\begin{array}{c}-0.01^{* *} \\
(0.004)\end{array}$ & $\begin{array}{l}-0.01^{*} \\
(0.004)\end{array}$ & $\begin{array}{l}-0.01^{*} \\
(0.01)\end{array}$ & $\begin{array}{l}-0.01 \\
(0.01)\end{array}$ & & & $\begin{array}{c}0.01 \\
(0.02)\end{array}$ & $\begin{array}{c}0.01 \\
(0.02)\end{array}$ & $\begin{array}{c}0.02 \\
(0.02)\end{array}$ & $\begin{array}{c}0.01 \\
(0.02)\end{array}$ \\
\hline Log of population & & & $\begin{array}{l}-0.20 \\
(0.74)\end{array}$ & $\begin{array}{l}-0.20 \\
(0.73)\end{array}$ & $\begin{array}{l}-0.06 \\
(0.71)\end{array}$ & $\begin{array}{l}-0.79 \\
(1.31)\end{array}$ & & & $\begin{array}{l}-0.59 \\
(0.72)\end{array}$ & $\begin{array}{l}-0.59 \\
(0.72)\end{array}$ & $\begin{array}{c}0.17 \\
(0.85)\end{array}$ & $\begin{array}{c}1.99 \\
(2.98)\end{array}$ \\
\hline Urban population (\%) & & & $\begin{array}{l}0.11^{* *} \\
(0.05)\end{array}$ & $\begin{array}{l}0.12^{* *} \\
(0.05)\end{array}$ & $\begin{array}{l}0.10^{* * *} \\
(0.05)\end{array}$ & $\begin{array}{c}0.06 \\
(0.07)\end{array}$ & & & $\begin{array}{l}-0.02 \\
(0.04)\end{array}$ & $\begin{array}{l}-0.02 \\
(0.04)\end{array}$ & $\begin{array}{l}-0.03 \\
(0.04)\end{array}$ & $\begin{array}{l}-0.03 \\
(0.06)\end{array}$ \\
\hline Civil violence & & & $\begin{array}{l}0.11^{*} \\
(0.06)\end{array}$ & $\begin{array}{l}0.11^{*} \\
(0.06)\end{array}$ & $\begin{array}{l}0.16^{* *} \\
(0.07)\end{array}$ & $\begin{array}{c}0.09 \\
(0.07)\end{array}$ & & & $\begin{array}{l}-0.04 \\
(0.07)\end{array}$ & $\begin{array}{l}-0.04 \\
(0.07)\end{array}$ & $\begin{array}{l}-0.06 \\
(0.08)\end{array}$ & $\begin{array}{l}-0.01 \\
(0.07)\end{array}$ \\
\hline Number of core members & & & $\begin{array}{l}-0.02 \\
(0.01)\end{array}$ & $\begin{array}{l}-0.02 \\
(0.01)\end{array}$ & $\begin{array}{l}-0.02 \\
(0.01)\end{array}$ & $\begin{array}{l}-0.02 \\
(0.01)\end{array}$ & & & $\begin{array}{l}-0.06 \\
(0.03)\end{array}$ & $\begin{array}{l}-0.06 \\
(0.03)\end{array}$ & $\begin{array}{l}-0.05 \\
(0.04)\end{array}$ & $\begin{array}{l}-0.06 \\
(0.04)\end{array}$ \\
\hline Oil rents ( $\%$ of GDP) & & & & & $\begin{array}{l}-0.01 \\
(0.01)\end{array}$ & $\begin{array}{l}0.004 \\
(0.02)\end{array}$ & & & & & $\begin{array}{c}0.02 \\
(0.02)\end{array}$ & $\begin{array}{l}-0.02 \\
(0.03)\end{array}$ \\
\hline Sample: & All & All & All & All & All & - Oil & All & All & All & All & All & -Oil \\
\hline Estimation method: Within country & Yes & Yes & Yes & Yes & Yes & Yes & Yes & Yes & Yes & Yes & Yes & Yes \\
\hline Estimation method: Within leader & Yes & Yes & Yes & Yes & Yes & Yes & Yes & Yes & Yes & Yes & Yes & Yes \\
\hline Estimation method: Within year & Yes & Yes & Yes & Yes & Yes & Yes & Yes & Yes & Yes & Yes & Yes & Yes \\
\hline Leaders: & 373 & 373 & 373 & 373 & 325 & 294 & 190 & 190 & 190 & 190 & 181 & 161 \\
\hline Countries: & 107 & 107 & 107 & 107 & 105 & 98 & 88 & 88 & 88 & 88 & 88 & 79 \\
\hline Observations & 2,898 & 2,898 & 2,891 & 2,891 & 2,477 & 2,074 & 1,056 & 1,056 & 1,055 & 1,055 & 993 & 848 \\
\hline $\mathrm{R}^{2}$ & 0.60 & 0.60 & 0.62 & 0.62 & 0.59 & 0.57 & 0.31 & 0.31 & 0.32 & 0.32 & 0.33 & 0.34 \\
\hline
\end{tabular}


Figure 6.9: Interaction plot for the effect of the level of constraints on changes in infant mortality
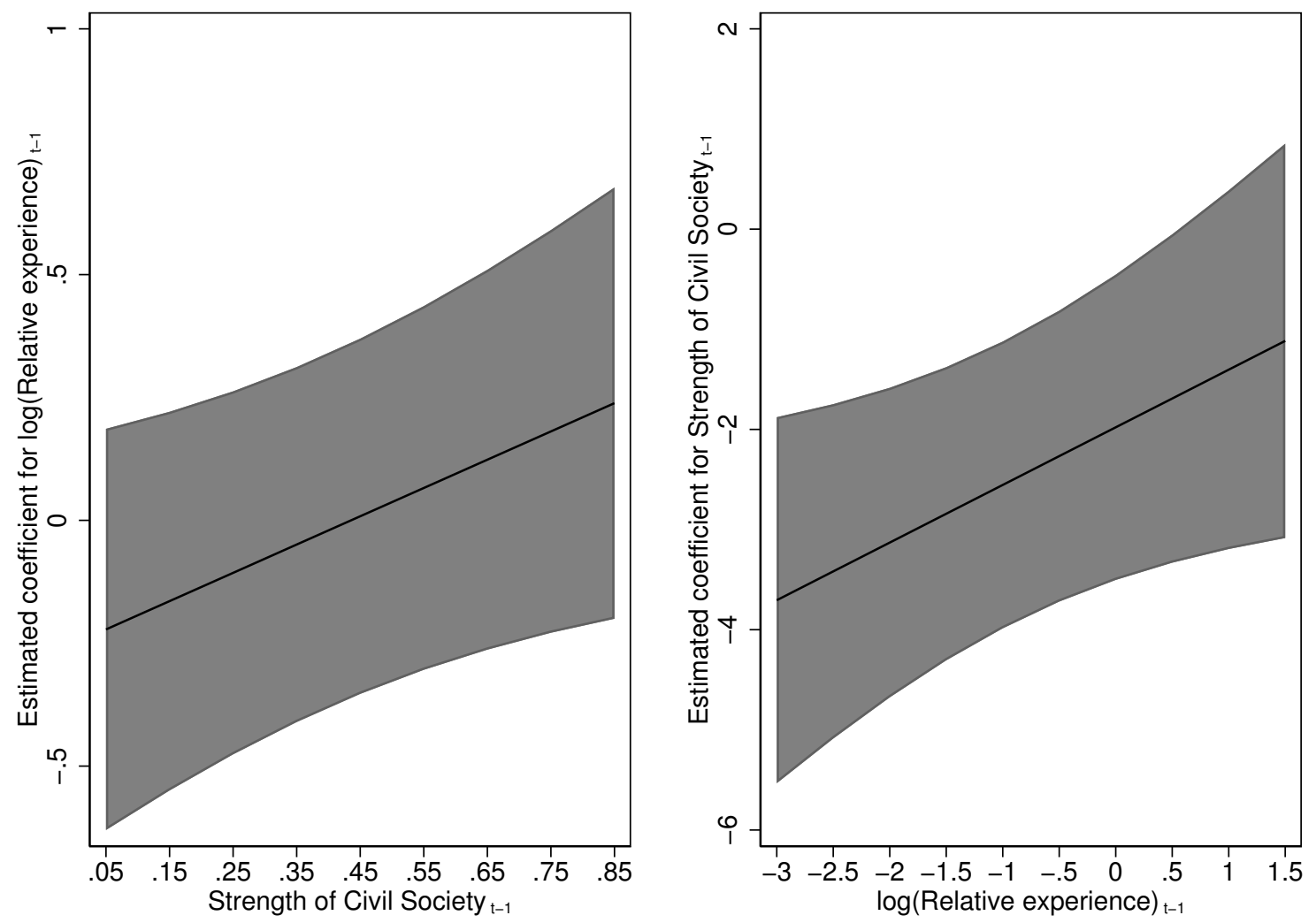

Notes: Whiskers represents 95 per cent confidence intervals. Based on model 5 in table 6.10 
Figure 6.10: Interaction plot for the effect of the level of constraints on changes in primary school enrolment
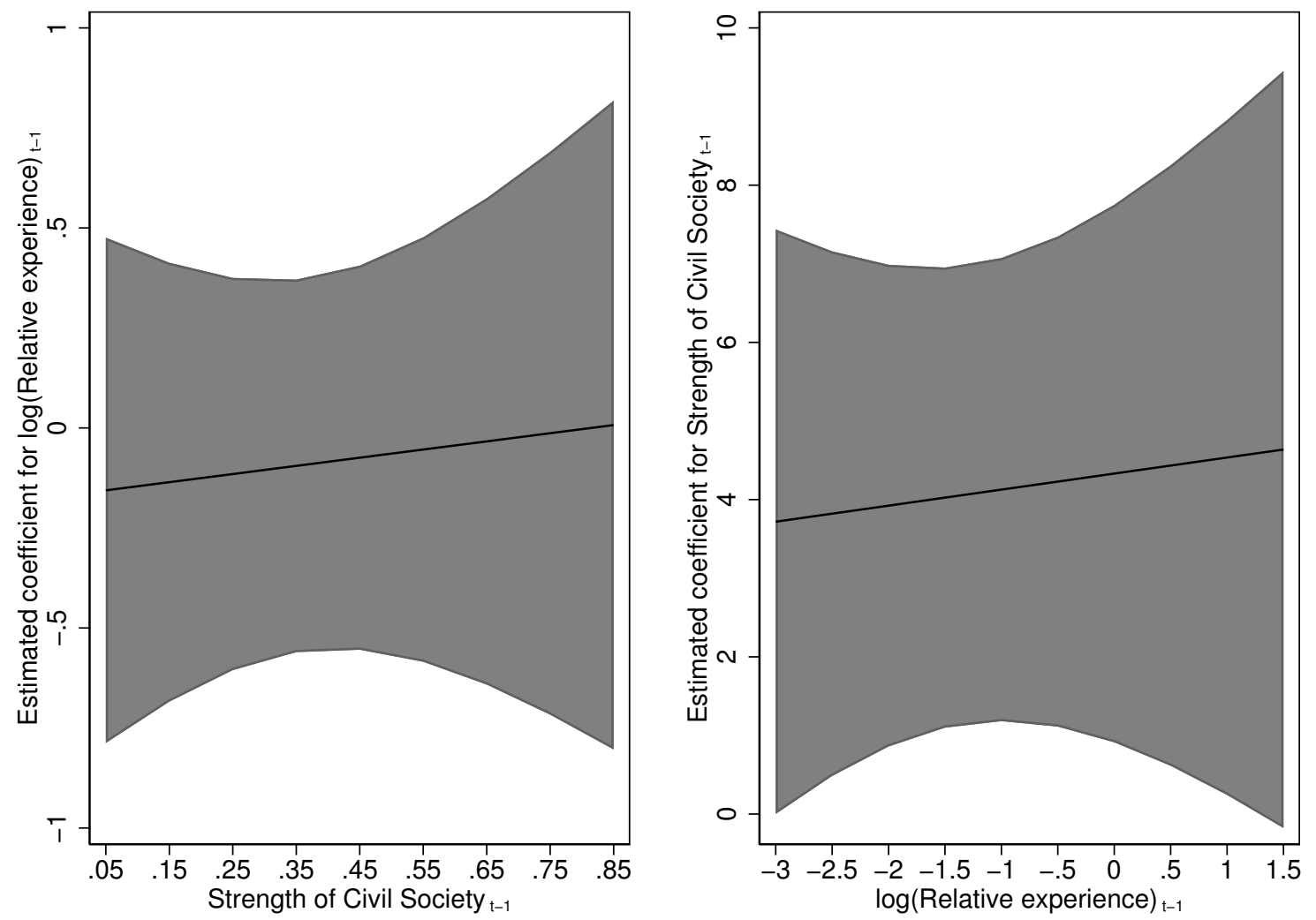

Notes: Whiskers represents 95 per cent confidence intervals. Based on model 11 in table 6.10

Next, I look at primary school enrolment in the last six columns of table 6.10. It should be noted that the number of observations drops drastically due to missing information on the dependent variable. Again, I look at year-to-year changes in the measure of human development, viz. the percentage of kids enrolled in primary school.

In column $7-12$, we see that strength of civil society is positively and significantly related to year-to-year changes in primary school enrolment across all specifications. The coefficient for relative experience is practically null. No other variables are significantly related to changes in primary school enrolment. The interaction between the measure 
of internal and external constraints is positive but insignificant. The interaction plot is shown in figure 6.10, and we see that the two measures of constraints hardly interact.

Overall, the results are in line with the predictions put forward in the theoretical chapter. We see that external constraints are strongly associated with better human development outcomes. The same autocrat will therefore govern over a society that is more just and takes better care of the poorest citizens, when he faces a strong and organized civil society. On the other hand, there is little association between having an organized and experienced ruling coalition and better outcomes in terms of human development. For infant mortality we see that when civil society is very weak an organized ruling coalition may have a positive effect. In the absence of other constraints a strong ruling coalition therefore can avoid the worst policy disasters.

The effects sizes for strength of civil society on human development are substantively large. For example, going from 0 to 1 on strength of civil society is associated with a yearly decrease in infant mortality rate of $-2,13$ infants per 1,000 infants (column 5 table 6.10). In comparison, the difference between Kyrgyzstan (15.7) and Denmark (4.2) is 11.5. Thus, the effects sizes are not only statistically significant, they are also of huge substantial significance and underline the importance of having a strong civil society.

\section{Redoing the analysis under democracy}

As discussed beforehand, the theoretical predictions should be unique to autocracies. Widespread human misery is unpopular and democratically elected leaders may be more likely to concern themselves with issues of human development than autocrats, since they want to be re-elected (Gerring et al. 2012). They should do so independent of the level 
of constraints, since this does not matter for their chances of re-election. To be sure, authoritarian leaders may also be concerned with the potentially destabilizing effects of widespread poverty, but they are not forced to act unless their hold to power depends on it; which is more likely when other actors are strong and can threaten the dictator.

In table 6.11. I replicate table 6.10. The coefficients for relative experience are small and statistically insignificant, indicating that there is no relationship between this variable and the two measures of human development. This is similar to the results for autocracy.

Strikingly, the coefficients for civil society are also small and insignificant. An objection to this finding is that democracies are richer and more developed, making in harder to improve development outcomes due to ceiling effects. However, the findings hold up, when I reduce the sample to poor democracies. This is seen in appendix C.5 where I run the analysis for democracies with a GDP per capita of less than 12,000 USD. On the whole, I find no evidence of a relationship between the two types of constraints and better human development outcomes in democracies. 
Table 6.11: Internal and external constraints and human development in democracies

\begin{tabular}{|c|c|c|c|c|c|c|c|c|c|c|c|c|}
\hline & \multicolumn{12}{|c|}{ Dependent variable: } \\
\hline & \multicolumn{6}{|c|}{ Change in infant mortality } & \multicolumn{6}{|c|}{ Change in primary school enrolment } \\
\hline & $(1)$ & $(2)$ & (3) & $(4)$ & $(5)$ & $(6)$ & (7) & $(8)$ & (9) & $(10)$ & (11) & $(12)$ \\
\hline $\log$ (Relative experience) & $\begin{array}{c}0.03 \\
(0.04)\end{array}$ & $\begin{array}{c}0.14 \\
(0.13)\end{array}$ & $\begin{array}{c}0.03 \\
(0.04)\end{array}$ & $\begin{array}{c}0.07 \\
(0.12)\end{array}$ & $\begin{array}{c}0.08 \\
(0.13)\end{array}$ & $\begin{array}{c}0.04 \\
(0.04)\end{array}$ & $\begin{array}{c}0.55^{* * *} \\
(0.19)\end{array}$ & $\begin{array}{c}1.03 \\
(0.75)\end{array}$ & $\begin{array}{c}0.48^{* *} \\
(0.19)\end{array}$ & $\begin{array}{c}0.65 \\
(0.71)\end{array}$ & $\begin{array}{c}0.80 \\
(0.71)\end{array}$ & $0.36^{* *}$ \\
\hline Strength of civil society & $\begin{array}{l}-0.38 \\
(0.23)\end{array}$ & $\begin{array}{c}-0.40^{*} \\
(0.23)\end{array}$ & $\begin{array}{l}-0.33 \\
(0.23)\end{array}$ & $\begin{array}{l}-0.34 \\
(0.23)\end{array}$ & $\begin{array}{l}-0.23 \\
(0.23)\end{array}$ & $\begin{array}{l}-0.27 \\
(0.22)\end{array}$ & $\begin{array}{c}0.87 \\
(1.21)\end{array}$ & $\begin{array}{c}0.80 \\
(1.19)\end{array}$ & $\begin{array}{c}1.42 \\
(1.37)\end{array}$ & $\begin{array}{c}1.40 \\
(1.35)\end{array}$ & $\begin{array}{c}1.04 \\
(1.40)\end{array}$ & $\begin{array}{c}0.74 \\
(1.42)\end{array}$ \\
\hline Tenure of the leader & $\begin{array}{c}0.01 \\
(0.01)\end{array}$ & $\begin{array}{c}0.01 \\
(0.01)\end{array}$ & $\begin{array}{c}0.01 \\
(0.01)\end{array}$ & $\begin{array}{c}0.01 \\
(0.01)\end{array}$ & $\begin{array}{c}0.01 \\
(0.01)\end{array}$ & $\begin{array}{c}0.01 \\
(0.01)\end{array}$ & $\begin{array}{c}0.13^{* *} \\
(0.05)\end{array}$ & $\begin{array}{c}0.13^{* *} \\
(0.05)\end{array}$ & $\begin{array}{c}0.13^{* *} \\
(0.05)\end{array}$ & $\begin{array}{c}0.13^{* *} \\
(0.05)\end{array}$ & $\begin{array}{c}0.13^{* *} \\
(0.05)\end{array}$ & $\begin{array}{c}0.10^{* *} \\
(0.05)\end{array}$ \\
\hline $\log (\mathrm{RE}) * \mathrm{SC}$ & & $\begin{array}{l}-0.13 \\
(0.13)\end{array}$ & & $\begin{array}{l}-0.05 \\
(0.14)\end{array}$ & $\begin{array}{l}-0.04 \\
(0.14)\end{array}$ & & & $\begin{array}{l}-0.55 \\
(0.82)\end{array}$ & & $\begin{array}{l}-0.19 \\
(0.79)\end{array}$ & $\begin{array}{l}-0.35 \\
(0.77)\end{array}$ & \\
\hline Growth & & & -0.002 & -0.002 & -0.001 & -0.001 & & & -0.02 & -0.02 & -0.02 & $-0.03^{*}$ \\
\hline & & & $(0.004)$ & $(0.004)$ & $(0.005)$ & $(0.005)$ & & & $(0.02)$ & $(0.02)$ & $(0.02)$ & $(0.02)$ \\
\hline Log of population & & & -0.75 & -0.74 & -0.83 & -0.80 & & & $-7.87^{* * *}$ & $-7.81^{* * *}$ & $-7.29^{* *}$ & $-7.39^{* * *}$ \\
\hline & & & $(0.62)$ & $(0.61)$ & $(0.62)$ & $(0.64)$ & & & $(2.89)$ & $(2.89)$ & $(2.89)$ & $(2.80)$ \\
\hline Urban population (\%) & & & $0.07^{* * *}$ & $0.07^{* * *}$ & $0.07^{* * *}$ & $0.07^{* * *}$ & & & -0.03 & -0.04 & -0.03 & -0.03 \\
\hline & & & $(0.03)$ & $(0.03)$ & $(0.02)$ & $(0.03)$ & & & $(0.04)$ & $(0.04)$ & $(0.04)$ & $(0.03)$ \\
\hline Civil violence & & & -0.05 & -0.05 & -0.04 & -0.04 & & & 0.23 & 0.23 & 0.23 & 0.22 \\
\hline Number of core members & & & 0.001 & 0.001 & 0.002 & 0.001 & & & 0.02 & 0.02 & 0.03 & 0.03 \\
\hline & & & $(0.003)$ & $(0.003)$ & $(0.003)$ & $(0.003)$ & & & $(0.02)$ & $(0.02)$ & $(0.02)$ & $(0.02)$ \\
\hline Oil rents (\% of GDP) & & & & & $-0.02^{*}$ & -0.01 & & & & & 0.07 & 0.09 \\
\hline & & & & & $(0.01)$ & $(0.01)$ & & & & & $(0.04)$ & $(0.08)$ \\
\hline Sample: & All & All & All & All & All & -Oil & All & All & All & All & All & -Oil \\
\hline Estimation method: Within leader & Yes & Yes & Yes & Yes & Yes & Yes & Yes & Yes & Yes & Yes & Yes & Yes \\
\hline Estimation method: Within year & Yes & Yes & Yes & Yes & Yes & Yes & Yes & Yes & Yes & Yes & Yes & Yes \\
\hline Leaders: & 685 & 685 & 685 & 685 & 618 & 617 & 433 & 433 & 433 & 433 & 432 & 432 \\
\hline Countries: & 108 & 108 & 108 & 108 & 101 & 101 & 47 & 47 & 47 & 47 & 46 & 46 \\
\hline Observations & 3,083 & 3,083 & 2,938 & 2,938 & 2,786 & 2,706 & 1,664 & 1,664 & 1,624 & 1,624 & 1,608 & 1,552 \\
\hline $\mathrm{R}^{2}$ & 0.88 & 0.88 & 0.89 & 0.89 & 0.90 & 0.90 & 0.37 & 0.37 & 0.38 & 0.38 & 0.37 & 0.35 \\
\hline
\end{tabular}




\subsection{Conclusion}

As argued in the beginning of this chapter, there is surprisingly little existing research on economic development in autocracies. Furthermore, there is almost no research that investigates patterns over time within leader. This chapter presents and uses a new dataset on political elites in both autocracies and democracies. The new dataset enables me to perceive the tenure of an autocrat as a process where the level of constraints varies over time. Overall, the findings in this chapter provides strong support for the theory outlined in the previous chapters.

In the first part of the analysis, I find that autocrats who are constrained are held accountable for bad economic outcomes. Autocrats who face an organized and experienced ruling elite and/or a strong civil society are more likely to be punished and removed from office in the aftermath of a severe economic recession. On the other hand, we see that powerful autocrats have little to fear from ruining their country's economy. The chapter starts with a quote from Robert Mugabe, where he - in the midst of an economy crisis - claims that Zimbabwe has one of the strongest economies in Africa. This exemplifies this finding. Very powerful dictators may not care or even be unaware of the calamities taking place in their country.

In the second part of the analysis, I show that there is a positive relationship between constraints on the autocrat and economic growth. This suggests that there are multiple paths to economic success in authoritarian regimes. Both regimes with a an experienced ruling coalition and regimes with a strong civil society can implement policies beneficial for economic development. However, dictators who are not held accountable for their 
actions will fare badly economically, and the population is more likely to experience a stark decline in living standards. Combined with the first finding, this indicate that there is a self-reinforcing mechanism. A lack of constraints on the autocrat causes bad economic results, but since unconstrained autocrats are not punished, they will survive and cause even worse outcomes. This helps explaining why growth rates are dispersed for autocracies. Furthermore, we see see that the two types of constraints are not related to economic growth in democracies.

In the last part of the analysis, I find that only external constraints are related to better human development outcomes. Thus, an oligarchic elite may help foster economic growth, but this will be of little benefit to the poorest in a country. A strong civil society is needed to ensure that the gains are redistributed to the wider population. There is very little literature on patterns of inequality in authoritarian regimes. The analysis presented here may offer some insight into why some authoritarian countries are more unequal than other.

The previous chapter outlined four types of dictatorships, namely one-man, machine, Goliath and balanced, and argued that the same autocrat could belong to different groups over the span of his rule. The analysis show that it matters which group a autocrat belongs to. There are multiple paths to economic success in authoritarian regimes; both machine-regimes, such as China, and regimes with some degree of civil society, such as Singapore or Malaysia, can implement policies beneficial for economic development. However, only regimes with a strong civil society are better at promoting human development. At last, we see that one-man regimes without any constraints will fare badly economically and that the population in these countries are more likely to 
experience stark declines in living standards.

The analyses presented here have limitations. First and most important, there are concerns with endogeneity, thus it may be that growth also affects the level of constraints. I discuss this to some degree, but this is insufficient to counter these concerns. Having a very tight causal identification strategy with this question is challenging. The analysis relies on different econometric methods to triangulate the results. However, as is practice, causal interpretations should be restrained.

Another concern is that I am unable to trace the full causal mechanism, and that I do not systematically test all aspects. The chapter provides some proof of preference diversification, and relates the two measures of constraints to investment and environment for conducting business. However, it does not directly test the third channel, namely a more competent elite. In future versions of the dataset presented in this chapter, I plan to include a measure of competence or education for ministers, which allows me to test whether they become less competent over time.

In addition, not all readers may be satisfied with the two measures of constraints and convinced that they capture the theoretical concepts. For example, it may be an issue that ministerial rotation is measured annually and that I include a broad section of the cabinet when constructing the measure. Furthermore, the measure of civil society is very broad, and does not capture that mass threats can be sudden and arise spontaneously. In defence of the two measures, it is worth nothing that while both may be deemed somewhat imperfect, they constitute a substantial improvement compared to existing measures. Both are measured on a year-to-year basis and have worldwide coverage, which allows me to 
take a dynamic approach. Furthermore, they are analytically separable from the outcomes of interest, and they are based on the concept of isolation which is found throughout the literature. Nonetheless, further work may be needed, and I could, for example, separate out different types of cabinet members, and see how they relate to economic development. I will go further into discussing the two types of constraints in the remaining chapters. 
People want visible and immediate changes, but that is difficult to do. There is an accumulating frustration. Whether one was for or against the revolution, people now ask, "Did we really have a revolution'? Was there a popular uprising?"

- Roza Otunbayeva, president of Kyrgyzstan

2010-2011, in Huskey 2005

\section{Unsuccessful revolutions and public spending patterns: Evidence from The Tulip Revolution}

\section{Contents}

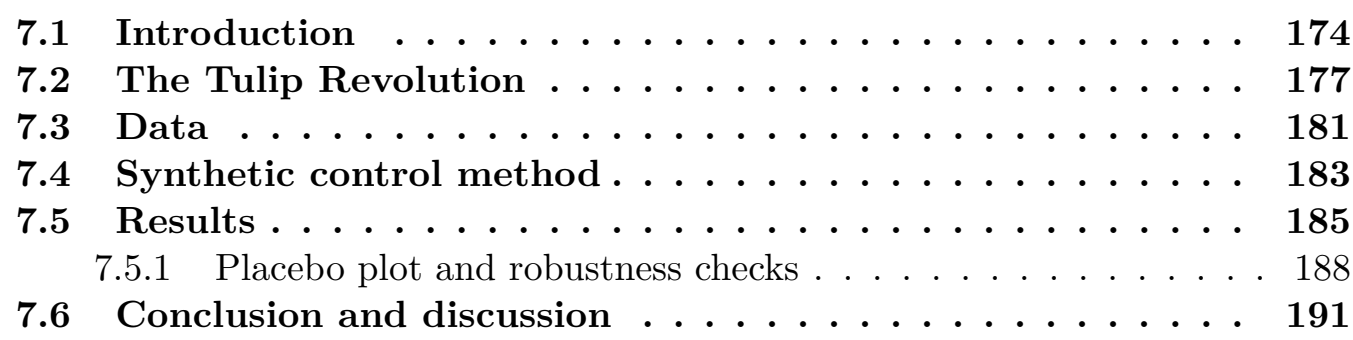

\section{$7.1 \quad$ Introduction}

In March 2005 protesters stormed the government building in Bishkek, Kyrgyzstan, and forced the Kyrgyz president Askar Akayev to flee to Moscow. This event is commonly known as the "Tulip revolution". Akayev resigned shortly thereafter. In his wake power was peacefully transferred and an acting prime minister was appointed (Radnitz 2006). Nonetheless, Kyrgyzstan did not become a full democracy. Instead, one authoritarian 
elite was replaced with another and we merely saw a transfer of power to another autocrat instead of real democratization (Kalandadze and Orenstein 2009, Kennedy 2014; PopEleches and Robertson 2014; Radnitz 2006). This did not entail that nothing changed; Political life was revitalized, old relationships were broken, and there was a real competition for power even though it was not solely through democratic means (Bunce and Wolchik 2011). While revolutions hardly can be perceived as exogenous events, there is evidence which suggests that revolutions often are unexpected and surprises both the citizens and the regime (Bunce and Wolchik 2011; Kuran 1991a; Kuran 1995). This can be referred back to the theory presented in chapter 2, where I argued that a group is more powerful, when it can act in concert. Thus, a revolution can be seen as shock to the level of external constraints that dramatically alters the power in favour of civil society and, thereby, forces the autocratic regime to become more responsive towards its citizens. The expectation is therefore that spending on human development increases in the aftermath of a revolution even if the revolution does not result in democratization.

In the previous chapter, I investigated how the two measures of constraints are related to economic development using cross-national data. In this chapter, I will mainly focus on a single case, namely Kyrgyzstan before and after the 2005 Tulip Revolution. Furthermore, this chapter will primarily explore the role of external constraints and devotes less attention to internal constraints. The main methodological approach used in this chapter is synthetic control method (SCM), which is advantageous because it allows me to bridge qualitative and quantitative research and provides a systematic way to choose a comparison unit (Abadie et al. 2015). The case of Kyrgyzstan is advantageous for several reasons. An 
unexpected revolution took place where the masses suddenly took to the streets and played a pivotal role in ousting the autocrat (Bunce and Wolchik 2011). Nonetheless, democracy did not flourish, and instead we saw a "a reorganization of government" (Juraev 2008; Wood 2006). This sets Kyrgyzstan apart from the other contemporary revolutions in Serbia, Georgia, and Ukraine where there was a real transition of power and democratization. Thus, we stay firmly within the authoritarian framework, but with a strengthened civil society. Furthermore, there is a sample of neighbouring post-Soviet countries which are (relatively) comparable to Kyrgyzstan on important factors such as history and geopolitical environment. This enables me to conduct a comparative study. Furthermore, enough time has passed to enable a systematic study. Overall, the results show that government spending on health care and primary education spiked in Kyrgyzstan as a result of the Tulip Revolution, but that there was little improvement in child mortality rates and primary school enrolment.

An issue with the study is that revolutions are modular in nature. Thus, the instance of a revolution in one country increase the likelihood that a revolution will happen elsewhere in the region (Beissinger 2007). This violates the SUTVA-assumption and makes it difficult to gain a precise estimate of the effect of The Tulip Revolution on human development outcomes. However, if anything, the estimates should be downward biased. Elites in the region may try to prevent such challenges by accommodating the wishes of the population and thus invest in broad based human development.

The remainder of the chapter is split into five parts. First, I discuss the case of Kyrgyzstan and the Tulip Revolution. Second, I put forward the data sources used in 
the analysis. Third, I describe the SCM. Fourth, I present the results and analyse the patterns. At last, I conclude on the chapter.

\subsection{The Tulip Revolution}

There is a breadth of literature discussing the causes and the effects of the "colour revolutions" (Beissinger 2007; Bunce and Wolchik 2011; Kalandadze and Orenstein 2009; Kennedy 2014) The term "colour revolutions" refers to the 2000 Serbian Bulldozer Revolution, the 2003 Rose Revolution in Georgia, Ukraine's Orange Revolution in 2004, and the Kyrgyz Tulip Revolution (Tucker 2007). While most scholars argue that the revolutions in Serbia, Georgia and Ukraine resulted in some degree of democratization, the case of Kyrgyzstan is less rosy and is often being characterized as an "unsuccessful revolution" (Freedman 2009; Radnitz 2006)

The political context is important to understanding the impact of The Tulip Revolution. Kyrgyzstan is a poor, post-communist, and predominantly Muslim country located in one of the most autocratic regions of the world. Kyrgyzstan declared independence from the Soviet Union in 1991 under the helm of Askaer Akaev, a physicist and chair of the Kyrgyz Academy of Sciences. He was, contrary to most other leaders in the region, a non-communist, and the transition therefore produced a sharp break from Communist Party Rule (Bunce and Wolchik 2011). Akaev began his rule as a liberal reformer, and carried out a liberalization of the political system, resulting in Kyrgyzstan being known as an "island of democracy" in Central Asia (Anderson 1999). However, Akaev's commitment to democracy and capitalism didn’t run deep, and he soon began to undermine democracy by expanding presidential powers, harassing opponents and flawing elections. Thus, 
Kyrgyzstan reverted to the the level of democracy of its neighbours, and by the turn of the millennium Kyrgyzstan placed itself firmly within the authoritarian camp (Bunce and Wolchik 2011; Collins 2011; Freedman 2009). Akaev did not only turn antidemocratic, but also became deeply corrupt. He relied on patronage networks and used the office to enrich his family and friends by appointing them to public office and by granting them monopolies. This caused the state institutions to grow more dysfunctional (Collins 2011), causing rival elites and civil society to turn against him. Kyrgyzstan lacked a strong standing opposition, but witnessed a flurry of new parties in the months leading up to the parliamentary elections of 2005. The most important group was the People's Movement of Kyrgyzstan (NDK) which was formed by nine small parties in September of 2004 (Radnitz 2006). The parliamentary election on the 27th of February 2005, where pro-Akayev candidates fared well, served as the catalyst for the revolution (Tucker 2007). People began to gather in small protests on behalf of individual candidates who had been disqualified or performed below expectations. The first large scale demonstrations took place in the southern province of Jalabad on March 3rd (Radnitz 2006). The protests grew larger and the protesters established control over Jalalabad, Osh, and other parts of the South. The protest were ad hoc and unplanned and took both opposition parties and civil organizations by surprise (Huskey 2005, Radnitz 2006). Roza Otunbayeva, president of Kyrgyzstan 2010-2011 and one of the opposition leaders, said in an interview that:

"Those of us in the opposition tried to lead this uprising, but we were often left in its wake. We didn't appreciate the degree of anger of the population, and the people passed us by. They decided to act, and we only appeared on the scene later" (Huskey 2005, p. 485). 
On March 13, the second round of the parliamentary elections took place. Even though some opposition leaders won their districts, the opposition still complained about electoral fraud. This galvanized the protest, and the protesters repelled the police and took over most of the southern part of Kyrgyzstan. Akaev's power had begun to crumble and he lost control over key ministries. The opposition and the NDK then began to mount protests in the capital Bishkek. Here, NDK leaders, unaffiliated politicians, NGO activists, businessmen, and activists from other regions formed a temporary alliance. On March 24th over ten thousand protesters gathered in Bishkek. The crowd then broke into the White House where Akaev lived, sealing the fate of Akaev. He fled to Russia and resigned shortly thereafter.

The main concern of this chapter is, however, not the revolution or the causes of the revolution, but the aftermath of the revolution. The opposition took power, set up an interim government and Kurmanbek Bakiyev, a former prime minister during Akaev, was made acting prime minister and acting president by the interim administration. His government also included other former members of Akaev's inner circle (Nyrup and Bramwell 2020; Wood 2006). Bakiev's interim government that followed the revolution soon faced the need to legitimize itself beyond its revolutionary credentials, and Bakiev therefore called a presidential election. The referendum was more a referendum on Bakiev than a competitive election, and Bakiev won it in a landslide, ending the interim period.

According to observers of Kyrgyz politics the period under Bakiyev did not result in a more democratic political system. Wood (2006, p. 45) writes that the Tulip Revolution was "a risorgimento - a reorganization of government - rather than a conventionally defined 
revolution", and Juraev (2008, p. 257) argues that "the post-2005 political developments seemed to give little optimism to those who believed in the democratic nature of the revolution. The long-debated constitutional reform proved rather to be a political bargaining between elite leaders". These views are supported by more quantitative and comparative studies. Kalandadze and Orenstein (2009) classify the Tulip Revolution in Kyrgyzstan as a "successful electoral revolution without democratic improvement" based on data from Freedom in the World (2007). Furthermore, they argue that the revolution did not resolve deeper issues of corruption, clientelism, and underdeveloped political parties. Likewise, Kennedy (2014) uses a synthetic control design to see how the Tulip Revolution and other revolutions affected political rights and corruption. He shows that Kyrgyzstan made no improvements after the revolution. Likewise, Kyrgyzstan did not fundamentally change on institutional measures; it had a legislature, elections, and multiple parties, both before and after the revolution, and Kyrgyzstan remained a personal autocracy in Geddes' classification during the entire period.

However, since the revolution did not result in a more democratic Kyrgyzstan, could it then result in a stronger civil society? The same observers, who argued that the revolution did not result in democracy, argues so. Wood (2006, p. 55) argues that "Kyrgyz attitudes towards President Bakiyev are forthright in threatening an outcome similar to Akayev's ouster, or worse, if they tire of his presidency", and Juraev (2008, p. 26) argues that "It is the traditionally competitive character of the relationship between various sub-ethnic groups at many levels that at least partially explains the existence of active contestation at all levels, be it at the village, or in local or even national presidential 
elections". Likewise, Marat 2005, p. 267) finds that "Following the March 24 popular demonstrations in Kyrgyzstan that resulted in the ousting of the Akayev government, the ability of Kyrgyz civil society to impact political processes in the country became difficult to deny.". Furthermore, the strength of civil society increases slightly from 0.51 to 0.54 in the measure of civil society used in chapter 5 .

The Kyrgyz revolution can be seen as a shock to the level of external constraints where civil society suddenly becomes stronger, and threaten the ruling elite. However, at the same time Kyrgyzstan remained firmly in the authoritarian camp, albeit with a new leader. According to the model presented in chapter 2, this should be decisive for who get to influence the decision making process, and change the preferences more in direction of the civil society. As argued before, civil society will have a strong interest in promoting policies beneficial for human development by increasing investment in public goods, such as health care and public education. These are areas that benefit a broad segment of the population, but is of little personal importance for the dictator. The expectation is therefore that investment in health and public education will increase in the aftermath of the revolution.

\subsection{Data}

The study will focus on two components of economic development: health care and education. In order to measure investment in health care, I will use the variable "Health expenditure, public (per cent of GDP)" from the World Health Organization (2016). The dataset contains data for Kyrgyzstan and nearby countries from 1995 and onwards. The other aspect, which I focus on is investment in education. Here, I will rely on the variable "Government expenditure on education, total (per cent of GDP)" from the UNESCO 
Institute for Statistics (2016). Unfortunately, the database only has credible data from 1998 and onwards for many countries, including Kyrgyzstan.

These two variables reflect the spending choices of the governments, and they are advantageous because they relatively easily can be influenced by political decisions. However, increased investment in education or health care does not imply that the population experiences real change. For example, the money can be misused or stolen through corruption. In addition, earlier studies have shown that increased health care spending is targeted at the middle class, but is unrelated to infant mortality (Ross 2006).

I will therefore also focus on two outcome measures: infant mortality rate, measured as the number of deaths prior to age one per 1,000 live births, and the percentage of age-appropriate children enrolled in primary and secondary education. Both measures are, as in the previous chapter, taken from the World Bank (2017). It is expected that these variables fluctuate less since it takes time for policies to materialize.

The dependent variable will be regressed on a number of candidate variables which can be used as predictors. I am using a dataset with predictor variables, which has kindly been put at my disposal by Ryan Kennedy. I am using the following variables as predictors in the models:

1. The natural log of per-capita Gross Domestic Product (The World Bank 2017).

2. Natural log of distance between capital city and Brussels, in kilometres, based on distances calculated using the World Distance Calculator.

3. Average of small-scale and large-scale privatization ratings from the EBRD's Transition Indicators (European Bank for Reconstruction \& Development 2016). 
4. Perceptions of corruption, conventionally defined as the exercise of public power for private gain (Kaufmann et al. 2011).

5. Presence of major oil resources (Gandhi and Przeworski 2007).

6. Annual GDP growth per capita (The World Bank 2017).

\subsection{Synthetic control method}

How do we know whether the Tulip revolution resulted in better human development in the absence of democratization? Ideally, we would like to be able to compare Kyrgyzstan both with and without a revolution in the period following the revolution. The obvious problem is, of course, that this is not possible; we will never be able to observe the outcome for Kyrgyzstan both with and without a revolution.

We must therefore rely on another way of establishing causal inference. Traditionally, social scientists have relied on comparative case studies, where a case in which the event did happen is compared with a sufficiently similar case, where the event did not occur. The assumption is then that the two cases are sufficiently similar, so they would have looked alike had the event not happened. However, this approach has several weaknesses.

Researchers often choose the comparison groups on the basis of subjective measures of affinity and the selection of cases, therefore, become somewhat arbitrary. Additionally, it is difficult to know to which degree the control cases can be treated as counterfactuals (Abadie et al. 2010). A way to overcome some of these problems is regression techniques, but they have their own problems. Regression ignores the heterogeneity of the units and as a basis give all cases the same weight (Kennedy 2014, p. 280). 
I will therefore rely on the SCM, which provides a rigorous and data-driven way of choosing comparison units in a comparative case study. The comparison unit in the SCM is selected as the weighted average of all potential comparison units that best resembles the characteristics of the case of interest (Abadie et al. 2015, p. 496).

Here, I will briefly explain how the method is used in this concrete study. We have $j=1, \ldots, J+1$ countries. In our case, country $j=1$ is the treated unit, Kyrgyzstan, where a revolution took place, while the remaining countries $j=2$ to $j=J+1$ are the "donor pool" which consists of other former communist countries that did not experience a revolution.

We observe the countries for $t=1, \ldots, T$ time periods. The sample includes a number of pre-intervention periods, $T_{0}$, where Kyrgyzstan did not yet experience a revolution, and a number of post-intervention periods, $T_{1}$ after Kyrgyzstan $j=1$ experienced a revolution. Since we cannot experience the treated country as if it had not experienced a revolution after the revolution takes place, we construct a synthetic case from the donor pool that resembles the treatment case in all relevant pre-intervention characteristics.

The synthetic control is defined as the weighted average of the units in the donor pool, so it is represented by a $(J x 1)$ vector of weights $W=\left(w_{2}, \ldots, w_{J}+1\right)^{\prime}$, where $0 \leq w_{j} \leq 1$ and $\sum_{w=2}^{w_{j}+1}=1$. The value of the weights is determined by finding the set of weights that minimizes the differences in the pre-treatment values of the predictors. We define $X_{1}$ as a $(k x 1)$ vector of pre-revolution values of $K$ predictors for treatment cases and $X_{0}$ as a $(k x J)$ of the same variables for the donor cases. Then the difference between the pre-intervention of characteristics of the treated unit and the synthetic unit is given by the vector $X_{1}-X_{0} W$. We then want to select a synthetic control unit that minimizes 
this difference. The ideal weights, $W^{*}$, are then found by minimizing:

$$
\sqrt{\left(X_{1}-X_{0} W\right)^{\prime} V\left(X_{1}-X_{0} W\right)}
$$

where $\mathrm{V}$ is a diagonal matrix of non-negative components that reflects the relative importance of the different predictors. This is done with a algorithm found in the package Synth in R. When the synthetic control is constructed, the estimated causal effect of the Tulip revolution on the given variable is:

$$
\widehat{\alpha_{i t}}=Y_{1 t}-\sum_{j=2}^{J+1} w_{j}^{*} Y_{j t}
$$

in periods $T_{0}+1, T_{0}+2, \ldots, T$.

\subsection{Results}

Figure 7.1 plots the trends for the four measures for Kyrgyzstan and its synthetic counterpart. The period varies dependent on the data availability for the dependent variable, but all are within the period 1996 to 2010 .

The synthetic trajectory follows the convex combination of countries in the donor pool that closely resembled Kyrgyzstan before the revolution. The actual combination for the four variables is seen in Table 7.1. For example, Armenia is accounting for 44 per cent of the weight for spending on health care. It should be noted that some countries are excluded from the sample for some variables due to missing data, and that the synthetic control only is constructed based on the countries with full data. We see that the synthetic trajectory almost perfectly mimics the actual trajectory for three out of the four variables, 
Figure 7.1: Actual versus the synthetic Kyrgyzstan on the four measures of human development.

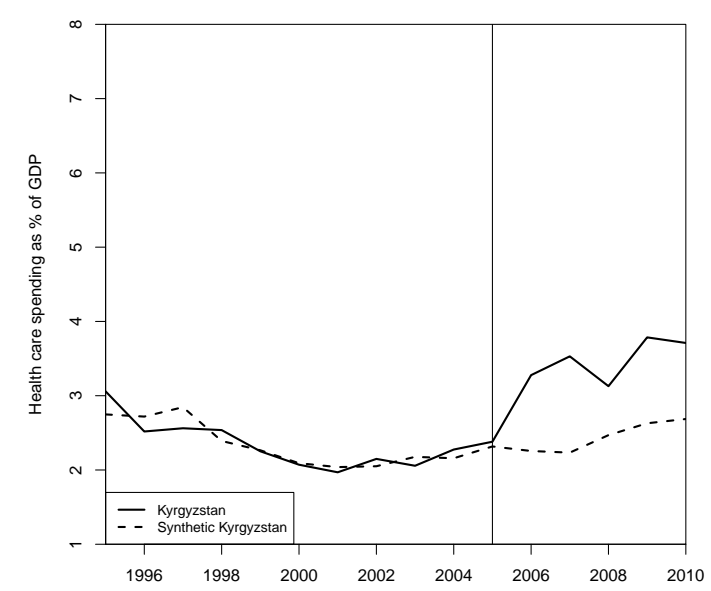

(a) Health care spending

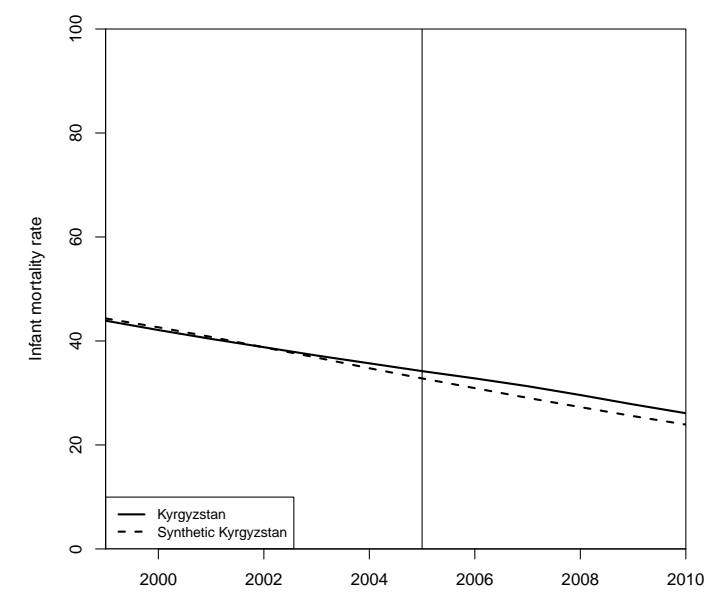

(c) Infant mortality

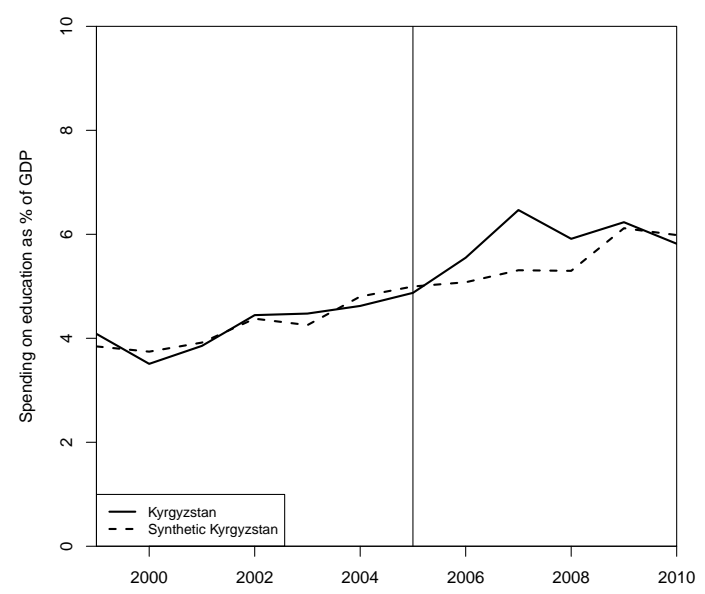

(b) Education spending

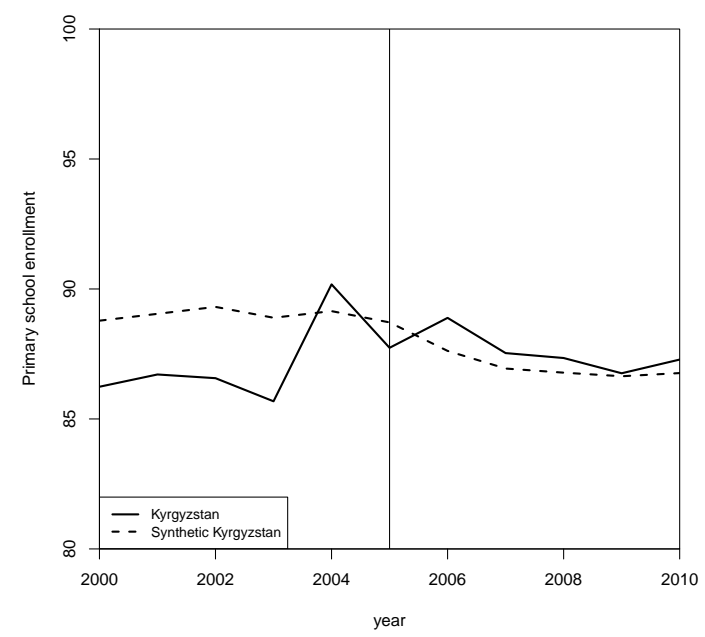

(d) Primary school enrolment

excluding infant mortality rate, in the years before the Tulip revolution. Kyrgyzstan is the worst performing country in the group of countries used in the analysis on primary school enrolment. This makes it impossible to create a good control.

The estimate of the impact of the Tulip revolution on the four variables is given by the difference between the actual value for Kyrgyzstan and the value for the synthetic 
control. In the years following the Tulip revolution, we see that Kyrgyzstan starts spending a larger share of the GDP on health care and education relative to the control. This suggests that the Tulip revolution had a sizeable effect on public spending on human development relative to the control. This is in line with the theoretical expectation which is that an autocrat who is facing concrete threats from the civil society, will direct policies benefiting the broader populace. Thereby, he can satisfy (some) of the demands and decrease the likelihood of unrest.

The bottom two panels show the outcomes for infant mortality and primary school enrolment. It would be expected that higher investment in health care and education would result in better outcomes on these development variables. However, this does not seem to be the case, and Kyrgyzstan actually performs slightly worse that the synthetic control on the measure of infant mortality. As mentioned above, Kyrgyzstan had a lower enrolment rate than all other countries, making it impossible to create a good synthetic control in the beginning of the millennia. However, Kyrgyzstan catches up in the run up to the Tulip Revolution and actually outperforms the synthetic control after the revolution, albeit not dramatically.

In sum, the findings suggest that the Kyrgyz regime increased spending on human development in the wake of the Tulip Revolution. However, the resulting improvements in human development leave much to be desired. 
Table 7.1: Country weights for synthetic Kyrgyzstan

\begin{tabular}{llllll}
\hline & Country & $\begin{array}{l}\text { Spending } \\
\text { on health } \\
\text { care }\end{array}$ & $\begin{array}{l}\text { Spending } \\
\text { on } \\
\text { education }\end{array}$ & $\begin{array}{l}\text { Infant mor- } \\
\text { tality rate }\end{array}$ & $\begin{array}{l}\text { Primary } \\
\text { school } \\
\text { enrollment }\end{array}$ \\
\hline 1 & ALB & 0.00 & & 0.00 & \\
2 & ARM & 0.44 & 0.00 & 0.00 & \\
3 & AZE & 0.00 & 0.00 & 0.00 & 0.00 \\
4 & BGR & 0.00 & & 0.00 & 0.00 \\
5 & BIH & 0.00 & & 0.00 & \\
6 & BLR & 0.00 & & 0.00 & \\
7 & CZE & 0.00 & 0.00 & 0.00 & \\
8 & EST & 0.25 & & 0.00 & 0.00 \\
9 & GEO & & & 0.46 & \\
10 & HRV & 0.00 & & 0.00 & \\
11 & HUN & 0.00 & 0.00 & 0.00 & 0.00 \\
12 & KAZ & 0.13 & & 0.00 & 0.34 \\
13 & KGZ & & & & \\
14 & LTU & 0.00 & & 0.00 & 0.00 \\
15 & LVA & 0.00 & & 0.00 & \\
16 & MDA & 0.00 & 0.38 & 0.00 & 0.00 \\
17 & MKD & 0.00 & & 0.00 & 0.66 \\
18 & POL & 0.00 & 0.00 & 0.00 & 0.00 \\
19 & ROU & 0.00 & & 0.00 & 0.00 \\
20 & RUS & 0.00 & & 0.00 & \\
21 & SRB & & & 0.00 & \\
22 & SVK & 0.00 & 0.39 & 0.00 & \\
23 & SVN & 0.00 & & 0.00 & 0.00 \\
24 & TJK & 0.18 & 0.23 & 0.00 & 0.00 \\
25 & TKM & 0.00 & & 0.00 & \\
26 & UKR & & & 0.00 & \\
27 & UZB & 0.00 & & 0.54 & \\
\hline
\end{tabular}

\subsubsection{Placebo plot and robustness checks}

One cannot apply traditional tests of statistical inference with a SCM, since the estimates are for the effects of treatment for a single unit, and this method does not rely on distributional assumptions. Therefore, I need to use permutation methods to test whether the results are likely to be a consequence of chance (Abadie et al. 2010; Abadie et al. 2015; Silva 2018). They work by creating a synthetic control for every country in the donor 
pool with the same treatment date as that used for Kyrgyzstan, namely 2005. Since units in the donor pool did not experience a revolution in 2005, the post 2005 gaps between them and their synthetic control are an estimate of the post-treatment variation we can expect by chance. Thus, if the observed effects for Kyrgyzstan is larger than those for the placebos, it means that it is unlike to be due to random variation.

The results from the placebo tests are seen in figure 7.2. While figure 7.1 shows the actual trends for the four variables, this figure shows the difference between a country and its synthetic control. Therefore, points above the line indicate that Kyrgyzstan is scoring higher on this variable than its control. The black line is referring to Kyrgyzstan, while each of the grey lines represent the difference for another country in the donor pool (a placebo) to its synthetic control.

Kyrgyzstan is one of the most extreme countries for the two measures of spending. This is especially the case in the years shortly after the Tulip Revolution. This gives us some indication that the results are not due to random chance, although this cannot be ruled out with certainty. Not surprisingly, this is not the case for infant mortality rate and primary school enrolment, where Kyrgyzstan is outperformed by most of the placebos just by chance. It should be noted that the measure of infant mortality is flip-sided compared to the other variables and that lower infant mortality is desired. This provides further proof that the Tulip Revolution did cause the spending patterns to change, but did not cause better human development.

In appendix E, I run two robustness test. First, I only include the authoritarian countries in the donor pool. I find that this does not change the results. Thus, the results 
are not driven by a different and unexplained mechanism in democracies. Furthermore, I exclude, in turn, the country with the highest weight from the donor pool for each variable and construct a new synthetic control on the basis of the restricted donor pool. Here, I obtain very similar results as in figure 7.1, even though the composition of the synthetic control is somewhat different in each case. The results are therefore not driven by comparing with one specific country. 
Figure 7.2: Placebo plots for the four variables
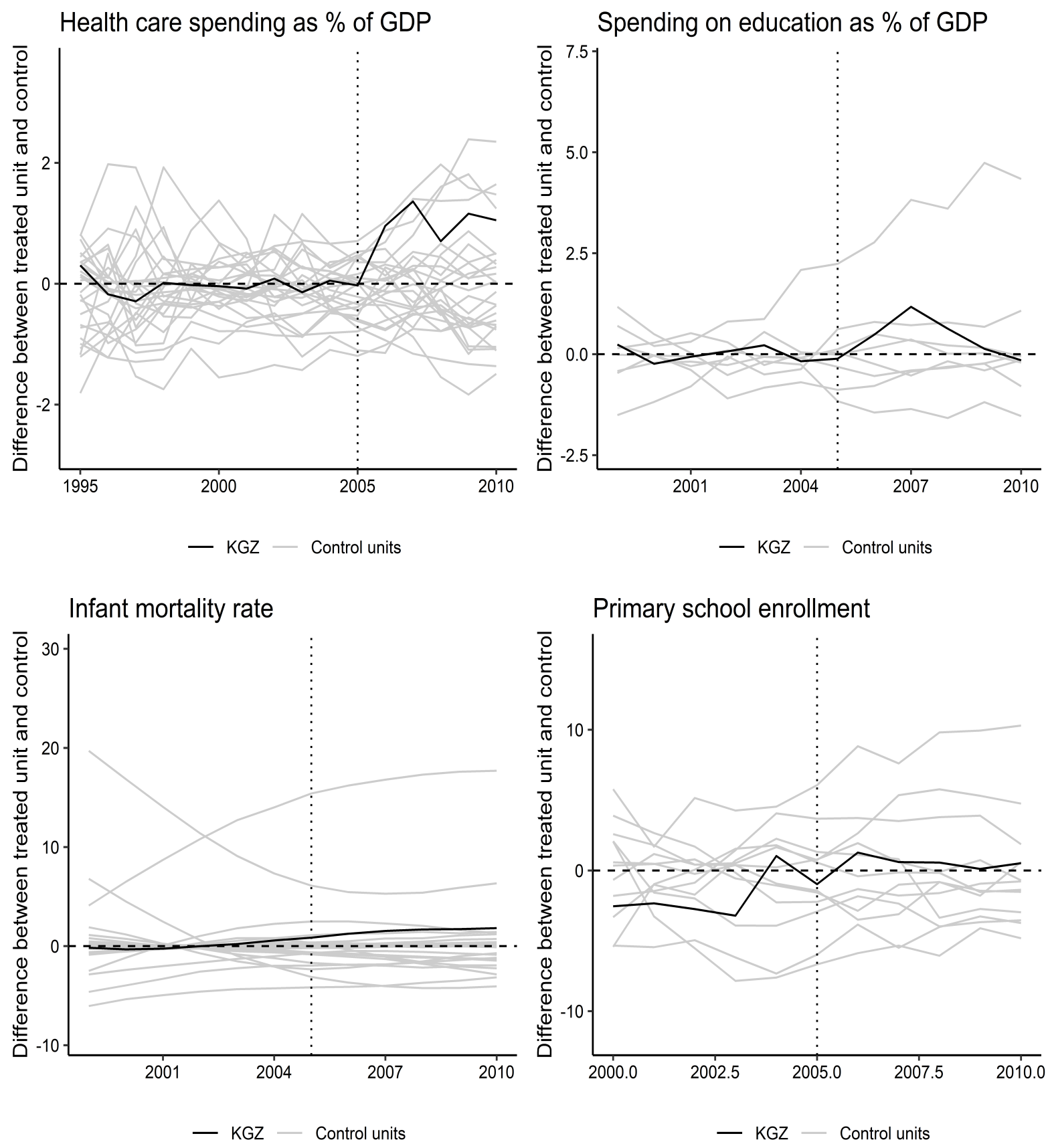

\subsection{Conclusion and discussion}

When the protesters stormed the government building in Bishkek in March 2005 it was with the hope of a better and more democratic future. These hopes were quickly dashed, 
and the Kyrgyz people merely saw a reorganization of government (Juraev 2008; Kennedy 2014 Wood 2006). Nonetheless, civil society sent an important signal to the new elite; they were a force capable of overthrowing the leader through a revolution. According to the theoretical model a potent threat from civil society, would cause the autocrat to direct policies towards pleasing civil society.

To test this, I employ a SCM to estimate the effect of the Tulip Revolution on human development. The results indicate that Bakiev's regime changed its policies in response to the sustained threat from civil society, and started investing a larger share of the GDP in health care and education. Alas, this did not result in markedly better outcomes on human development. How does this relate to the theory outlined in this manuscript?

Broadly, the results support the theory. As argued above, the Tulip Revolution can be perceived as a sudden increase in the strength of the civil society. The formal model argues that the dictator will change policies and divert rents towards the preferences of the civil society, when it gets stronger. Therefore, the change in spending patterns aligns with the theory. However, we do not see improvements on the two measures of human development despite more investment in health care and education. This is somewhat surprising given that there is an inflow of resources. However, there are at least three explanations for why we do not see improvements.

First, the two measures of human development are (somewhat) static and it takes time before spending, for example, materialises in more teachers and nurses and new schools and hospitals. Therefore, we do not see improvements straight away. Second, I only look at two narrow measures of human development. It may be the case that the increase in 
education spending were allocated to high schools or universities and not primary schools, while health care resources could have been allocated to, for example, cancer treatment. Thus, we may see improvements elsewhere in the educational and health care systems. Third, there is a risk that the extra resources are spoilt through both corruption and a weak state incapable of implementing reforms. According to Transparency International corruption was and still is endemic in Kyrgyzstan, and the Tulip Revolution did little to solve this (International 2020; Kennedy 2014; Pop-Eleches and Robertson 2014).

This may explain why the aftermath of the revolution did little to lessen the frustrations of the Kyrgyz people. Bakiev's repressive and corrupt regime quickly grew deeply unpopular amongst the wider population (Cheterian 2010, Collins 2011). This created fertile soil for a new revolution, and in 2010 a popular uprising toppled Bakiev. This revolution brought Roza Otunbayeva to power as interim president. She started the "Return to Democracy"-program which led to parliamentary elections "that both local and international observers have hailed as the freest, fairest, and most competitive Central Asia has ever seen" (Collins 2011, p. 150). Therefore, the events in 2010, contrary to the events in 2005, seem to represent an organized and successful attempt by the Kyrgyz political and civil society to overthrow a dictatorship and establish a democracy in its place.

While STM arguably is an improvement compared to more traditional comparative analysis, it is not a golden bullet and the research design used in this chapter suffers from limitations. First, the analysis suffers from lack of available data. For some variables, there is no consistent data for many of the countries in the donor pool which limits the analysis. For example, it is not possible to construct a good control for primary school 
enrolment in the pre-treatment period, where Kyrgyzstan is performing worse than all countries in the donor pool. Furthermore, the design may violate the stable unit treatment value assumption (SUTVA). The Tulip revolution did not go unnoticed in the nearby countries in the donor pool. Social movements and NGO's in surrounding countries closely followed the events in Kyrgyzstan, and the success in the Tulip Revolution could therefore nurture protest abroad (Beissinger 2007; Bunce and Wolchik 2011). Likewise, the leaders in surrounding countries were aware of this, and therefore had an incentive to diffuse and avoid protest. As argued, one way of doing so is by leaning into the demands of civil society, and invest more in human development. Thus, the Tulip Revolution can have inspired leaders in surrounding countries to change their policies. This violation of the SUTVA-assumption would cause an underestimation of the effect.

Another drawback of this analysis is that while the revolution arguably constitutes a shock to the level of external constraints, it also impacts internal constraints. One may say the design breaks the exclusion restriction, and I am therefore unable to isolate the effect of external constraints. Nonetheless, the chapter provides evidence that sudden changes in the strength of civil society can direct policies towards the preferences of civil society. In the next chapter, I will focus on shocks to the strength of the ruling elite. 
I know that there are scores of people plotting to kill me, and this is not difficult to understand. After all, did we not seize power by plotting against our predecessors?

— Saddam Hussein (Karsh and Rautsi 2002, p. 3)

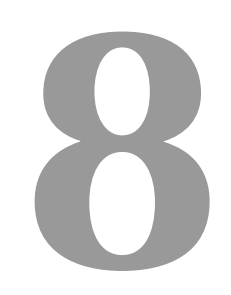

\section{The costs and benefits to the ruling coalition after a failed coup attempt}

\section{Contents}

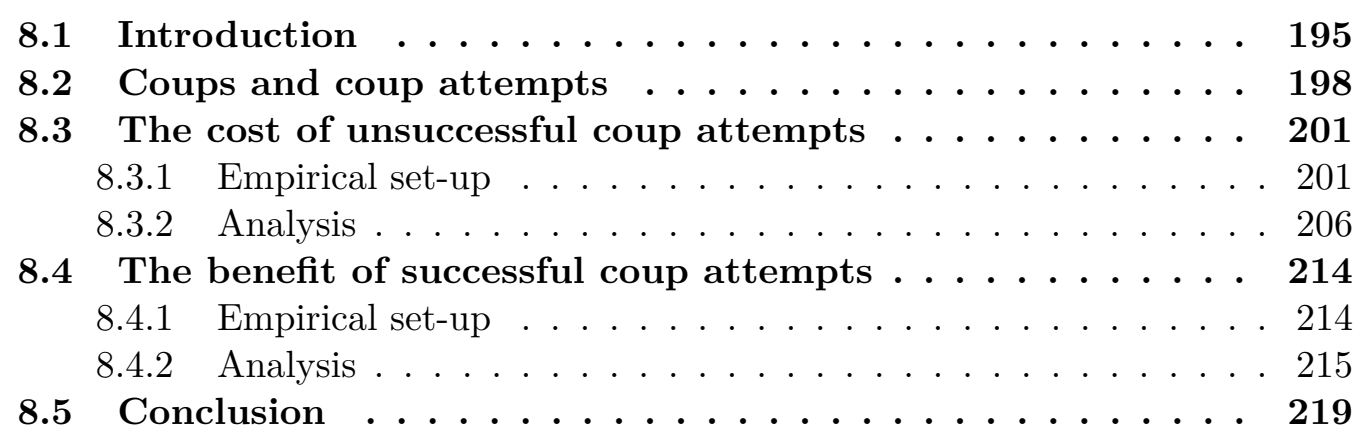

\subsection{Introduction}

On July 221979 Saddam Hussein convened an assembly of leaders of the Ba'ath Party which was recorded on videotape. The tape starts with Hussein announcing that something very sad has happened. He then claimed that he has uncovered a conspiracy against him, and says that "I will pick up my gun and fight to the end". Then, a man named 
Muhyi Abdel-Hussein who until few days prior had been the general secretary of the Revolutionary Command Council, the executive committee that ran the state, came to the stage. Here, he admitted to a plot against the regime, and moreover, he started listing names of co-plotters, many of them in the room. One by one senior members of the Ba'ath Party were taken out of the room and tried immediately. Some were executed, while others were imprisoned. In just a few hours Saddam Hussein had eliminated all internal opposition and established his totalitarian rule (Karsh and Rautsi 2002, p. 115).

The 1979 Ba'ath Party Purge is a very visible and public example of an autocrat acquiring more power at the expense of his allies. However, in most dictatorships, politics is highly informal and secretive, and the dictator, therefore, gradually expands his power without public knowledge (Frantz 2018, Geddes et al. 2018, Svolik 2012). This is what I exploit in chapter 6, where I look at how gradual changes in both internal and external constrains are related to economic development. However, as discussed in the formal model, the dictator sometimes overplay his hand, provoking the ruling coalition to rebel and attempt to remove him from power. Such rebellions are typically labelled coups d'état or plots (Svolik 2012).

This chapter sets out to test two implications of the formal model, when there is an overt attempt at overthrowing the dictator from within the regime. First, I will look at what happens, when the coup d'etat fails. According to the formal model there is a significant cost to the ruling coalition if they unsuccessfully try to rebel against the dictator. Using data from the WhoGov dataset, presented in Chapter 5, I show that the average cabinet replacement rate increases by 11 percentage points in the year following 
a coup-attempt. This roughly implies that two members more than usual are purged from the core group of governing members. However, this, of course, depends on the size of the ruling coalition. Furthermore, I show that the dictator purges those, who are most likely to be a threat to his rule and those, who can be perceived as disloyal. A failed coup attempt may therefore, as the model predicts, accelerate the process towards a weaker ruling coalition and a one-man dictatorship. This chapter is inspired by the paper "The Morning After: Cabinet Instability and the Purging of Ministers after Failed Coup Attempts in Autocracies" co-authored with Lasse Aaskoven, Laure Bokobza, Suthan Khrisnarajan and Casper Sakstrup (2020), but I have altered the analysis, so it fits the theoretical and analytical framework of the thesis.

However, coup attempts just as often succeed (Jones and Olken 2009; Lachapelle 2020; Powell and Thyne 2011). Here, the implication of the formal model is that there is a benefit to the ruling coalition, if they manage to successfully remove the dictator from office. More precisely, I argue that a successful coup is a tool to avoid the equilibria where a "bad dictator" governs without accountability. This should, all else equal, result in higher economic growth and therefore better economic fortunes for the ruling elite. Nonetheless, as argued in the formal model, removing the dictator does not come without a risk for the ruling coalition. While they may be successful in removing the dictator, a new leader has to be found, which is a risky process that can cause political instability and spur the hopes of a better future. Therefore, we should only see better economic growth in transitions, where the elite manages to stay in power and secure an orderly transition. Using a fixed effects design, I show that successful coups are associated with a bump in 
the growth rate, but only insofar the majority of the ruling elite remains in power.

The chapter progresses in four parts. The first part presents previous research on coup-attempts and put forward testable hypotheses. The second part presents the analysis of the impact of failed coups, while the third part present the analysis for successful coups. At last, I briefly conclude on the chapter.

\subsection{Coups and coup attempts}

Powell and Thyne (2011, p. 252) define coup attempts as "illegal and overt attempts by the military or other elites within the state apparatus to unseat the sitting executive". Therefore, unlike revolutions, the attempt to remove the leader comes from within the ruling coalition. Furthermore, the most basic goal of a coup is to bring about a change in leadership. Thus, independent of whether a coup attempt actually succeeds in removing the leader, coups are drastic events that reveals that the dictator has been exposed to an immediate and patent threat to his rule.

As a result, the morning after a failed coup attempt marks the shift from one autocratic equilibrium to another. Previous research has shown that coup attempts - independent of whether they succeed or not - have profound effects for outcomes such as democracy (Chacha and Powell 2017; Derpanopoulos et al. 2016; Goemans and Marinov 2014, Thyne and Powell 2016), repression by the leader (Lachapelle 2020; Wig and Rød 2016) and economic growth (Alesina et al. 1996; Fosu 2002; Jong-A-Pin and Yu 2010).

This chapter investigate the effects of both unsuccessful coups and successful coups in the light of the theoretical framework presented in this thesis. The claim in the model is that there is a cost, $c$, to the ruling coalition if they attempt to rebel against the 
dictator, but fails to overthrow him. It is generally assumed that autocrats respond to failed coup attempts by engaging in large-scale purges (Easton and Siverson 2018; Geddes et al. 2018, Svolik 2012). However, this is untested in a global perspective, and previous research focuses on the military and not the broader ruling coalition, including the cabinet. (Braithwaite and Sudduth 2016; Easton and Siverson 2018; Sudduth 2017b).

There are several ways of punishing the elite. These range from relatively mild punishments, such as the confiscation of assets, to brutal punishments, such as imprisonment, torture, or even execution both of the member of the ruling coalition and their relatives (Geddes et al. 2018). The empirical part of the chapter focuses on whether members of the ruling coalition are purged from the ruling coalition following a coup attempt. This measure best encapsulates atomization, because the purged individuals are isolated and thus unable to influence policies and participate in holding the leader accountable.

Coup attempts provide a powerful signal in an otherwise high-uncertainty and lowtransparency environment that the ruler's hold on power was at risk, if only briefly (Barros 2016, Easton and Siverson 2018). The autocrat does not know whether he was lucky or prevailed due to strength (Lachapelle 2020). He is, therefore, forced to play his cards right to tighten his grip on power and thereby prevent future challenges. As argued, one way of doing so is by purging members of the ruling coalition. Thus, the expectation is that coup attempts increase cabinet instability.

However, he cannot purge blindly or get rid of too many ministers. Purging comes at a cost since it creates discontent and makes him unable to govern the country (Davenport 2007). This risks further destabilizing the regime and may provoke a new 
coup attempt or a revolution (Sudduth 2017a; Sudduth 2017b). Therefore, I expect that some ministers will be more targeted than others. The model is indifferent to which members of the ruling coalition that are most likely to be purged, and I therefore refrain from making any predictions.$^{1}$

I now turn towards successful coup attempts. The implication of the model is that there can be a benefit to the ruling coalition, if they manage to successfully rebel against the dictator, e.g. there is a successful coup attempt and the leader is removed. The benefit in the model comes from the ruling coalition being able to remove a "bad dictator" who are taking actions that only benefits himself, but hurts everyone else, and replace him with a "good dictator", who can be held accountable and acts in the general interest.

However, the model also argued that a rebellion is a risky business. When a coup is successful in removing the leader, it raises a new question; Who will be the new leader? This is a good question, and often there are too many people saying "Me", causing the process to be unpredictable (Gerring and Knutsen 2019). Outside groups may attempt to take power, as argued in the model, or members of the seizure group may renege on their promises and try to seize power themselves, causing further coups. It is well-known that a new leader is most vulnerable in the beginning of his tenure (Aisen and Veiga 2013; Bienen and Van de Walle 1992; De Mesquita and Smith 2011). Thus, a coup may cause political instability, which is detrimental for economic growth (Alesina et al. 1996). Therefore, the expectation is that successful coups, where the leader is removed, are associated with higher economic growth, when the rest of the ruling coalition remains in power.

\footnotetext{
${ }^{1}$ I delve into this with co-authors in a separate project that goes beyond the thesis (Aaskoven et al. 2020 .
} 


\subsection{The cost of unsuccessful coup attempts}

\subsubsection{Empirical set-up}

To examine whether there is a cost associated with a failed coup attempt, I rely on the widely used coup data compiled by Powell and Thyne (2011). They define a failed coups as instances where the perpetrators did not manage to "seize and hold power for at least seven days" (Powell and Thyne 2011, p. 252). I also conduct robustness tests using an alternative coup variable constructed by Bjørnskov and Rode (2018). These are found in Appendix E.

The coup variable is merged with data from the WhoGov-dataset presented in Chapter 5. This allows for a detailed and extensive analysis of the argument in two parts. To investigate whether failed coup attempts increase purges I look at the replacement rate for core members of the cabinet. In other words, the dependent variable is the share of core members of government, who are purged from the cabinet from one year to the next. Second, I utilize the fact that the dataset contains individual level information, and I can therefore look at whether individuals with specific traits are more likely to be purged.

I focus solely on people who are purged from the cabinet, and, therefore, do not exist in the dataset in the following year. Thus, I do not look at individuals who remain in cabinet, but are shuffled to another position. All models in the analysis are restricted to autocratic regimes based on the classification as classified by Cheibub et al. (2010) and updated by Bjørnskov and Rode (2018). Lagging the democracy score by one year ensures that failed coup attempts that take place in democracies, but where the attempt results in the regime shifting to autocracy in that same year, are not included in the analysis. 


\section{Country-level analysis}

The country-level analysis consists of time-series cross-sectional OLS models estimated using the following equation:

$$
P_{i, t}=\varphi C_{i, t}+\beta X_{i, t}+\alpha_{i}+\lambda_{t}+\varepsilon_{i, t}
$$

for $i=1, \ldots, n$ countries and $t=1, \ldots, T$ years, where the outcome denotes the yearto-year replacement-rate of cabinet ministers, $P_{i, t}$, ranging from 0 to 1 . $C_{i, t}$ is the main independent variable, failed coup attempt, taking the value 0 in years without a failed coup attempt and 1 in years with a failed coup attempt, with data from the (Powell and Thyne 2011) dataset. All models include both country fixed effects, $\alpha_{i}$, and year fixed effects, $\lambda_{t}$. This is important for identification as countries with a history of frequent coup attempts and cabinet instability (e.g. Nigeria) are likely different from generally stable countries (e.g. Vietnam) on a range of unobservable confounding characteristics, such as political culture or historical legacies. Country fixed effects therefore control for such country-specific, time-invariant factors. Meanwhile, the year dummies control for yearly shocks, which may impact cabinet stability globally, such as the dissolution of the Soviet Union in 1991.

However, to do a stricter test I also run all models, where I use leader fixed effects instead of country fixed effects. These models control for all time-invariant factors specific to each dictator in a given country, and thus rely solely on within-dictator effects for identification. That is, these models explicitly compare cabinet stability within the spell of a given autocrat, before and after a failed coup attempt. As such, these 
models provide a more restrictive - though more inefficient - test of whether the elite is punished after a failed coup attempt.

The error term is given by $\varepsilon_{i, t}$, and all standard errors are clustered by country. The models include up to 3,794 country-year observations in 113 autocracies for the period 1966-2016.

As discussed before the data from WhoGov is recorded in July. Given that the cabinet data is coded for July each year (that is, the replacement rate from July in previous year to July in the current year), I recode the coup variable so that only failed coup attempts occurring before 1st of July are coded as 1 in a given year, whereas failed coup attempts after this date are coded as 1 in the year after. For example, if a failed coup attempt has occurred in May 2004, it is coded as 1 in 2004, but if it occurred in September 2004, it is coded as 1 in the year 2005

To address concerns with endogeneity, I include both control variables and conduct placebo tests. Both the independent (failed coup attempt) and dependent (purges) variable are instances of instability, and it is therefore important to control for time dependent variables related to this that might induce biases in the estimated coefficients. The control variables are included in $X_{i, t}$, which represents a $k \times 1$ vector of all control variables (lagged one year). In the "Base models", I include (logged) GDP/capita and (logged) population size that both originates from the Penn World Table V9.0 (Feenstra et al. 2015).

These base and main models include the most important potential confounders without inducing risks of post-estimation biases. Still, in order to guard against more proximate potential confounders, I present separate models that add a different set of controls to 
the "Base models". In the "Electoral controls" model, I account for the relationship between elections and coups (Wig and Rød 2016) and add controls for all national elections, with data from the Nelda dataset (Hyde and Marinov 2012) as well as a counting variable denoting years since last election. The "Economic controls" model accounts for the economic impacts on coups and leader-instability (Kim 2016; Krishnarajan 2019) by adding short-term economic fluctuations such as annual GDP/capita growth from the Penn World Table V9.0 (Feenstra et al. 2015) and oil income from Ross Oil and Gas Data (Ross and Mahdavi 2015).

I also account for general instability by presenting an "Instability controls" model, which includes variables for civil war onsets using data from the UCDP conflict dataset (Gleditsch et al. 2002), nonviolent campaigns with data from the NAVCO dataset (Chenoweth and Lewis 2013), onsets of military disputes and interstate war with data from Correlates of War dataset (Maoz et al. 2019, Palmer et al. 2020, Sarkees and Wayman 2010), and strikes with data from the Cross-National Time-Series (CNTS) Data Archive (Banks and Wilson 2015). In addition, I present a model in which I include a one-, two-, and three-year moving average of cabinet purges leading up to a given year, which is called "Purges MA's". This model constitutes a more fine-grained lagged-dependent variable model that controls for previous developments in cabinet purges leading up to a failed coup attempt in order to account for any cabinet purges leading up to a failed coup attempts. Finally, as the most extensive model, I include all the mentioned controls in the same model, "All controls". Furthermore, I undertake a set of placebo tests where the main independent variable, failed coup attempt is substituted with alternative instability measures, including: civil 
war onset, non-violent campaigns, onsets of military disputes, onsets of interstate war, and strikes (from the data sources listed above), while using the variables from the "Base model". The rationale behind these tests is to examine whether it is indeed failed coup attempts that drive the findings, or whether it is simply instability more generally that induces cabinet purges. If the latter is the case, we should see these alternative variables exerting the same effect as failed coup attempts. On the other hand, if it turns out that they do not, it substantiates the argument that there is indeed something specific about failed coup attempts, and improves the confidence in the main findings.

\section{Individual-level analysis}

The purpose of the minister-level analyses is to investigate which type of cabinet members that are most likely to be purged following a coup attempt. For this purpose I utilize time-series cross-sectional linear probability models models given by:

$$
F_{i, j, t}=\varphi C_{i, j, t}+\zeta M_{i, j, t}+\gamma\left(C_{i, j, t} M_{i, j, t}\right)+\beta X_{i, j, t}+\alpha_{i}+\lambda_{t}+\varepsilon_{i, j, t}
$$

for $i=1, \ldots, n$ countries, $j=1, \ldots, n$ ministers, and $t=1, \ldots, T$ years, where the outcome denotes the fate of the minister, $F_{i, j, t}$. This variable is binary, where 1 denotes that the minister is purged and removed from office in the year following a coup attempt, while 0 denotes that the person remains in office. These analyses covers the same 113 autocracies during the same 1966-2016 time period, yielding a total of 22,129 cabinet members and totally 95,936 individual-year observations.

I include the same control variables as the base models in the country-level analysis, but add cubic polynomials $\left(t, t^{2}, t^{3}\right)$ for how many years a given minister has been in office at 
a particular point in time to account for time dependencies (Carter and Signorino 2010) 22

To test whether specific types of ministers are particularly vulnerable after a coup attempt, I include different product terms, one by one, where failed coup attempts, $C_{i, t}$ are interacted with minister characteristics, $M_{i, t}$. . That is, while it is expected ministers to be generally more likely to leave office after failed coup attempts, it also expected that some ministers are particularly targeted, which is denoted by $\gamma$. Thus, $\gamma$ is the difference in likelihood for this specific type of ministers to be purged in years following a coup attempt relative to years without a coup attempt.

I include four types of minister characteristics. First, I include a measure of experience, which counts the number of years a person has been in cabinet at the year of the coupattempt. Second, I include a measure of partisan alignment, where a cabinet member either can be from the same party as the leader, from another party than the leader or unaffiliated with a party. Third, I include a measure for strategic responsibility. WhoGov categorize all portfolios into 43 different types. I have sorted these into 5 broad groups. Fourth, I use a measure of importance, where all cabinet members are assigned to five different tiers of importance (excluding the leader; for further information see Appendix E.7).

\subsubsection{Analysis}

Figure 8.1 presents the distribution of replacement rates in years with and without a coup attempt. In years without a coup attempt 23 per cent of cabinet members are removed in a given year, while it is approximately 37 per cent following a coup attempt. This indicates that members of the core group of governing members are more likely to be

\footnotetext{
${ }^{2}$ The cubic polynomials are not included, when experience is included as the main explanatory variable.
} 
purged following an unsuccessful coup attempt, and there therefore is a cost to rebelling against the dictator. However, as argued above, a coup attempt may be more likely to happen in countries with unstable governments or in tumultuous times. Thus, I turn to a more systematic investigation of the relationship.

Figure 8.1: Distribution of retention rates in years with and without a coup attempt.

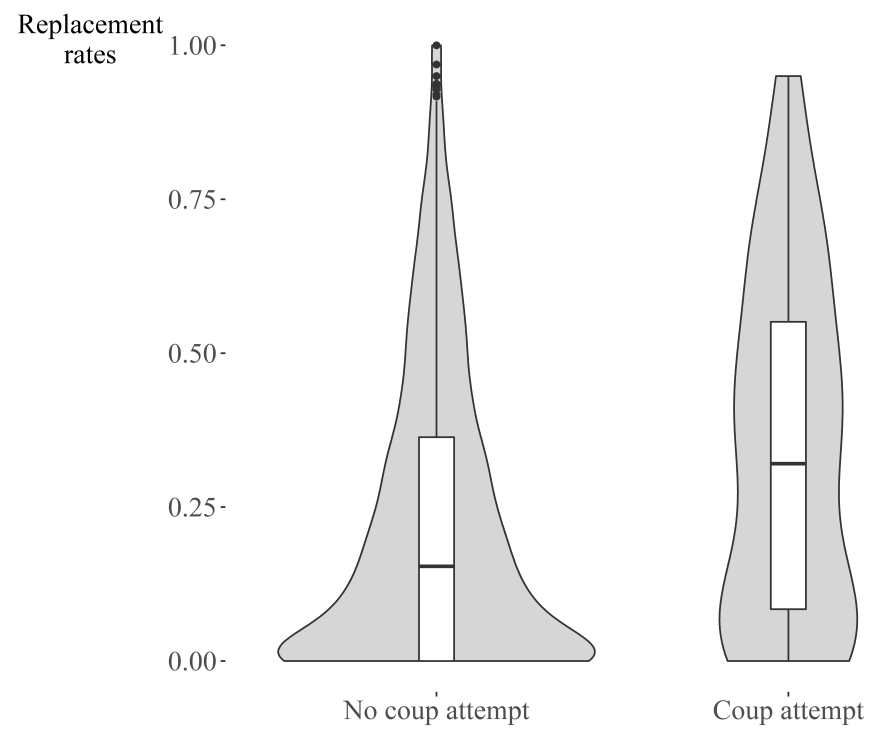

Figure 8.2 presents the main results of the regression analysis described above The regression tables containing the full results of the models in figure 8.2 can be found in Appendix E.1. As is evident, I find robust evidence supporting that members of the ruling coalition are purged in the year following a failed coup attempt. The average replacement rate increases with 11 percentage points in years following a coup attempt relative to non-coup years. The estimated replacement rate of cabinets conditional on all covariates in the "main model" is around 27 per cent, an increase of 11 percentage points means that failed coup attempts leads to an estimated replacement of almost two fifths of all ministers. Importantly, these results are highly robust regardless of the model specification, and remain highly statistically significant and on conventional $95 \%$ levels with an effect of 7-11 
percentage point increase in the replacement rate. The results are slightly weaker with leader fixed effects, but remain highly significant. Furthermore, they are also robust to adding a number of additional control variables to the estimation. This includes controlling for the occurrence of elections and time since last elections ("Electoral controls"), as well as adding further controls for economic events (GDP growth and oil income in the "Economic controls"), and when controlling for other events, including civil war onsets, nonviolent campaigns, military disputes, interstate war, and strikes in the "Instability Controls". In addition, it is robust to adding a one-, two- and three-year moving average of cabinet replacement rate to the estimation in "Purges MA's". Finally, all controls are included simultaneously in the same model dubbed "All controls".

In the right half of figure 8.2 , I investigate whether other events that may cause political instability have the same effect on replacement of core members of government. We see that neither civil wars, non-violent campaigns, military disputes, interstate wars, nor strikes robustly and significantly increase purges of cabinet ministers. This corroborates the theory by underscoring that failed coups are unique in altering the relationship between the ruling coalition and the autocrat, and is more costly to the ruling coalition than other events. Since coup attempts present a direct threat to the dictator from inside the regime, a dictator reacts to this threat by purging members of the regime elite, including his ministers, while outside threats to the regime do not have this effect. 
Figure 8.2: Main results

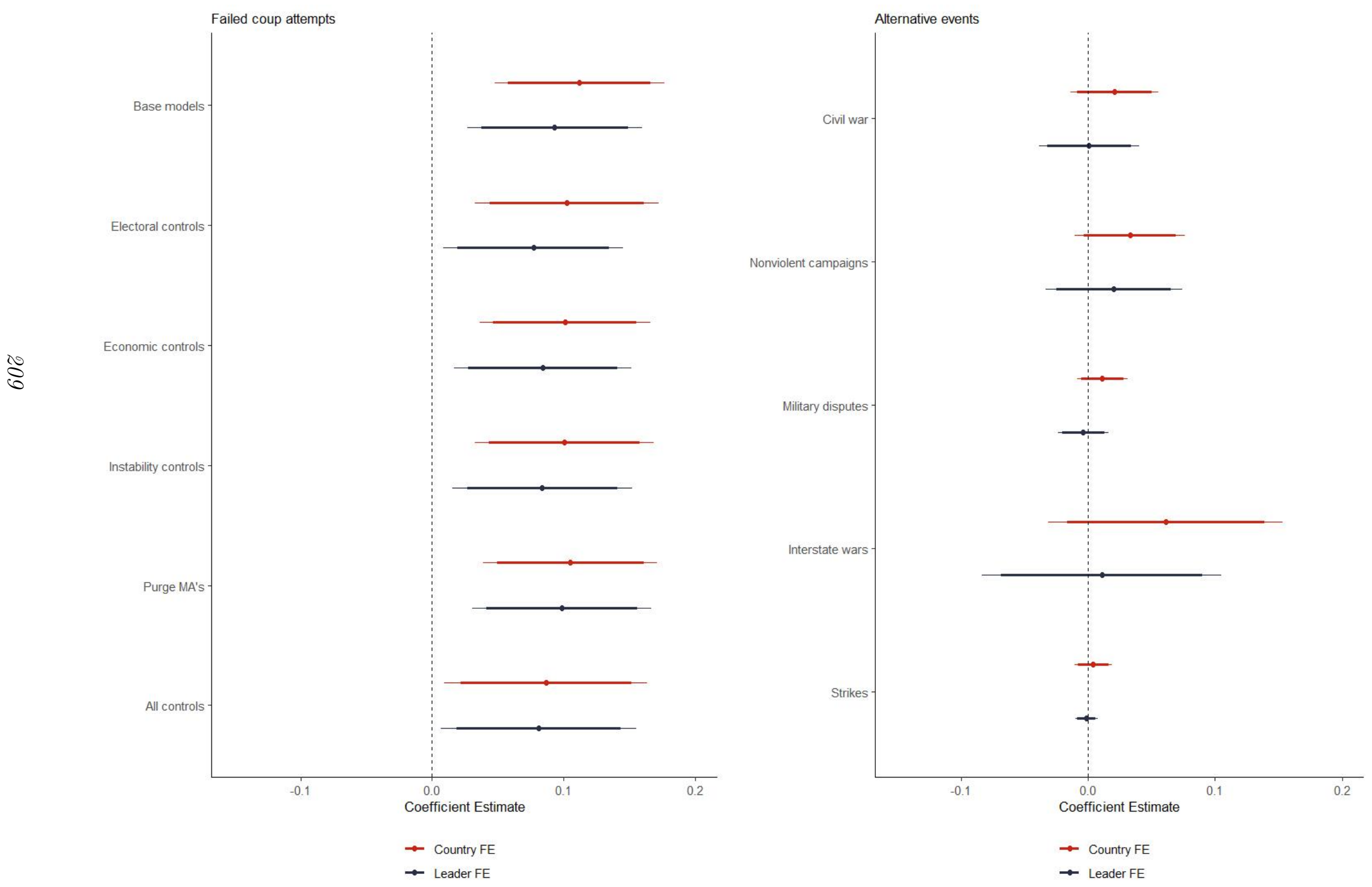

Thin lines represent 95 percent confidence intervals. Thick lines represent 90 percent confidence intervals. 
Next, I investigate whether ministers with specific characteristics are more likely to be ousted following a coup attempt. In some ways this is outside the theoretical framework which assumes that members of the ruling coalition are interchangeable. Much of the literature makes similar assumptions (De Mesquita et al. 2005, Svolik 2012). However, in practice, we should expect autocrats to be highly selective in which individuals to purge after a failed coup attempt. The following analysis shows the strength and level of detail in WhoGov and sets a direction for future research.

Figure 8.3 presents the result of this analysis. Specifically, I plot the marginal effects. This can be interpreted as the change in likelihood of being removed in years with a coup attempt relative to years without a coup attempt. Thus, if the estimate is 0.15 , this type of minister experience a 15 percentage point increase in the likelihood of being purged compared to a non-failed-coup-attempt year.

In the top left corner, we see that the dictator particularly targets the newest members of the government, while officials with more than 12 years of experience are no more likely to be fired in years following a coup attempt relative to years, where there were no coup attempt. There are two competing explanations for this. First, experience can signal strength, which is the view taken in this thesis. Experienced ministers may be more powerful, since they have connections and access to resources (Woldense 2018). Therefore, they may be more costly to purge. Second, experience can signal loyalty. Veteran ministers have survived previous purges and have had the opportunity to demonstrate their support to the ruler on several occasions. Empirically, I cannot at the moment distinguish the two, and this is an avenue for future research. 
In the top right corner, we see that cabinet members from parties other than that of the autocrat and independents are more likely to be purged following a coup attempt than the dictator's co-partisans, although the error bands are large, particularly for members from another party. This suggests that dictators purge members of the governing elite who are not connected via party affiliation, indicating that the dictator prefers to rely on loyalists in uncertain times.

In the bottom left corner, I find that the Minister of Defense and Foreign Affairs is most likely to be purged, closely followed by "other types of ministers" and the Minister of Finance, while the Minister of Natural Resources is less likely to be purged in the aftermath of a coup attempt. We should be careful interpreting on this, since the groups of ministers are not statistically significant from each other (apart from the Minister of Natural Resources). However, it suggests that ministers "with guns" - i.e. those responsible for defense and security, are those most likely to be purged from office. By contrast, ministers in charge of economic affairs and, particularly, natural resources only experience a slight and/or insignificant increase in their likelihood of being fired. The cost associated with firing these ministers may be higher, since they are important for distributing rents and managing economic affairs, which is key to avoid mounting discontent from both masses and other elites following the coup.

In the bottom right corner, I show that dictators are more likely to remove the most powerful and high-profile subordinates from their cabinets following a failed coup attempt, while there is no increase for low ranking ministers and junior ministers. Thus, higherprofile cabinet members who have more political clout and visibility and, therefore, pose 
a potentially larger threat to the ruler, are the most likely to experience the dictator's wrath in the wake of the failed coup. 
Figure 8.3: Who is purged?
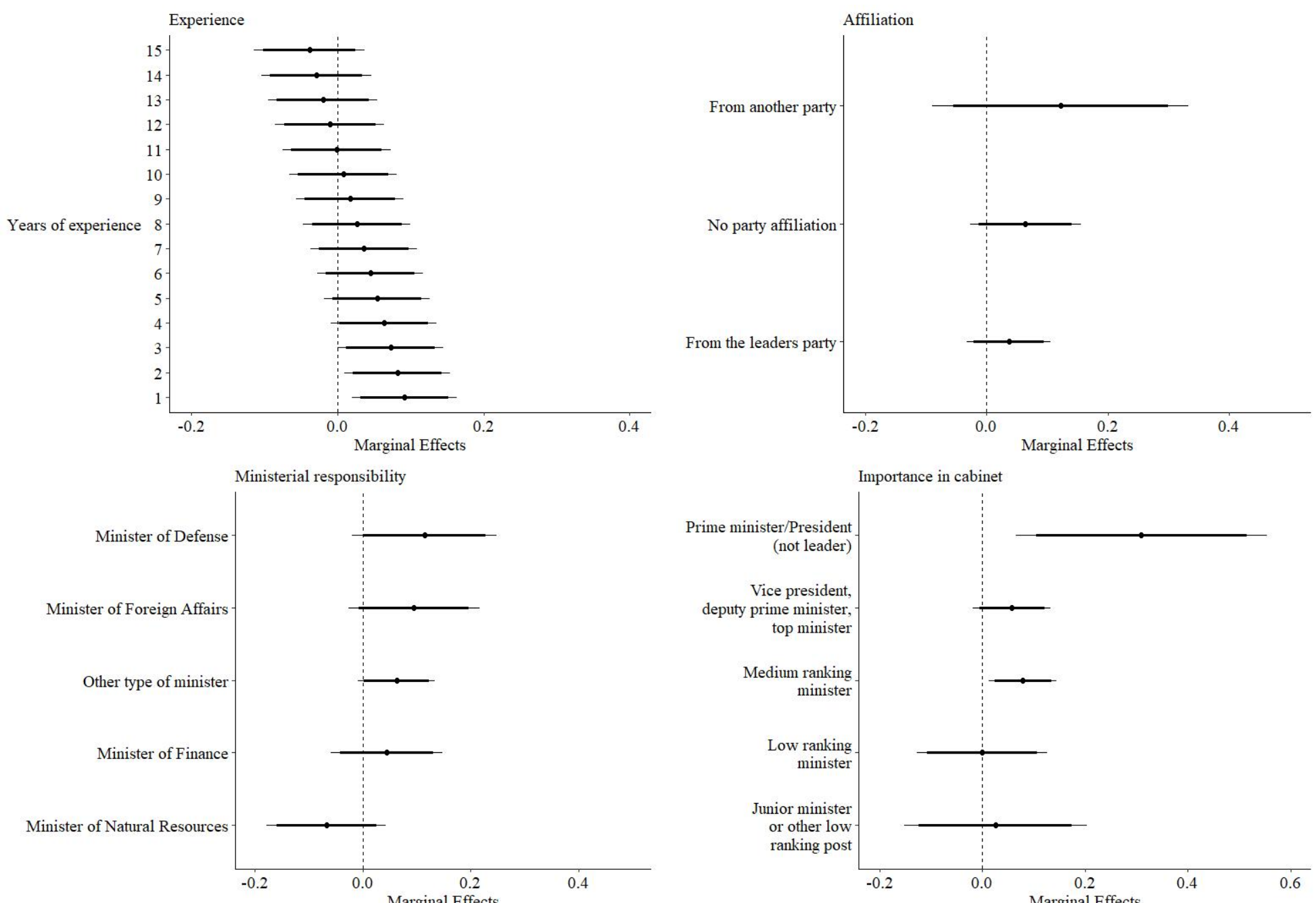

Note: $\mathrm{N}=106,144$ minister-years (103,980 in years without a coup attempt and 2,164 in years with a coup attempt). The models show the difference in likelihood of being fired for the given type of minister in years with a coup attempt relative to years without a coup attempt. All models include country-fixed effects, year-fixed effects and country-clustered standard errors and the set of controls used in the main model in figure 8.2. I do not include the different variables in the same regression. The thick bars indicate the 95 per cent confidence intervals, while the thin bars indicate the 90 per cent confident intervals. 


\subsection{The benefit of successful coup attempts}

The analysis above shows that there is a cost to the ruling elite if they unsuccessfully try to remove the dictator. However, as argued theoretically, there should also be a benefit to removing the dictator. Not only to the individual, who takes his place, but to the broader ruling coalition. Yet, is this also the case empirically?

\subsubsection{Empirical set-up}

Again, I rely on the coup data compiled by Powell and Thyne (2011). However, instead of using failed coup attempts as the independent variable, I use successful coup attempts. A coup attempt is defined as successful if the perpetrators "seize and hold power for at least seven days" (Powell and Thyne 2011, p. 252). Thus, the dictator is removed from power, and another person takes his place.

The dependent variable is changes in economic growth from the Penn World Tables (Feenstra et al. 2015), which I also used in Chapter 5. The main claim is that coups only are associated with higher economic growth if the ruling coalition manages to stay in office and secure an orderly transition of power. To measure whether the ruling coalition stays in power, I use the measure of replacement rate in the year of the coup, which was introduced in the previous analysis. Second, I also include a measure of how experienced new members of the ruling elite are on average in the year of the coup.

The analysis consists of time-series cross-sectional OLS models estimated using the following equation:

$$
\Delta Y_{i, t}=\beta_{1} C_{i, t}+\beta_{2} R_{i, t}+\beta_{3} C_{i, t} * R_{i, t}+\beta_{3} X_{i, t}+\alpha_{i}+\lambda_{t}+\varepsilon_{i, t},
$$


for $i=1, \ldots, n$ countries and $t=1, \ldots, T$ years. Where the outcome, $\Delta Y_{i, t}$, is the difference in average growth rates in the years after the coup attempt and the years before. The two main variables of interest are $R_{i, t}$, which is the replacement rate, and $C_{i, t}$, which denotes a successful coup attempt, and takes the value 0 in years without a successful coup attempt and 1 in years with a failed coup attempt. $C_{i, t} * R_{i, t}$ denotes the interaction between the two. All models include both country fixed effects, $\alpha_{i}$, and year fixed effects, $\lambda_{t}$, At last, $\varepsilon_{i, t}$ is the error term.

The econometric model is very similar to the analysis for failed coups, but differ in two ways. First, the dependent variable is now the difference in economic growth before and after the event. This differs from the variable used in chapter 5, where I looked at levels. I do so because, the claim is that a successful coup causes a positive shift in the growth rate and not in higher growth per se. Second, I include the replacement rate as one of the main independent variables. This variable is interacted with successful coups to test the claim that only coups with an orderly transition where the elite remains the same (apart from the leader) are associated with an increase in the growth rate.

\subsubsection{Analysis}

The distribution of replacement rates in years with and without a coup is shown in figure 8.4. The graph shows that replacement rates are much higher in the year following a coup, indicating that in most cases the vast majority of the cabinet are replaced when the dictator is forced from power by his own elite. However, we do also see that some successful coups leave the cabinet - or most of the cabinet - unscathed. In 19 out of the 104 successful coups in the dataset, the majority of the cabinet stays despite the change in leader. 
Figure 8.4: Distribution of replacement rates in years with and without a successful coup.

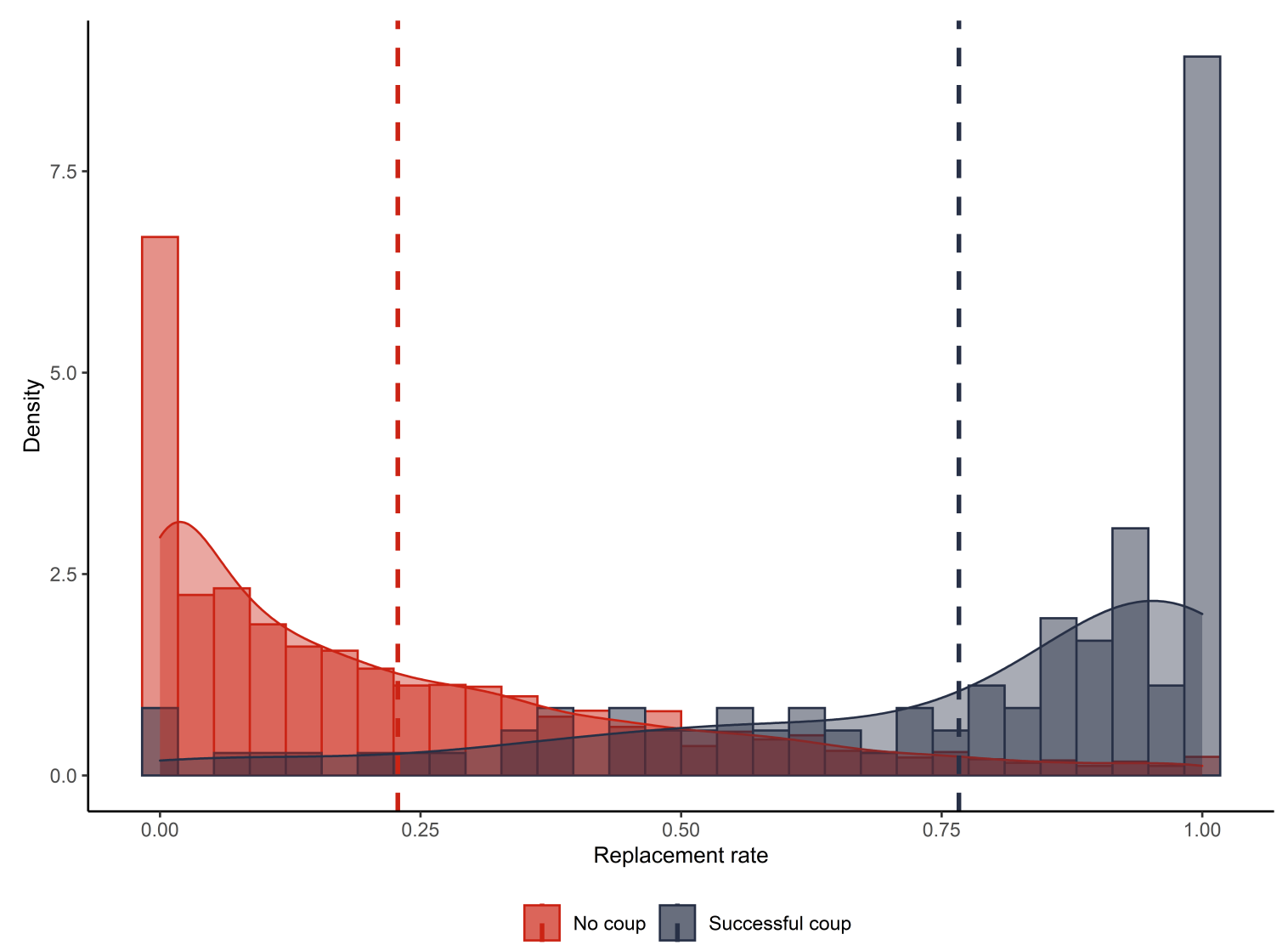

The question in this analysis is whether - or when - coups are associated with higher economic growth. The main results are found in table E.6. In the first column I run the analysis without including the interaction effect. We see that coups are unrelated to a shift in growth rates, while a higher replacement rate is related to higher economic growth.

This is surprising in the light of the results from chapter 6 , where a higher replacement rate is associated with lower economic growth. It should, however, be remembered that the set-up is different here for two reasons. First, I do not use leader fixed effects, and therefore a high replacement rate may be due to a change in leader. Thus, as discussed in chapter 6 , an economic crisis may cause a change in leader, causing the cabinet to change, and simultaneously be followed by better economic growth. Second, I look at changes in 
growth rates before and after the given year, and not the growth rate in the following year.

In the second column, I add the interaction between the coup variable and the replacement rate. The coup variable now becomes positive and statistically significant. This indicates that the growth rate, on average, is 3.77 percentage points higher per year in the three years following a successful coup, where the entire cabinet stays, compared to the three years before.

However, it is also seen that replacement rate remains positive with a coefficient size of 2.05, while the interaction between the two is larger (4.90) and negative. Thus, the positive relationship between coups and shifts in economic growth diminishes, when more of the government is replaced.

Column 3 and 4 replicate the first two columns with country and year fixed effects, and the results remain the same. In column 5, I add the alternative events from figure 8.2 to ensure that coups do not coincide with other pivotal events, which might confound the results. The coefficients become larger when these variables are added. In column 6, I use a binary measure for whether the majority of the cabinet is replaced, and find that the results replicate using this measure.

Lastly, I replace the independent variable with the difference in the average growth rate one year before and one year after (column 7) and two years before and two years after (column 8). Here, I find that the results remain similar, but that they are less significant. This indicates that it takes some time to see the association between a successful coup, where the elite remains in power, and economic growth. 
Table 8.1: Are successful coups assocaited with higher growth?

\begin{tabular}{|c|c|c|c|c|c|c|c|c|}
\hline & $(1)$ & $(2)$ & $(3)$ & $(4)$ & $(5)$ & $(6)$ & $(7)$ & $(8)$ \\
\hline Intercept & $\begin{array}{c}-0.59^{* * *} \\
(0.17)\end{array}$ & $\begin{array}{c}-0.63^{* * *} \\
(0.17)\end{array}$ & & & & & & \\
\hline Replacement rate & $\begin{array}{c}1.88^{* * *} \\
(0.61)\end{array}$ & $\begin{array}{c}2.05^{* * *} \\
(0.63)\end{array}$ & $\begin{array}{c}2.42^{* * *} \\
(0.76)\end{array}$ & $\begin{array}{c}2.61^{* * *} \\
(0.78)\end{array}$ & $\begin{array}{c}2.72^{* * *} \\
(0.99)\end{array}$ & & $\begin{array}{c}3.81^{* * *} \\
(1.22)\end{array}$ & $\begin{array}{c}2.94^{* * *} \\
(0.78)\end{array}$ \\
\hline Coup & $\begin{array}{c}0.11 \\
(0.66)\end{array}$ & $\begin{array}{l}3.77^{* *} \\
(1.65)\end{array}$ & $\begin{array}{c}0.39 \\
(0.69)\end{array}$ & $\begin{array}{l}3.99^{* *} \\
(1.72)\end{array}$ & $\begin{array}{l}4.80^{* *} \\
(2.07)\end{array}$ & $\begin{array}{l}3.41^{* *} \\
(1.47)\end{array}$ & $\begin{array}{c}3.61 \\
(2.85)\end{array}$ & $\begin{array}{c}3.56 \\
(2.27)\end{array}$ \\
\hline Replacement rate*Coup & & $\begin{array}{c}-4.90^{* *} \\
(2.05)\end{array}$ & & $\begin{array}{c}-4.86^{* *} \\
(2.18)\end{array}$ & $\begin{array}{c}-5.43^{* *} \\
(2.60)\end{array}$ & & $\begin{array}{l}-5.13 \\
(3.49)\end{array}$ & $\begin{array}{c}-4.89^{*} \\
(2.78)\end{array}$ \\
\hline Replaced $>60 \%$ & & & & & & $\begin{array}{c}1.35^{* * *} \\
(0.42)\end{array}$ & & \\
\hline Replaced $>60 \% *$ Coup & & & & & & $\begin{array}{c}-3.13^{*} \\
(1.64)\end{array}$ & & \\
\hline Notes & & & - & & + Event variables & & Dif 1 year & Dif 2 years \\
\hline Estimation method: Within year & No & No & Yes & Yes & Yes & Yes & Yes & Yes \\
\hline Estimation method: Within country & No & No & Yes & Yes & Yes & Yes & Yes & Yes \\
\hline Num. obs. & 2998 & 2998 & 2998 & 2998 & 2571 & 2998 & 3407 & 3218 \\
\hline $\mathrm{R}^{2}$ (full model) & 0.00 & 0.01 & 0.07 & 0.07 & 0.09 & 0.07 & 0.04 & 0.06 \\
\hline $\mathrm{R}^{2}($ proj model $)$ & 0.00 & 0.01 & 0.01 & 0.01 & 0.01 & 0.01 & 0.01 & 0.01 \\
\hline Num. groups: COUNTRY_ID & & & 111 & 111 & 110 & 111 & 113 & 111 \\
\hline Num. groups: year & & & 45 & 45 & 37 & 45 & 49 & 47 \\
\hline
\end{tabular}

${ }^{* * *} p<0.01 ;{ }^{* *} p<0.05 ;{ }^{*} p<0.1 . \mathrm{N}=104$ coups. Dependent variable: Difference in economic growth 3 years after compared to 3 years before. Country-clustered standard errors in parentheses. 
The interaction plot for column 4 is seen in figure 8.5, and shows that coups where the majority of the cabinet remains in office are associated with a bump in economic growth. The coefficient is significant on conventional $95 \%$ confidence level, when less than 15 percent of the cabinet is purged. On the other hand coups, where the vast majority (replacement rate $>80$ percent) of the cabinet are replaced are associated with a small negative shock to growth.

In appendix E, I run two robustness tests. First, I include the alternative measure of coups from Bjørnskov and Rode $(2018)$, and show that the results are consistent. Second, I use another measure of political instability: the average governing experience for cabinet members in the year of the coup. This is another measure of political instability, since experienced members have been in the previous administration. These results are found in Appendix E.9, and are actually stronger and clearer than the results for replacement rate.

Overall, we therefore see that successful coups are associated with higher economic growth in the years succeeding the coup compared to the years preceding the coup only if there is low political instability.

\subsection{Conclusion}

It is dangerous to be a part of the dictator's inner circle as the members of Saddam Hussein's cabinet experienced. This chapter tests what happens, when the members of the ruling coalition attempt to unseat the dictator in the light of the theory outlined earlier in this thesis.

Overall, the findings support the theory. I find that failed coup attempts lead to a substantial increase in cabinet instability immediately after the failed coup meaning that 
Figure 8.5: Marginal effect of a successful coup on difference in economic growth three years after and three years before a coup dependent on the replacement rate in the year of the coup.

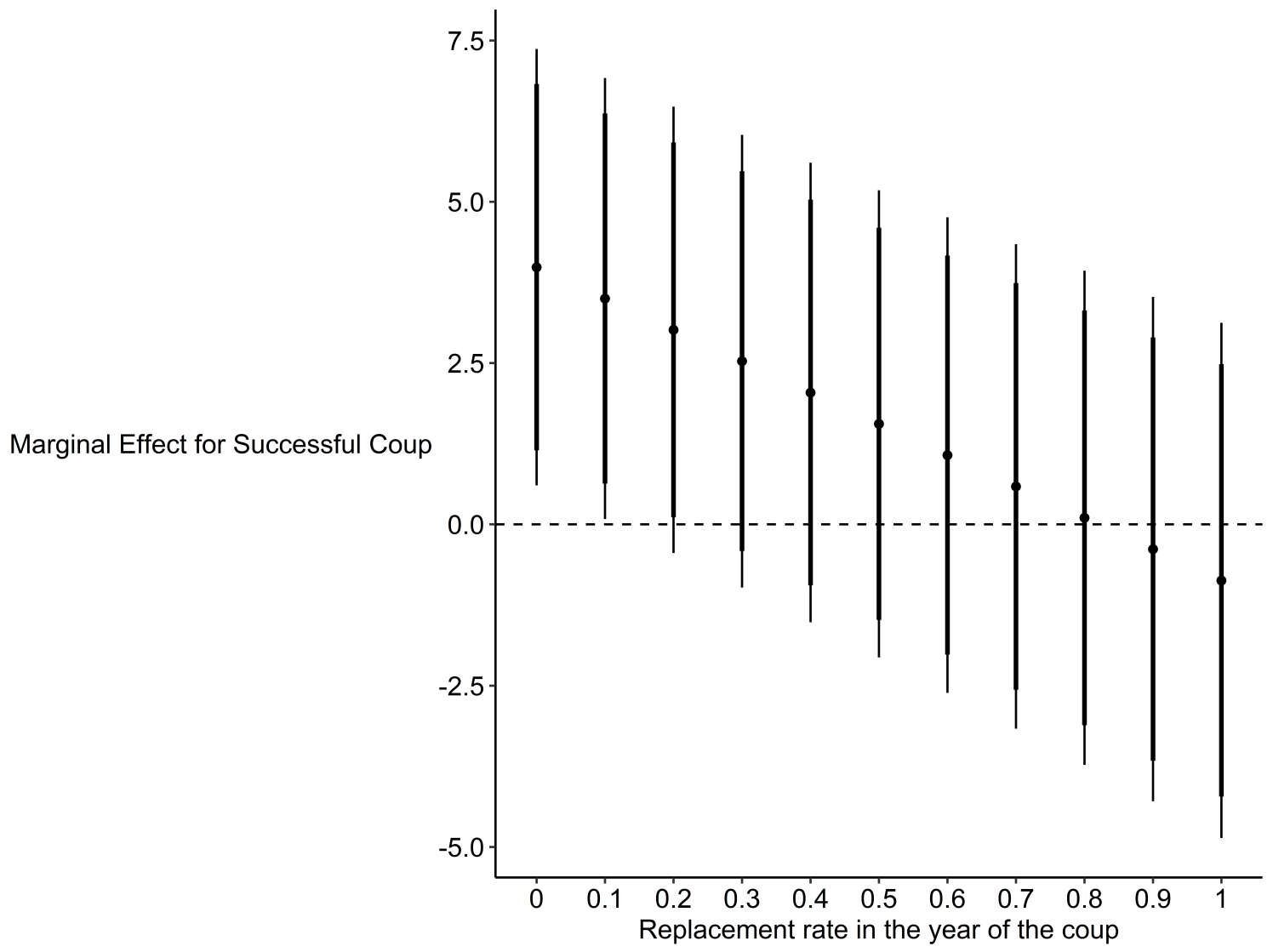

more cabinet members are purged in the aftermath of the unsuccessful coup. Furthermore, I find that dictators are most likely to purge high-profile and strategically important ministers, such as the Minister of Defense, following a coup attempt. On the other hand, cabinet members, who are experienced or politically aligned with the dictator experience a smaller increase in the likelihood of being purged.

However, the trouble for the ruling coalition does not end if they successfully stage a coup. Instead, I find that in most cases - and as predicted by the model - much of the elite is replaced in the tumultuous period following the coup. Nonetheless, this is not always the case and there are coups, where the majority of the elite remains in office after the successful coup. In these cases we generally see an up-tick in growth rates. On 
the contrary, successful coups where there are large changes in the composition of the governing coalition are not associated with better economic growth.

To sum up, if you try to overthrow the dictator, you best not miss. There is a clear cost to the ruling elite if they fail to overthrow the leader, and even if the succeed much uncertainty lies ahead. Most likely most of the ruling elite will be replaced in the aftermath. This may speak to another argument made in the theory chapter. The dictator will try to acquire more power at the expense of his allies, and they can only deter him with a credible threat of removal. Nonetheless, even if they are sufficiently powerful and consolidated to credibly threaten to overthrow the dictator, they may 1) often fail, and 2) even if they succeed it is uncertain whether they will actually remain in power. Therefore, they will be reluctant to rebel under most circumstances which gives the dictator the upper hand by default. These dynamics may further the emergence of a "one-man" dictatorship. 
It is true, those who maintain that the goodness of all government consists in the goodness of the administration may cite many particular instances in history where the very same government, in different hands, has varied suddenly into the two opposite extremes of good and bad.

— David Hume (Hume 1994)

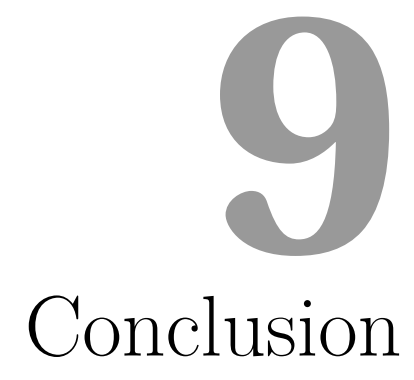

At 12:10 on the 9th of September 1976 Mao changed world history and started a process which lifted hundreds of millions of people out of poverty through one simple and involuntary action; he got a heart attack and died.

There was no clear successor to Mao, and his death was followed by a struggle between the Gang of Four and the acting premier, Hua Guofeng, and his allies, resulting in the comeuppance of the Gang of Four. This resulted in the end of "radical Maoism" which had brought such chaos and destruction (Vogel 2011, p. 183). Hua, lacking Mao's control over the party, was under pressure and was looked down upon by senior members of the party. Deng Xiaoping outmaneuvered Hua in December 1978, and became the paramount leader, despite never becoming the official head of government.

Deng did not become as powerful as Mao within the party and embraced the notion of inner-party democracy,. Furthermore, he believed that economic growth would strengthen his rule and the authority of the party (Vogel 2011, p. 384). In his wake a new collective political system was established. Zhang Weiwei, a professor at Fudan University, defended 
the post-Mao system in the New York Times in 2012 when he wrote that "Collective leadership is practiced within the Politburo in part to prevent the type of personality cult we witnessed during the Cultural Revolution. These carefully designed changes have eliminated any possibility of permanent entrenchment of power in the hands of any individual leader" (Weiwei 2012).

Alas, Zhang's words did not age well. In 2018, Xi Jinping removed the term limits on the Chinese president, and he was thereby allowed to become president for life. Xi is not alone in amassing power. Across the globe we are seeing authoritarian leaders consolidating power, while democracy is struggling. As argued in the introduction, this process is being imitated in the hearts and minds of the population. We have seen a resurgence in the belief of the developmental benefits of having a strong authoritarian leader. This is what I dub "the myth of the benevolent autocrat".

This thesis investigates this myth using a wealth of historic data sources, including the largest available dataset on political elites. Overall, the conclusion is clear; the thesis renders little support for the developmental beliefs in a strong leader. Instead, we see that autocrats who crush civil society and purge members of the ruling coalition govern over lower economic development.

The thesis reaches this conclusion through several steps. First, I argue that existing approaches to explaining growth within authoritarian regimes can be improved. The literature often relies on a static approach to autocracies by categorizing the regime according to the organization the leader belongs to or based on whether quasi-democratic institutions exist. The thesis proposes a new approach to classifying authoritarian regimes. The approach 
is based on Svolik's (2012) two challenges to the dictator. The first comes from the masses over which they rule, while the second comes from those with whom they rule. I argue that these constitute two types of constraints, namely external and internal constraints. However, the thesis does not define constraints in institutional terms which has been the norm in recent literature. Instead, constraints are perceived as being the result of power relationships, where other powerful actors can constrain the leader with the threat of violence. To measure the power balance, I rely on Arendt's concept of isolation. She focuses on actors ability to act together in the pursuit of a common concern. Thus, I argue that at dictator can be held accountable in the absence of democratic elections by a cohesive ruling elite (internal constraints) and an organized civil society (external constraints). Next, I use a formal model to show that a dictator will act differently, when the ruling elite or the civil society credibly can threaten the dictator with removal and thereby hold him to account. This increases the likelihood that he will choose actions that are costly for him individually, but yields benefits to others. This will result in a pluralistic and thoughtful decision-making process and a better environment for investment. Ultimately, the expectation, therefore, is that both types of constraints are related to better economic development. Furthermore, I theorize that both types of constraints are related to higher economic growth, while only external constraints are related to better human development.

To operationalize the two types of constraints and test the theoretical model I introduce a new dataset, WhoGov, which was created for the purpose of this thesis. The dataset is the largest available dataset on members of cabinets and is useful for answering the questions put forward in this thesis. Moreover, WhoGov is a useful resource both for comparativists 
and country experts for answering many other questions. WhoGov enables me to perceive the tenure of an autocrat as a process where the level of constraints varies over time.

The analysis proceeds in several steps. Most importantly, I find that autocrats who are constrained are held accountable for bad economic outcomes. Thus, autocrats who face an organized and experienced ruling elite and/or a strong civil society are more likely to be punished and removed from office in the aftermath of a severe economic recession. Second, I use the dynamic nature of the two variables, and show that the same dictator governs over worse economic outcomes when there are less constraints on his rule. Furthermore, the two types of constraints function as imperfect substitutes. An increase in one type of constraints decreases the importance of the other. Combined, these two findings indicate a vicious circle, where unconstrained dictators produce lower growth and are less likely to be punished for this. I also find that only external constraints are related to better human development outcomes. Thus, an oligarchic elite may help foster economic growth by securing investments and holding the autocrat accountable. Nonetheless, this will be of little benefit to the poorest in a country. A strong civil society is needed to ensure that the gains are redistributed to the wider population.

The main analysis is supported by two additional analyses. In the first, I use the Tulip Revolution that took place in Kyrgyzstan in 2005 to show that a shock to the level of external constraints caused public spending on education and health care to increase. However, I am unable to find such effects for actual development outcomes. In the second analysis, I show that it is risky for the ruling elite to launch a coup attempt against the dictator. An unsuccessful coup is usually followed by massive purges. However, I 
also show that successful coups are associated with higher economic growth insofar as the coup does not destabilize the governing coalition.

The conclusions from this thesis are not set in stone. Critical readers may come up with several points of critique. Here, I shall discuss three weaknesses and use this to outline agendas for future research.

First, readers may ask: does the cabinet capture the ruling coalition? WhoGov primarily contains data on cabinet members and not the wider ruling coalition. Autocracies are notoriously opaque and in some cases the most powerful people in the country do not possess official roles (Frantz 2018, p. 22). Yet, there is good reason to suspect that the government is a particularly pertinent group of individuals. The government constitutes an executive body made up of top-level regime officials with substantial decision-making power and direct links to other elites (Kroeger 2018). This is all the more relevant as most leaders have a political background before becoming the leader (Ellis et al. 2015), and a substantial amount of coups are organized by civilians, including cabinet members (Bjørnskov and Rode 2018). A famous recent example is Emmerson Mnangagwa, who was Mugabe's Vice-President before coming to power via a coup in November 2017. Furthermore, the data was originally gathered by the CIA to brief US Government officials, meaning that the officials mentioned were important for US intelligence. Additionally, I was able to gather this data consistently over time. Thus, while the ministerial cabinet is not a perfect reflection of the ruling elite or "winning coalition" (De Mesquita et al. 2005), it constitutes one of the most important parts. WhoGov is therefore a great contribution to the study of autocratic politics. Nonetheless, WhoGov is only in its infancy, and future 
research should focus on mapping a larger section of the ruling elite. There are already promising projects such as Matthew's (2020) ARED-database or Gerring et al.'s (2019) GLP-database. It will be exciting to see how added data nuance the results presented in this thesis. In addition, there are other projects trying to measure the power balance within leader such as Geddes et al. (2017) and Gandhi and Sumner (2020). Future research could triangulate the results from this project using these measures. ${ }^{1}$

Second, readers focusing on causal inference may doubt whether the relationship between the two types of constraints and economic development is causal. It is challenging to have a very tight causal identification strategy with this question. The manuscript relies on different econometric methods to triangulate the results, and it is the first attempt to examine the role of constraints over time within leader. Therefore, I maintain that there is value added even in the absence of a design using a clear causal identification strategy. However, as is practice, causal interpretations should be restrained, and there is much scope for future research using other methods to better identify the causal mechanism. Because of the country and leader fixed effects, time-variant confounders are of particular concern. The optimal strategy would therefore be to find exogenenous time-variant determinants of the two measures of constraints and use these as instrument variables. In the last two empirical chapters I attempt to look at chocks to both external and internal constraints, but there is still much research to be done to convince sceptical critics.

Third, readers may argue that this framework downplays the role of institutions. Even though I do not not focus on institutions, institutions can play an important

\footnotetext{
${ }^{1}$ It is patent that I should cross-validate the new measure with these datasets. However, both measures are very new and were developed in parallel with the WhoGov dataset. I did therefore not have the opportunity to do so before the submission deadline.
} 
role since they can work to solve collective actions problems. For example, Bunce and Wolchik (2011) make a strong case for the causal role of elections and electoral campaigns during the Colour Revolutions, and other researchers have used election timing as a source of exogenous variation in dictatorships (Wig and Rød 2016). Likewise, there is a growing literature on the existence of organized parties in autocracies, and how they solve coordination problems (Bizzarro et al. 2018, Miller 2019). Thus, institutions can serve as focal points for concerted actions among otherwise atomized opposition forces. Institutions can therefore be influential in interaction with the two measures of constraints. For example, an organized civil society may react very differently in a dictatorship with and without elections, causing the dictator pay more attention to external constraints if there are elections. It is therefore possible to further develop the framework by paying closer attention to the role of institutions. Related, the thesis does not, in depth, explore the sources of cohesion in both the ruling elite and the civil society. These can, for example, be ethnic ties, material resources, or foreign support. Some sources are held constant due to the fixed effects design in the analysis, while others are not. Nonetheless, future research should delve into this further.

Despite these critiques, I contend that the theory and findings presented in this thesis has important implications for at least three current debates.

\section{Why do some dictators preside over disasters?}

The manuscript mentions several examples of autocrats governing over policy disasters. For example, Mao's Great Leap Forward, Bokassa's lavish coronation ceremony and Banda's corruption. These are only some of the many historical examples. Nicolae 
Ceausescu attempted to expand the size of Romania's labour force by imposing taxes on childless couples, banning contraception and abortion, restricting divorce, and giving gifts to mothers with more than five children. This caused a short spike in birth rates that was followed by a crisis of the welfare system and increasing poverty rates (Kligman 1998).

The manuscript argues that these disasters can be explained by the lack of constraints in the form of actors who are able to hold the dictator accountable. It is not new that the lack of constraints on the leader can lead to policy disasters. Many scholars make similar arguments (Acemoglu and Robinson 2012, Rizio and Skali 2019; Svolik 2012). Yet, the thesis add nuances to this argument.

Much of the previous literature jumps from the lack of constraints to catastrophic outcomes without discussing the paths that connect the two. The thesis put forward a more stringent explanation for how the lack of constraints leads to policy disasters, and argue that it works through three channels; 1) preference diversification, 2) a more competent and thoughtful decision making process and 3) a better environment for investment.

A dictatorship that develops into a one-man regime is characterized by a virtual absence of both internal and external constraints. Here, the dictator is free to implement any policy they want, however misguided it might be. In addition, the decision making-process is severely hampered at this point, since competent members of the ruling coalition will have been replaced and the advisors who are left may be reluctant to share their information with the dictator due to the fear of punishment. This will create great uncertainty for investors who will respond by seeking opportunities outside the country for their capital or by choosing short-term and less risky forms of investments. 
However, the main contribution to this discussion is empirical. In chapter 6, I show that a vicious circle is built into dictatorship. Dictators will govern over worse economic development when they become more powerful, and in addition they will be less likely to be held accountable for the outcomes they govern over. This logic helps us understand why so many autocrats lead their country to ruin.

\section{Why do some people support authoritarian leaders?}

Thus, troubled times may be ahead for populations governed by increasingly powerful dictators. Therefore, the results serve as a warning for people who may support the rule of a dictator in the making. The long term costs may be high for everyone - with the possible exception of the dictator.

Despite the potential costs why do some people support an increasingly authoritarian leader? This is a question a rapidly growing literature tries to answer. Researchers point toward different explanations such as polarization (Graham and Svolik 2020, Svolik 2019), preference falsification (Kuran 1991a; Kuran 1991b), clientelism (Ellen Lust 2009; Magaloni 2006) or the need for stability (Pepinsky 2017).

The findings in this thesis can add nuances to this. The rational for supporting a leader may vary over time within leader. In the first years of the tenure, the leader may not be powerful and therefore relies on "performance legitimacy," namely, popular support based on sound economic performance (Hansen 1974). Thus, explanations based on the need for stability and perceived benefits from a strong leader may be more prevalent in the early years of the regime. However, as argued, autocrats try to atomize their subjects by destroying their potential for collective action. Thus, polarization and preference 
falsification may be better explanations for support when the dictator becomes more powerful. As argued in the formal model, the dictator may first show his true colours, when he successfully has consolidated power.

\section{Is this an argument for a (more) democratic future?}

This leads me to the third debate, where the thesis can refine old debates. The manuscript does not explicitly deal with the question of whether autocracy or democracy promotes higher economic growth, but the question naturally arises. When telling laymen about this project I am surprisingly often asked the question Is autocracy better for development than democracy?. I discuss the literature answering this question in Chapter 4, and argue that the answer is inconclusive; although newer research tilts toward supporting democracy. Throughout this piece I argue that we should perceive authoritarian rule as a process where the ruler continuously tries to atomize the ruling elite and civil society, so he can rule unconstrained. If he succeeds we will, on average, expect worse economic development. Thus, autocracy can be a trap. The population and the ruling coalition risk being lulled into the false belief that they are governed by a benevolent leader. Alas, this belief has too many times turned out to be misplaced, resulting in catastrophic outcomes. While democracy may be imperfect, the institutional framework is stronger, and should be able to hold the leader accountable. This is not the case in autocracy. Therefore, democracy does not suffer from the same inbuilt risk. Autocracy is a gamble with the devil; where the devil often wins. 


\section{Works Cited}

Aaskoven, Lasse, Laure Bokobza, Suthan Khrisnarajan, Jacob Nyrup, and Casper Sakstrup (2020). "The Morning After: Cabinet Instability and the Purging of Ministers after Failed Coup Attempts in Autocracies". In: Working paper.

Aaskoven, Lasse and Jacob Nyrup (2020). "Performance and Promotions in an Autocracy:

Evidence from Nazi Germany". In: Forthcoming in Comparative Politics.

Abadie, Alberto, Alexis Diamond, and Jens Hainmueller (2010). "Synthetic Control Methods for Comparative Case Studies: Estimating the Effect of California's Tobacco Control Program". In: Journal of the American statistical Association 105.490, pp. 493-505.

- (2015). "Comparative Politics and the Synthetic Control Method". In: American Journal of Political Science 59.2, pp. 495-510.

Acemoglu, Daron (2009). Introduction to Modern Economic Growth. Princeton: Princeton University Press.

Acemoglu, Daron, Simon Johnson, James Robinson, and Pierre Yared (2008). "Income and Democracy". In: American Economic Review 98.3, pp. 808-842.

Acemoglu, Daron, Simon Johnson, and James A. Robinson (2005). "Institutions as a Fundamental Cause of Long-Run Growth". In: Handbook of Economic Growth. Vol. 1. Amsterdam; Boston: Elsevier, pp. 385-472.

Acemoglu, Daron, Suresh Naidu, Pascual Restrepo, and James A. Robinson (2019). "Democracy Does Cause Growth". In: Journal of Political Economy 127.1, pp. 47-100.

Acemoglu, Daron and James A Robinson (2006). "Economic Backwardness in Political Perspective". In: American Political Science Review 100.1, pp. 115-131.

- (2012). Why Nations Fail: The Origins of Power, Prosperity, and Poverty. London: Profile Books.

Aisen, Ari and Francisco José Veiga (2013). "How Does Political Instability Affect Economic Growth?" In: European Journal of Political Economy 29, pp. 151-167.

Alesina, Alberto, Sule Özler, Nouriel Roubini, and Phillip Swagel (1996). "Political Instability and Economic Growth". In: Journal of Economic Growth 1.2, pp. 189-211.

Alexiadou, Despina (2016). Ideologues, Partisans, and Loyalists: Ministers and Policymaking in Parliamentary Cabinets. Oxford: Oxford University Press.

Alexiadou, Despina and Hakan Gunaydin (2019). "Commitment or Expertise? Technocratic Appointments as Political Responses to Economic Crises". In: European Journal of Political Research 58.3, pp. 845-865.

Anderson, John (1999). Kyrgyzstan: Central Asia's Island of Democracy? London: Routledge. Ansell, Ben W. (2010). From the Ballot to the Blackboard: The Redistributive Political Economy of Education. New York: Cambridge University Press.

Ansell, Ben W and David J Samuels (2014). Inequality and Democratization. New York: Cambridge University Press.

Arendt, Hannah (1951). The Origins of Totalitarianism. London: Penguin Books.

Arriola, Leonardo R. (2009). "Patronage and Political Stability in Africa". In: Comparative Political Studies 42.10, pp. 1339-1362. 
Arriola, Leonardo R. and Martha C. Johnson (2014). "Ethnic Politics and Women's Empowerment in Africa: Ministerial Appointments to Executive Cabinets". In: American Journal of Political Science 58.2, pp. 495-510.

Bäck, Hanna, Patrick Dumont, Henk Erik Meier, Thomas Persson, and Kaare Vernby (2009). "Does European Integration Lead to a Presidentialization'of Executive Politics? Ministerial Selection in Swedish Postwar Cabinets". In: European Union Politics 10.2, pp. 226-252.

Bank, World (2019). Doing Business 2019. Tech. rep., p. 311.

Banks, Arthur and Kenneth A. Wilson (2015). Cross-National Time-Series Data Archive. Jerusalem: Databanks International.

Barnes, Tiffany D. and Diana Z. O'Brien (2018). "Defending the Realm: The Appointment of Female Defense Ministers Worldwide". In: American Journal of Political Science 62.2, pp. 355-368.

Barros, Robert (2016). "On the Outside Looking in: Secrecy and the Study of Authoritarian Regimes". In: Social Science Quarterly 97.4, pp. 953-973.

Beauchamp, Zack (Nov. 2017). The Purge in Saudi Arabia, Explained. https://www.vox.com/world/2017/11/6/16613088/saudi-arabia-princes-arrestedmohammed-bin-salman.

Bego, Ingrid (2014). "Accessing Power in New Democracies: The Appointment of Female Ministers in Postcommunist Europe". In: Political Research Quarterly 67.2, pp. 347-360.

Beissinger, Mark R. (2007). "Structure and Example in Modular Political Phenomena: The Diffusion of Bulldozer/Rose/Orange/Tulip Revolutions". In: Perspectives on Politics 5.02.

Bellows, Thomas J. (2009). "Meritocracy and the Singapore Political System". In: Asian Journal of Political Science 17.1, pp. 24-44.

Berlinski, Samuel, Torun Dewan, and Keith Dowding (2010). "The Impact of Individual and Collective Performance on Ministerial Tenure". In: The Journal of Politics 72.2, pp. 559-571.

Bernhard, Michael, Staffan Lindberg, Eitan Tzelgov, Dong-Joon Jung, and Michael Coppedge (2015). "The Varieties of Democracy Core Civil Society Index". In: Available from https://www.v-dem.net/media/filer_public/b4/66/b4667c50-1a31-4092-9e44425f76fae191/v-dem_working_paper_2015_13.pdf.

Berry, Christopher R. and Anthony Fowler (2017). "Leadership or Luck? Randomization Inference for Leader Effects (RIFLE)". In: Working paper.

Bértoa, Fernando Casal (2020). Database on WHO GOVERNS in Europe and beyond, PSGo. Available from https://www.whogoverns.eu/.

Besley, Timothy (2006). Principled Agents?: The Political Economy of Good Government. New York: Oxford University Press.

Besley, Timothy and Masayuki Kudamatsu (2008). "Making Autocracy Work". In: Institutions and Economic Performance. Cambridge, Massachusetts: Harvard University Press, pp. $452-510$.

Besley, Timothy and Marta Reynal-Querol (2011). "Do Democracies Select More Educated Leaders?" In: American Political Science Review, pp. 552-566.

Bienen, Henry and Nicolas Van de Walle (1992). "A Proportional Hazard Model of Leadership Duration". In: The Journal of Politics 54.3, pp. 685-717.

Bizzarro, Fernando, John Gerring, Carl Henrik Knutsen, Allen Hicken, Michael Bernhard, Svend-Erik Skaaning, Michael Coppedge, and Staffan I Lindberg (2018). "Party Strength and Economic Growth". In: World Politics 70.2, pp. 275-320.

Bjørnskov, Christian and Martin Rode (2018). "Regime Types and Regime Change: A New Dataset". In: Available from http://www.christianbjoernskov.com/bjoernskovrodedata/. Blaydes, Lisa and Mark Andreas Kayser (2011). "Counting Calories: Democracy and Distribution in the Developing World". In: International Studies Quarterly 55.4, pp. 887-908. 
Boix, Carles and Milan W Svolik (2013). "The Foundations of Limited Authoritarian Government: Institutions, Commitment, and Power-Sharing in Dictatorships". In: The Journal of Politics 75.2, pp. 300-316.

Bolt, Jutta, Inklaar, Robert, Jong, Herman de and Jan Luiten van Zanden (2018). "Rebasing 'Maddison': New Income Comparisons and the Shape of Long-Run Economic Development". In: Available from https://www.rug.nl/ggdc/html_publications/memorandum/gd174.pdf.

Box-Steffensmeier, Janet M and Bradford S Jones (2004). Event History Modeling: A Guide for Social Scientists. Cambridge University Press.

Braithwaite, Jessica Maves and Jun Koga Sudduth (2016). "Military Purges and the Recurrence of Civil Conflict". In: Research \& Politics 3.1, p. 2053168016630730.

Braun, Matías and Claudio Raddatz (2010). "Banking on Politics: When Former High-Ranking Politicians Become Bank Directors". In: The World Bank Economic Review 24.2, pp. 234-279.

Bright, Jonathan, Holger Döring, and Conor Little (2015). "Ministerial Importance and Survival in Government: Tough at the Top?" In: West European Politics 38.3, pp. 441-464.

Broström, Göran (2012). Event History Analysis with R. CRC Press.

Brown, Archie (2014). The Myth of the Strong Leader: Political Leadership in the Modern Age. Boulder: Basic Books.

Brownlee, Jason (2007). Authoritarianism in an Age of Democratization. New York: Cambridge University Press.

Buehler, Matt and Mehdi Ayari (2018). "The Autocrat's Advisors: Opening the Black Box of Ruling Coalitions in Tunisia's Authoritarian Regime". In: Political Research Quarterly 71.2, pp. 330-346.

Bunce, Valerie J. and Sharon L. Wolchik (2011). Defeating Authoritarian Leaders in Postcommunist Countries. Cambridge University Press.

Burke, Edmund (1842). The Works of the Right Hon. Edmund Burke, with a Biographical and Critical Introduction, by Henry Rogers, and Portrait after Sir Joshua Reynolds. Samuel Holdsworth.

Camerlo, Marcelo and Cecilia Martinez-Gallardom (2020). The Presidential Cabinets Project. Available from https://www.presidentialcabinets.org.

Camerlo, Marcelo and Aníbal Pérez-Liñán (2015). "Minister Turnover, Critical Events, and the Electoral Calendar in Presidential Democracies". In: The Journal of Politics 77.3, pp. 608-619.

Cammack, Diana and Tim Kelsall (2011). "Neo-Patrimonialism, Institutions and Economic Growth: The Case of Malawi, 1964-2009". In: IDS Bulletin 42.2, pp. 88-96.

Campello, Daniela and Cesar Zucco (2016). "Presidential Success and the World Economy". In: The Journal of Politics 78.2, pp. 589-602.

Carter, David B. and Curtis S. Signorino (2010). "Back to the Future: Modeling Time Dependence in Binary Data". In: Political Analysis 18.3, pp. 271-292.

Chacha, Mwita and Jonathan Powell (2017). "Economic Interdependence and Post-Coup Democratization". In: Democratization 24.5, pp. 819-838.

Chandra, Siddharth and Nita Rudra (2015). "Reassessing the Links between Regime Type and Economic Performance: Why Some Authoritarian Regimes Show Stable Growth and Others Do Not". In: British Journal of Political Science 45.2, pp. 253-285.

Chang, Jung (2003). Wild Swans: Three Daughters of China. New York: Simon and Schuster.

Cheibub, José Antonio, Jennifer Gandhi, and James Raymond Vreeland (2010). "Democracy and Dictatorship Revisited". In: Public choice 143.1-2, pp. 67-101.

Chenoweth, Erica and Orion A Lewis (2013). "Unpacking Nonviolent Campaigns: Introducing the NAVCO 2.0 Dataset". In: Journal of Peace Research 50.3, pp. 415-423. 
Cheterian, Vicken (2010). "Kyrgyzstan: Central Asia's Island of Instability". In: Survival 52.5, pp. 21-27.

Collins, Kathleen (2011). "Kyrgyzstan's Latest Revolution". In: Journal of Democracy 22.3, pp. 150-164.

Coppedge, Michael (2012). Democratization and Research Methods. New York: Cambridge University Press.

Crabb, John H (1978). "The Coronation of Emperor Bokassa". In: Africa Today 25.3, pp. 25-44.

Cullen, Trevor (1994). Malawi: A Turning Point. Edinburgh: Pentland Press.

Dahlum, Sirianne and Tore Wig (Jan. 2019). "Educating Demonstrators: Education and Mass Protest in Africa". In: Journal of Conflict Resolution 63.1, pp. 3-30.

Davenport, Christian (2007). "State Repression and Political Order". In: Annual Review of Political Science 10.1, pp. 1-23.

De Mesquita, Bruce Bueno and Alastair Smith (2011). The Dictator's Handbook: Why Bad Behavior Is Almost Always Good Politics. New York: Public Affairs.

De Mesquita, Bruce Bueno, Alastair Smith, James D. Morrow, and Randolph M. Siverson (2005). The Logic of Political Survival. Cambridge, Massachusetts: MIT press.

Derpanopoulos, George, Erica Frantz, Barbara Geddes, and Joseph Wright (2016). "Are Coups Good for Democracy?" In: Research ES Politics 3.1, p. 2053168016630837.

Diamond, Larry (2002). "Thinking about Hybrid Regimes". In: Journal of democracy 13.2, pp. 21-35.

Dikötter, Frank (2010). Mao's Great Famine: The History of China's Most Devastating Catastrophe, 1958-1962. London: Bloomsbury.

Döring, Holger and Philip Manow (2019). "Parliaments and Governments Database (ParlGov): Information on Parties, Elections and Cabinets in Modern Democracies". In: Working paper.

Döring, Holger and Sven Regel (2019). "Party Facts: A Database of Political Parties Worldwide". In: Party Politics 25.2, pp. 97-109.

Doucouliagos, Hristos and Mehmet Ali Ulubasogly (2008). "Democracy and Economic Growth: A Meta-Analysis". In: American Journal of Political Science 52.1, pp. 61-83.

Dowding, Keith and Patrick Dumont (2008). The Selection of Ministers in Europe: Hiring and Firing. Routledge.

Easterly, William (2014). The Tyranny of Experts: Economists, Dictators, and the Forgotten Rights of the Poor. Basic Books.

Easterly, William and Steven Pennings (2016). "Shrinking Dictators: How Much Economic Growth Can We Attribute to National Leaders?" In: Development Research Institute Working Paper 94.

Easton, Malcolm R. and Randolph M. Siverson (2018). "Leader Survival and Purges after a Failed Coup d'état". In: Journal of Peace Research 55.5, pp. 596-608.

Egorov, Georgy and Konstantin Sonin (2011). "Dictators and Their Viziers: Endogenizing the Loyalty-Competence Trade-Off". In: Journal of the European Economic Association 9.5, pp. 903-930.

Eibl, Ferdinand and Steffen Hertog (2017). "Why Are Some Oil Dictators Nice to Their People?" In: Working paper.

Elgie, Robert and Iain McMenamin (2008). "Political Fragmentation, Fiscal Deficits and Political Institutionalisation". In: Public Choice 136.3-4, pp. 255-267.

Ellen Lust (2009). "Competitive Clientelism in the Middle East". In: Journal of Democracy 20.3, pp. $122-135$.

Ellis, Cali Mortenson, Michael C. Horowitz, and Allan C. Stam (2015). "Introducing the LEAD Data Set". In: International Interactions 41.4, pp. 718-741. 
Er, Lam Peng (1999). "Singapore: Rich State, Illiberal Regime". In: Driven by Growth: Political Change in the Asia-Pacific Region. James William Morley. Armonk, NY ; London: M.E. Sharpe, pp. 255-274.

Escobar Lemmon, Maria and Michelle M. Taylor-Robinson (2005). "Women Ministers in Latin American Government: When, Where, and Why?" In: American Journal of Political Science 49.4, pp. 829-844.

European Bank for Reconstruction \& Development (2016). Macro Economic Data.

Fails, Matthew D. (2020). "Are Electoral Autocracies Better for the Poor? Evidence from Social Assistance Programs". In: Research \& Politics 7.3.

Fearon, James D (2005). "Primary Commodity Exports and Civil War". In: Journal of conflict Resolution 49.4, pp. 483-507.

Feenstra, Robert C, Robert Inklaar, and Marcel P Timmer (2015). "The next Generation of the Penn World Table". In: American Economic Review 105.10, pp. 3150-82.

Fischer, Jörn, André Kaiser, and Ingo Rohlfing (2006). "The Push and Pull of Ministerial Resignations in Germany, 1969-2005". In: West European Politics 29.4, pp. 709-735.

Flores, Alejandro Quiroz (2016). Ministerial Survival During Political and Cabinet Change: Foreign Affairs, Diplomacy and War. London: Taylor \& Francis.

Foa, Roberto Stefan and Yascha Mounk (2016). "The Democratic Disconnect". In: Journal of democracy 27.3 , pp. 5-17.

Foa, Roberto Stefano, A. Claystone, M. Slade, A. Rand, and R. Williams (2020). "The Global Satisfaction with Democracy Report 2020". In: Bennett Institute for Public Policy, University of Cambridge.

Foges, Clare (2018). "Our Timid Leaders Can Learn from Strongmen". In: The Times.

Fosu, Augustin Kwasi (2002). "Political Instability and Economic Growth: Implications of Coup Events in Sub-Saharan Africa". In: American Journal of Economics and Sociology 61.1, pp. 329-348.

Francois, Patrick, Ilia Rainer, and Francesco Trebbi (2014). The Dictator's Inner Circle. Tech. rep. National Bureau of Economic Research.

Frantz, Erica (2018). Authoritarianism: What Everyone Needs to Know. New York: Oxford University Press.

Freedman, Eric (2009). "When a Democratic Revolution Isn't Democratic or Revolutionary: Press Restraints and Press Freedoms after Kyrgyzstan's Tulip Revolution". In: Journalism: Theory, Practice EJ Criticism 10.6, pp. 843-861.

Friedman, Thomas L. (Sept. 2009). "Our One-Party Democracy". en-US. In: The New York Times. Available from https://www.nytimes.com/2009/09/09/opinion/09friedman.html.

Frye, Timothy, Ora John Reuter, and David Szakonyi (2014). "Political Machines at Work Voter Mobilization and Electoral Subversion in the Workplace". In: World Politics 66.2, pp. $195-228$.

Fukuyama, Francis (2014). Political Order and Political Decay: From the Industrial Revolution to the Globalization of Democracy. London: Profile Books.

Gandhi, Jennifer (2008). Political Institutions under Dictatorship. Cambridge: Cambridge University Press.

Gandhi, Jennifer and Ellen Lust-Okar (2009). "Elections under Authoritarianism". In: Annual Review of Political Science 12, pp. 403-422.

Gandhi, Jennifer and Adam Przeworski (2006). "Cooperation, Cooptation, and Rebellion under Dictatorships". In: Economics $\& 3$ Politics 18.1, pp. 1-26.

- (2007). "Authoritarian Institutions and the Survival of Autocrats". In: Comparative political studies 40.11, pp. 1279-1301. 
Gandhi, Jennifer and Jane Lawrence Sumner (2020). "Measuring the Consolidation of Power in Nondemocracies". In: The Journal of Politics 82.4.

Geddes, Barbara (1999). "What Do We Know about Democratization after Twenty Years?" In: Annual Review of Political Science 2.1, pp. 115-144.

Geddes, Barbara, Joseph Wright, and Erica Frantz (2014). "Autocratic Breakdown and Regime Transitions: A New Data Set". In: Perspectives on Politics 12.02, pp. 313-331.

- (2017). "A Measure of Personalism in Dictatorships". In: Available from http://sites.psu.edu/dictators/files/2017/10/PersMeasure-1ph2gwp.pdf.

- (2018). How Dictatorships Work: Power, Personalization, and Collapse. New York: Cambridge University Press.

Gehlbach, Scott and Philip Keefer (2011). "Investment without Democracy: Ruling-Party Institutionalization and Credible Commitment in Autocracies". In: Journal of Comparative Economics 39.2, pp. 123-139.

- (2012). "Private Investment and the Institutionalization of Collective Action in Autocracies: Ruling Parties and Legislatures". In: The Journal of Politics 74.2, pp. 621-635.

Gerring, John, Philip Bond, William T Barndt, and Carola Moreno (2005). "Democracy and Economic Growth: A Historical Perspective". In: World Politics 57.3, pp. 323-364.

Gerring, John and Carl Henrik Knutsen (Dec. 2019). "Polity Size and the Institutionalization of Leadership Succession". In: Studies in Comparative International Development 54.4, pp. 451-472.

Gerring, John, Erzen Oncel, Kevin Morrison, and Daniel Pemstein (2019). "Who Rules the World? A Portrait of the Global Leadership Class". In: Perspectives on Politics 17.4, pp. 1079-1097.

Gerring, John, Strom C Thacker, and Rodrigo Alfaro (2012). "Democracy and Human Development". In: The Journal of Politics 74.1, pp. 1-17.

Gerschewski, Johannes (2013). "The Three Pillars of Stability: Legitimation, Repression, and Co-Optation in Autocratic Regimes". In: Democratization 20.1, pp. 13-38.

Gjerløw, Haakon and Carl Henrik Knutsen (2019). "Leaders, Private Interests, and Socially Wasteful Projects: Skyscrapers in Democracies and Autocracies". In: Political Research Quarterly, p. 1065912919840710.

Gleditsch, Nils Petter, Peter Wallensteen, Mikael Eriksson, Margareta Sollenberg, and Haavard Strand (2002). "Armed Conflict 1946-2001: A New Dataset". In: Journal of peace research 39.5, pp. 615-637.

Goemans, Hein and Nikolay Marinov (2014). "Coups and Democracy". In: British Journal of Political Science 44.4, pp. 799-825.

Goemans, Henk E., Kristian Skrede Gleditsch, and Giacomo Chiozza (2009). "Introducing Archigos: A Dataset of Political Leaders". In: Journal of Peace Research 46.2, pp. 269-283.

Graham, Matthew H. and Milan W. Svolik (2020). "Democracy in America? Partisanship, Polarization, and the Robustness of Support for Democracy in the United States". In: American Political Science Review 114.2, pp. 392-409.

Gueorguiev, Dimitar D. and Paul J. Schuler (2016). "Keeping Your Head down: Public Profiles and Promotion under Autocracy". In: Journal of East Asian Studies 16.1, pp. 87-116.

Gwatkin, Davison R (2004). "Are Free Government Health Services The Best Way to Reach to Poor?" In: World Bank Group.

Haber, Stephen and Victor Menaldo (2011). "Do Natural Resources Fuel Authoritarianism? A Reappraisal of the Resource Curse". In: American Political Science Review 105.1, pp. 1-26. Hadenius, Axel and Jan Teorell (2007). "Pathways from Authoritarianism". In: Journal of democracy 18.1, pp. 143-157. 
Hansen, Roger D. (1974). The Politics of Mexican Development. 338.9172 H3. Baltimore: Johns Hopkins University Press.

Holland, Heidi (2012). Dinner with Mugabe: The Untold Story of a Freedom Fighter Who Became a Tyrant. London: Penguin Books.

Holler, Sherman (2019). Lee Hsien Loong / Prime Minister of Singapore. https://www.britannica.com/biography/Lee-Hsien-Loong.

House, Freedom (2007). Freedom in the World 2007: The Annual Survey of Political Rights and Civil Liberties. Oxford: Rowman \& Littlefield.

Huber, John D. and Cecilia Martinez-Gallardo (2008). "Replacing Cabinet Ministers: Patterns of Ministerial Stability in Parliamentary Democracies". In: American Political Science Review 102.2, pp. 169-180.

Hume, David (1994). "That Politics May Be Reduced to a Science (1741)". In: Political Essays, pp. $4-15$.

Huntington, Samuel P and Joan M Nelson (1976). No Easy Choice: Political Participation in Developing Countries. Vol. 3. Cambridge, Massachusetts: Harvard University Press.

Huskey, Eugene (2005). "Kyrgyzstan's Tulip Revolution: Interview with Roza Otunbayeva". In: Demokratizatsiya 13.4, pp. 483-490.

Hyde, Susan D. and Nikolay Marinov (2012). "Which Elections Can Be lLst?" In: Political Analysis 20.2, pp. 191-210.

Indridason, Indridi H. and Shaun Bowler (2014). "Determinants of Cabinet Size". In: European Journal of Political Research 53.2, pp. 381-403.

Inglehart, Ronald and Christian Welzel (2005). Modernization, Cultural Change, and Democracy: The Human Development Sequence. Cambridge: Cambridge University Press.

International, Transparency (2020). Corruption Perception Index.

Jacob, Suraj, John A. Scherpereel, and Melinda Adams (2014). "Gender Norms and Women's Political Representation: A Global Analysis of Cabinets, 1979-2009". In: Governance 27.2, pp. 321-345.

Johnson, Keith (2018). How Venezuela Struck Poor. https://foreignpolicy.com/2018/07/16/how-venezuela-struck-it-poor-oil-energy-chavez/.

Jones, Benjamin F and Benjamin A Olken (2005). "Do Leaders Matter? National Leadership and Growth since World War II". In: The Quarterly Journal of Economics 120.3, pp. 835-864.

Jones, Benjamin F. and Benjamin A. Olken (2009). "Hit or Miss? The Effect of Assassinations on Institutions and War". In: American Economic Journal: Macroeconomics 1.2, pp. 55-87.

Jong-A-Pin, Richard and Shu Yu (2010). "Do Coup Leaders Matter? Leadership Change and Economic Growth in Politically Unstable Countries". In: Working paper.

Juraev, Shairbek (2008). "Kyrgyz Democracy? The Tulip Revolution and Beyond". In: Central Asian Survey 27.3-4, pp. 253-264.

Kalandadze, Katya and Mitchell A Orenstein (2009). "Electoral Protests and Democratization beyond the Color Revolutions". In: Comparative Political Studies 42.11, pp. 1403-1425.

Kam, Christopher, William T. Bianco, Itai Sened, and Regina Smyth (2010). "Ministerial Selection and Intraparty Organization in the Contemporary British Parliament". In: American Political Science Review 104.2, pp. 289-306.

Karsh, Efraim and Inari Rautsi (2002). Saddam Hussein: A Political Biography. New York: Grove Press.

Kaufmann, Daniel, Aart Kraay, and Massimo Mastruzzi (2011). "The Worldwide Governance Indicators: Methodology and Analytical Issues". In: Hague Journal on the Rule of Law 3.2, pp. 220-246. 
Kennedy, Ryan (2014). "Fading Colours? A Synthetic Comparative Case Study of the Impact of "Colour Revolutions"". In: Comparative Politics 46.3, pp. 273-292.

Kenyon, Paul (2018). Dictatorland: The Men Who Stole Africa. London: Head of Zeus.

Kerby, Matthew (2011). "Combining the Hazards of Ministerial Appointment AND Ministerial Exit in the Canadian Federal Cabinet". In: Canadian Journal of Political Science/Revue canadienne de science politique 44.3, pp. 595-612.

Keynes, John Maynard (1936). Allgemeine Theorie Der Beschäftigung, Des Zinses Und Des Geldes. Berlin: Duncker \& Humblot.

Kim, Nam Kyu (2016). "Revisiting Economic Shocks and Coups". In: Journal of Conflict Resolution 60.1, pp. 3-31.

Kligman, Gail (1998). The Politics of Duplicity: Controlling Reproduction in Ceausescu's Romania. Berkeley: University of California Press.

Kolstad, Ivar (2020). "What Happens to Growth When a Long-Term Political Leader Leaves Office?" en. In: Governance First view, pp. 1-19.

Krishnarajan, Suthan (2019). "Economic Crisis, Natural Resources, and Irregular Leader Removal in Autocracies". In: International Studies Quarterly 63.3, pp. 726-741.

Kroeger, Alex M (2018). "Dominant Party Rule, Elections, and Cabinet Instability in African Autocracies". In: British Journal of Political Science, pp. 1-23.

Krook, Mona Lena and Diana Z. O'Brien (2012). "All the President's Men? The Appointment of Female Cabinet Ministers Worldwide". In: The Journal of Politics 74.3, pp. 840-855.

Kung, James Kai-Sing and Shuo Chen (2011). "The Tragedy of the Nomenklatura: Career Incentives and Political Radicalism during China's Great Leap Famine". In: American Political Science Review 105.1, pp. 27-45.

Kuran, Timur (1991a). "Now out of Never: The Element of Surprise in the East European Revolution of 1989". In: World Politics 44.1, pp. 7-48.

- (1991b). "The East European Revolution of 1989: Is It Surprising That We Were Surprised?" In: The American Economic Review 81.2, pp. 121-125.

- (1995). "The Inevitability of Future Revolutionary Surprises". In: American Journal of Sociology 100.6, pp. 1528-1551.

Lachapelle, Jean (2020). "No Easy Way out: The Effect of Military Coups on State Repression". In: The Journal of Politics First view.

Lee, Kuan Yew (1998). The Singapore Story: Memoirs of Lee Kuan Yew. Vol. 1. Singapore: Prentice Hall.

Levitsky, Steven and Lucan A Way (2010). Competitive Authoritarianism: Hybrid Regimes after the Cold War. New York: Cambridge University Press.

Lewis-Beck, Michael S. (1990). Economics and Elections: The Major Western Democracies. Ann Arbor: University of Michigan Press.

Lewis-Beck, Michael S. and Mary Stegmaier (2000). "Economic Determinants of Electoral Outcomes". In: Annual Review of Political Science 3.1, pp. 183-219.

Limited, Europa Publications (1975). Africa South of the Sahara. London, United Kingdom: Europa Publications Limited.

Linz, Juan José (2000). Totalitarian and Authoritarian Regimes. Boulder: Lynne Rienner Publishers.

Lipset, Seymour Martin (1959). "Some Social Requisites of Democracy: Economic Development and Political Legitimacy". In: American Political Science Review 53.1, pp. 69-105.

Lü, Xiaobo and Pierre F Landry (2014). "Show Me the Money: Interjurisdiction Political Competition and Fiscal Extraction in China". In: American Political Science Review 108.3, pp. $706-722$. 
Lust-Okar, Ellen (2006). "Elections under Authoritarianism: Preliminary Lessons from Jordan". In: Democratization 13.3, pp. 456-471.

Machiavelli, Niccolo (1961). The Prince. London: Penguin.

Magaloni, Beatriz (2006). Voting for Autocracy: Hegemonic Party Survival and Its Demise in Mexico. Cambridge: University Press Cambridge.

Magaloni, Beatriz, Jonathan Chu, and Eric Min (2013). "Autocracies of the World, 1950-2012 (Version 1.0)". In: Dataset, Stanford University.

Magaloni, Beatriz and Ruth Kricheli (2010). "Political Order and One-Party Rule". In: Annual Review of Political Science 13, pp. 123-143.

Malesky, Edmund, Regina Abrami, and Yu Zheng (2011). "Institutions and Inequality in Single-Party Regimes: A Comparative Analysis of Vietnam and China". In: Comparative Politics 43.4, pp. 409-427.

Malesky, Edmund and Paul Schuler (2010). "Nodding or Needling: Analyzing Delegate Responsiveness in an Authoritarian Parliament". In: American Political Science Review 104.3, pp. 482-502.

Maoz, Zeev, Paul L. Johnson, Jasper Kaplan, Fiona Ogunkoya, and Aaron P. Shreve (2019). "The Dyadic Militarized Interstate Disputes (MIDs) Dataset Version 3.0: Logic, Characteristics, and Comparisons to Alternative Datasets". In: Journal of Conflict Resolution 63.3, pp. 811-835.

Marat, Erica (2005). "Civil Society in Kyrgyzstan before, during and after the March 24 Revolution". In: Helsinki monitor 16, p. 267.

Marshall, Monty G (2017). "Center for Systemic Peace: Major Episodes of Political Violence (MEPV) and Conflict Regions, 1946-2016". In: Available from http://www.systemicpeace.org/inscr/MEPVcodebook2015.pdf.

Martinez, Luis R (2017). "How Much Should We Trust the Dictator's GDP Estimates?" In: Working paper. Available from http://pubdocs.worldbank.org/en/350051528721174623/Nightlights.pdf.

Matthews, Austin S. (2020). Authoritarian Ruling Elites Database (ARED).

McGregor, Richard (2010). The Party: The Secret World of China's Communist Rulers. London: Penguin UK.

McGuire, Martin C. and Mancur Olson (1996). "The Economics of Autocracy and Majority Rule: The Invisible Hand and the Use of Force". In: Journal of Economic Literature 34.1, pp. $72-96$.

McNeill, William Hardy (1983). The Pursuit of Power: Technology, Armed Force, and Society since A.D. 1000. Oxford: Basil Blackwell.

Meng, Anne (2020). Constraining Dictatorship: From Personalized Rule to Institutionalized Regimes. Cambridge: Cambridge University Press.

Mesquita, Bruce Bueno De and Alastair Smith (2010). "Leader Survival, Revolutions, and the Nature of Government Finance". In: American Journal of Political Science 54.4, pp. 936-950.

Michener, Gregory (2015). "How Cabinet Size and Legislative Control Shape the Strength of Transparency Laws". In: Governance 28.1, pp. 77-94.

Miller, Michael K. (2015). "Electoral Authoritarianism and Human Development". In: Comparative Political Studies, pp. 1526-1562.

Miller, Michael K. (2019). "The Autocratic Ruling Parties Dataset: Origins, Durability, and Death". In: Journal of Conflict Resolution.

- (2020). "The Strategic Origins of Electoral Authoritarianism". In: British Journal of Political Science, pp. 1-28.

Montefiore, Simon Sebag (2004). Stalin: The Court of the Red Tsar. London: Weidenfeld and Nicolson. 
Munck, Gerardo L and Jay Verkuilen (2002). "Conceptualizing and Measuring Democracy: Evaluating Alternative Indices". In: Comparative Political Studies 35.1, pp. 5-34.

Mutalib, Hussin (2000). "Illiberal Democracy and the Future of Opposition in Singapore". In: Third World Quarterly 21.2, pp. 313-342.

Nations, United (2019). About Human Development / Human Development Reports. http://hdr.undp.org/en/humandev.

Nooruddin, Irfan (2010). Coalition Politics and Economic Development: Credibility and the Strength of Weak Governments. Cambridge: Cambridge University Press.

North, Douglass C. (1990). Institutions, Institutional Change and Economic Performance. Political Economy of Institutions and Decisions. Cambridge: University Press.

North, Douglass C (1991). "Institutions". In: Journal of Economic Perspectives 5.1, pp. 97-112.

North, Douglass C. and Barry R. Weingast (1989). "Constitutions and Commitment: The Evolution of Institutions Governing Public Choice in Seventeenth-Century England". In: The Journal of Economic History 49.4, pp. 803-832.

Nyrup, Jacob and Stuart Bramwell (2020). "Who Governs? A New Global Data Set on Members of Cabinets". In: American Political Science Review, pp. 1-9.

O'Donnell, Guillermo, Philippe C Schmitter, and Laurence Whitehead (1986). Transitions from Authoritarian Rule: Southern Europe. Vol. 1. Baltimore: John Hopkins University Press.

Olson, Mancur (1993). "Dictatorship, Democracy, and Development". In: American Political Science Review 87.3, pp. 567-576.

Organization, World Health (2016). Global Health Expenditure Database. https://apps.who.int/nha/database.

Paine, Jack. "The Dictator's Power-Sharing Dilemma: Countering Dual Outsider Threats". In: American Journal of Political Science First view ().

Palmer, Glenn, Vito D’Orazio, Michael R. Kenwick, and Roseanne W. McManus (2020). "Updating the Militarized Interstate Dispute Data: A Response to Gibler, Miller, and Little". In: International Studies Quarterly 64.2, pp. 469-475.

Papaioannou, Kostadis J and Jan Luiten Van Zanden (2015). "The Dictator Effect: How Long Years in Office Affect Economic Development". In: Journal of Institutional Economics 11.01, pp. 111-139.

Peng, Xizhe (1987). "Demographic Consequences of the Great Leap Forward in China's Provinces". In: Population and Development Review, pp. 639-670.

Pepinsky, Thomas (2009). Economic Crises and the Breakdown of Authoritarian Regimes: Indonesia and Malaysia in Comparative Perspective. Cambridge: Cambridge University Press.

- (2014). "The Institutional Turn in Comparative Authoritarianism". In: British Journal of Political Science 44.03, pp. 631-653.

- (2017). "Southeast Asia: Voting Against Disorder". In: Journal of Democracy 28.2, pp. $120-131$.

Pernecky, Mark and Thomas Richter (2011). "Keynes' Preface to the German Edition of the General Theory: Nazi Sympathies or Methodological Empathies?" In: Forum for Social Economics. Vol. 40, pp. 253-264.

Pop-Eleches, Grigore and Graeme Robertson (2014). "After the Revolution: Long-Term Effects of Electoral Revolutions". In: Problems of Post-Communism 61.4, pp. 3-22.

Powell, Jonathan M. and Clayton L. Thyne (2011). "Global Instances of Coups from 1950 to 2010: A New Dataset". In: Journal of Peace Research 48.2, pp. 249-259.

Przeworski, Adam (2000). Democracy and Development: Political Institutions and Well-Being in the World, 1950-1990. Vol. 3. Cambridge University Press. 
Przeworski, Adam and Fernando Limongi (1997). "Modernization: Theories and Facts". In: World Politics 49.2, pp. 155-183.

Przeworski, Adam, Fernando Limongi, and Salvador Giner (1995). "Political Regimes and Economic Growth". In: Democracy and Development. Berlin: Springer, pp. 3-27.

Radnitz, Scott (2006). "What Really Happened in Kyrgyzstan?" In: Journal of Democracy 17.2, pp. $132-146$.

Raffo, Julio and Gema Lax-Martinez (2018). WGND 1.0.

Reno, William (1997). "Sovereignty and Personal Rule in Zaire". In: African Studies Quarterly 1.3 , pp. 39-64.

Reuter, Ora John and Graeme B Robertson (2012). "Subnational Appointments in Authoritarian Regimes: Evidence from Russian Gubernatorial Appointments". In: The Journal of Politics 74.4, pp. 1023-1037.

Reuters (2018). "Chinese Papers Defend Removing Term Presidential Limits". In:

Riker, William H. (1962). The Theory of Political Coalitions. New Haven: Yale University Press. Rizio, Stephanie M. and Ahmed Skali (2019). "How Often Do Dictators Have Positive Economic Effects? Global Evidence, 1858-2010". In: The Leadership Quarterly.

Robinson, James A (1998). "Theories of "Bad Policy"”. In: The Journal of Policy Reform 2.1, pp. $1-46$.

Rodríguez-Teruel, Juan (2011). "Ministerial and Parliamentary Elites in Multilevel Spain 1977-2009". In: Comparative Sociology 10.6, pp. 887-907.

Rodrik, Dani, Arvind Subramanian, and Francesco Trebbi (2004). "Institutions Rule: The Primacy of Institutions over Geography and Integration in Economic Development". In: Journal of economic growth 9.2, pp. 131-165.

Ross, Michael (2006). "Is Democracy Good for the Poor?" In: American Journal of Political Science 50.4, pp. 860-874.

Ross, Michael and Paasha Mahdavi (2015). "Oil and Gas Data, 1932-2014". In: Harvard Dataverse 2.

Ross, Michael L (1999). "The Political Economy of the Resource Curse". In: World Politics 51.2, pp. 297-322.

Sarkees, Meredith Reid and Frank Whelon Wayman (2010). Resort to War: A Data Guide to Inter-State, Extra-State, Intra-State, and Non-State Wars, 1816-200\%. Washington D.C.: CQ Press.

Schedler, Andreas (1998). "What Is Democratic Consolidation?" In: Journal of Democracy 9.2, pp. 91-107.

Schleiter, Petra (2013). "Democracy, Authoritarianism, and Ministerial Selection in Russia: How Presidential Preferences Shape Technocratic Cabinets". In: Post-Soviet Affairs 29.1, pp. 31-55.

Schumpeter, Joseph A. (1976). Capitalism, Socialism and Democracy. 5. ed., with a new introduction by Tom Bottomore. London: Routledge.

Semenova, Elena (2018). "Recruitment and Careers of Ministers in Central Eastern Europe and Baltic Countries". In: Technocratic Ministers and Political Leadership in European Democracies. Berlin: Springer, pp. 173-202.

Sen, Amartya (1999). Development as Freedom. Oxford: Oxford University Press.

Sen, Amartya (2001). Development as Freedom. Oxford Paperbacks.

Shih, Victor, Christopher Adolph, and Mingxing Liu (2012). "Getting Ahead in the Communist Party: Explaining the Advancement of Central Committee Members in China". In: American Political Science Review 106.1, pp. 166-187.

Silva, Bruno Castanho (2018). "Populist Radical Right Parties and Mass Polarization in the Netherlands". In: European Political Science Review 10.2, pp. 219-244. 
Skaaning, Svend-Erik, John Gerring, and Henrikas Bartusevičius (2015). "A Lexical Index of Electoral Democracy". In: Comparative Political Studies 48.12, pp. 1491-1525.

Slater, Dan (2003). "Iron Cage in an Iron Fist: Authoritarian Institutions and the Personalization of Power in Malaysia". In: Comparative Politics, pp. 81-101.

Smith, Daniel M. and Shane Martin (2017). "Political Dynasties and the Selection of Cabinet Ministers". In: Legislative Studies Quarterly 42.1, pp. 131-165.

Snyder, Timothy (2018). The Road to Unfreedom: Russia, Europe, America. New York: Tim Duggan Books.

Spence, Michael et al. (2008). "The Growth Report: Strategies for Sustained Growth and Inclusive Development". In: Commission on Growth and Development Final Report, Washington, $D C$.

Stockemer, Daniel (2017). "The Proportion of Women in Legislatures and Cabinets: What Is the Empirical Link?" In: Polity 49.3, pp. 434-460.

Sudduth, Jun Koga (2017a). "Coup Risk, Coup-Proofing and Leader Survival". In: Journal of Peace Research 54.1, pp. 3-15.

- (2017b). "Strategic Logic of Elite Purges in Dictatorships". In: Comparative Political Studies 50.13, pp. 1768-1801.

Suny, Ronald Grigor (1997). "Stalin and His Stalinism: Power and Authority in the Soviet Union, 1930-1953". In: Stalinism and Nazism: Dictatorships in Comparison. Ed. by Ian Kershaw and Moshe Lewin. Cambridge: Cambridge University Press. Chap. 1, pp. 26-52.

Svolik, Milan W. (2009). "Power Sharing and Leadership Dynamics in Authoritarian Regimes". In: American Journal of Political Science 53.2, pp. 477-494.

Svolik, Milan W (2012). The Politics of Authoritarian Rule. Cambridge University Press.

Svolik, Milan W. (2019). "Polarization versus Democracy". In: Journal of Democracy 30.3, pp. 20-32.

Teiwes, Frederick C (2001). "Normal Politics with Chinese Characteristics". In: The China Journal 45, pp. 69-82.

The World Bank (2017). World Development Indicators Online (WDI).

Therneau, Terry (2015). "Mixed Effects Cox Models". In: CRAN repository.

Thomas, Simon (1975). "Economic Developments in Malawi since Independence". In: Journal of Southern African Studies 2.1, pp. 30-51.

Thyne, Clayton L. and Jonathan M. Powell (2016). "Coup d'état or Coup d'autocracy? How Coups Impact Democratization, 1950-2008”. In: Foreign policy analysis 12.2, pp. 192-213.

Truex, Rory (2014). "The Returns to Office in a "Rubber Stamp" Parliament". In: American Political Science Review 108.2, pp. 235-251.

Tucker, Joshua A (2007). "Enough! Electoral Fraud, Collective Action Problems, and Post-Communist Colored Revolutions". In: Perspectives on Politics 5.3, pp. 535-551.

Tullock, Gordon (1987). Autocracy. Dordrecht: Kluwer Academic Publishers Group.

Tzu, Han Fei (1964). Han Fei Tzu: Basic Writings, Trans. B. Watson. New York: Columbia University Press.

UNESCO Institute for Statistics (2016). Education Finance. UNESCO. Available from http://uis.unesco.org/.

Vogel, Ezra F. (2011). Deng Xiaoping and the Transformation of China. Vol. 10. Cambridge, Massachusetts: Belknap Press of Harvard University Press.

Voigtländer, Nico and Hans-Joachim Voth (2017). "Highway to Hitler". In: Working paper. Available from https://www.nber.org/papers/w20150.pdf.

Wallace, Jeremy (2013). "Cities, Redistribution, and Authoritarian Regime Survival". In: The Journal of Politics 75.3, pp. 632-645. 
Wallace, Jeremy L (2016). "Juking the Stats? Authoritarian Information Problems in China". In: British Journal of Political Science 46.1, pp. 11-29.

Wehner, Joachim (2010). "Cabinet Structure and Fiscal Policy Outcomes". In: European Journal of Political Research 49.5, pp. 631-653.

Weiwei, Zhang (2012). Meritocracy Versus Democracy. https://www.nytimes.com/2012/11/10/opinion/meritocracy-versus-democracy.html.

Wig, Tore, Håvard Hegre, and Patrick M Regan (2015). "Updated Data on Institutions and Elections 1960-2012: Presenting the IAEP Dataset Version 2.0". In: Research \& Politics 2.2.

Wig, Tore and Espen Geelmuyden Rød (2016). "Cues to Coup Plotters: Elections as Coup Triggers in Dictatorships". In: Journal of Conflict Resolution 60.5, pp. 787-812.

Wike, Richard, Katie Simmons, Bruce Stokes, and Janell Fetterolf (2017). "Globally, Broad Support for Representative and Direct Democracy". In: Pew Research Center, Washington, $D C$.

Williams, T. David (1978). Malawi: The Politics of Despair. Ithaca: Cornell University Press.

Wintrobe, Ronald (2000). The Political Economy of Dictatorship. Cambridge: Cambridge University Press.

Woldense, Josef (2018). "The Ruler's Game of Musical Chairs: Shuffling during the Reign of Ethiopia's Last Emperor". In: Social Networks 52, pp. 154-166.

Wood, Tom (2006). "Reflections on the Revolution in Kyrgyzstan". In: The Fletcher Forum of World Affairs 30.2, pp. 43-56.

Wright, Joseph (2008). "Do Authoritarian Institutions Constrain? How Legislatures Affect Economic Growth and Investment". In: American Journal of Political Science 52.2, pp. 322-343.

Yamagishi, Hikaru, Jacob Nyrup, and Stuart Bramwell (2020). "Figurines and Doyennes: The Selection of Female Ministers in Autocracies and Democracies". In: Workng paper.

Zakharov, Alexei V (2016). "The Loyalty-Competence Trade-Off in Dictatorships and Outside Options for Subordinates". In: The Journal of Politics 78.2, pp. 457-466.

Zucco, Cesar and Daniela Campello (2020). "Endogenous Policy Making". In: The Journal of Politics 82.2, pp. 800-807. 
Appendices 


\section{A \\ Appendices to chapter 3}

\section{A.1 Appendix to the formal model}

\section{A.1.1 Calculations}

This appendix provides details on the results in the model presented above. First, it will be seen how the size of $m$ is found for the four different situations. Then the same will be done for the size of $l$. The first calculation will be detailed for each of the two parameters, while the remaining will be less comprehensive.

\section{The size of $\mathrm{m}$}

The size of $\mathrm{m}$ is found by setting the payoffs from the competing and not competing equal to each other for each situation. Then $\mathrm{m}$ is isolated to find the point, where the expected utility for the two actions are the same. The payoffs can be found in 3.1. For situation 1. where group B observes the bad action and group A does not rebel $m$ can either choose to compete or not. The left side of the equation denotes the pay-off from competing, while the right side denotes the pay-off from not competing:

$$
(1-m)\left(\underline{\sigma} T-c_{b}\right)+m(\bar{\sigma} T+\pi \Delta)+\underline{\sigma} T \geq 2 \underline{\sigma} T
$$

The left side is expanded:

$$
\underline{\sigma} T-c_{b}-m \underline{\sigma} T+m c_{b}+m \bar{\sigma} T+m \pi \Delta+\underline{\sigma} T \geq 2 \underline{\sigma} T
$$

This can be reduced to:

$$
-c_{b}-m \underline{\sigma} T+m c_{b}+m \bar{\sigma} T+m \pi \Delta \geq 0
$$

Then $\mathrm{m}$ is isolated:

$$
m \geq \frac{c_{b}}{c_{b}+\bar{\sigma} T-\underline{\sigma} T+\pi \Delta}
$$

Since $\bar{\sigma} T-\underline{\sigma} T$ is defined as $\tau, \mathrm{m}$ must be larger than

$$
m \geq \frac{c_{b}}{c_{b}+\tau+\pi \Delta}
$$

before it in expectation is better for group B to compete than not compete. The procedure for the remaining three situations is the same. 
For situation 2. where group B observes the bad action and group A does rebel rebel $\mathrm{m}$ can either choose to compete or not. The dilemma is then:

$$
\left.\left.\left.(1-m)\left(\underline{\sigma} T-c_{b}\right)+(1-((1-l)(1-m)) \pi \Delta)\right)\right)+m(\bar{\sigma} T)\right)+\underline{\sigma} T \geq l(\pi \Delta)+2 \underline{\sigma} T
$$

This can be rewritten as:

$$
-c_{b}+c_{b} m+\Delta m \pi-\Delta l m \pi+m \bar{\sigma} T-m \underline{\sigma} T \geq 0
$$

Then $\mathrm{m}$ is isolated and again $\bar{\sigma} T-\underline{\sigma} T$ is defined as $\tau$. Then it in expectation is best for group $B$ to compete in this situation if $m$ is larger than:

$$
m \geq \frac{c_{b}}{c_{b}+\tau+(1-l) \pi \Delta},
$$

For situation 3. where group B observes the good action and group A does not rebel rebel $\mathrm{m}$ can either choose to compete or not. The associated utilities are then:

$\left.(1-m)\left(\underline{\sigma} T+\frac{\pi}{\pi+(1-\pi) \lambda} \Delta-c_{b}\right)+m(\bar{\sigma} T+\pi \Delta)\right)+\Delta+\underline{\sigma} T \geq \frac{\pi}{\pi+(1-\pi) \lambda} \Delta+\Delta+2 \underline{\sigma} T$

This can be rewritten as:

$$
-c_{b}+c_{b} m+\Delta m \pi-\Delta \frac{\pi}{\pi+(1-\pi) \lambda}+m \bar{\sigma} T-m \underline{\sigma} T \geq 0
$$

Then $\mathrm{m}$ is isolated and again $\bar{\sigma} T-\sigma T$ is defined as $\tau$. Then it in expectation is best for group $\mathrm{B}$ to compete in this situation if $\mathrm{m}$ is larger than:

$$
m \geq \frac{c_{b}}{c_{b}+\tau+\left(\pi-\frac{\pi}{\pi+(1-\pi) \lambda}\right) \Delta}
$$

For situation 4. where group B observes the good action and group A does rebel rebel $\mathrm{m}$ can either choose to compete or not. The associated utilities are then:

$$
\begin{gathered}
\left.(1-m)\left(\underline{\sigma} T-c_{b}\right)+(1-l)(1-m)\left(\frac{\pi}{\pi+(1-\pi) \lambda} \Delta\right)+(1-l((1-l)(1-m))(\pi \Delta))\right)+m(\bar{\sigma} T+\Delta+\underline{\sigma} T) \geq \\
l \pi \Delta+(1-l) \frac{\pi}{\pi+(1-\pi) \lambda} \Delta+\Delta+2 \underline{\sigma}
\end{gathered}
$$

This can be rewritten as:

$$
-c_{b}+c_{b} m-\frac{\pi}{\pi+(1-\pi) \lambda} \Delta+\frac{\pi}{\pi+(1-\pi) \lambda} \Delta l+\Delta m \pi-\Delta l m \pi+m \bar{\sigma} T-m \underline{\sigma} T \geq 0
$$

Then $\mathrm{m}$ is isolated and again $\bar{\sigma} T-\underline{\sigma} T$ is defined as $\tau$. Then it in expectation is best for group $\mathrm{B}$ to compete in this situation if $\mathrm{m}$ is larger than:

$$
m \geq \frac{c_{b}}{c_{b}+\tau+(1-l) \pi \Delta+(l-1) \frac{\pi}{\pi+(1-\pi) \lambda} \Delta}
$$

\section{The size of 1}


We now turn our attention to group A, who has to decide whether they should rebel against the dictator or not. Group A can face 6 different situations. The procedure is the same as above. First, we look at the case, where the dictator choose the bad action and Group B will not compete given $\mathrm{m}$. Then Group A has to decide whether to rebel or not. Then it is beneficial for Group A to rebel if:

$$
(1-l)-c_{A}+l \pi \Delta+2 \bar{\sigma} T \geq 2 \bar{\sigma} T-o
$$

The expression is expanded:

$$
-c_{A}+l c_{A}+l \pi \Delta++2 \bar{\sigma} T \geq 2 \bar{\sigma} T-o
$$

This can be reduced to:

$$
-c_{A}+l c_{A}+l \pi \Delta \geq-o
$$

Then I isolate l, which then must be larger than:

$$
l \geq \frac{c_{A}-o}{c_{A}+\pi \Delta}
$$

before it in expectation is better for group A to rebel in this situation. If we instead look at the case, where the dictator chose the bad action and Group A know that Group B will compete given the size of $\mathrm{m}$. Then it in expectation is best for group A to compete if:

$$
\begin{aligned}
(1-l)-c_{A}+((1-(1-m)(1-l))(\pi * \Delta)+m \underline{\sigma} T+(1-m) \bar{\sigma} T+\bar{\sigma} T \geq \\
(1-m) \bar{\sigma} T+m(\underline{\sigma} T+\pi \Delta)+\bar{\sigma} T-o
\end{aligned}
$$

This can be rewritten as:

$$
-c_{A}+c_{A} l+l \Delta \pi-\operatorname{lm} \Delta \pi \geq 0
$$

Then I isolate 1 . If $l$ is larger than:

$$
l \geq \frac{c_{A}-o}{c_{A}+(1-m) \pi \Delta}
$$

Now, we look at the case, where the dictator chose the bad action and Group B only competes if A does not compete. Then it is beneficial for Group A to rebel if:

$$
(1-l)-c_{A}+l \pi \Delta+2 \bar{\sigma} T \geq(1-m) \bar{\sigma} T+m(\underline{\sigma} T+\pi \Delta)+\bar{\sigma} T-o
$$

This can be rewritten as:

$$
-c_{A}+c_{A} l+l \Delta \pi-m \Delta \pi+m \bar{\sigma} T-m \underline{\sigma} T \geq-o
$$

$l$ is then isolated. In expectation it is best for group A to rebel in this situation if 1 is larger than:

$$
l \geq \frac{c_{A}-o+m(-\tau+\Delta \pi)}{c_{A}+\pi \Delta}
$$

Now we turn to the case, where the dictator chose the good action and Group B will not compete given $\mathrm{m}$. Then Group A has to decide whether to rebel or not. Then it is beneficial for Group A to rebel if:

$$
(1-l)\left(-c_{A}+\frac{\pi}{\pi+(1-\pi) \lambda} \Delta\right)+l \pi \Delta+\Delta+2 \bar{\sigma} T \geq \frac{\pi}{\pi+(1-\pi) \lambda} \Delta+\Delta+2 \bar{\sigma} T-o
$$

This can be rewritten as:

$$
-c_{A}+c_{A} l+l \Delta \pi-l \Delta \frac{\pi}{\pi+(1-\pi) \lambda} \geq-o
$$

$l$ is then isolated. In expectation it is best for group A to rebel in this situation if 1 is larger than:

$$
l \geq \frac{c_{A}-o}{c_{A}+\left(\pi-\frac{\pi}{\pi+(1-\pi) \lambda}\right) \Delta}
$$


Then, we look at the case, where the dictator chose the good action and Group B will compete given $\mathrm{m}$. Then it is beneficial for Group A to rebel if:

$$
\begin{gathered}
(1-l)\left(-c_{A}\right)+(1-((1-l)(1-m))(\pi \Delta))+(1-l)(1-m)\left(\frac{\pi}{\pi+(1-\pi) \lambda} \Delta\right)+(1-m)(\bar{\sigma} T)+m \underline{\sigma} T+\Delta+\bar{\sigma} T \geq \\
(1-m)\left(\bar{\sigma} T+\frac{\pi}{\pi+(1-\pi) \lambda} \Delta\right)+m(\underline{\sigma} T+\pi \Delta)+\bar{\sigma} T-o+\Delta
\end{gathered}
$$

This can be rewritten as:

$$
-c_{A}+c_{A} l+\operatorname{lm} \Delta \frac{\pi}{\pi+(1-\pi) \lambda}-l \Delta \frac{\pi}{\pi+(1-\pi) \lambda}+l \Delta \pi-l m \Delta \pi \geq-o
$$

$l$ is then isolated. In expectation it is best for group A to rebel in this situation if 1 is larger than:

$$
l \geq \frac{c_{A}-o}{c_{A}+(1-m) \pi \Delta+(m-1) \frac{\pi}{\pi+(1-\pi) \lambda} \Delta}
$$

Now, we look at the case, where the dictator chose the good action and Group B only competes if A competes. Then it is beneficial for Group A to rebel if:

$$
\begin{gathered}
(1-l)\left(-c_{A}\right)+(1-((1-l)(1-m))(\pi \Delta))+(1-l)(1-m)\left(\frac{\pi}{\pi+(1-\pi) \lambda} \Delta\right)+(1-m)(\bar{\sigma} T)+m \underline{\sigma} T+\Delta+\bar{\sigma} T \geq \\
\frac{\pi}{\pi+(1-\pi) \lambda} \Delta+\Delta+2 \bar{\sigma} T-o
\end{gathered}
$$

This can be rewritten as:

$$
-c_{A}+c_{A} l-l \frac{\pi}{\pi+(1-\pi) \lambda} \Delta-m \frac{\pi}{\pi+(1-\pi) \lambda} \Delta+\ln \frac{\pi}{\pi+(1-\pi) \lambda} \Delta+l \pi \Delta+m \pi \Delta-\operatorname{lm} \Delta \pi+m \underline{\sigma} T-m \bar{\sigma} T \geq
$$

Then I isolate 1 and define $\bar{\sigma} T-\underline{\sigma} T$ as $\tau$. In expectation it is best for group A to rebel in this situation if 1 is larger than:

$$
l \geq \frac{c_{A}-o+m\left(\tau+\left(\frac{\pi}{\pi+(1-\pi \lambda}-\pi\right) \Delta\right)}{c_{A}+(m-1)\left(\frac{\pi}{\pi+(1-\pi) \lambda}-\pi\right) \Delta}
$$

\section{A.1.2 The case of a very strong ruling coalition and/or op- position}

In the following it is shown why $\lambda=0$ when there is 1 ) a very strong ruling coalition and a weak opposition, 2) A weak ruling coalition and a very strong opposition and 3) a very strong ruling coalition and a very strong opposition.

A very strong ruling coalition and a weak opposition

Proposition 7. If $m<\frac{c_{b}}{c_{b}+\tau+(1-l) \pi \Delta}$ and $\frac{c_{A}-o}{c_{A}+\left(\pi-\frac{\pi}{\pi+(1-\pi) \lambda}\right) \Delta} \leq l$ then $\lambda=0$

This is so because $G((1-l)(\mu+\bar{\sigma} T)-(1-l)(\mu+\bar{\sigma} T)+\Delta)=G(\Delta)=0$

A weak ruling coalition and a very strong opposition

Proposition 8. If $\frac{c_{b}}{c_{b}+\tau+\left(\pi-\frac{\pi}{\pi+(1-\pi) \lambda}\right) \Delta} \leq m$ and $l<\frac{c_{A}-o}{c_{A}+(1-m) \pi \Delta}$ then $\lambda=0$

This is so because $G((1-m)(\mu+\bar{\sigma} T)-(1-m)(\mu+\bar{\sigma} T)+\Delta)=G(\Delta)=0$

The case of a very strong ruling coalition and a very strong opposition:

Proposition 9. If $\frac{c_{b}}{c_{b}+\tau+(1-l) \pi \Delta+(l-1)_{\frac{\pi}{\pi+(1-\pi) \lambda}}} \leq m$ and $\frac{c_{A}-o}{c_{A}+(1-m) \pi \Delta+(m-1) \frac{\pi}{\pi+(1-\pi) \lambda} \Delta} \leq l$ then $\lambda=0$

This is so because $G((1-l)(1-m)(\mu+\bar{\sigma} T)-(1-l)(1-m)(\mu+\bar{\sigma} T)+\Delta)=G(\Delta)=0$ 


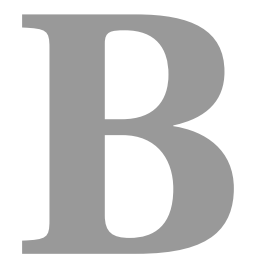

\section{Appendices to chapter 5}

\section{B.1 Codebook for the within-country dataset}

year Year. We are using July for all years apart from 1966, where data was only available for September and 1970, where we are using January instead of July.

country_isocode The country's alpha-3 ISO code.

country_name Country name.

id A row id.

position The person's position in the cabinet.

name The person's name. The names have been standardized across years.

title The person's title, such as Dr., Gen. or Lt. Gen. The titles are standardized, so the most frequent title used in the original dataset for the given person is used across all year for the same person. It should be noted that we have not done any extra checks on this variable, and solely have relied on the information provided in the "Chief of State And Cabinet Members Of Foreign Governments"-directory. The coding is based on national customs. For example, some countries consistently address people with a PhD as 'Dr.', while this is not the case in other countries.

gender The person's gender. We have primarily coded the gender based on the person's name. However, in some cases we have looked up the person to confirm their gender or relied on country experts.

birthyear The person's year of birth. We have added year of birth when the data was available. However, in some cases we would only have the age of a person at a given point in time. Here, we have subtracted the age from the year.

deadyear The person's year of death. If the person is still alive at the time when the data was gathered, the entry is A (2020).

party The abbreviation for the person's party affiliation. For further information on this variable, see Appendix F in Nyrup and Bramwell (2020) 
party_english The name of the party in English.

party_otherlanguage The name of the party in the local language or other commonly used language in the country. We have prioritized languages using the Latin alphabet.

core The variable takes the value 1 if the person is perceived as being a core member of the cabinet. We consider cabinet ministers, prime ministers, presidents, vice presidents, vice prime ministers, members of the politburo and members of a military junta as core positions. The variable is coded manually on a country by country basis.

minister The variable takes the value 1 if the person is a cabinet minister. Deputy and junior ministers are not coded as being cabinet ministers. The variable is coded manually on a country by country basis.

leader The variable takes the value 1 if the person is coded as being the de facto leader for the given country in the given year. We have relied on Archigos to code the leader $(2009) \cdot 1 \cdot$

classification A classification of the position. See appendix B.6 for further information.

portfolio_1 A standard category of the portfolio. See appendix B.6 for further information.

prestige_1 The prestige of portfolio_1. See appendix B.6 for further information.

portfolio_2 A standard category of the portfolio if the position includes several portfolios. See appendix B.6 for further information.

prestige_2 The prestige of portfolio_2. See appendix $\bar{B}$.6 for further information.

portfolio_3 A standard category of the portfolio if the position includes several portfolios. See appendix B.6 for further information.

prestige_3 The prestige of portfolio_3. See appendix B.6 for further information.

portfolio_4 A standard category of the portfolio if the position includes several portfolios. See appendix B.6 for further information.

prestige_4 The prestige of portfolio_4. See appendix B.6 for further information.

$\mathrm{m}$ finance The variable takes the value 1 if the person is minister of finance.

$\mathrm{m} \_$defense The variable takes the value 1 if the person is the minister of defense.

m_agriculture The variable takes the value 1 if the person is minister of agriculture.

$\mathrm{m}$ _foreignaffairs The variable takes the value 1 if the person is minister of foreign affairs.

\footnotetext{
${ }^{1}$ We have decided to deviate from Archigos in a few instances. These are: Romania after 1990. Finland after 2000, Croatia after 2000, Portugal after 1976, Bhutan in the period 1998-2007, Syria from 1966-1970, Timor Leste (2002-2018), Papua New Guinea (2011, mistake in Archigos), Somalia (1966-1969, parliamentary system), Albania (1992-1997, parliamentary system).
} 


\section{B.2 Codebook for the cross-sectional dataset}

year Year. We are using July for all years apart from 1966, where data was only available for September and 1970, where we are using January instead of July.

country_isocode The country's alpha-3 ISO code.

country_name Country name.

$\mathrm{n} \_$total Number of entries for the country in the dataset. This number includes unoccupied positions and multiple positions held by the same persons.

$\mathrm{n}$ _individuals Number of unique persons in the cabinet. This number exclude unoccupied positions and positions, which are held by the same person.

$\mathrm{n}$ _core Number of core members in cabinet. This number exclude unoccupied positions, positions, which are held by the same person, and posts, which are not considered core positions.

n_minister Number of cabinet ministers. This number only include cabinet ministers.

leader Name of the person coded as being the de facto leader of the country.

leader_start_date Day the leader enters office. We have relied on Archigos to code the date (2009).

leader_end_date Day the leader exits office. We have relied on Archigos to code the date (2009).

leader_party Party of the leader.

leaderexperience_continuous The number of years the person has been leader of the country in a row. Thus, it starts over if the leader is removed. The count starts at 1 , when the leader first appear as leader in the dataset. Therefore, the measure is imprecise for leaders, who came to power before 1966.

leaderexperience_continuous The number of years the person has been leader of the country in total. The count starts at 1 , when the leader first appear as leader in the dataset. Therefore, the measure is imprecise for leaders, who came to power before 1966.

$\mathrm{n}$ _female_total The number of women in $\mathrm{n}$ _total.

$\mathrm{n} \_$female_core The number of women in n_core.

$\mathrm{n} \_$female_minister The number of women in $\mathrm{n} \_$ministers.

$\mathrm{n}$ _militarytitle_total The number of people in n.total with a military title. It should be noted that we have not done any extra checks on this variable, and solely have relied on the information provided in the "Chief of State And Cabinet Members Of Foreign Governments" directory. The information is based on national customs. Thus, in some countries military titles are consistently used, while this not the case in other countries, and we therefore encourage researchers to be cautious when using this variable.

n_militarytitle_core The number of people in $\mathrm{n}$ _core with a military title. It should be noted that we have not done any extra checks on this variable, and solely have relied on the information provided in the "Chief of State And Cabinet Members Of Foreign Governments" directory. The information is based on national customs. Thus, in some countries military titles are consistently used, while this not the case in other countries, and we therefore encourage researchers to be cautious when using this variable. 
$\mathrm{n}$ _militarytitle_minister The number of people in n.ministers with a military title. It should be noted that we have not done any extra checks on this variable, and solely have relied on the information provided in the "Chief of State And Cabinet Members Of Foreign Governments" directory. The information is based on national customs. Thus, in some countries military titles are consistently used, while this not the case in other countries, and we therefore encourage researchers to be cautious when using this variable.

average_total The average tenure for people in $n \_$total.

average_core The average tenure for people in $\mathrm{n} \_$core.

average_minister The average tenure for people in $\mathrm{n} \_$ministers.

retention_rate_total The share of people in n_total, who were in n.total the previous year.

retention_rate_core The share of people in $n \_$core, who were in $n \_$core in the previous yearr.

retention_rate_minister The share of people in $\mathrm{n} \_$ministers, who where in $\mathrm{n} \_$ministers the previous year.

retention_rateadj_total The share of people in $n \_$total, who were $\mathrm{in} n$ _total the previous year. This measure is adjusted for an expansion of the size of $n$ _total, so $n$ _total stays constant and the retention rate is therefore not influenced by an expansion of the cabinet.

retention_rateadj_core The share of people in $\mathrm{n}$ _ministers, who where in n.ministers the previous year. This measure is adjusted for an expansion of the size of $n$ _core, so n.total stays constant and the retention rate is therefore not influenced by an expansion of the cabinet.

retention_rateadj_minister The share of people in $\mathrm{n} \_$ministers, who where in $\mathrm{n}$ _ministers the previous year. This measure is adjusted for an expansion of the size of $\mathrm{n}_{\text {_minister, }}$ so $\mathrm{n}$ total stays constant and the retention rate is therefore not influenced by an expansion of the cabinet.

age_total Average age for people in n_total.

age_core Average age for people in $n \_$core.

age_minister Average age for people in n_minister.

age_share Share of $\mathrm{n}$ _total, where the age is coded.

n_party Number of parties represented in the government.

party_share Share of members in n.total (excluding UN representative, Ambassadors and Central Bank governors), where party is coded.

m_finance The name of the minister of finance.

$\mathrm{m} \_$agriculture The name of the minister of agriculture.

$\mathrm{m} \_$defense The name of the minister of defense.

$\mathrm{m}$ _foreignaffairs The name of the minister of foreign affairs.

govern_name The name of the government based on Doring $(2019)$ or Bertoa $(2020)$. 
govern_start_date Day the government enters office based on Doring (2019) or Bertoa (2020).

govern_end_date_Day the government exits office based Doring (2019) or Bertoa (2020). system_category The regimetype as classified by Cheibub et al. (2010) and updated by Bjørnskov and Rode (2018). 


\section{B.3 Descriptive statistics}

Table B.1: Descriptive statistics

\begin{tabular}{lccccc}
\hline \hline Statistic & $\mathrm{N}$ & Mean & St. Dev. & Min & Max \\
\hline n_total & 8,057 & 28.13 & 13.09 & 1 & 146 \\
n_individuals & 8,057 & 25.50 & 11.64 & 1 & 133 \\
n_core & 8,057 & 22.08 & 9.26 & 0 & 109 \\
n_minister & 8,057 & 18.11 & 7.47 & 0 & 65 \\
leaderexperience_continuous & 8,057 & 6.83 & 6.96 & 1 & 46 \\
leaderexperience_total & 8,057 & 7.16 & 7.04 & 0 & 46 \\
n_female_total & 8,057 & 2.17 & 2.60 & 0 & 21 \\
n_female_core & 8,057 & 1.85 & 2.24 & 0 & 15 \\
n_female_minister & 8,057 & 1.66 & 2.12 & 0 & 15 \\
n_militarytitle_total & 8,057 & 1.56 & 3.68 & 0 & 65 \\
n_militarytitle_core & 8,057 & 1.44 & 3.18 & 0 & 38 \\
n_militarytitle_minister & 8,057 & 1.06 & 2.56 & 0 & 35 \\
average_total & 8,053 & 4.18 & 2.38 & 1.00 & 18.50 \\
average_core & 8,049 & 4.47 & 2.66 & 1.00 & 18.50 \\
average_minister & 8,020 & 3.96 & 2.37 & 1.00 & 18.12 \\
retention_rate_total & 8,057 & 0.70 & 0.30 & 0 & 1 \\
retention_rate_core & 8,049 & 0.70 & 0.31 & 0.00 & 1.00 \\
retention_rate_minister & 8,020 & 0.67 & 0.33 & 0.00 & 1.00 \\
retention_rateadj_total & 7,880 & 0.73 & 0.28 & 0.00 & 1.00 \\
retention_rateadj_core & 7,872 & 0.72 & 0.30 & 0.00 & 1.00 \\
retention_rateadj_minister & 7,843 & 0.69 & 0.31 & 0.00 & 1.00 \\
age_total & 4,482 & 54.05 & 6.47 & 28.00 & 82.00 \\
age_core & 4,470 & 53.99 & 6.62 & 28.00 & 82.00 \\
age_minister & 4,191 & 52.58 & 6.19 & 25.67 & 78.00 \\
age_share & 8,057 & 0.38 & 0.43 & 0 & 1 \\
n_party & 8,038 & 2.16 & 2.05 & 0.00 & 18.00 \\
party_share & 8,057 & 0.94 & 0.16 & 0.00 & 1.00 \\
\hline
\end{tabular}




\section{B.4 List of countries}

\begin{tabular}{|c|c|c|c|c|c|c|}
\hline ISO & Country name & Number of years & First year & Last year & \%-party & $\%$-age \\
\hline AFG & Afghanistan & 47 & 1966 & 2018 & 0.91 & 0.00 \\
\hline $\mathrm{AGO}$ & Angola & 42 & 1975 & 2016 & 1.00 & 0.00 \\
\hline ALB & Albania & 51 & 1966 & 2016 & 0.99 & 0.00 \\
\hline ARE & United Arab Emirates & 45 & 1972 & 2016 & 1.00 & 0.20 \\
\hline $\mathrm{ARG}$ & Argentina & 53 & 1966 & 2018 & 1.00 & 0.93 \\
\hline ARM & Armenia & 25 & 1992 & 2016 & 0.95 & 0.00 \\
\hline AUS & Australia & 53 & 1966 & 2018 & 1.00 & 1.00 \\
\hline AUT & Austria & 53 & 1966 & 2018 & 1.00 & 0.99 \\
\hline AZE & Azerbaijan & 25 & 1992 & 2016 & 0.96 & 0.81 \\
\hline BDI & Burundi & 51 & 1966 & 2016 & 0.93 & 0.00 \\
\hline BEL & Belgium & 53 & 1966 & 2018 & 0.98 & 0.98 \\
\hline BEN & Benin & 51 & 1966 & 2016 & 0.72 & 0.00 \\
\hline BFA & Burkina Faso & 51 & 1966 & 2016 & 0.99 & 0.00 \\
\hline BGD & Bangladesh & 45 & 1972 & 2016 & 0.93 & 0.00 \\
\hline BGR & Bulgaria & 50 & 1966 & 2016 & 0.98 & 0.49 \\
\hline $\mathrm{BHR}$ & Bahrain & 46 & 1971 & 2016 & 1.00 & 0.38 \\
\hline BIH & Bosnia \& Herzegovina & 25 & 1992 & 2016 & 0.79 & 0.00 \\
\hline BLR & Belarus & 25 & 1992 & 2016 & 1.00 & 0.07 \\
\hline BOL & Bolivia & 51 & 1966 & 2016 & 0.90 & 0.05 \\
\hline BRA & Brazil & 51 & 1966 & 2016 & 0.97 & 0.99 \\
\hline $\mathrm{BRN}$ & Brunei & 33 & 1984 & 2016 & 1.00 & 0.00 \\
\hline BTN & Bhutan & 46 & 1971 & 2016 & 1.00 & 0.62 \\
\hline BWA & Botswana & 50 & 1967 & 2016 & 1.00 & 0.78 \\
\hline $\mathrm{CAF}$ & $\begin{array}{l}\text { Central African Re- } \\
\text { public }\end{array}$ & 51 & 1966 & 2016 & 0.94 & 0.00 \\
\hline $\mathrm{CAN}$ & Canada & 53 & 1966 & 2018 & 1.00 & 1.00 \\
\hline CHE & Switzerland & 53 & 1966 & 2018 & 1.00 & 1.00 \\
\hline CHL & Chile & 53 & 1966 & 2018 & 0.98 & 0.82 \\
\hline $\mathrm{CHN}$ & China & 51 & 1966 & 2016 & 1.00 & 0.98 \\
\hline CIV & Cote d'Ivoire & 51 & 1966 & 2016 & 1.00 & 0.00 \\
\hline CMR & Cameroon & 51 & 1966 & 2016 & 0.98 & 0.00 \\
\hline COD & Congo - Kinshasa & 53 & 1966 & 2018 & 0.94 & 0.00 \\
\hline $\mathrm{COG}$ & Congo - Brazzaville & 51 & 1966 & 2016 & 0.96 & 0.00 \\
\hline COL & Colombia & 53 & 1966 & 2018 & 0.99 & 0.78 \\
\hline $\mathrm{COM}$ & Comoros & 51 & 1966 & 2016 & 0.54 & 0.00 \\
\hline CPV & Cape Verde & 43 & 1976 & 2018 & 0.88 & 0.00 \\
\hline CRI & Costa Rica & 53 & 1966 & 2018 & 0.91 & 0.76 \\
\hline CUB & Cuba & 53 & 1966 & 2018 & 1.00 & 0.05 \\
\hline CYP & Cyprus & 53 & 1966 & 2018 & 0.98 & 0.81 \\
\hline CZE & $\begin{array}{l}\text { Czech Republic (incl. } \\
\text { Czechoslovakia) }\end{array}$ & 51 & 1966 & 2016 & 1.00 & 0.88 \\
\hline DDR & East Germany & 24 & 1966 & 1989 & 1.00 & 0.93 \\
\hline DEU & Germany & 53 & 1966 & 2018 & 1.00 & 1.00 \\
\hline
\end{tabular}




\begin{tabular}{|c|c|c|c|c|c|c|}
\hline DJI & Djibouti & 40 & 1977 & 2016 & 0.95 & 0.00 \\
\hline DNK & Denmark & 54 & 1966 & 2019 & 1.00 & 1.00 \\
\hline DOM & Dominican Republic & 53 & 1966 & 2018 & 0.51 & 0.00 \\
\hline DVN & North Vietnam & 10 & 1966 & 1975 & 1.00 & 0.87 \\
\hline DZA & Algeria & 51 & 1966 & 2016 & 0.88 & 0.00 \\
\hline ECU & Ecuador & 51 & 1966 & 2016 & 0.84 & 0.00 \\
\hline EGY & Egypt & 51 & 1966 & 2016 & 1.00 & 0.06 \\
\hline ERI & Eritrea & 24 & 1993 & 2016 & 1.00 & 0.49 \\
\hline ESP & Spain & 51 & 1966 & 2016 & 1.00 & 1.00 \\
\hline EST & Estonia & 27 & 1992 & 2018 & 0.99 & 0.96 \\
\hline ETH & Ethiopia & 51 & 1966 & 2016 & 1.00 & 0.00 \\
\hline FIN & Finland & 53 & 1966 & 2018 & 1.00 & 0.99 \\
\hline FJI & Fiji & 46 & 1971 & 2016 & 0.96 & 0.00 \\
\hline FRA & France & 53 & 1966 & 2018 & 1.00 & 1.00 \\
\hline GAB & Gabon & 51 & 1966 & 2016 & 0.99 & 0.18 \\
\hline GBR & United Kingdom & 53 & 1966 & 2018 & 1.00 & 1.00 \\
\hline GEO & Georgia & 25 & 1992 & 2016 & 0.79 & 0.00 \\
\hline GHA & Ghana & 51 & 1966 & 2016 & 0.95 & 0.00 \\
\hline GIN & Guinea & 51 & 1966 & 2016 & 0.94 & 0.00 \\
\hline GMB & Gambia & 51 & 1966 & 2016 & 1.00 & 0.00 \\
\hline GNB & Guinea-Bissau & 42 & 1975 & 2016 & 0.90 & 0.00 \\
\hline GNQ & Equatorial Guinea & 49 & 1968 & 2016 & 0.98 & 0.27 \\
\hline GRC & Greece & 51 & 1966 & 2016 & 0.89 & 0.69 \\
\hline GRD & Grenada & 45 & 1974 & 2018 & 0.99 & 0.11 \\
\hline GTM & Guatemala & 51 & 1966 & 2016 & 0.35 & 0.00 \\
\hline GUY & Guyana & 51 & 1966 & 2016 & 1.00 & 0.00 \\
\hline HND & Honduras & 51 & 1966 & 2016 & 0.64 & 0.03 \\
\hline HRV & Croatia & 25 & 1992 & 2016 & 0.99 & 0.81 \\
\hline HTI & Haiti & 51 & 1966 & 2016 & 0.87 & 0.00 \\
\hline HUN & Hungary & 51 & 1966 & 2016 & 1.00 & 0.80 \\
\hline IDN & Indonesia & 51 & 1966 & 2016 & 0.92 & 0.96 \\
\hline IND & India & 53 & 1966 & 2018 & 0.99 & 0.97 \\
\hline IRL & Ireland & 53 & 1966 & 2018 & 1.00 & 0.99 \\
\hline IRN & Iran & 51 & 1966 & 2016 & 0.99 & 0.00 \\
\hline IRQ & Iraq & 51 & 1966 & 2016 & 0.99 & 0.16 \\
\hline ISL & Iceland & 53 & 1966 & 2018 & 1.00 & 0.97 \\
\hline ISR & Israel & 53 & 1966 & 2018 & 1.00 & 1.00 \\
\hline ITA & Italy & 53 & 1966 & 2018 & 1.00 & 1.00 \\
\hline JAM & Jamaica & 53 & 1966 & 2018 & 1.00 & 0.33 \\
\hline JOR & Jordan & 51 & 1966 & 2016 & 1.00 & 0.00 \\
\hline JPN & Japan & 53 & 1966 & 2018 & 0.99 & 1.00 \\
\hline KAZ & Kazakhstan & 25 & 1992 & 2016 & 0.80 & 0.69 \\
\hline $\mathrm{KEN}$ & Kenya & 51 & 1966 & 2016 & 0.99 & 0.57 \\
\hline KGZ & Kyrgyzstan & 25 & 1992 & 2016 & 0.83 & 0.10 \\
\hline KHM & Cambodia & 51 & 1966 & 2016 & 1.00 & 0.00 \\
\hline KOR & South Korea & 51 & 1966 & 2016 & 0.79 & 0.94 \\
\hline
\end{tabular}




$\begin{array}{ll}\text { KWT } & \text { Kuwait } \\ \text { LAO } & \text { Laos } \\ \text { LBN } & \text { Lebanon } \\ \text { LBR } & \text { Liberia } \\ \text { LBY } & \text { Libya } \\ \text { LKA } & \text { Sri Lanka } \\ \text { LSO } & \text { Lesotho } \\ \text { LTU } & \text { Lithuania } \\ \text { LUX } & \text { Luxembourg } \\ \text { LVA } & \text { Latvia } \\ \text { MAR } & \text { Morocco } \\ \text { MDA } & \text { Moldova } \\ \text { MDG } & \text { Madagascar } \\ \text { MDV } & \text { Maldives } \\ \text { MEX } & \text { Mexico } \\ \text { MKD } & \text { Macedonia } \\ \text { MLI } & \text { Mali } \\ \text { MLT } & \text { Malta } \\ \text { MMR } & \text { Myanmar (Burma) } \\ \text { MNE } & \text { Montenegro } \\ \text { MNG } & \text { Mongolia } \\ \text { MOZ } & \text { Mozambique } \\ \text { MRT } & \text { Mauritania } \\ \text { MUS } & \text { Mauritius } \\ \text { MWI } & \text { Malawi } \\ \text { MYS } & \text { Malaysia } \\ \text { NAM } & \text { Namibia } \\ \text { NER } & \text { Niger } \\ \text { NGA } & \text { Nigeria } \\ \text { NIC } & \text { Nicaragua } \\ \text { NLD } & \text { Netherlands } \\ \text { NOR } & \text { Norway } \\ \text { NPL } & \text { Nepal } \\ \text { NZL } & \text { New Zealand } \\ \text { OMN } & \text { Oman } \\ \text { PAK } & \text { Pakistan } \\ \text { PAN } & \text { Panama } \\ \text { PER } & \text { Peru } \\ \text { PHL } & \text { Philippines } \\ \text { PNG } & \text { Papua New Guinea } \\ \text { POL } & \text { Poland } \\ \text { PRK } & \text { North Korea } \\ \text { PRT } & \text { Portugal } \\ \text { PRY } & \text { Paraguay } \\ \text { QAT } & \text { Qatar } \\ \text { ROU } & \text { Romania } \\ & \\ \text { MA }\end{array}$

$\begin{array}{lllll}51 & 1966 & 2016 & 1.00 & 0.00 \\ 51 & 1966 & 2016 & 1.00 & 0.38 \\ 51 & 1966 & 2016 & 0.86 & 0.00 \\ 51 & 1966 & 2016 & 1.00 & 0.02 \\ 51 & 1966 & 2016 & 0.98 & 0.18 \\ 51 & 1966 & 2016 & 0.93 & 0.00 \\ 50 & 1967 & 2016 & 1.00 & 0.00 \\ 27 & 1992 & 2018 & 0.99 & 0.98 \\ 53 & 1966 & 2018 & 0.99 & 0.99 \\ 27 & 1992 & 2018 & 0.99 & 0.94 \\ 51 & 1966 & 2016 & 0.69 & 0.01 \\ 25 & 1992 & 2016 & 0.84 & 0.79 \\ 51 & 1966 & 2016 & 1.00 & 0.00 \\ 53 & 1966 & 2018 & 0.99 & 0.00 \\ 53 & 1966 & 2018 & 0.99 & 0.96 \\ 22 & 1995 & 2016 & 1.00 & 0.74 \\ 51 & 1966 & 2016 & 0.96 & 0.00 \\ 53 & 1966 & 2018 & 1.00 & 0.79 \\ 51 & 1966 & 2016 & 1.00 & 0.18 \\ 20 & 1997 & 2016 & 0.99 & 0.73 \\ 51 & 1966 & 2016 & 0.99 & 0.22 \\ 42 & 1975 & 2016 & 1.00 & 0.04 \\ 51 & 1966 & 2016 & 0.97 & 0.08 \\ 53 & 1966 & 2018 & 0.98 & 0.00 \\ 51 & 1966 & 2016 & 0.93 & 0.00 \\ 51 & 1966 & 2016 & 1.00 & 0.91 \\ 27 & 1990 & 2016 & 1.00 & 0.96 \\ 51 & 1966 & 2016 & 0.93 & 0.00 \\ 51 & 1966 & 2016 & 0.93 & 0.00 \\ 51 & 1966 & 2016 & 0.77 & 0.17 \\ 53 & 1966 & 2018 & 1.00 & 0.99 \\ 53 & 1966 & 2018 & 0.99 & 0.99 \\ 51 & 1966 & 2016 & 0.99 & 0.00 \\ 53 & 1966 & 2018 & 1.00 & 0.99 \\ 51 & 1966 & 2016 & 1.00 & 0.00 \\ 51 & 1966 & 2016 & 0.97 & 0.00 \\ 51 & 1966 & 2016 & 0.70 & 0.00 \\ 51 & 1966 & 2016 & 0.98 & 0.74 \\ 53 & 1966 & 2018 & 1.00 & 0.00 \\ 43 & 1976 & 2018 & 0.80 & 0.00 \\ 51 & 1966 & 2016 & 0.88 & 0.90 \\ 53 & 1966 & 2018 & 1.00 & 0.32 \\ 51 & 1966 & 2016 & 0.99 & 0.96 \\ 51 & 1966 & 2016 & 0.87 & 0.20 \\ 46 & 1971 & 2016 & 1.00 & 0.29 \\ 51 & 1966 & 2016 & 1.00 & 0.89\end{array}$




\begin{tabular}{|c|c|c|c|c|c|c|}
\hline RUS & Russia & 25 & 1992 & 2016 & 0.97 & 0.99 \\
\hline RVN & South Vietnam & 9 & 1966 & 1974 & 1.00 & 0.33 \\
\hline RWA & Rwanda & 51 & 1966 & 2016 & 0.80 & 0.00 \\
\hline SAU & Saudi Arabia & 53 & 1966 & 2018 & 1.00 & 0.58 \\
\hline SDN & Sudan & 51 & 1966 & 2016 & 0.95 & 0.00 \\
\hline SEN & Senegal & 51 & 1966 & 2016 & 0.96 & 0.00 \\
\hline SGP & Singapore & 53 & 1966 & 2018 & 1.00 & 0.99 \\
\hline SLE & Sierra Leone & 51 & 1966 & 2016 & 0.96 & 0.00 \\
\hline SLV & El Salvador & 51 & 1966 & 2016 & 0.69 & 0.00 \\
\hline SOM & Somalia & 51 & 1966 & 2016 & 0.56 & 0.00 \\
\hline SRB & Serbia & 20 & 1997 & 2016 & 1.00 & 0.86 \\
\hline SSD & South Sudan & 5 & 2012 & 2016 & 0.96 & 0.00 \\
\hline STP & Sao Tome \& Principe & 44 & 1975 & 2018 & 0.91 & 0.00 \\
\hline SUN & Soviet Union & 26 & 1966 & 1991 & 1.00 & 0.02 \\
\hline SUR & Suriname & 40 & 1979 & 2018 & 0.89 & 0.00 \\
\hline SVK & Slovakia & 24 & 1993 & 2016 & 1.00 & 0.92 \\
\hline SVN & Slovenia & 25 & 1992 & 2016 & 0.99 & 0.98 \\
\hline SWE & Sweden & 53 & 1966 & 2018 & 1.00 & 1.00 \\
\hline SWZ & Swaziland & 48 & 1969 & 2016 & 1.00 & 0.00 \\
\hline SYR & Syria & 51 & 1966 & 2016 & 1.00 & 0.02 \\
\hline TCD & Chad & 51 & 1966 & 2016 & 0.82 & 0.00 \\
\hline TGO & Togo & 51 & 1966 & 2016 & 0.98 & 0.00 \\
\hline THA & Thailand & 51 & 1966 & 2016 & 0.86 & 0.00 \\
\hline TJK & Tajikistan & 25 & 1992 & 2016 & 1.00 & 0.14 \\
\hline TKM & Turkmenistan & 25 & 1992 & 2016 & 1.00 & 0.12 \\
\hline TLS & Timor-Leste & 17 & 2002 & 2018 & 0.98 & 0.00 \\
\hline TTO & Trinidad \& Tobago & 53 & 1966 & 2018 & 0.98 & 0.18 \\
\hline TUN & Tunisia & 51 & 1966 & 2016 & 1.00 & 0.05 \\
\hline TUR & Turkey & 51 & 1966 & 2016 & 1.00 & 0.97 \\
\hline TWN & Taiwan & 51 & 1966 & 2016 & 0.99 & 0.00 \\
\hline TZA & Tanzania & 51 & 1966 & 2016 & 0.95 & 0.25 \\
\hline UGA & Uganda & 51 & 1966 & 2016 & 0.88 & 0.00 \\
\hline UKR & Ukraine & 25 & 1992 & 2016 & 0.98 & 0.72 \\
\hline URY & Uruguay & 51 & 1966 & 2016 & 0.97 & 0.90 \\
\hline USA & United States & 56 & 1963 & 2018 & 1.00 & 1.00 \\
\hline UZB & Uzbekistan & 25 & 1992 & 2016 & 0.60 & 0.43 \\
\hline VEN & Venezuela & 51 & 1966 & 2016 & 0.66 & 0.48 \\
\hline VNM & Vietnam & 41 & 1976 & 2016 & 1.00 & 0.08 \\
\hline YEM & $\begin{array}{l}\text { Yemen (incl. North } \\
\text { Yemen) }\end{array}$ & 51 & 1966 & 2016 & 0.78 & 0.00 \\
\hline YPR & South Yemen & 22 & 1968 & 1989 & 1.00 & 0.21 \\
\hline YUG & Yugoslavia & 37 & 1966 & 2002 & 0.64 & 0.00 \\
\hline ZAF & South Africa & 51 & 1966 & 2016 & 0.97 & 0.81 \\
\hline ZMB & Zambia & 51 & 1966 & 2016 & 1.00 & 0.00 \\
\hline ZWE & Zimbabwe & 36 & 1981 & 2016 & 0.99 & 0.88 \\
\hline
\end{tabular}




\section{B.5 Description of the data gathering process}

The data gathering process can be divided into 6 steps. Below, we give a description of each step separately.

\section{Step 1: Gathering the main files}

The dataset is based on the entries in the "Chiefs of State and Cabinet Members of Foreign Governments", which is published by The Central Intelligence Agency (CIA). The directory is identifying chiefs of state and cabinet members of foreign governments and the data has been prepared and collected by The Central Intelligence Agency. The directory is originally prepared for the use of US Government officials. The earliest available version dates back to 1966 and the directory has been updated at least half-yearly until today. The versions dating back to 2001 are freely available on the CIA's website through https: //www.cia.gov/library/publications/world-leaders-1/. The versions before 2001 have been downloaded either from Hathi'Trust Digital Library or have been obtained through Freedom of Information Requests (FOI) to the CIA. We assembled all the files in a folder and ran an optical character recognition (OCR) on all the files using the text scanning program ABBYY.

\section{Step 2: Creating the country datasets}

After digitalizing the files we were able to read the files into $\mathrm{R}$ using the tm-package. We then ran a script, which we developed, on the files. First, the script singled out a country in a given year and provided a list of cabinet members for the given country. The script then looped over all the files in the folder, so we had a list of cabinet members for all years in a given country. Afterwards, the script ran a long number of checks, regular expressions and matching algorithms on the data to ensure that names and titles were written in a consistent way for the given country. For example, a fuzzy-matching algorithm compared all names and singled those out, which only differed by one letter, while another algorithm checked whether there were cases, where the first and last names were swapped. These could then be corrected if the difference was due to an error. All information in the files were entered using the Latin alphabet, and we therefore did not have to account for different types of writing systems. The data for the given country was then exported to a xlsx-file.

\section{Step 3: Manual cleaning of the data}

Although the automatized approach made the process of creating the data significantly easier, we still needed to conduct a thorough manual cleaning of the data to ensure that the entries were correct. While double checking the entries against other sources, we found that the CIA correctly identified the cabinet members at a given point in time in almost all instances. We found two exceptions, namely that the CIA has started updating the registry less frequently after 2013 for smaller countries. Here, we have manually edited the data to make sure that it reflects the cabinet in July every year. Furthermore, we found a few instances, where the CIA did not remove the minister, when the ministry was closed or merged with another ministry. Here, we could use the party affiliation of ministers to single out ministers not belonging to the governing coalition and validate these entries. Despite the fact that the data from the CIA was very reliable, there were issues with around 15 percent of the entries for other reasons. Some of the scans were of poor quality and therefore not readable for the OCR. These entries were therefore added or corrected manually. Furthermore, we needed to ensure that the same persons name was spelled consistently over time. This might not be the case for at least four reasons. First, a person may change their name during the period of investigation ${ }^{2}$ Second, the original

\footnotetext{
${ }^{2}$ For example, a number of African countries, such as the Democratic Republic of Congo and Equatorial Guinea, have seen an Africanization of names.
} 
files were not consistent in whether they included middle names or not. Third, the same name may be spelled in different way ${ }^{3}$, and fourth, the OCR may have incorrectly loaded some characters ${ }^{4}$ As mentioned before, we used an algorithm to correct the names, where the inconsistency in the spelling was due to an obvious mistake. However, in many cases it is not possible to immediately know whether it is the same person or another person with a slightly different name. Thus, we looked up every person when in doubt about the entry and used alternative biographical information to triangulate the data. All entries were checked by two people to ensure that the entries were as accurate as possible. In addition, we had country experts and native speakers looking over many of the countries, and these found very few mistakes in the data. In the end, we therefore ended up with a list of members of the cabinet for all years in a given country.

\section{Step 4: Classifying positions}

The names of cabinet portfolios are notoriously idiosyncratic, and in the dataset we have 21,958 distinct names for positions in the dataset. We therefore classified the names of position in four different ways, enabling researchers easily to filter out specific members of the governing elite. We refer the reader to Appendix B.6 for a description of the approach used here.

\section{Step 5: Adding background variables}

The original files only contained the name of the position, the name and, in some cases, the title. The title can, for example, be Dr., Gen. or Lt. Gen. See the codebook in B.1 for a further discussion of this variable. We used this dataset as a basis for adding further variables, namely gender, party affiliation and year of birth/death. To code the background variables, we produced a script, which printed the list of people listed for every country. Using these lists, we added the background variables, and then merged the list with the original datasets to add these new variables.

We have primarily coded the gender based on the person's first name, where we developed a script, which matched the first names in our dataset against the information in the "World Gender Name Dictionary" (Raffo and Lax-Martinez 2018). Using this method, we were able to classify the majority of the names. However, some names did not exist in the directory or were gender neutral. In these cases, we looked up the person and used biographical information to classify the name. Some countries, such as Nepal, China, Cambodia and Ethiopia, use names, which are not covered by the directory. In these cases, we got help from a person, who were familiar with the language and the country to code the names. ${ }^{5}$ In addition, we looked up all ministers, who are classified as female to make sure no ministers mistakenly are coded as female. As a result, we might slightly underestimate the number of female ministers.

The year of birth/death is added by looking up the person on Google. In many cases, the information is readily available on Wikipedia. We find Wikipedia to be a trustful source for this type of information. In some cases, we had to rely on obituaries or newspaper articles. Obituaries and newspaper articles often only list the age of the person and not the year of birth. Here, we subtracted the age from the year the article is published, which may cause us to overestimate the age with up to a year in a few instances.

We also added party affiliation. The process for adding the party affiliation is described in Appendix F in Nyrup and Bramwell (2020).

\footnotetext{
${ }^{3}$ This is especially the case for countries, which do not use a Latin alphabet. For example, Muhammed can be translated from Arabic in many different ways.

${ }^{4}$ For example, the OCR often reads "u" as "ii".

${ }^{5}$ These countries were Bangladesh, Cambodia, China, Cyprus, Ethiopia, Fiji, Finland, Greece, India, Indonesia, Japan, Laos, Nepal, Mauritius, Myanmar, Mongolia, South Korea, Thailand and Vietnam
} 


\section{Step 6: Creating the cross national dataset}

We transform the yearly data on members of cabinets into a cross-country panel dataset. We do so by running a script on top of the within country datasets. This code creates variables for each country for each year and then assembles the data into one large dataset. This dataset contains variables on, for example, the size of the cabinet in a given year, the share of female ministers, the retention rate for the given year, average experience of the cabinet ministers and the name of ministers, who possess important portfolios. The list of variables covered in the cross-country panel dataset can be seen in B.2.

\section{B.6 Title Classifications}

We have assigned 23 different classifications of the titles found in the raw data. The classifications were chosen in order to, at once, adequately simplify and represent the sheer organizational diversity found within different varieties of democracy and autocracy. While many classifications will be self-explanatory, we would like draw the reader's attention to specific coding decisions made in regard to leaders and their deputies, minister, members of juntas, monarchies and regional elites.

While many countries assign standard classifications for leaders and their deputies (e.g. President or Deputy Prime Minister), some countries and regimes tend to assign idiosyncratic classifications for their leaders such as Chancellor, Premier, Secretary General or Chairman. For these cases, we use the 'Chief of State' for the leaders and 'Deputy Chief of State' for leaders and their deputies. For all deputy leader classifications (a.k.a. Deputy Prime Minister, Vice President and Deputy Chief of State) we include second, third, fourth etc. deputies.

Ministers can either be of full rank or junior. We obviously identify which is which in a majority of cases by looking at whether the words 'deputy' or 'junior' are used. For Ministers/Secretaries of State, we ascertain whether or not they have full rank by looking at (a) the order in which they are listed in the raw data; (b) the stability of their portfolios throughout the period of observation and; (c) colonial history (e.g. many former French colonies will accord Ministers of State ministers of full-ministerial rank).

For military- or civilian-led juntas, we include 'Member (Ruling Group)' which is used to classify individuals who are named members of a Military Council or Politburo respectively. We have also included 'Governor (Military)' to classify military elites who have named governing competencies based on their titles alone.

For monarchies, we include a classification for Princes, Kings, Queens and Princesses called 'Member (Royal Family)'. It should be noted, however, that we only include these classifications based on titles alone and not on a comprehensive analysis of familial affiliations for all cabinet members. This is beyond the scope of our data just now but we hope to add this information in future iterations.

Finally, for decentralised political systems, we have included a classification for regional governors called 'Governor (Regional)' as and when they are included in the raw data. While we are confident that our dataset represents a relatively complete picture of executive politics at the central level we cannot make similar assumptions regarding equivalent politics at the regional level. Users are therefore encouraged to draw upon country-based expertise to determine whether or not these individuals should be included. Table B.4 presents a complete list of title classifications. 
Table B.3: List of Portfolios

\begin{tabular}{|c|c|}
\hline Portfolio & Prestige \\
\hline Defense, Military \& National Security & High \\
\hline Foreign Relations & High \\
\hline Government, Interior \& Home Affairs & High \\
\hline Finance, Budget \& Treasury & High \\
\hline Agriculture, Food, Fisheries \& Livestock & Medium \\
\hline Audit, Oversight \& Internal Affairs & Medium \\
\hline Civil Service & Medium \\
\hline Communications \& Information & Medium \\
\hline Construction \& Public Works & Medium \\
\hline Correctional Services \& Police & Medium \\
\hline Culture \& Heritage & Medium \\
\hline Education, Training \& Skills & Medium \\
\hline Energy & Medium \\
\hline Enterprises, Companies \& Business & Medium \\
\hline Environment & Medium \\
\hline Executive \& Legislative Relations & Medium \\
\hline Foreign Economic Relations & Medium \\
\hline General Economic Affairs & Medium \\
\hline Health \& Social Welfare & Medium \\
\hline Housing & Medium \\
\hline Industry \& Commerce & Medium \\
\hline Justice \& Legal Affairs & Medium \\
\hline Labor, Employment \& Social Security & Medium \\
\hline Local Government & Medium \\
\hline Natural Resources & Medium \\
\hline Planning \& Development & Medium \\
\hline Political Reform & Medium \\
\hline Properties \& Buildings & Medium \\
\hline Religion & Medium \\
\hline Regional & Medium \\
\hline Tax, Revenue \& Fiscal Policy & Medium \\
\hline Transport & Medium \\
\hline Ageing \& Elderly & Low \\
\hline Children \& Family & Low \\
\hline Immigration \& Emigration & Low \\
\hline Minorities & Low \\
\hline Science, Technology \& Research & Low \\
\hline Sports & Low \\
\hline Tourism & Low \\
\hline Veterans & Low \\
\hline Without Portfolio & Low \\
\hline Women & Low \\
\hline Youth & Low \\
\hline Other & \\
\hline
\end{tabular}


Table B.4: List of Classifications

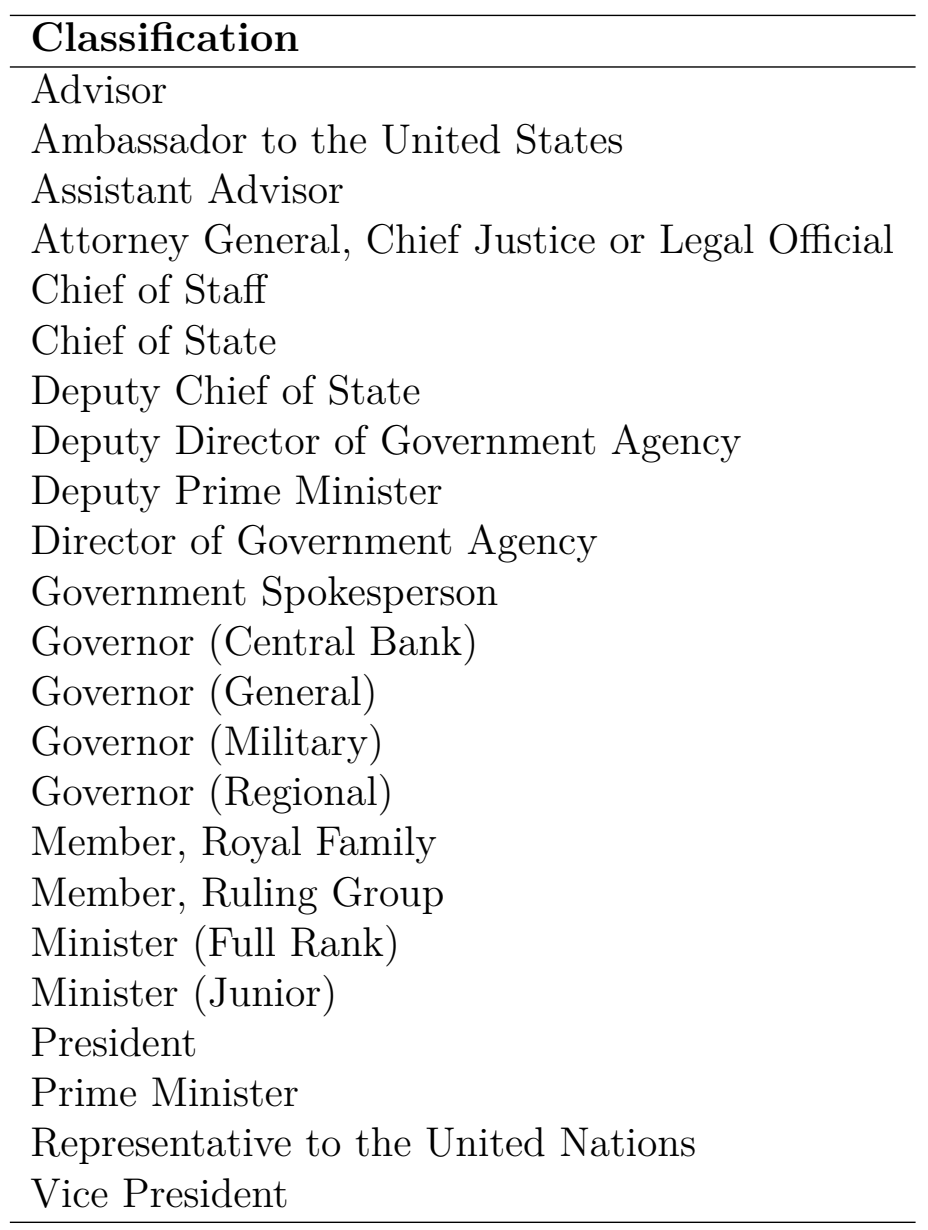


Appendices to chapter 6 


\section{C.1 Log-transformation}

The graphs below show two graphical methods for assessing whether the variable for internal constraints is normally distributed. It is seen that the variable for relative experience fits a normal distribution much better when it is log-transformed. 1 . As a result, the log transformed version of the variable is used in the analysis.

Relative Experience - not logged

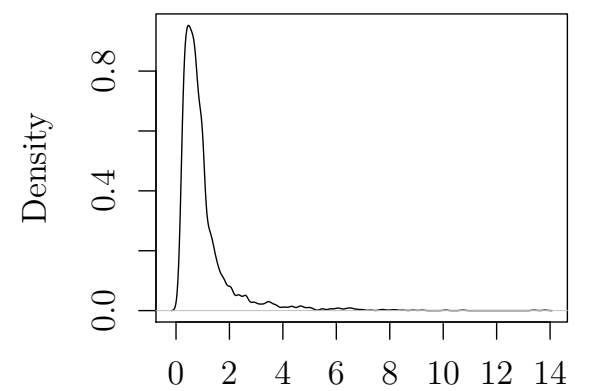

$\mathrm{N}=2882$ Bandwidth $=0.08868$

QQ plot of Relative Experience

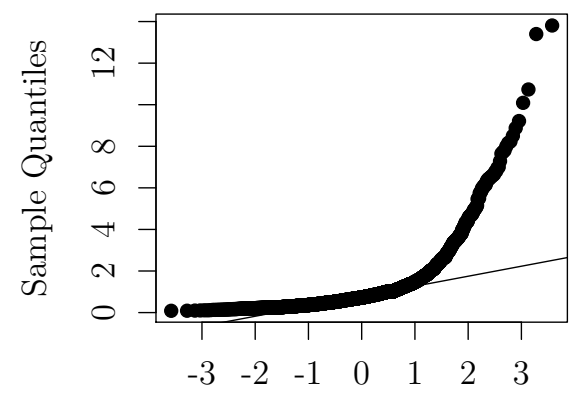

Theoretical Quantiles

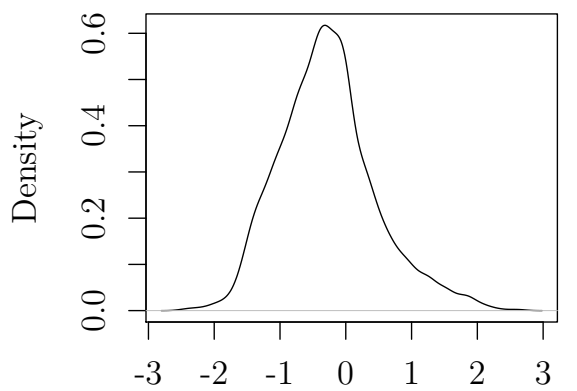

$\mathrm{N}=2882$ Bandwidth $=0.1199$

QQ plot of $\log ($ Relative Experience)

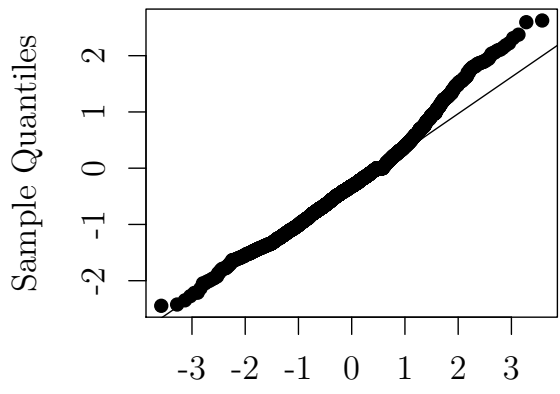

Theoretical Quantiles

\section{C.2 Cox proportional hazard with interaction}

\footnotetext{
${ }^{1}$ The fit is far from perfect after the transformation, which is confirmed by a Shapiro-Wilk test. The $\mathrm{p}$-value is $2.2 \mathrm{e}-16$ for the non-transformed variable, while the p-value is $3.11 \mathrm{e}-12$ for the log-transformed variable
} 
Table C.1: Replication of Model 7 and Model 8 in Table 6.3 with interaction between time and main variables.

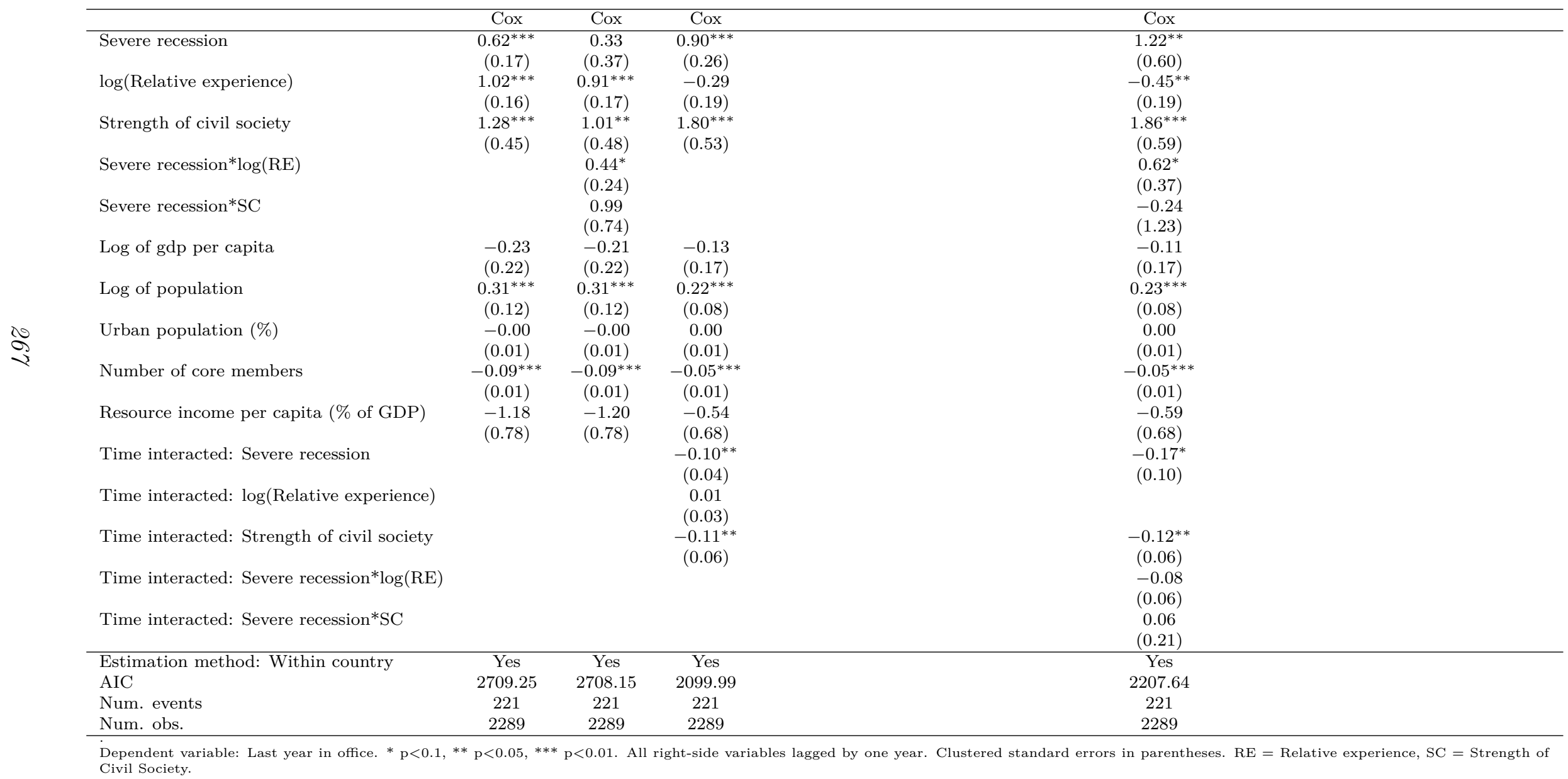


C.3 Repeating the analysis with The Maddison Project Database 
Table C.2: Internal and external constraints and economic growth in autocracies

\begin{tabular}{|c|c|c|c|c|c|c|c|c|c|}
\hline & $(1)$ & $(2)$ & (3) & $(4)$ & $(5)$ & (6) & $(7)$ & $(8)$ & (9) \\
\hline Log(Relative experience) & $\begin{array}{l}-0.01 \\
(0.51)\end{array}$ & $\begin{array}{l}-2.55 \\
(1.60)\end{array}$ & $\begin{array}{c}0.70 \\
(0.50)\end{array}$ & $\begin{array}{l}1.26^{*} \\
(0.65)\end{array}$ & $\begin{array}{l}1.08^{* *} \\
(0.54)\end{array}$ & $\begin{array}{l}2.26^{* * *} \\
(0.75)\end{array}$ & $\begin{array}{c}0.88 \\
(0.54)\end{array}$ & $\begin{array}{l}1.96^{* * *} \\
(0.71)\end{array}$ & \\
\hline Strength of civil society & $\begin{array}{c}0.57 \\
(2.44)\end{array}$ & $\begin{array}{l}-3.35 \\
(5.32)\end{array}$ & $\begin{array}{c}2.24 \\
(2.23)\end{array}$ & $\begin{array}{l}1.60 \\
(2.28)\end{array}$ & $\begin{array}{l}6.68^{* *} \\
(2.95)\end{array}$ & $\begin{array}{l}5.56^{*} \\
(2.82)\end{array}$ & $\begin{array}{l}6.11^{*} \\
(3.23)\end{array}$ & $\begin{array}{c}5.13 \\
(3.22)\end{array}$ & \\
\hline Tenure of the leader & $\begin{array}{c}0.02 \\
(0.08)\end{array}$ & $\begin{array}{l}-0.10 \\
(0.12)\end{array}$ & $\begin{array}{c}0.07 \\
(0.09)\end{array}$ & $\begin{array}{c}0.07 \\
(0.09)\end{array}$ & $\begin{array}{c}0.05 \\
(0.07)\end{array}$ & $\begin{array}{c}0.05 \\
(0.07)\end{array}$ & $\begin{array}{c}0.02 \\
(0.07)\end{array}$ & $\begin{array}{c}0.02 \\
(0.07)\end{array}$ & $\begin{array}{c}-0.09^{*} \\
(0.05)\end{array}$ \\
\hline $\log (\mathrm{RE}) * \mathrm{SC}$ & & & & $\begin{array}{l}-1.35 \\
(1.16)\end{array}$ & & $\begin{array}{c}-2.56^{* *} \\
(1.26)\end{array}$ & & $\begin{array}{c}-2.30^{*} \\
(1.19)\end{array}$ & \\
\hline Log(Population) & & & & & $\begin{array}{c}-9.54^{* *} \\
(4.47)\end{array}$ & $\begin{array}{c}-10.02^{* *} \\
(4.39)\end{array}$ & $\begin{array}{c}-8.51^{* *} \\
(3.95)\end{array}$ & $\begin{array}{c}-9.25^{* *} \\
(3.96)\end{array}$ & $\begin{array}{l}-6.07 \\
(3.75)\end{array}$ \\
\hline Urban population (\%) & & & & & $\begin{array}{l}-0.27 \\
(0.29)\end{array}$ & $\begin{array}{l}-0.28 \\
(0.29)\end{array}$ & $\begin{array}{l}-0.17 \\
(0.29)\end{array}$ & $\begin{array}{l}-0.20 \\
(0.29)\end{array}$ & $\begin{array}{l}-0.16 \\
(0.31)\end{array}$ \\
\hline Civil violence & & & & & $\begin{array}{c}-0.30^{* *} \\
(0.12)\end{array}$ & $\begin{array}{c}-0.30^{* * *} \\
(0.11)\end{array}$ & $\begin{array}{c}-0.26^{* *} \\
(0.11)\end{array}$ & $\begin{array}{c}-0.27^{* *} \\
(0.11)\end{array}$ & $\begin{array}{c}-0.24^{* *} \\
(0.11)\end{array}$ \\
\hline Number of core members & & & & & $\begin{array}{c}0.08 \\
(0.05)\end{array}$ & $\begin{array}{c}0.09 \\
(0.05)\end{array}$ & $\begin{array}{c}0.07 \\
(0.05)\end{array}$ & $\begin{array}{c}0.07 \\
(0.05)\end{array}$ & $\begin{array}{c}0.07 \\
(0.05)\end{array}$ \\
\hline Oil rents ( $\%$ of GDP) & & & & & $\begin{array}{l}0.09^{*} \\
(0.05)\end{array}$ & $\begin{array}{l}0.09^{*} \\
(0.05)\end{array}$ & $\begin{array}{c}0.07 \\
(0.05)\end{array}$ & $\begin{array}{c}0.07 \\
(0.05)\end{array}$ & $\begin{array}{c}0.08 \\
(0.05)\end{array}$ \\
\hline Year & $\begin{array}{l}-0.03 \\
(0.06)\end{array}$ & $\begin{array}{l}-0.01 \\
(0.10)\end{array}$ & $\begin{array}{l}-0.04 \\
(0.07)\end{array}$ & $\begin{array}{l}-0.03 \\
(0.07)\end{array}$ & $\begin{array}{c}0.32^{* * *} \\
(0.12)\end{array}$ & $\begin{array}{c}0.34^{* * *} \\
(0.12)\end{array}$ & & & \\
\hline Sample & All & Oil & Oil & & Oil & Oil & Oil & Oil & Oil \\
\hline Estimation method: Within leader & Yes & Yes & Yes & Yes & Yes & Yes & Yes & Yes & Yes \\
\hline Estimation method: Within country & Yes & Yes & Yes & Yes & Yes & Yes & Yes & Yes & Yes \\
\hline Estimation method: Within year & No & No & No & No & No & No & Yes & Yes & Yes \\
\hline Num. obs. & 2956 & 504 & 2452 & 2452 & 1952 & 1952 & 1952 & 1952 & 1970 \\
\hline $\mathrm{R}^{2}$ (full model) & 0.34 & 0.10 & 0.46 & 0.46 & 0.36 & 0.36 & 0.40 & 0.40 & 0.39 \\
\hline $\mathrm{R}^{2}$ (proj model) & 0.00 & 0.01 & 0.00 & 0.00 & 0.04 & 0.04 & 0.03 & 0.03 & 0.02 \\
\hline Num. groups: Dictator & 368 & 29 & 339 & 339 & 270 & 270 & 270 & 270 & 271 \\
\hline Num. groups: country.isocode & 108 & 19 & 105 & 105 & 95 & 95 & 95 & 95 & 96 \\
\hline Num. groups: year & & & & & & & 46 & 46 & 46 \\
\hline
\end{tabular}

${ }^{*} \mathrm{p}<0.1,{ }^{* *} \mathrm{p}<0.05,{ }^{* * *} \mathrm{p}<0.01$. Dependent variable: Growth (The Maddison Project Database). All right-side variables lagged by one year. Clustered standard errors in parentheses. $\mathrm{RE}=$ Relative experience, $\mathrm{SC}=$ Strength of Civil Society. 
Table C.3: Internal and external constraints and recessions in autocracies (The Maddision Project Database)

\begin{tabular}{|c|c|c|c|c|c|c|}
\hline & (1) & (2) & (3) & (4) & (5) & (6) \\
\hline \multirow[t]{2}{*}{ Log(Relative experience) } & -0.00 & -0.05 & -0.03 & $-0.07^{*}$ & -0.03 & $-0.05^{* *}$ \\
\hline & $(0.03)$ & $(0.05)$ & $(0.03)$ & $(0.04)$ & $(0.02)$ & $(0.03)$ \\
\hline \multirow[t]{2}{*}{ Strength of civil society } & -0.14 & -0.10 & -0.28 & -0.24 & $-0.30^{*}$ & -0.28 \\
\hline & $(0.24)$ & $(0.24)$ & $(0.21)$ & $(0.21)$ & $(0.17)$ & $(0.18)$ \\
\hline \multirow[t]{2}{*}{ Tenure of the leader } & 0.01 & 0.01 & -0.00 & -0.00 & -0.00 & -0.00 \\
\hline & $(0.01)$ & $(0.01)$ & $(0.00)$ & $(0.00)$ & $(0.00)$ & $(0.00)$ \\
\hline \multirow[t]{2}{*}{$\log (\mathrm{RE}) * \mathrm{SC}$} & & 0.10 & & $0.09^{*}$ & & 0.05 \\
\hline & & $(0.08)$ & & $(0.05)$ & & $(0.05)$ \\
\hline \multirow[t]{2}{*}{ Log(Population) } & 0.13 & 0.16 & $0.43^{* *}$ & $0.46^{* *}$ & $0.60^{* * *}$ & $0.62^{* * *}$ \\
\hline & $(0.24)$ & $(0.24)$ & $(0.19)$ & $(0.19)$ & $(0.19)$ & $(0.19)$ \\
\hline \multirow[t]{2}{*}{ Urban population (\%) } & $0.02^{*}$ & $0.02^{* *}$ & $0.02^{* *}$ & $0.02^{* *}$ & $0.02^{* *}$ & $0.02^{* *}$ \\
\hline & $(0.01)$ & $(0.01)$ & $(0.01)$ & $(0.01)$ & $(0.01)$ & $(0.01)$ \\
\hline \multirow[t]{2}{*}{ Civil violence } & 0.01 & 0.01 & 0.01 & 0.01 & $0.01^{* *}$ & $0.01^{* *}$ \\
\hline & $(0.01)$ & $(0.01)$ & $(0.01)$ & $(0.01)$ & $(0.00)$ & $(0.00)$ \\
\hline \multirow[t]{2}{*}{ Number of core members } & -0.01 & $-0.01^{*}$ & $-0.01^{*}$ & $-0.01^{*}$ & -0.00 & -0.00 \\
\hline & $(0.00)$ & $(0.00)$ & $(0.00)$ & $(0.00)$ & $(0.00)$ & $(0.00)$ \\
\hline \multirow[t]{2}{*}{ Oil rents ( $\%$ of GDP) } & -0.01 & -0.01 & -0.00 & -0.00 & $-0.00^{* *}$ & $-0.00^{* *}$ \\
\hline & $(0.00)$ & $(0.00)$ & $(0.00)$ & $(0.00)$ & $(0.00)$ & $(0.00)$ \\
\hline Size of recession & $<0$ & $<0$ & $<-3$ & $<-3$ & $<-6$ & $<-6$ \\
\hline Sample & -Oil & -Oil & -Oil & -Oil & -Oil & -Oil \\
\hline Estimation method: Within leader & Yes & Yes & Yes & Yes & Yes & Yes \\
\hline Estimation method: Within country & Yes & Yes & Yes & Yes & Yes & Yes \\
\hline Estimation method: Within year & Yes & Yes & Yes & Yes & Yes & Yes \\
\hline Observations: & 1952 & 1952 & 1952 & 1952 & 1952 & 1952 \\
\hline Leaders: & 270 & 270 & 270 & 270 & 270 & 270 \\
\hline Countries: & 95 & 95 & 95 & 95 & 95 & 95 \\
\hline $\mathrm{R}^{2}$ & 0.35 & 0.35 & 0.33 & 0.33 & 0.32 & 0.32 \\
\hline
\end{tabular}

$* \mathrm{p}<0.1, * * \mathrm{p}<0.05, * * * \mathrm{p}<0.01$. Dependent variable: Likelihood of a severe recession (The Maddison Project Database). All right-side variables lagged by one year. Clustered standard errors in parentheses. $\mathrm{RE}=$ Relative experience, $\mathrm{SC}=$ Strength of Civil Society. 


\section{C.4 Logit regression for economic recession}

Table C.4: Statistical models

\begin{tabular}{|c|c|c|c|c|c|c|}
\hline & Model 1 & Model 2 & Model 3 & Model 4 & Model 5 & Model 6 \\
\hline Log(Relative experience) & $-0.45(0.19)^{* *}$ & $-1.05(0.32)^{* * *}$ & $-0.37(0.25)$ & $-0.75(0.41)^{*}$ & $-0.48(0.40)$ & $-1.28(0.62)^{* *}$ \\
\hline Strength of civil society & $-1.13(0.92)$ & $-0.46(0.97)$ & $-2.30(1.16)^{* *}$ & $-1.86(1.21)$ & $-4.28(1.56)^{* * *}$ & $-3.41(1.61)^{* *}$ \\
\hline Tenure of the leader & $-0.05(0.03)^{* *}$ & $-0.05(0.03)^{*}$ & $-0.07(0.04)^{* *}$ & $-0.07(0.04)^{*}$ & $-0.05(0.04)$ & $-0.04(0.04)$ \\
\hline $\log (\mathrm{RE}) * \mathrm{SC}$ & & $1.32(0.55)^{* *}$ & & $0.85(0.71)$ & & $1.90(1.04)^{*}$ \\
\hline Log(Population) & $0.21(1.08)$ & $0.15(1.09)$ & $1.62(1.44)$ & $1.50(1.45)$ & $-2.17(1.84)$ & $-2.77(1.89)$ \\
\hline Urban population (\%) & $0.21(0.08)^{* * *}$ & $0.21(0.08)^{* * *}$ & $0.23(0.10)^{* *}$ & $0.22(0.10)^{* *}$ & $0.26(0.12)^{* *}$ & $0.24(0.12)^{* *}$ \\
\hline Civil violence & $0.06(0.04)$ & $0.06(0.04)$ & $0.08(0.05)$ & $0.08(0.05)$ & $0.20(0.08)^{* * *}$ & $0.21(0.08)^{* * *}$ \\
\hline Number of core members & $-0.05(0.02)^{* * *}$ & $-0.05(0.02)^{* * *}$ & $-0.06(0.02)^{* * *}$ & $-0.06(0.02)^{* * *}$ & $-0.05(0.03)^{* *}$ & $-0.05(0.03)^{*}$ \\
\hline Oil rents (\% of GDP) & $-0.01(0.02)$ & $-0.01(0.02)$ & $-0.05(0.03)^{*}$ & $-0.05(0.03)^{*}$ & $-0.07(0.04)$ & $-0.07(0.04)^{*}$ \\
\hline Size of recession & $<0$ & $<0$ & $<-3$ & $<-3$ & $<-6$ & $<-6$ \\
\hline Sample & - Oil & -Oil & - Oil & - Oil & -Oil & - Oil \\
\hline Estimation method: Within leader & Yes & Yes & Yes & Yes & Yes & Yes \\
\hline $\mathrm{AIC}$ & 1143.00 & 1139.18 & 766.36 & 766.95 & 433.02 & 431.64 \\
\hline $\mathrm{R}^{2}$ & 0.01 & 0.02 & 0.02 & 0.02 & 0.02 & 0.02 \\
\hline Max. $\mathrm{R}^{2}$ & 0.44 & 0.44 & 0.32 & 0.32 & 0.20 & 0.20 \\
\hline Num. events & 441 & 441 & 258 & 258 & 127 & 127 \\
\hline Num. obs. & 2012 & 2012 & 2012 & 2012 & 2012 & 2012 \\
\hline Missings & 870 & 870 & 870 & 870 & 870 & 870 \\
\hline
\end{tabular}

\footnotetext{
* $\mathrm{p}<0.1, * * \mathrm{p}<0.05, * * * \mathrm{p}<0.01$. All right-side variables lagged by one year. Clustered standard errors in parentheses. $\mathrm{RE}=$ Relative experience, $\mathrm{SC}=\mathrm{Strength}$ of Civil Society.
} 


\section{C.5 Human development in poor democracies}

Table C.5: Internal and external constraints and human development in democracies

\begin{tabular}{|c|c|c|c|c|c|c|c|c|c|c|c|c|}
\hline & \multicolumn{12}{|c|}{ Dependent variable: } \\
\hline & \multicolumn{6}{|c|}{ Change in infant mortality } & \multicolumn{6}{|c|}{ Change in primary school enrolment } \\
\hline & $(1)$ & $(2)$ & $(3)$ & $(4)$ & $(5)$ & $(6)$ & $(7)$ & $(8)$ & $(9)$ & $(10)$ & $(11)$ & $(12)$ \\
\hline $\log ($ Relative experience $)$ & $\begin{array}{c}0.06 \\
(0.06)\end{array}$ & $\begin{array}{c}0.17 \\
(0.18)\end{array}$ & $\begin{array}{c}0.05 \\
(0.06)\end{array}$ & $\begin{array}{c}0.05 \\
(0.16)\end{array}$ & $\begin{array}{c}0.05 \\
(0.16)\end{array}$ & $\begin{array}{c}0.06 \\
(0.06)\end{array}$ & $\begin{array}{c}0.29 \\
(0.34)\end{array}$ & $\begin{array}{c}1.20 \\
(1.29)\end{array}$ & $\begin{array}{c}0.16 \\
(0.35)\end{array}$ & $\begin{array}{c}1.18 \\
(1.18)\end{array}$ & $\begin{array}{c}1.22 \\
(1.21)\end{array}$ & $\begin{array}{c}0.18 \\
(0.35)\end{array}$ \\
\hline Strength of civil society & $\begin{array}{c}-0.59^{*} \\
(0.30)\end{array}$ & $\begin{array}{c}-0.62^{* *} \\
(0.31)\end{array}$ & $\begin{array}{l}-0.38 \\
(0.28)\end{array}$ & $\begin{array}{l}-0.38 \\
(0.28)\end{array}$ & $\begin{array}{l}-0.24 \\
(0.29)\end{array}$ & $\begin{array}{l}-0.24 \\
(0.30)\end{array}$ & $\begin{array}{c}2.00 \\
(1.72)\end{array}$ & $\begin{array}{c}1.78 \\
(1.66)\end{array}$ & $\begin{array}{c}2.17 \\
(2.01)\end{array}$ & $\begin{array}{c}1.89 \\
(1.91)\end{array}$ & $\begin{array}{c}1.51 \\
(2.10)\end{array}$ & $\begin{array}{c}1.78 \\
(2.21)\end{array}$ \\
\hline Tenure of the leader & $\begin{array}{c}0.01 \\
(0.01)\end{array}$ & $\begin{array}{c}0.01 \\
(0.01)\end{array}$ & $\begin{array}{c}0.01 \\
(0.01)\end{array}$ & $\begin{array}{c}0.01 \\
(0.01)\end{array}$ & $\begin{array}{c}0.01 \\
(0.01)\end{array}$ & $\begin{array}{c}0.01 \\
(0.01)\end{array}$ & $\begin{array}{l}0.14^{*} \\
(0.08)\end{array}$ & $\begin{array}{l}0.15^{*} \\
(0.09)\end{array}$ & $\begin{array}{c}0.13 \\
(0.08)\end{array}$ & $\begin{array}{c}0.13 \\
(0.09)\end{array}$ & $\begin{array}{c}0.13 \\
(0.09)\end{array}$ & $\begin{array}{c}0.13 \\
(0.09)\end{array}$ \\
\hline $\log (\mathrm{RE}) * \mathrm{SC}$ & & $\begin{array}{l}-0.14 \\
(0.21)\end{array}$ & & $\begin{array}{l}0.002 \\
(0.20)\end{array}$ & $\begin{array}{c}0.02 \\
(0.20)\end{array}$ & & & $\begin{array}{l}-1.13 \\
(1.41)\end{array}$ & & $\begin{array}{l}-1.28 \\
(1.31)\end{array}$ & $\begin{array}{l}-1.31 \\
(1.34)\end{array}$ & \\
\hline Growth & & & $\begin{array}{l}-0.003 \\
(0.005)\end{array}$ & $\begin{array}{l}-0.003 \\
(0.005)\end{array}$ & $\begin{array}{c}-0.002 \\
(0.01)\end{array}$ & $\begin{array}{c}-0.002 \\
(0.01)\end{array}$ & & & $\begin{array}{c}-0.04^{*} \\
(0.02)\end{array}$ & $\begin{array}{c}-0.04^{*} \\
(0.02)\end{array}$ & $\begin{array}{c}-0.05^{*} \\
(0.03)\end{array}$ & $\begin{array}{c}-0.05^{*} \\
(0.03)\end{array}$ \\
\hline Log of population & & & $\begin{array}{l}-1.35 \\
(1.05)\end{array}$ & $\begin{array}{l}-1.35 \\
(1.05)\end{array}$ & $\begin{array}{l}-1.50 \\
(1.09)\end{array}$ & $\begin{array}{l}-1.50 \\
(1.09)\end{array}$ & & & $\begin{array}{c}-11.18^{* *} \\
(4.25)\end{array}$ & $\begin{array}{c}-11.12^{* *} \\
(4.21)\end{array}$ & $\begin{array}{c}-10.73^{* *} \\
(4.34)\end{array}$ & $\begin{array}{c}-10.75^{* *} \\
(4.36)\end{array}$ \\
\hline Urban population (\%) & & & $\begin{array}{c}0.08^{* * *} \\
(0.03)\end{array}$ & $\begin{array}{c}0.08^{* * *} \\
(0.02)\end{array}$ & $\begin{array}{c}0.08^{* * *} \\
(0.03)\end{array}$ & $\begin{array}{c}0.08^{* * *} \\
(0.03)\end{array}$ & & & $\begin{array}{l}-0.06 \\
(0.04)\end{array}$ & $\begin{array}{c}-0.07^{*} \\
(0.04)\end{array}$ & $\begin{array}{c}-0.07^{*} \\
(0.04)\end{array}$ & $\begin{array}{l}-0.06 \\
(0.04)\end{array}$ \\
\hline Civil violence & & & $\begin{array}{l}-0.04 \\
(0.04)\end{array}$ & $\begin{array}{l}-0.04 \\
(0.04)\end{array}$ & $\begin{array}{l}-0.03 \\
(0.04)\end{array}$ & $\begin{array}{l}-0.03 \\
(0.04)\end{array}$ & & & $\begin{array}{c}0.28 \\
(0.41)\end{array}$ & $\begin{array}{c}0.26 \\
(0.40)\end{array}$ & $\begin{array}{c}0.26 \\
(0.40)\end{array}$ & $\begin{array}{c}0.28 \\
(0.41)\end{array}$ \\
\hline Number of core members & & & $\begin{array}{c}0.001 \\
(0.004)\end{array}$ & $\begin{array}{c}0.001 \\
(0.004)\end{array}$ & $\begin{array}{c}0.001 \\
(0.004)\end{array}$ & $\begin{array}{c}0.001 \\
(0.004)\end{array}$ & & & $\begin{array}{c}0.03 \\
(0.04)\end{array}$ & $\begin{array}{c}0.03 \\
(0.04)\end{array}$ & $\begin{array}{c}0.03 \\
(0.04)\end{array}$ & $\begin{array}{c}0.03 \\
(0.04)\end{array}$ \\
\hline Oil rents ( $\%$ of GDP) & & & & & $\begin{array}{l}-0.03 \\
(0.02) \\
\end{array}$ & $\begin{array}{l}-0.03 \\
(0.02) \\
\end{array}$ & & & & & $\begin{array}{c}0.12 \\
(0.13) \\
\end{array}$ & $\begin{array}{c}0.13 \\
(0.12) \\
\end{array}$ \\
\hline Sample: & All & All & All & All & All & -Oil & All & All & All & All & All & -Oil \\
\hline Estimation method: Within leader & Yes & Yes & Yes & Yes & Yes & Yes & Yes & Yes & Yes & Yes & Yes & Yes \\
\hline Estimation method: Within year & Yes & Yes & Yes & Yes & Yes & Yes & Yes & Yes & Yes & Yes & Yes & Yes \\
\hline Leaders: & 321 & 321 & 321 & 321 & 298 & 298 & 181 & 181 & 181 & 181 & 432 & 432 \\
\hline Countries: & 72 & 72 & 72 & 72 & 71 & 71 & 62 & 62 & 62 & 62 & 62 & 62 \\
\hline Observations & 1,473 & 1,473 & 1,446 & 1,446 & 1,362 & 1,362 & 639 & 639 & 631 & 631 & 616 & 616 \\
\hline $\mathrm{R}^{2}$ & 0.84 & 0.84 & $\begin{array}{l}1,+85 \\
0.85\end{array}$ & 0.85 & 0.86 & 0.86 & 0.44 & 0.44 & 0.46 & 0.46 & 0.45 & 0.45 \\
\hline
\end{tabular}




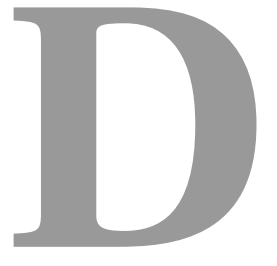

Appendices to chapter 7 
D.1 Only including autocracies

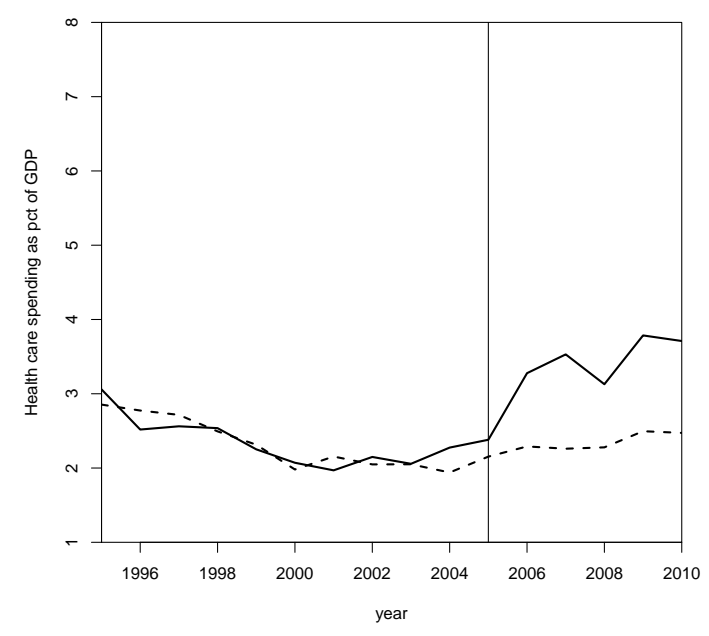

(a) Health care spending

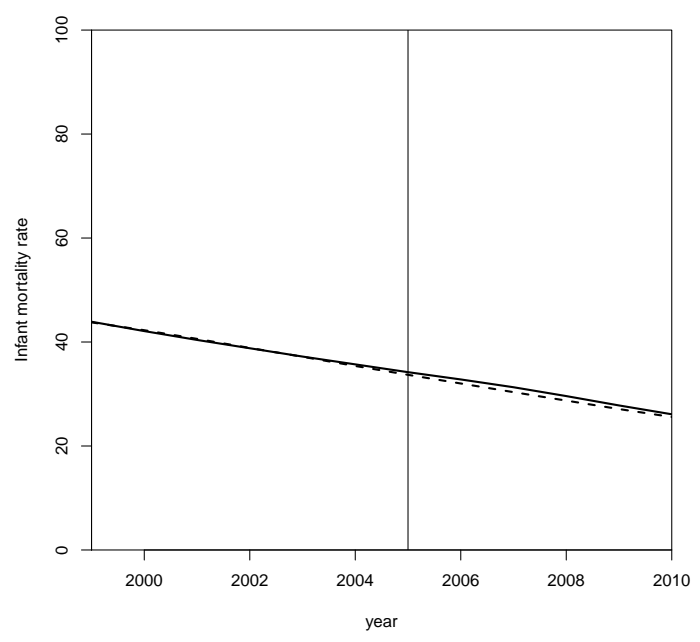

(b) Infant mortality 


\section{D.2 Leave one out}

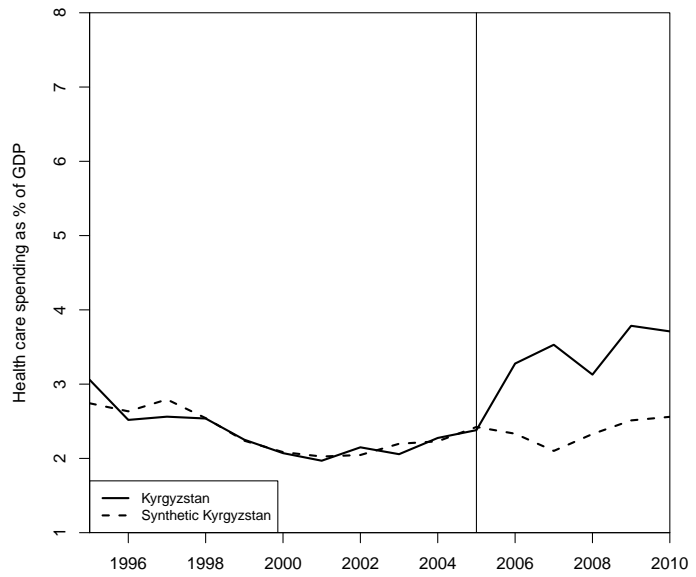

(a) Health care spending

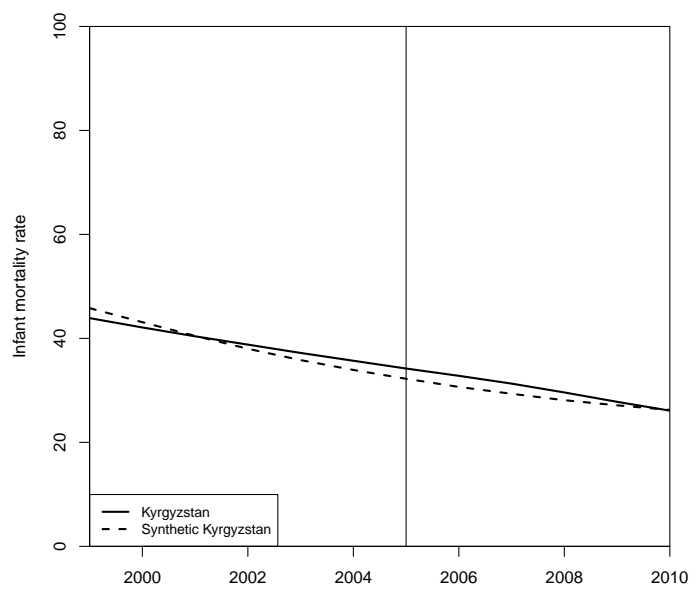

(c) Infant mortality

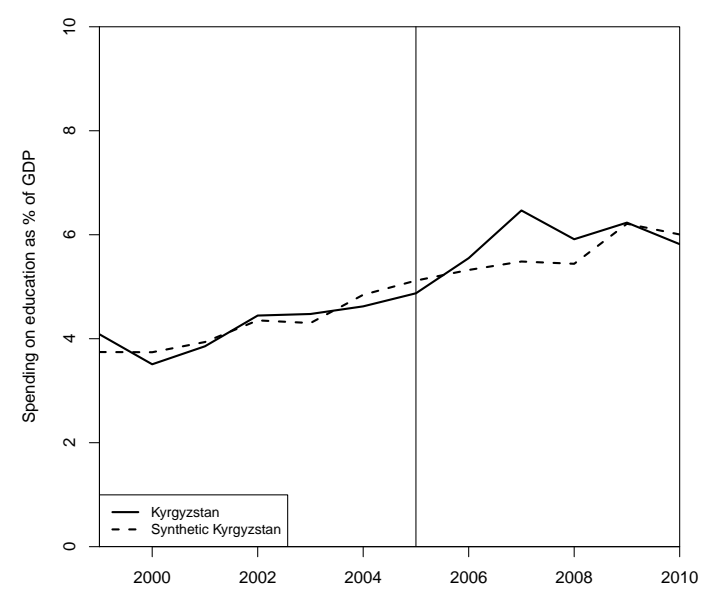

(b) Education spending

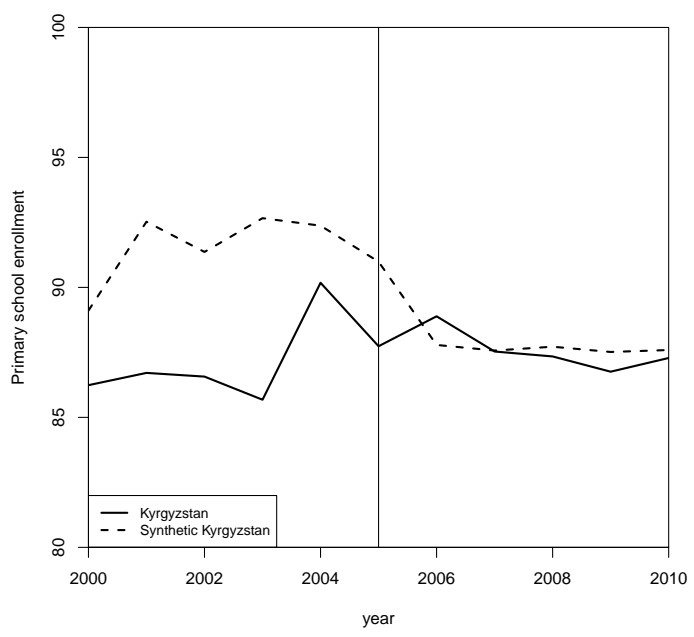

(d) Primary school enrollment 
Table D.1: Country weights for synthetic Kyrgyzstan when leaving one out

\begin{tabular}{llllll}
\hline & Country & $\begin{array}{l}\text { Spending } \\
\text { on health } \\
\text { care }\end{array}$ & $\begin{array}{l}\text { Spending } \\
\text { on } \\
\text { education }\end{array}$ & $\begin{array}{l}\text { Infant mor- } \\
\text { tality rate }\end{array}$ & $\begin{array}{l}\text { Primary } \\
\text { school } \\
\text { enrollment }\end{array}$ \\
\hline 1 & ALB & 0.00 & & 0.00 & \\
2 & ARM & & 0.00 & 0.00 & \\
3 & AZE & 0.00 & 0.00 & 0.00 & 0.00 \\
4 & BGR & 0.00 & & 0.00 & 0.00 \\
5 & BIH & 0.00 & & 0.00 & \\
6 & BLR & 0.00 & & 0.00 & \\
7 & CZE & 0.00 & 0.35 & 0.00 & \\
8 & EST & 0.01 & & 0.00 & 0.00 \\
9 & HRV & 0.00 & & 0.00 & \\
10 & HUN & 0.17 & 0.00 & 0.00 & 0.00 \\
11 & KAZ & 0.29 & & 0.00 & 0.00 \\
12 & LTU & 0.00 & & 0.00 & 0.00 \\
13 & LVA & 0.00 & & 0.00 & \\
14 & MDA & 0.00 & 0.38 & 0.00 & 1.00 \\
15 & MKD & 0.00 & & 0.52 & \\
16 & POL & 0.00 & 0.05 & 0.00 & 0.00 \\
17 & ROU & 0.00 & & 0.00 & 0.00 \\
18 & RUS & 0.00 & & 0.00 & \\
19 & SVK & 0.00 & & 0.00 & \\
20 & SVN & 0.00 & & 0.00 & 0.00 \\
21 & TJK & 0.48 & 0.22 & 0.48 & 0.00 \\
22 & TKM & 0.00 & & 0.00 & \\
23 & UZB & 0.04 & & & \\
\hline
\end{tabular}




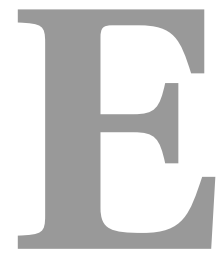

Appendices to chapter 8 


\section{E.1 Tables for Figure 8.2}

Table E.1: Table for Figure 8.1: Country-fixed effects

\begin{tabular}{|c|c|c|c|c|c|c|}
\hline & Base model & Electoral controls & Economic controls & Instability controls & Purgers MA's & All controls \\
\hline Failed coup attempt & $0.11(0.03)^{* * *}$ & $0.10(0.04)^{* * *}$ & $0.10(0.03)^{* * *}$ & $0.10(0.03)^{* * *}$ & $0.11(0.03)^{* * *}$ & $0.09(0.04)^{* *}$ \\
\hline Log of GDP per capita & $-0.03(0.01)^{*}$ & $-0.05(0.02)^{* * *}$ & $-0.02(0.02)$ & $-0.03(0.02)^{*}$ & $-0.04(0.01)^{* * *}$ & $-0.05(0.02)^{* *}$ \\
\hline Log of Population & $0.01(0.05)$ & & $0.05(0.06)$ & $-0.01(0.07)$ & $-0.06(0.05)$ & $-0.01(0.10)$ \\
\hline Election & & $0.01(0.01)$ & & & & $0.01(0.01)$ \\
\hline Years since last election & & $-0.00(0.00)^{* * *}$ & & & & $-0.00(0.00)^{* * *}$ \\
\hline Log of oil value/population & & & $-0.00(0.00)^{*}$ & & & $-0.00(0.00)$ \\
\hline GDP growth & & & $-0.00(0.00)^{*}$ & & & $-0.00(0.00)$ \\
\hline Civil war onset & & & & $0.01(0.02)$ & & $0.00(0.02)$ \\
\hline Nonviolent campaign & & & & $0.03(0.02)$ & & $0.02(0.02)$ \\
\hline Military dispute & & & & $0.00(0.01)$ & & $0.00(0.01)$ \\
\hline Interstate war & & & & $0.04(0.05)$ & & $0.02(0.05)$ \\
\hline Strikes & & & & $0.01(0.09)$ & & $0.02(0.08)$ \\
\hline Replacement rate_t-3 & & & & & $-0.01(0.06)$ & $-0.03(0.07)$ \\
\hline Replacement rate_t-2 & & & & & $0.09(0.06)$ & $0.09(0.07)$ \\
\hline Replacement rate_t-1 & & & & & $-0.02(0.03)$ & $0.01(0.04)$ \\
\hline Num. obs. & 3659 & 2943 & 3370 & 3001 & 3492 & 2436 \\
\hline $\mathrm{R}^{2}$ (full model) & 0.30 & 0.31 & 0.31 & 0.32 & 0.22 & 0.24 \\
\hline $\mathrm{R}^{2}($ proj model $)$ & 0.01 & 0.01 & 0.01 & 0.01 & 0.01 & 0.02 \\
\hline Num. groups: COUNTRY_ID & 114 & 105 & 109 & 114 & 114 & 102 \\
\hline Num. groups: YEAR_DATA & 52 & 47 & 49 & 41 & 50 & 39 \\
\hline
\end{tabular}

${ }^{* * *} p<0.01 ;{ }^{* *} p<0.05 ;{ }^{*} p<0.1$. Dependent variable: Replacement rate. All models include country and year fixed effects. Country-clustered standard errors in parentheses. 
Table E.2: Table for Figure 8.2: Leader-fixed effects

\begin{tabular}{|c|c|c|c|c|c|c|}
\hline & Base model & Electoral controls & Economic controls & Instability controls & Purgers MA's & All controls \\
\hline Failed coup attempt & $0.09(0.03)^{* * *}$ & $0.08(0.03)^{* *}$ & $0.08(0.03)^{* *}$ & $0.08(0.03)^{* *}$ & $0.10(0.03)^{* * *}$ & $0.08(0.04)^{* *}$ \\
\hline Log of GDP per capita & $-0.04(0.01)^{* * *}$ & $-0.05(0.02)^{* *}$ & $-0.02(0.03)$ & $-0.02(0.02)$ & $-0.07(0.01)^{* * *}$ & $-0.06(0.03)^{* *}$ \\
\hline Log of Population & $0.03(0.01)^{* * *}$ & $-0.10(0.07)$ & $0.10(0.10)$ & $0.09(0.10)$ & $0.01(0.02)$ & $-0.11(0.08)$ \\
\hline Election & & $-0.01(0.01)$ & & & & $-0.01(0.01)$ \\
\hline Years since last election & & $-0.01(0.00)^{* * *}$ & & & & $-0.01(0.00)^{* * *}$ \\
\hline Log of oil value/population & & & $0.00(0.00)$ & & & $-0.00(0.00)$ \\
\hline GDP growth & & & $-0.00(0.00)$ & & & $-0.00(0.00)$ \\
\hline Civil war onset & & & & $-0.01(0.02)$ & & $-0.01(0.02)$ \\
\hline Nonviolent campaign & & & & $0.02(0.03)$ & & $-0.00(0.03)$ \\
\hline Military dispute & & & & $-0.00(0.01)$ & & $-0.00(0.01)$ \\
\hline Interstate war & & & & $0.01(0.05)$ & & $0.03(0.06)$ \\
\hline Strikes & & & & $-0.02(0.10)$ & & $0.05(0.08)$ \\
\hline Replacement rate_t-3 & & & & & $-0.16(0.06)^{* * *}$ & $-0.16(0.07)^{* *}$ \\
\hline Replacement rate_t-2 & & & & & $0.03(0.05)$ & $0.02(0.06)$ \\
\hline Replacement rate_t-1 & & & & & $-0.03(0.02)$ & $-0.01(0.03)$ \\
\hline Num. obs. & 3659 & 2943 & 3370 & 3001 & 3492 & 2436 \\
\hline $\mathrm{R}^{2}$ (full model) & 0.43 & 0.44 & 0.44 & 0.45 & 0.36 & 0.37 \\
\hline $\mathrm{R}^{2}($ proj model $)$ & 0.01 & 0.01 & 0.01 & 0.01 & 0.02 & 0.02 \\
\hline Num. groups: leader & 405 & 349 & 378 & 351 & 389 & 297 \\
\hline Num. groups: YEAR_DATA & 52 & 47 & 49 & 41 & 50 & 39 \\
\hline
\end{tabular}

\footnotetext{
${ }^{* * *} p<0.01 ;{ }^{* *} p<0.05 ;{ }^{*} p<0.1$. Dependent variable: Replacement rate. All models include leader and year fixed effects. Country-clustered standard errors in parentheses.
} 
Table E.3: Table for Figure 8.3: Alternative events

\begin{tabular}{|c|c|c|c|c|c|c|c|c|c|c|}
\hline & $(1)$ & $(2)$ & $(3)$ & $(4)$ & $(5)$ & $(6)$ & $(7)$ & $(8)$ & $(9)$ & $(10)$ \\
\hline Alternative event: Civil war & $\begin{array}{c}0.02 \\
(0.02)\end{array}$ & & & & & $\begin{array}{c}0.00 \\
(0.02)\end{array}$ & & & & \\
\hline Alternative event: Nonviolent campaign & & $\begin{array}{c}0.03 \\
(0.02)\end{array}$ & & & & & $\begin{array}{c}0.02 \\
(0.03)\end{array}$ & & & \\
\hline Alternative event: Military dispute & & & $\begin{array}{c}0.01 \\
(0.01)\end{array}$ & & & & & $\begin{array}{l}-0.00 \\
(0.01)\end{array}$ & & \\
\hline Alternative event: Interstate war & & & & $\begin{array}{c}0.06 \\
(0.05)\end{array}$ & & & & & $\begin{array}{c}0.01 \\
(0.05)\end{array}$ & \\
\hline Alternative event: Strikes & & & & & $\begin{array}{c}0.00 \\
(0.01)\end{array}$ & & & & & $\begin{array}{l}-0.00 \\
(0.00)\end{array}$ \\
\hline Log of GDP per capita & $\begin{array}{c}-0.03^{* *} \\
(0.01)\end{array}$ & $\begin{array}{c}-0.04^{* *} \\
(0.02)\end{array}$ & $\begin{array}{c}-0.04^{* *} \\
(0.02)\end{array}$ & $\begin{array}{c}-0.04^{* *} \\
(0.02)\end{array}$ & $\begin{array}{c}-0.03^{* *} \\
(0.01)\end{array}$ & $\begin{array}{c}-0.04^{* * *} \\
(0.01)\end{array}$ & $\begin{array}{l}-0.02 \\
(0.03)\end{array}$ & $\begin{array}{l}-0.03 \\
(0.03)\end{array}$ & $\begin{array}{l}-0.03 \\
(0.03)\end{array}$ & $\begin{array}{c}-0.05^{* * *} \\
(0.01)\end{array}$ \\
\hline Log of Population & $\begin{array}{c}0.01 \\
(0.05) \\
\end{array}$ & $\begin{array}{c}0.00 \\
(0.07) \\
\end{array}$ & $\begin{array}{l}-0.00 \\
(0.06) \\
\end{array}$ & $\begin{array}{c}0.00 \\
(0.06) \\
\end{array}$ & $\begin{array}{l}-0.01 \\
(0.05) \\
\end{array}$ & $\begin{array}{c}0.03^{* * *} \\
(0.01) \\
\end{array}$ & $\begin{array}{c}0.05 \\
(0.08) \\
\end{array}$ & $\begin{array}{c}0.08 \\
(0.10) \\
\end{array}$ & $\begin{array}{c}0.08 \\
(0.10) \\
\end{array}$ & $\begin{array}{c}0.03^{* * *} \\
(0.01) \\
\end{array}$ \\
\hline Estimation method: Within country & Yes & Yes & Yes & Yes & Yes & No & No & No & No & No \\
\hline Estimation method: Within leader & No & No & No & No & No & Yes & Yes & Yes & Yes & Yes \\
\hline Estimation method: Within year & Yes & Yes & Yes & Yes & Yes & Yes & Yes & Yes & Yes & Yes \\
\hline Num. obs. & 3659 & 3046 & 3292 & 3292 & 3614 & 3659 & 3046 & 3292 & 3292 & 3614 \\
\hline $\mathrm{R}^{2}$ (full model) & 0.29 & 0.33 & 0.32 & 0.32 & 0.28 & 0.43 & 0.46 & 0.46 & 0.46 & 0.42 \\
\hline $\mathrm{R}^{2}($ proj model $)$ & 0.00 & 0.00 & 0.00 & 0.00 & 0.00 & 0.01 & 0.00 & 0.00 & 0.00 & 0.01 \\
\hline Num. groups: COUNTRY_ID & 114 & 114 & 114 & 114 & 114 & & & & & \\
\hline Num. groups: YEAR_DATA & 52 & 41 & 45 & 45 & 52 & 52 & 41 & 45 & 45 & 52 \\
\hline Num. groups: leader & & & & & & 405 & 360 & 381 & 381 & 396 \\
\hline
\end{tabular}

\footnotetext{
${ }^{* * *} p<0.01 ;{ }^{* *} p<0.05 ;{ }^{*} p<0.1$. Dependent variable: Replacement rate. All models include year fixed effects. Country-clustered standard errors in parentheses.
} 


\section{E.2 Alternative measure of failed coup}

Figure E.1: Cabinet-level results: Bjornskov and Rode measure of coup

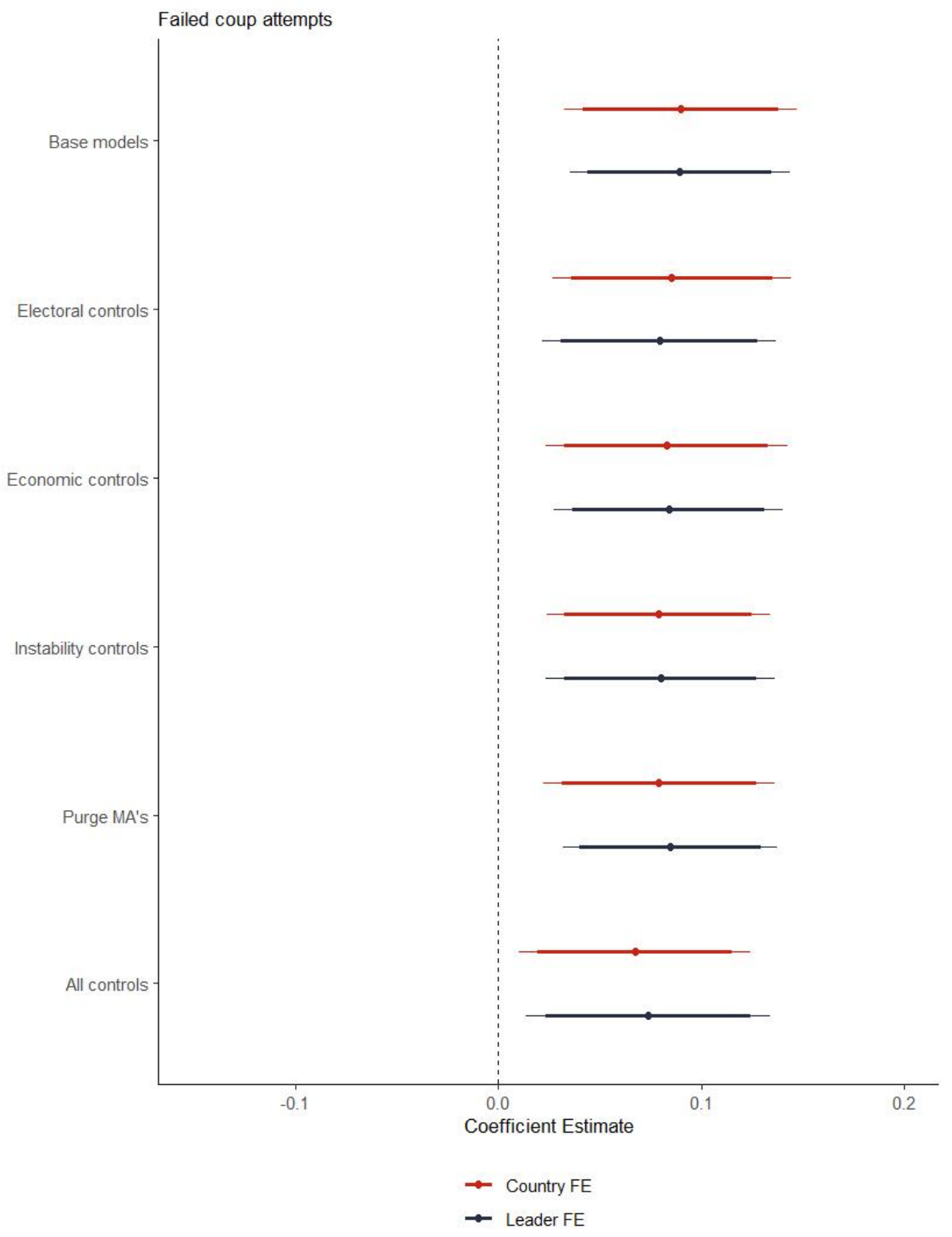

Thin lines represent 95 percent confidence intervals. Thick lines represent 90 percent confidence intervals. N: Up to 3.608 country-years. 


\section{E.3 Using polity as a democratic/autocratic classi- fication variable}

Figure E.2: Cabinet-level results: Polity $(<7)$ as classification variable for autocracy

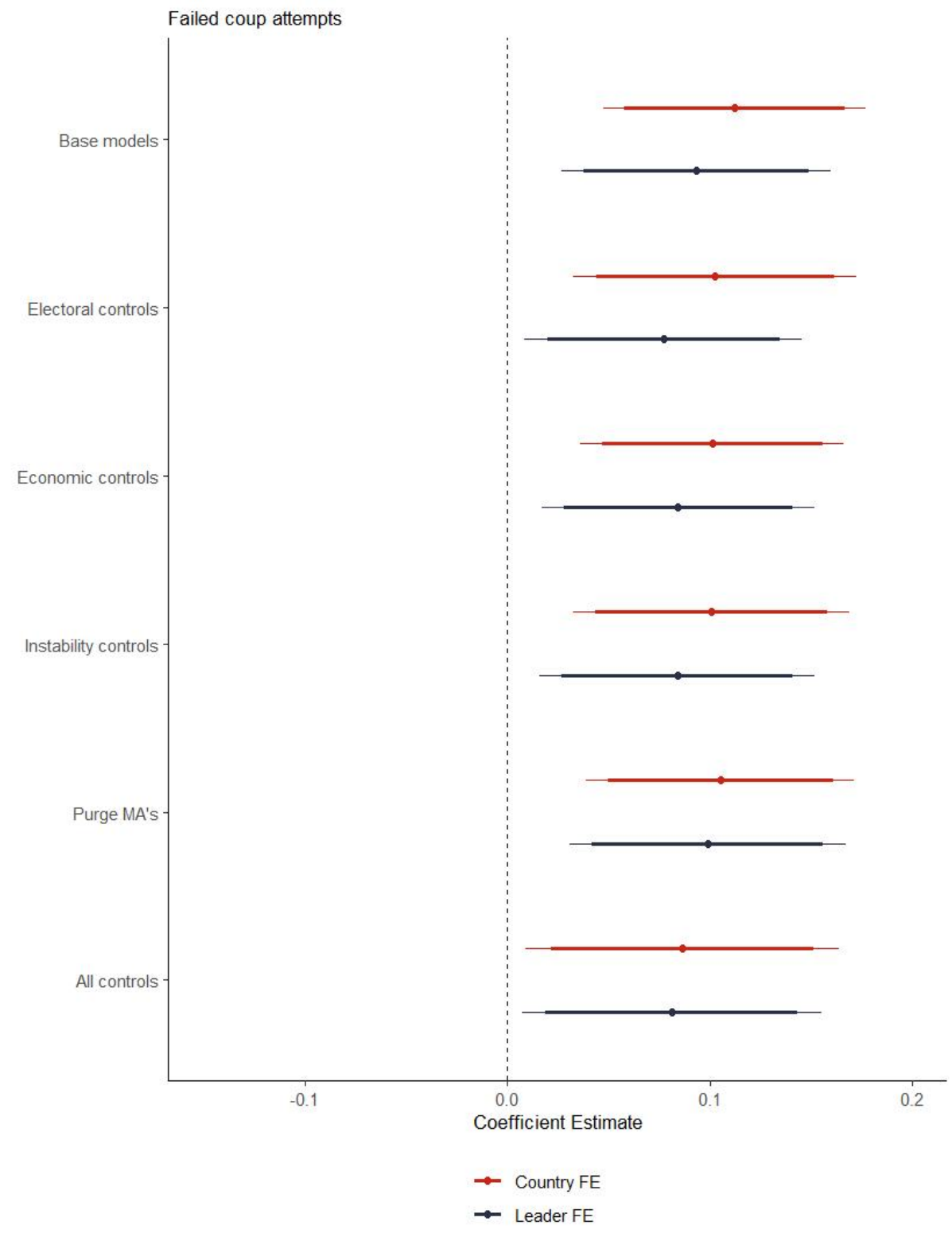

Thin lines represent 95 percent confidence intervals. Thick lines represent 90 percent confidence intervals. N: Up to 3.659 country-years. 


\section{E.4 Tables for Figure 8.3}

Table E.4: Table for Figure 8.3

\begin{tabular}{lcc}
\hline & Experience & Affiliation \\
\hline Experience & $0.00(0.00)$ & $0.00(0.00)^{*}$ \\
No party affiliation (Ref: Other party) & & $0.03(0.02)^{*}$ \\
From the leaders party (Ref: Other party) & $0.10(0.04)^{* * *}$ & $0.01(0.01)$ \\
Failed coup attempt & $-0.01(0.00)^{* *}$ & $0.12(0.11)$ \\
FCA*Experience & & $-0.06(0.11)$ \\
FCA $^{*}$ No party affiliation (Ref: Other party) & & $-0.09(0.11)$ \\
FCA*From the leaders party (Ref: Other party) & $-0.03(0.02)$ & $-0.02(0.02)$ \\
Log of GDP per capita & $-0.08(0.06)$ & $-0.09(0.06)$ \\
Log of Population & & $-0.00(0.00)$ \\
Experience ${ }^{2}$ & & $0.00(0.00)$ \\
Experience ${ }^{3}$ & 85996 & 78152 \\
\hline Num. obs. & 0.12 & 0.13 \\
$\mathrm{R}^{2}$ (full model) & 0.00 & 0.00 \\
$\mathrm{R}^{2}$ (proj model) & 114 & 114 \\
Num. groups: country_isocode & 51 & 51 \\
Num. groups: year $^{* * *} p<0.01 ;{ }^{* *} p<0.05 ;{ }^{*} p<0.1$. Dependent variable: Purged next year. All models include country and year fixed \\
effects. Country-clustered standard errors in parentheses. FCA = Failed coup attempt &
\end{tabular}


Table E.5: Table for Figure 8.3

\begin{tabular}{|c|c|c|}
\hline & Responsibility & Importance \\
\hline Minister of Foreign Affairs (Ref: D) & $-0.01(0.01)$ & \\
\hline Minister of Finance (Ref: D) & $0.03(0.01)^{* *}$ & \\
\hline Other type of minister (Ref: D) & $0.05(0.01)^{* * *}$ & \\
\hline Minister of Natural Resources (Ref: D) & $0.04(0.01)^{* * *}$ & \\
\hline VP, DP, top minister (Ref: PMP) & & $-0.01(0.01)$ \\
\hline Medium ranking minister (Ref: PMP) & & $0.03(0.01)^{*}$ \\
\hline Low ranking minister (Ref: PMP) & & $0.05(0.02)^{* * *}$ \\
\hline Junior minister (Ref: PMP) & & $0.01(0.02)$ \\
\hline Failed coup attempt & $0.11(0.07)^{*}$ & $0.31(0.12)^{* *}$ \\
\hline FCA: Minister of Foreign Affairs (Ref: D) & $-0.02(0.07)$ & \\
\hline FCA*Minister of Finance (Ref: D) & $-0.07(0.07)$ & \\
\hline FCA*Other type of minister (Ref: D) & $-0.05(0.06)$ & \\
\hline FCA*Minister of Natural Resources (Ref: D) & $-0.18(0.09)^{*}$ & \\
\hline FCA*VP, DP, top minister (Ref: PMP) & & $-0.25(0.13)^{* *}$ \\
\hline FCA*Medium ranking minister (Ref: PMP) & & $-0.23(0.12)^{*}$ \\
\hline FCA*Low ranking minister (Ref: PMP) & & $-0.31(0.14)^{* *}$ \\
\hline FCA*Junior minister (Ref: PMP) & & $-0.28(0.11)^{* *}$ \\
\hline Log of GDP per capita & $-0.04(0.02)^{*}$ & $-0.03(0.02)$ \\
\hline Log of Population & $-0.11(0.06)^{*}$ & $-0.09(0.06)$ \\
\hline Experience & $0.01(0.00)^{* *}$ & $0.00(0.00)$ \\
\hline Experience $^{2}$ & $-0.00(0.00)^{* *}$ & $-0.00(0.00)$ \\
\hline Experience $^{3}$ & $0.00(0.00)^{* *}$ & $0.00(0.00)$ \\
\hline Num. obs. & 68428 & 80109 \\
\hline $\mathrm{R}^{2}$ (full model) & 0.13 & 0.13 \\
\hline $\mathrm{R}^{2}($ proj model $)$ & 0.00 & 0.00 \\
\hline Num. groups: country_isocode & 114 & 114 \\
\hline Num. groups: year & 51 & 51 \\
\hline
\end{tabular}




\section{E.5 Alternative measure of failed coup - Individual results}

Figure E.3: Individual analysis using Bjørnskov and Rode (2019)

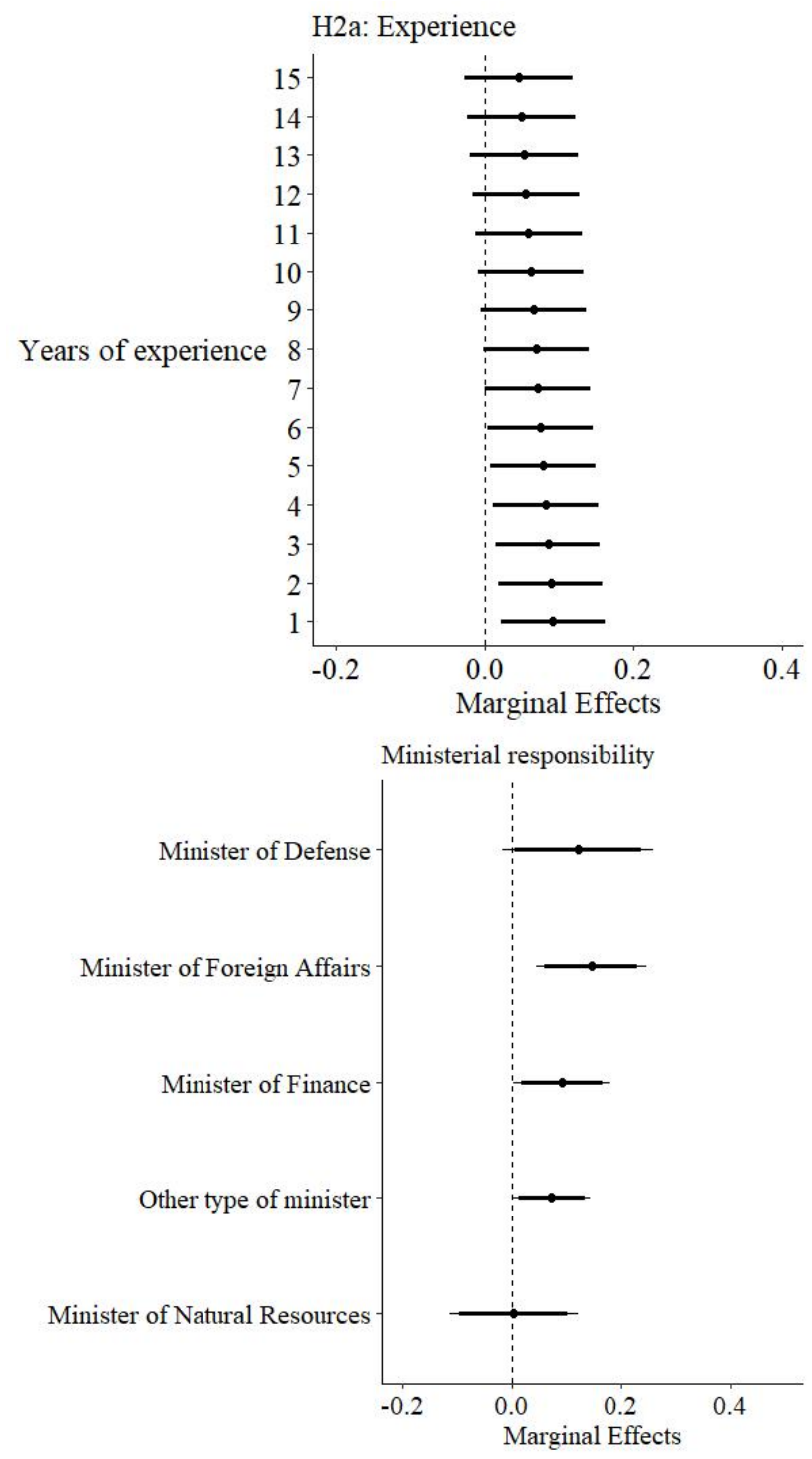

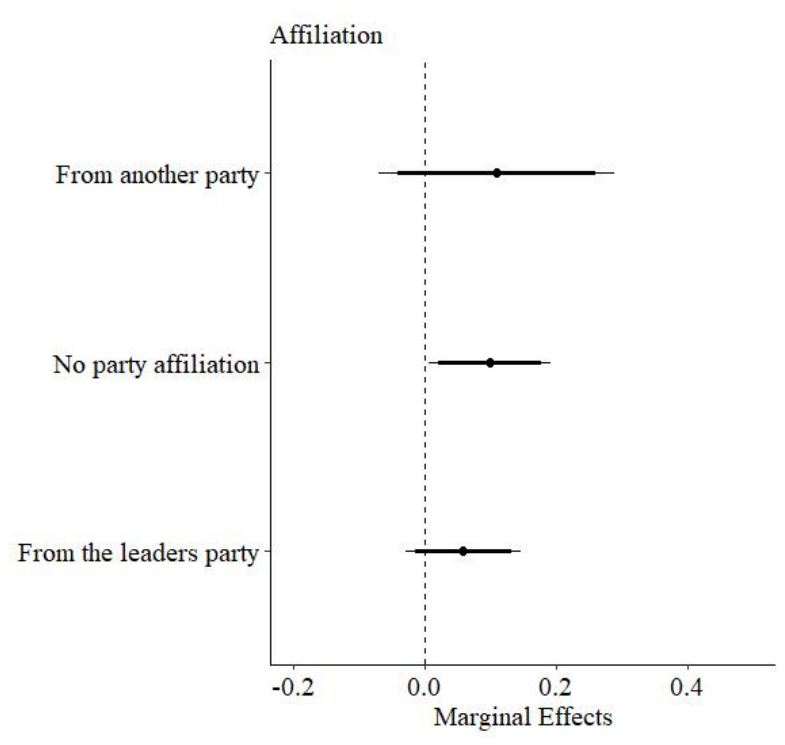

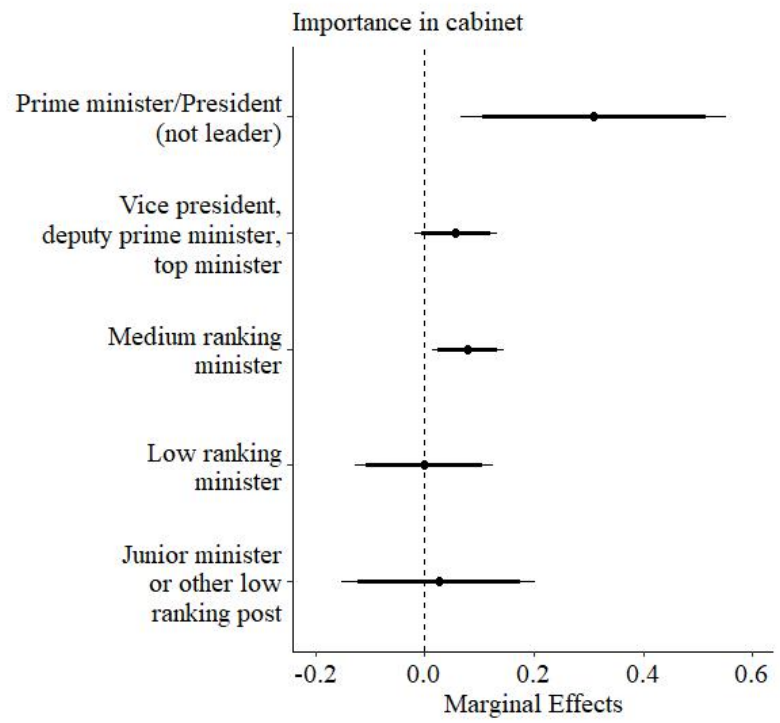

Note: $\mathrm{N}=85,644$ minister years (81,182 in years without a coup attempt and 2,269 in years with a coup attempt). Thin lines represent 95 percent confidence intervals. Thick lines represent 90 percent confidence intervals. 


\section{E.6 Alternative democracy measure - Individual re- sults}

Figure E.4: Individual analysis using Polity IV

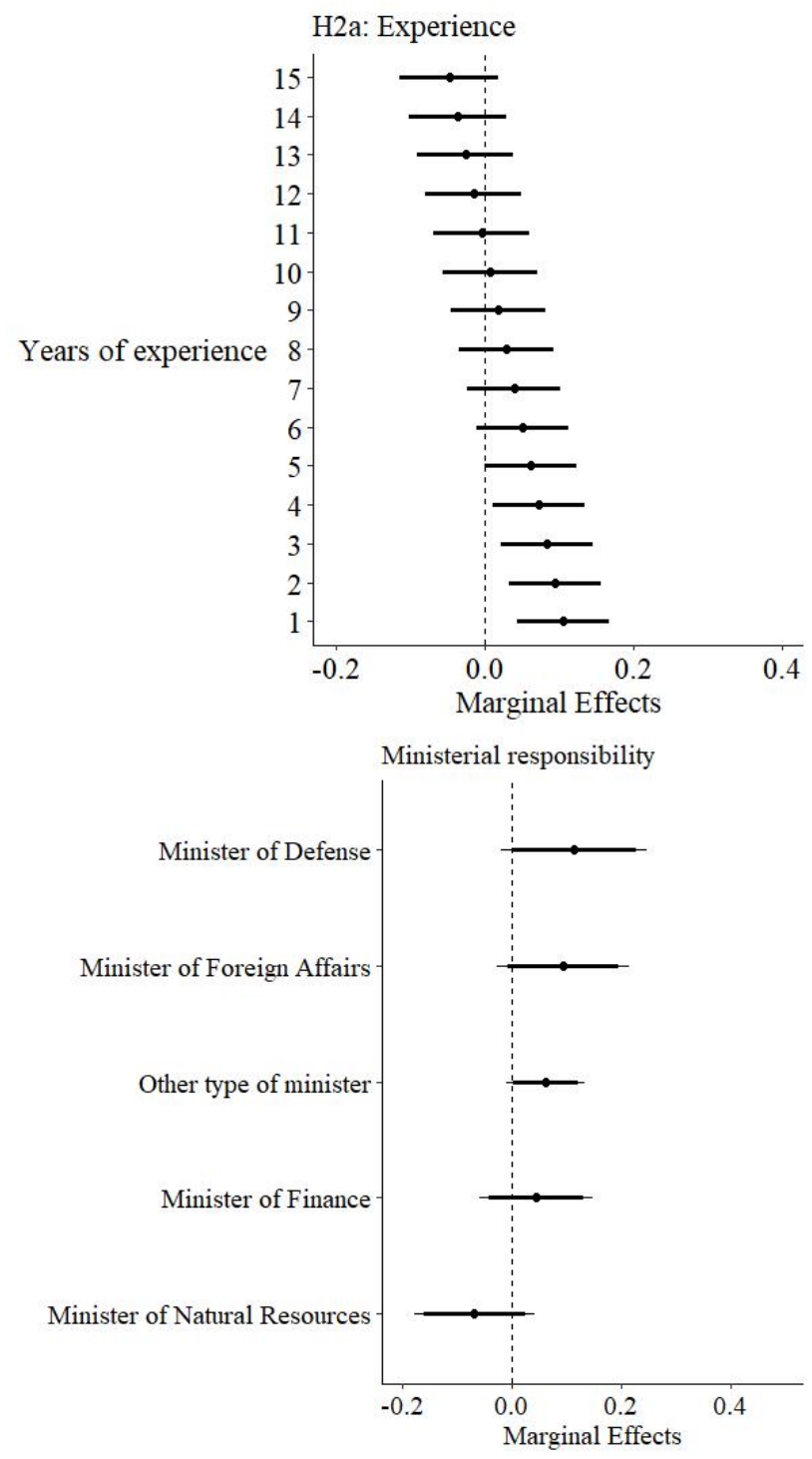

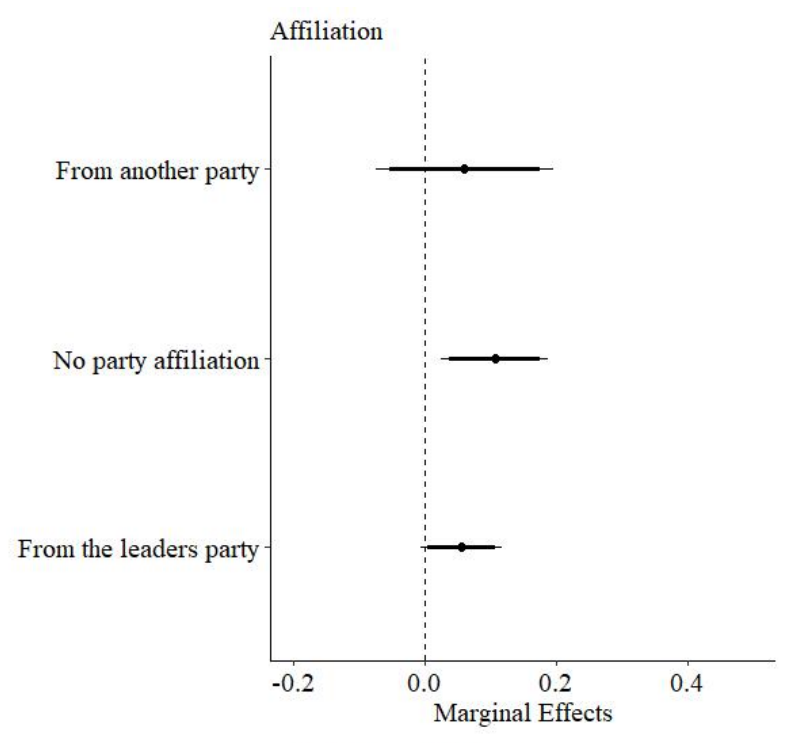

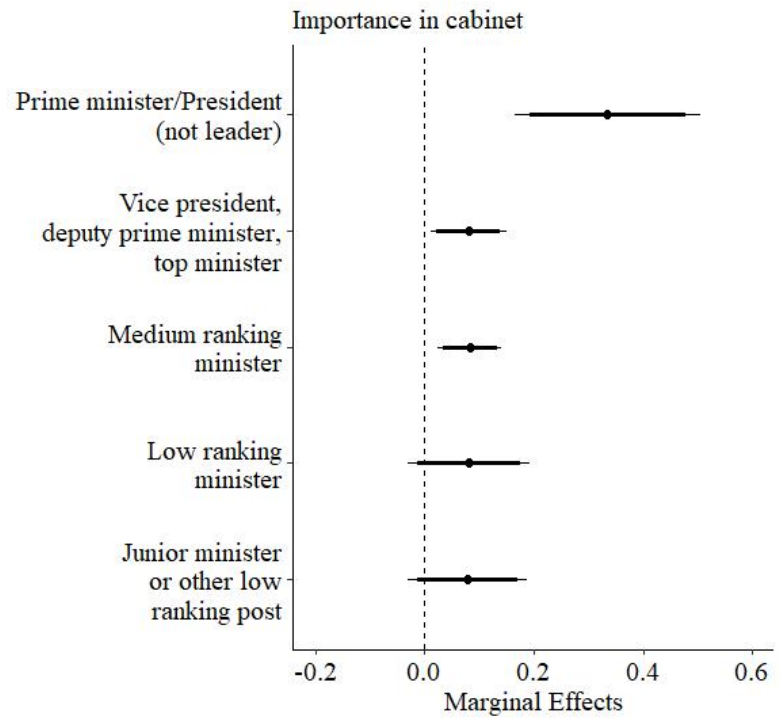

Note: $\mathrm{N}=\mathrm{Up}$ to 104.534 minister years (2,516 in years without a coup attempt and 3,144 in years with a coup attempt).

Thin lines represent 95 percent confidence intervals. Thick lines represent 90 percent confidence intervals. 


\section{E.7 Importance index}

Leader (1)

Leader

Prime minister/President (not leader) (2)

President, Chief of State, Prime minister, who is not the leader

Vice president, deputy prime minister and top minister (3)

Vice-president, Deputy Prime Minister, Deputy Chief of State

Full ranking minister's of high prestige portfolio

Medium ranking minister (4)

Full ranking minister of medium prestige portfolio

Attorney General, Chief Justice or Legal Official

Governor (Military)

Member, Royal Family

Member, Ruling Group

Low ranking minister(5)

Full ranking minister of low prestige portfolio

Director of Government Agency

Government Spokesperson

Governor (Regional)

Junior minister or other low ranking post (6)

Junior minister (independent of prestige)

Advisor

Ambassador to the United States

Assistant Advisor

Chief of Staff

Deputy Director of Government Agency

Governor (Central Bank)

Representative to the United Nations 
Table E.6: Repeating Table 8.1 using Bjornskov and Rode (2019)

\begin{tabular}{|c|c|c|c|c|c|c|c|c|}
\hline & $(1)$ & $(2)$ & $(3)$ & $(4)$ & $(5)$ & $(6)$ & $(7)$ & $(8)$ \\
\hline Intercept & $\begin{array}{c}-0.58^{* * *} \\
(0.17)\end{array}$ & $\begin{array}{c}-0.61^{* * *} \\
(0.17)\end{array}$ & & & & & & \\
\hline Replacement rate & $\begin{array}{c}1.74^{* * *} \\
(0.61)\end{array}$ & $\begin{array}{c}1.89^{* * *} \\
(0.64)\end{array}$ & $\begin{array}{c}2.23^{* * *} \\
(0.76)\end{array}$ & $\begin{array}{c}2.41^{* * *} \\
(0.79)\end{array}$ & $\begin{array}{l}2.50^{* *} \\
(1.01)\end{array}$ & & $\begin{array}{c}3.55^{* * *} \\
(1.24)\end{array}$ & $\begin{array}{c}2.72^{* * *} \\
(0.79)\end{array}$ \\
\hline Coup & $\begin{array}{c}0.64 \\
(0.63)\end{array}$ & $\begin{array}{l}3.17^{*} \\
(1.66)\end{array}$ & $\begin{array}{l}1.10^{*} \\
(0.64)\end{array}$ & $\begin{array}{c}3.96^{* * *} \\
(1.41)\end{array}$ & $\begin{array}{c}4.44^{* * *} \\
(1.69)\end{array}$ & $\begin{array}{l}3.25^{* *} \\
(1.40)\end{array}$ & $\begin{array}{c}2.57 \\
(2.64)\end{array}$ & $\begin{array}{l}3.15^{*} \\
(1.88)\end{array}$ \\
\hline Replacement rate*Coup & & $\begin{array}{c}-3.46^{*} \\
(2.09)\end{array}$ & & $\begin{array}{c}-3.93^{* *} \\
(1.88)\end{array}$ & $\begin{array}{c}-4.14^{*} \\
(2.18)\end{array}$ & & $\begin{array}{l}-2.73 \\
(3.21)\end{array}$ & $\begin{array}{l}-3.44 \\
(2.31)\end{array}$ \\
\hline Replaced $>60 \%$ & & & & & & $\begin{array}{c}1.26^{* * *} \\
(0.43)\end{array}$ & & \\
\hline Replaced $>60 \% *$ Coup & & & & & & $\begin{array}{l}-2.15 \\
(1.59)\end{array}$ & & \\
\hline Notes & & & - & & + Event variables & & Dif 1 year & Dif 2 years \\
\hline Estimation method: Within year & No & No & Yes & Yes & Yes & Yes & Yes & Yes \\
\hline Estimation method: Within country & No & No & Yes & Yes & Yes & Yes & Yes & Yes \\
\hline Num. obs. & 2999 & 2999 & 2999 & 2999 & 2572 & 2999 & 3408 & 3219 \\
\hline $\mathrm{R}^{2}$ (full model) & 0.01 & 0.01 & 0.07 & 0.07 & 0.09 & 0.07 & 0.04 & 0.06 \\
\hline $\mathrm{R}^{2}($ proj model $)$ & 0.01 & 0.01 & 0.01 & 0.01 & 0.01 & 0.01 & 0.01 & 0.01 \\
\hline Num. groups: COUNTRY_ID & & & 111 & 111 & 110 & 111 & 113 & 111 \\
\hline Num. groups: year & & & 45 & 45 & 37 & 45 & 49 & 47 \\
\hline
\end{tabular}
in parentheses.

\section{E.8 Alternative measure of successful coup for table 8.2.}




\section{E.9 Using average years of experience as an alterna- tive measure of political instability}

Figure E.5: Distribution of replacement rates in years with and without a successful coup.

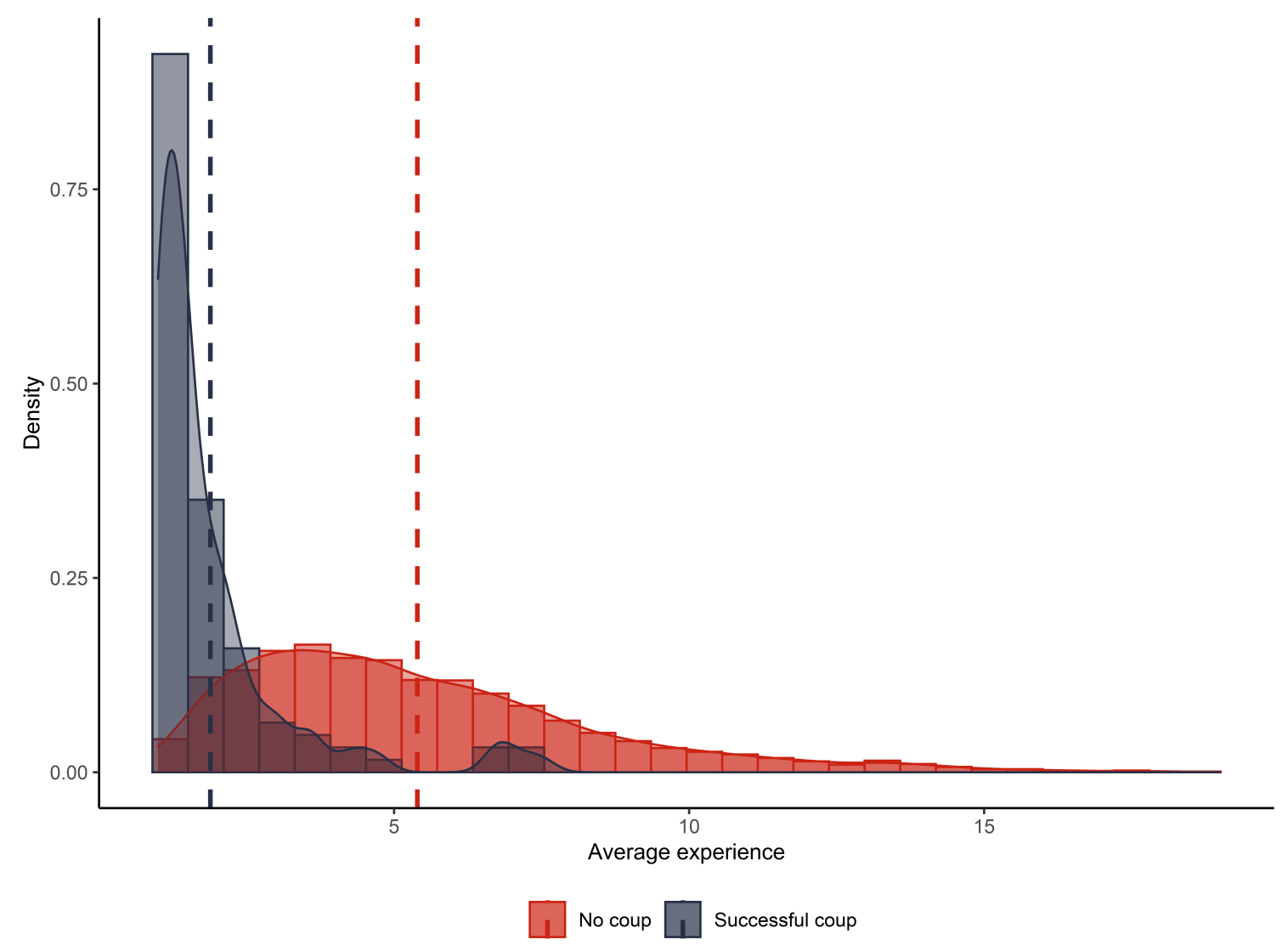


Table E.7: Are successful coups assocaited with higher growth?

\begin{tabular}{|c|c|c|c|c|c|c|c|c|}
\hline & (1) & (2) & (3) & (4) & (5) & (6) & (7) & (8) \\
\hline Intercept & $\begin{array}{c}0.53 \\
(0.33)\end{array}$ & $\begin{array}{c}0.56^{*} \\
(0.33)\end{array}$ & & & & & & \\
\hline Average experience & $\begin{array}{c}-0.12^{* *} \\
(0.05)\end{array}$ & $\begin{array}{c}-0.13^{* *} \\
(0.05)\end{array}$ & $\begin{array}{c}-0.38^{* * *} \\
(0.10)\end{array}$ & $\begin{array}{c}-0.39^{* * *} \\
(0.10)\end{array}$ & $\begin{array}{c}-0.39^{* * *} \\
(0.11)\end{array}$ & & $\begin{array}{c}-0.34^{* * *} \\
(0.09)\end{array}$ & $\begin{array}{c}-0.37^{* * *} \\
(0.09)\end{array}$ \\
\hline Coup & $\begin{array}{c}0.68 \\
(0.60)\end{array}$ & $\begin{array}{l}-0.94 \\
(0.87)\end{array}$ & $\begin{array}{c}0.83 \\
(0.64)\end{array}$ & $\begin{array}{l}-0.69 \\
(0.85)\end{array}$ & $\begin{array}{l}-0.85 \\
(0.87)\end{array}$ & $\begin{array}{l}-0.31 \\
(0.88)\end{array}$ & $\begin{array}{l}-0.95 \\
(1.49)\end{array}$ & $\begin{array}{c}-1.73^{*} \\
(0.93)\end{array}$ \\
\hline Average experience*Coup & & $\begin{array}{l}0.79^{* *} \\
(0.35)\end{array}$ & & $\begin{array}{l}0.72^{* *} \\
(0.30)\end{array}$ & $\begin{array}{c}1.05^{* * *} \\
(0.32)\end{array}$ & & $\begin{array}{c}0.89 \\
(0.72)\end{array}$ & $\begin{array}{c}1.12^{* * *} \\
(0.36)\end{array}$ \\
\hline $\begin{array}{l}\text { Experience }>1 \text { year } \\
\text { Experience }>2 \text { years }\end{array}$ & & & & & & $\begin{array}{c}-1.63^{* *} \\
(0.64) \\
2.91^{* *} \\
(1.46) \\
\end{array}$ & & \\
\hline Notes & & & - & & + Event variables & & Dif 1 year & Dif 2 years \\
\hline Estimation method: Within year & No & No & Yes & Yes & Yes & Yes & Yes & Yes \\
\hline Estimation method: Within country & No & No & Yes & Yes & Yes & Yes & Yes & Yes \\
\hline Num. obs. & 2999 & 2999 & 2999 & 2999 & 2572 & 2999 & 3408 & 3219 \\
\hline $\mathrm{R}^{2}$ (full model) & 0.00 & 0.00 & 0.08 & 0.08 & 0.09 & 0.07 & 0.04 & 0.06 \\
\hline $\mathrm{R}^{2}($ proj model $)$ & 0.00 & 0.00 & 0.01 & 0.01 & 0.01 & 0.01 & 0.00 & 0.01 \\
\hline Num. groups: COUNTRY_ID & & & 111 & 111 & 110 & 111 & 113 & 111 \\
\hline Num. groups: year & & & 45 & 45 & 37 & 45 & 49 & 47 \\
\hline
\end{tabular}

${ }^{* * *} p<0.01 ;{ }^{* *} p<0.05 ;{ }^{*} p<0.1 . \mathrm{N}=104$ coups. Dependent variable: Difference in economic growth 3 years after compared to 3 years before. Country-clustered standard errors

in parentheses. 
Figure E.6: Marginal effect of a successful coup on difference in economic growth three years after and three years before a coup dependent on the replacement rate in the year of the coup.

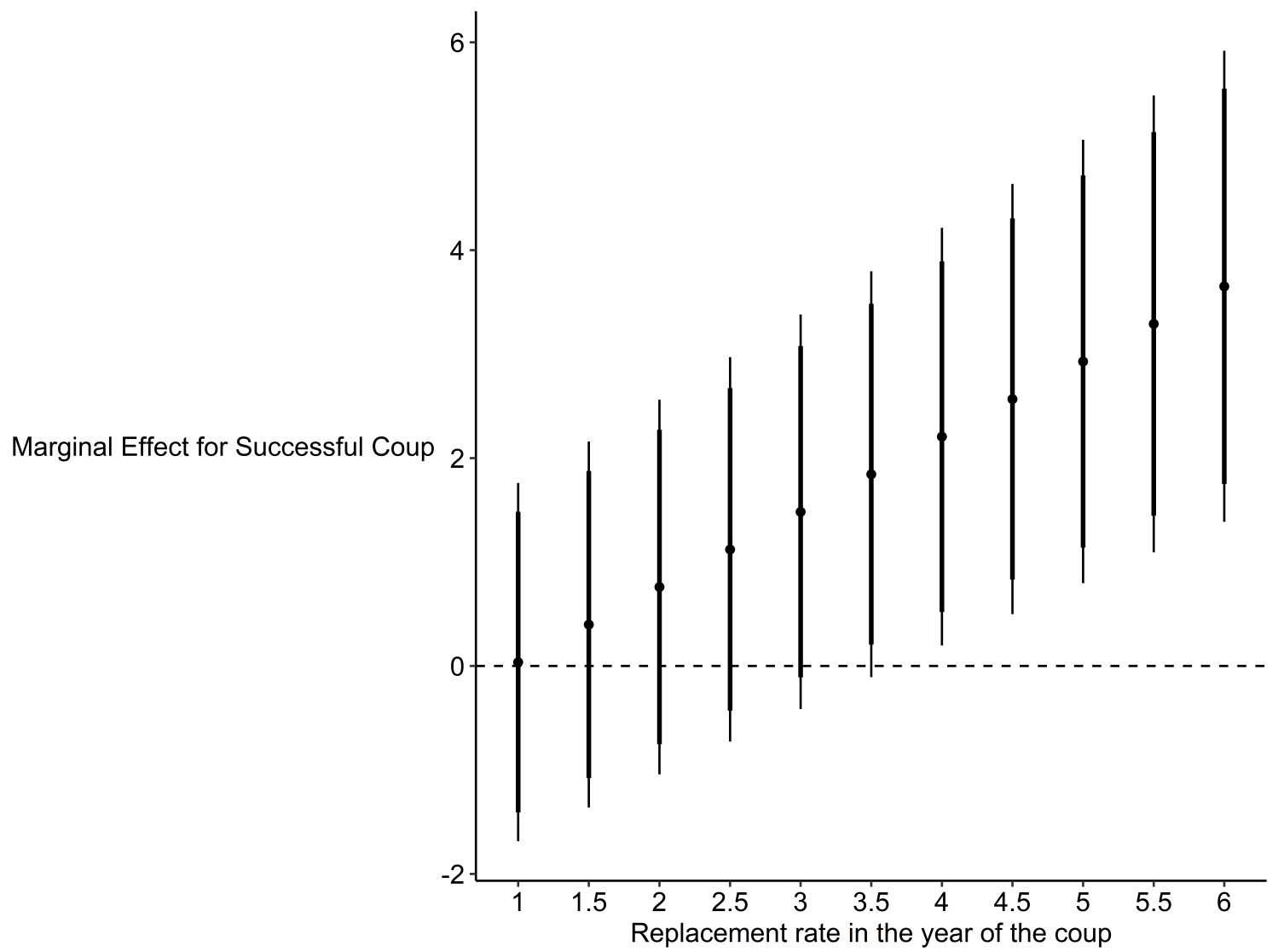

